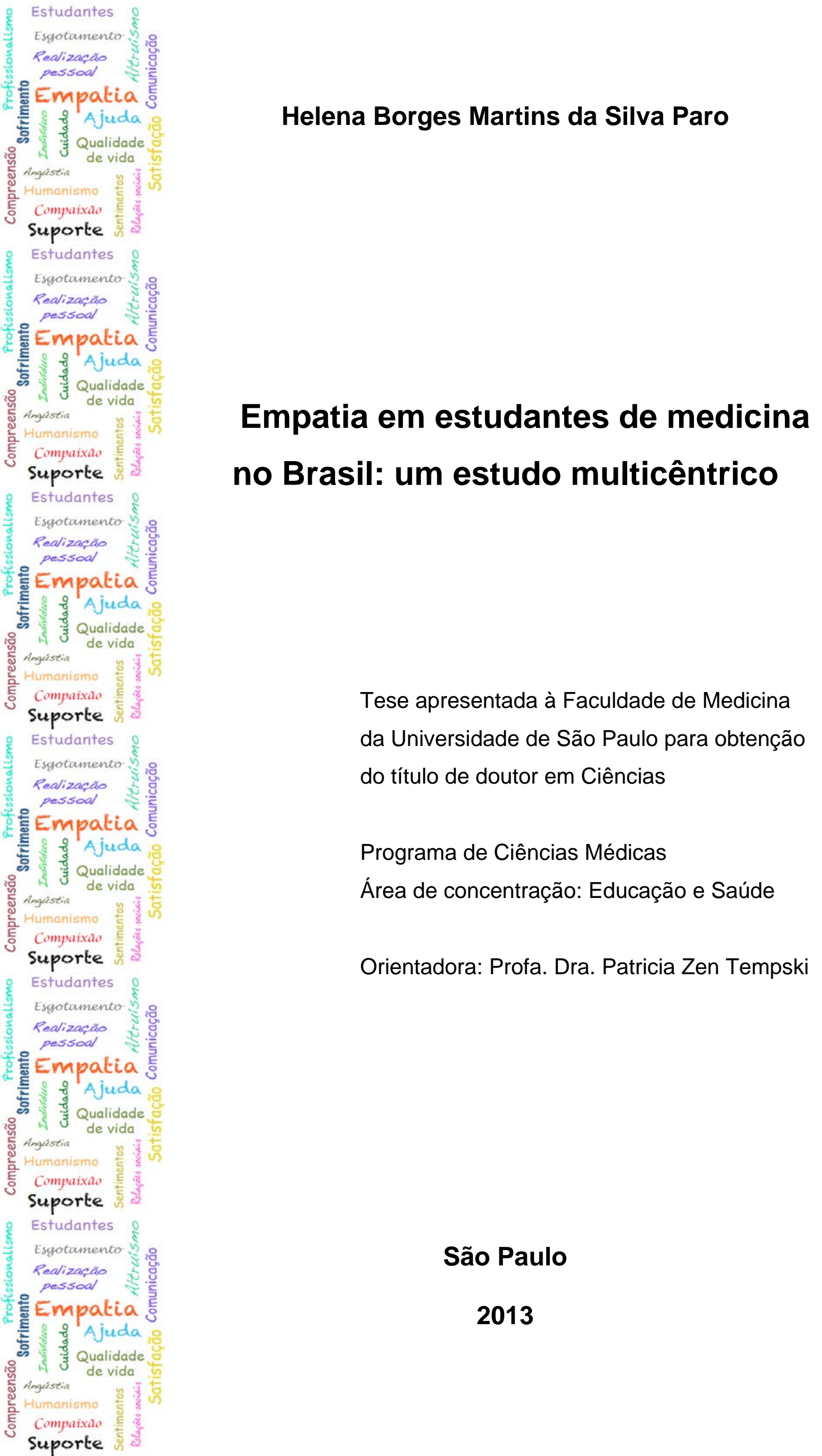


Helena Borges Martins da Silva Paro

\title{
Empatia em estudantes de medicina no Brasil: um estudo multicêntrico
}

\author{
Tese apresentada à Faculdade de Medicina \\ da Universidade de São Paulo para obtenção \\ do título de doutor em Ciências \\ Programa de Ciências Médicas \\ Área de concentração: Educação e Saúde \\ Orientadora: Profa. Dra. Patricia Zen Tempski
}

São Paulo

2013 
Dados Internacionais de Catalogação na Publicação (CIP)

Preparada pela Biblioteca da

Faculdade de Medicina da Universidade de São Paulo

Creprodução autorizada pelo autor

Paro, Helena Borges Martins da Silva

Empatia em estudantes de medicina no Brasil : um estudo multicêntrico / Helena Borges Martins da Silva Paro. -- São Paulo, 2013.

Tese(doutorado)--Faculdade de Medicina da Universidade de São Paulo.

Programa de Ciências Médicas. Área de concentração: Educação e Saúde. Orientadora: Patricia Zen Tempski.

Descritores: 1.Empatia 2.Qualidade de vida 3.Esgotamento profissional 4.Distúrbios do sono por sonolência excessiva 5.Estudantes de medicina

USP/FM/DBD-247/13 
À Laura. Minha inspiração. Sempre. 


\section{AGRADECIMENTOS}

Aos meus pais, Marco Túlio e Maria de Fátima, exemplos de amor incondicional e de cuidado. O apoio que recebo de vocês alimenta-me o sentido da vida.

Às minhas amadas irmãs, Lúcia e Mariana. Lúcia, o carinho que você sempre dedicou à nossa família, em especial à Laura, tornaram esse caminho mais ameno. Mariana, mesmo à distância, você trouxe à tese o diálogo com as ciências sociais, além de despertar-me para as questões de gênero aqui discutidas.

À Profa. Patricia Tempski, minha orientadora. Com o seu exemplo, aprendi que a empatia está muito além da capacidade de "vestir os sapatos" do outro: está no cuidado sincero com o outro. Obrigada por acolher-me de forma tão carinhosa na "Casa de Arnaldo". Ao Prof. Mílton de Arruda Martins, que ofereceu-me a oportunidade de conviver e aprender com pessoas tão especiais na Faculdade de Medicina da Universidade de São Paulo (FMUSP). Minha sincera gratidão a esses dois grandes mestres.

Aos amigos do grupo de pesquisa VERAS: Silmar Gannam, Sylvia Claassen Enns e Munique Almeida. A amizade que cultivamos foi, com certeza, um dos maiores prêmios dessa jornada. Meu agradecimento especial ao meu amigo Bruno Perotta, que vivenciou comigo todas as alegrias e dificuldades dessa caminhada: desde a construção dos questionários na plataforma VERAS, em 2009, à interminável confecção de tabelas de randomização, relatórios de respondentes, tabelas e cálculos do tamanho do efeito! Você 
compartilhou comigo seu conhecimento, seu tempo e sua bondade. Espero ter deixado um pouquinho de mim com você também.

À Regina Albanese Pose, pelos cálculos estatísticos, e acima de tudo, pela generosidade em ensinar e em acolher as ansiedades da confecção dos modelos de regressão.

Ao Prof. Rogério de Melo Costa Pinto, da Universidade Federal de Uberlândia (UFU), que também me orientou nos estudos estatísticos, principalmente na escolha dos modelos de regressão múltipla.

A todos os professores da rede colaborativa de pesquisa VERAS pelo empenho na construção das perguntas da pesquisa e, principalmente, pelo esforço no recrutamento dos estudantes: Alicia Navarro Souza (UFRJ), Ana Carolina Faedrich dos Santos (UFCSPA), Benedita Andrade Leal de Abreu (UESPI), Cláudia Vasconcelos (FMP), Cleane Toscano S. Bezerra (FCMPB), Cleidilene Ramos Magalhães (UFCSPA), Cristiane Barelli (UPF), Derly Streit (FMP), Daniel Silvestre (USP), Emilia Perez (FCMPB), Emirene M. T. Navarro da Cruz (FAMERP), Eugenio Paes Campos (UNIFESO), Itágores Hoffman (UFT), Ivan Antonello (PUC-RS), Katia Burle dos Santos Guimarães (FAMEMA), Luís Fernando Tófoli (UFC), Maria Amélia Dias Pereira (UFG), Maria Cristina Lima (UNESP), Maria Helena Itaqui Lopes (PUC-RS), Maria Helena Senger (PUC-Sorocaba), Maria Luísa Carvalho Soliani (EBMSP), Nilson Rodrigues da Silva (FMABC), Olívia Maria Veloso Costa Coutinho (UFT), Paulo Sérgio Panse Silveira (USP), Raitany Almeida (UNIR), Renata Rocha Barreto Giaxa (UNIFOR), Rosuita Fratari Bonito (UFU), Sérgio Baldassin (FMABC), Vera Lúcia Garcia (UNESP). 
À Profa. Rosuita Fratari Bonito (UFU), por acreditar neste trabalho e pelo incentivo incondicional à minha carreira acadêmica. Seu carisma foi fundamental ao sucesso de participação da nossa instituição nesse projeto.

Às Professoras Iolanda Calvo Tibério e Renata Daud-Gallotti, que também me acolheram com carinho na FMUSP e com quem compartilhei a oportunidade de validar a Escala Jefferson de Empatia para o Brasil.

Ao Prof. Luiz Antônio de Nogueira Martins, da Universidade Federal de São Paulo, grande mestre, que compartilhou comigo textos valiosos para a construção deste trabalho.

À Andressa Andrade Teymeny, minha amiga querida, pelo trabalho de ilustração e diagramação da tese. Sua amizade sempre foi ímpar para mim e contar com ela até no último segundo desse trabalho foi muito importante.

A todos os estudantes de medicina que participaram deste trabalho, em especial, aos queridos Allison Abrahão, Anarosa Naves, Geisyane Ferreira e Jacqueline Paiva pela preciosa ajuda na coleta de dados na UFU. 
"One of the essential qualities of the clinician is interest in humanity, for the secret of the care of the patient is in caring for the patient."

- Francis W. Peabody, 1927- 



\section{Normalização adotada}

Esta tese está de acordo com as seguintes normas, em vigor no momento desta publicação:

Referências: adaptado de International Committee of Medical Journals Editors (Vancouver).

Universidade de São Paulo. Faculdade de Medicina. Divisão de Biblioteca e Documentação. Guia de apresentação de dissertações, teses e monografias. Elaborado por Anneliese Carneiro da Cunha, Maria Julia de A. L. Freddi, Maria F. Crestana, Marinalva de Souza Aragão, Suely Campos Cardoso, Valéria Vilhena. 3a ed. São Paulo: Divisão de Biblioteca e Documentação; 2011. Abreviaturas dos títulos dos periódicos de acordo com List of Journals Indexed in Index Medicus. 


\section{Sumário}

Lista de abreviaturas e siglas

Lista de figuras

Lista de quadros

Lista de tabelas

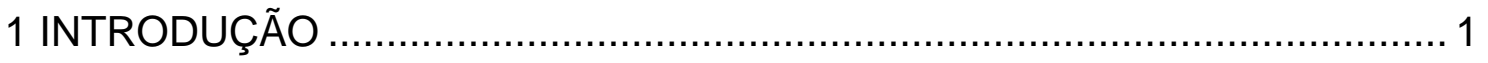

1.1 Empatia: aspectos conceituais e questionários ................................. 6

1.2 Qualidade de vida: aspectos conceituais e questionários...................... 12

1.3 Empatia, qualidade de vida, sono e outras variáveis............................ 16

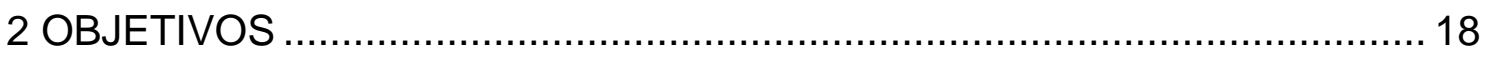



3.1 Instituições de ensino superior participantes ................................... 21

3.2 Sujeitos da pesquisa ........................................................... 24

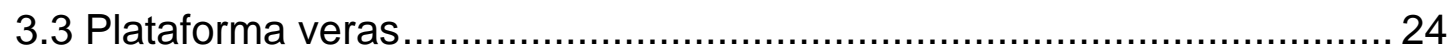

3.3.1 Instrumentos ................................................................... 26

3.4 Formação da rede multicêntrica de pesquisa ................................... 48

3.5 Coleta de dados.......................................................................... 52

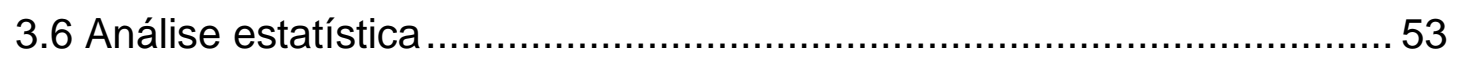

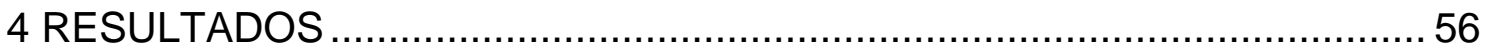

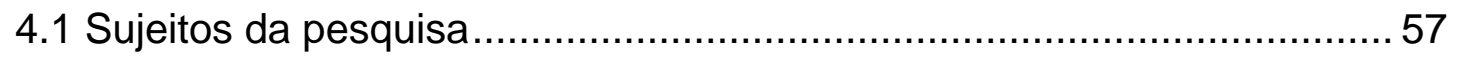

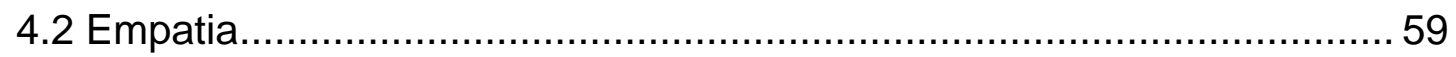

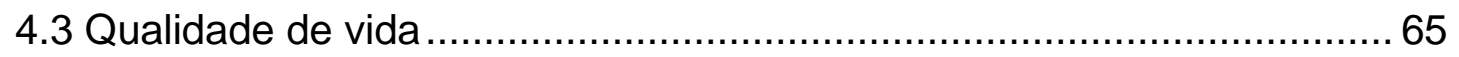

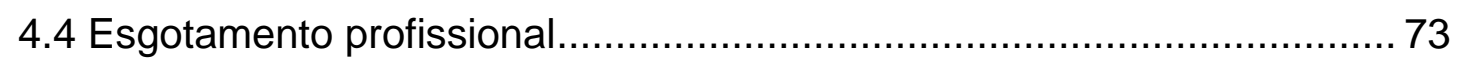



4.6 Empatia, qualidade de vida, esgotamento profissional e sonolência diurna

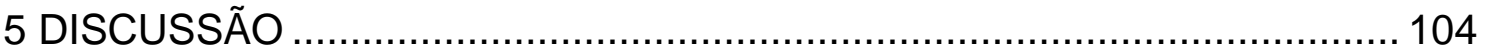

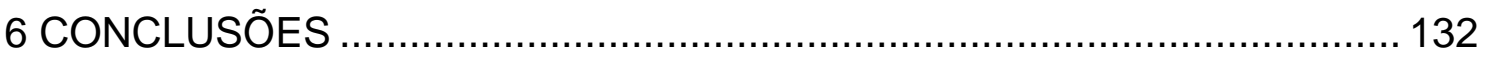

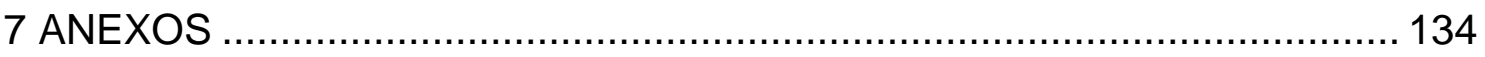

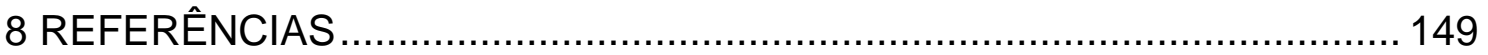

Apêndice 


\section{LISTA DE ABREVIATURAS E SIGLAS}

ABIM

ABP

ANOVA

AP

BEES

CAPES

CARE

CE

CEP-FMUSP

COBEM

DCN

DP

Desp

DREEM

ECRS

EMRI

EpwT

ESS

Exau

FHCS

HTML

IDATE

IDB

IES

JSE

$\mathrm{MBI}$
American Board of Internal Medicine

Aprendizagem Baseada em Problemas

Análise de Variância

Domínio angústia pessoal da EMRI

Balanced Emotional Empathy Scale

Coordenação de Aperfeiçoamento de Pessoal de Nível Superior

Consultation and Relational Empathy

Domínio consideração empática da EMRI

Comitê de Ética em Pesquisa da Faculdade de Medicina de São Paulo

Congresso Brasileiro de Educação Médica

Diretrizes Curriculares Nacionais

Desvio Padrão

Domínio despersonalização do MBI

Dundee Ready Educational Environment Measurement

Empathy Construct Rating Scale

Escala Multidimensional de Reatividade Interpessoal de Davis

Escore total da ESS

Escala de sonolência diurna de Epworth

Domínio exaustão emocional do MBI

The Four Habits Coding Scheme

HyperText Markup Language

Inventário de Ansiedade Traço-Estado

Inventário de Depressão de Beck

Instituição de Ensino Superior

Jefferson Scale of Empathy (Escala Jefferson de

Empatia)

Maslach Burnout Inventory 


\begin{tabular}{|c|c|}
\hline MBI-HSS & Maslach Burnout Inventory Human Services Survey \\
\hline MBI-SS & Maslach Burnout Inventory Human Student Survey \\
\hline MSWBI & Medical Student Well-Being Index \\
\hline MySQL & Structured Query Language \\
\hline OMS & Organização Mundial da Saúde \\
\hline PERL & Practical Extracting and Reporting Language \\
\hline PRIME-MD & Primary Care Evaluation of Mental Disorder \\
\hline PSQI-Br & Pittsburgh Sleep Quality Index - versão brasileira \\
\hline PSS & Perceived Stress Scale \\
\hline QVG & Autoavaliação da qualidade de vida geral \\
\hline QVC & Autoavaliação da qualidade de vida no curso \\
\hline Real & Domínio realização pessoal do MBI \\
\hline RS-14 & Resilience Scale \\
\hline SF-8 & Medical Outcomes Survey - Short Form \\
\hline TP & Domínio tomada de perspectiva da EMRI \\
\hline VERAS & Vida do Estudante e Residente da Área da Saúde \\
\hline Veras-q & $\begin{array}{l}\text { Vida de Estudante e Residente da Área da Saúde: } \\
\text { questionário para avaliar a qualidade de vida do } \\
\text { estudante de medicina }\end{array}$ \\
\hline VerAE & Domínio ambiente de ensino do Veras-q \\
\hline VerF & Domínio físico do Veras-q \\
\hline VerP & Domínio psicológico do Veras-q \\
\hline VerT & Domínio uso do tempo do Veras-q \\
\hline WHO & World Health Organization \\
\hline WhoA & Domínio ambiente do WHOQOL \\
\hline WhoF & Domínio físico do WHOQOL \\
\hline WhoP & Domínio psicológico do WHOQOL \\
\hline Whos & Domínio relações sociais do WHOQOL \\
\hline WHOQOL & World Health Organization Quality of Life Ass \\
\hline
\end{tabular}




\section{LISTA DE FIGURAS}

Figura 1 - O modelo organizacional de empatia de Davis

Figura 2 - Distribuição geográfica das Instituições de Ensino Superior participantes do Projeto VERAS .

Figura 3 - Fluxograma de perdas e número de participantes do projeto Veras .....57

Figura 4 - Número de respondentes na plataforma Veras de acordo com mês e ano de início e término dos questionários ........................................58

Figura 5 - Análise por item das respostas à Escala Multidimensional de Reatividade Interpessoal de Davis (EMRI) da população geral do estudo ( $n=1350)$, domínio consideração empática (EmrCE) ...............61

Figura 6 - Análise por item das respostas à Escala Multidimensional de Reatividade Interpessoal de Davis (EMRI) da população geral do estudo ( $n=1350)$, domínio tomada de perspectiva (EmrTP) 61

Figura 7 - Análise por item das respostas à Escala Multidimensional de Reatividade Interpessoal de Davis (EMRI) da população geral do estudo ( $\mathrm{n}=1350)$, domínio angústia pessoal (EmrA)

Figura 8 - Modelo de regressão linear múltipla para os domínios da EMRI entre o grupo do sexo masculino. 99

Figura 9 - Modelo de regressão linear múltipla para os domínios da EMRI entre o grupo do sexo feminino 103 


\section{LISTA DE QUADROS}

Quadro 1 - Questionários de avaliação de empatia validados 10

Quadro 2 - Caracterização das Instituições de Ensino Superior participantes do

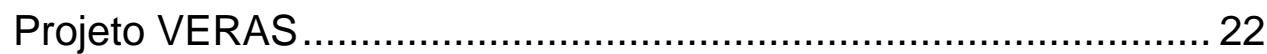

Quadro 3 - Questionários utilizados na Plataforma VERAS ........................ 27

Quadro 4 - Subescalas e itens da Escala Multidimensional de Reatividade Interpessoal de Davis (EMRI) ............................................ 32

Quadro 5 - Domínios e facetas do WHOQOL-BREF .............................. 37

Quadro 6 - Definição dos domínios do VERAS-q e respectivos itens ............. 41

Quadro 7 - Categorização dos escores do Inventário de Burnout de Maslach (MBI) para amostra geral e para área de medicina .................... 45

Quadro 8 - Itens da Escala de Sonolência Diurna de Epworth (ESS) .............46 46 


\section{LISTA DE TABELAS}

Tabela 1 - Idade média (desvio padrão) e distribuição dos respondentes de acordo com sexo e ano do curso ....................................... 59

Tabela 2 - Qualidade dos dados (efeitos piso e teto) e confiabilidade da EMRI

Tabela 3 - Escores de empatia obtidos por meio da EMRI de acordo com sexo 63

Tabela 4 - Escores de empatia obtidos por meio da EMRI de acordo com sexo nos diferentes anos do curso

Tabela 5 - Escores de empatia obtidos por meio da EMRI de acordo com ano do curso. 65

Tabela 6 - Qualidade dos dados obtidos (efeitos piso e teto) e confiabilidade da autoavaliação da qualidade de vida, WHOQOL-BREF e Veras-q. 66

Tabela 7 - Escores obtidos por meio da autoavaliação da qualidade de vida geral e da qualidade de vida no curso de acordo com sexo.

Tabela 8 - Comparação dos escores obtidos por meio da autoavaliação da qualidade de vida geral e da qualidade de vida no curso de acordo com ano do curso 67

Tabela 9 - Escores obtidos por meio da autoavaliação da qualidade de vida (geral e no curso) de acordo com ano do curso 68

Tabela 10 - Escores de qualidade de vida obtidos por meio do WHOQOLBREF de acordo com sexo

Tabela 11 - Escores de qualidade de vida obtidos por meio do WHOQOLBREF de acordo com sexo nos diferentes anos do curso.

Tabela 12 - Escores de qualidade de vida obtidos por meio do WHOQOLBREF de acordo com ano do curso 70

Tabela 13 - Escores de qualidade de vida obtidos por meio do Veras-q de acordo com sexo

Tabela 14 - Escores de qualidade de vida obtidos por meio do Veras-q de acordo com sexo nos difentes anos do curso 
Tabela 15 - Escores de qualidade de vida obtidos por meio do Veras-q de acordo com ano do curso

Tabela 16 - Qualidade dos dados (efeitos piso e teto) e confiabilidade do MBI

Tabela 17 - Escores de esgotamento profissional obtidos por meio do $\mathrm{MBI}$ de acordo com sexo ........................................................ 75

Tabela 18 - Frequência de esgotamento profissional nos domínios do MBI ... 75

Tabela 19 - Escores de esgotamento profissional obtidos por meio do $\mathrm{MBI}$ de acordo com sexo nos diferentes anos do curso 76

Tabela 20 - Escores de esgotamento profissional obtidos por meio do $\mathrm{MBI}$ de acordo com ano do curso.

Tabela 21 - Qualidade dos dados (efeitos piso e teto) e confiabilidade da Escala de Sonolência Diurna de Epworth 78

Tabela 22 - Escores obtidos por meio da Escala de Sonolência Diurna de Epworth de acordo com sexo e ano de curso 79

Tabela 23 - Percentual de estudantes com escores patológicos de sonolência diurna

Tabela 24 - Coeficientes de correlação de Pearson entre os domínios das variáveis do estudo (empatia, qualidade de vida, esgotamento profissional e sonolência diurna) para a população geral do estudo

Tabela 25 - Coeficientes de correlação de Pearson entre os domínios d as variáveis do estudo (empatia, qualidade de vida, esgotamento profissional e sonolência diurna) para os estudantes do sexo masculino

Tabela 26 - Coeficientes de correlação de Pearson entre os domínios das variáveis do estudo (empatia, qualidade de vida, esgotamento profissional e sonolência diurna) para os estudantes do sexo feminino. 86

Tabela 27 - Comparação dos escores de empatia obtidos por meio da EMRI entre os estudantes com escores nos percentis 25 e 75 do domínio físico do WHOQOL-BREF . 86 
Tabela 28 - Comparação dos escores de empatia obtidos por meio da EMRI entre os estudantes com escores nos percentis 25 e 75 do domínio psicológico do WHOQOL-BREF

Tabela 29 - Comparação dos escores de empatia obtidos por meio da EMRI entre os estudantes com escores nos percentis 25 e 75 do domínio relações sociais do WHOQOL-BREF 88

Tabela 30 - Comparação dos escores de empatia obtidos por meio da EMRI entre os estudantes com escores nos percentis 25 e 75 do domínio ambiente do WHOQOL-BREF 89

Tabela 31 - Comparação dos escores de empatia obtidos por meio da EMRI entre os estudantes com escores nos percentis 25 e 75 do domínio uso do tempo do Veras-q ................................... 90

Tabela 32 - Comparação dos escores de empatia obtidos por meio da EMRI entre os estudantes com escores nos percentis 25 e 75 do domínio psicológico do Veras-q ........................................... 91

Tabela 33 - Comparação dos escores de empatia obtidos por meio da EMRI entre os estudantes com escores nos percentis 25 e 75 do domínio físico do Veras-q................................................ 92

Tabela 34 - Comparação dos escores de empatia obtidos por meio da EMRI entre os estudantes com escores nos percentis 25 e 75 do domínio ambiente de ensino do Veras-q............................... 93

Tabela 35 - Escores de empatia obtidos por meio da EMRI de acordo com a presença de esgotamento profissional no domínio exaustão emocional do $\mathrm{MBI}$ 94

Tabela 36 - Escores de empatia obtidos por meio da EMRI de acordo com a presença de esgotamento profissional no domínio despersonalização do $\mathrm{MBI}$.................................................. 95

Tabela 37 - Escores de empatia obtidos por meio da EMRI de acordo com a presença de esgotamento profissional no domínio realização pessoal do $\mathrm{MBI}$ 96

Tabela 38 - Análise de regressão simples entre os domínios da EMRI e os domínios dos questionários de qualidade de vida e esgotamento profissional no grupo do sexo masculino 
Tabela 39 - Análise de regressão múltipla entre os domínios da EMRI e os domínios dos questionários de qualidade de vida e esgotamento profissional no grupo do sexo masculino ............................ 98

Tabela 40 - Análise de regressão simples entre os domínios da EMRI e os domínios dos questionários de qualidade de vida e esgotamento profissional no grupo do sexo feminino ............................. 101

Tabela 41 - Análise de regressão múltipla entre os domínios da EMRI e os domínios dos questionários de qualidade de vida e esgotamento profissional no grupo do sexo feminino ............................... 102 


\section{Resumo}

Paro HBMS. Empatia em estudantes de medicina no Brasil: um estudo multicêntico [tese]. São Paulo: Faculdade de Medicina, Universidade de São Paulo; 2013.

INTRODUÇÃO: A empatia representa um dos domínios centrais das habilidades sociais e de comunicação e é frequentemente associada a melhores resultados diagnósticos e terapêuticos. Por esse motivo, as habilidades empáticas dos profissionais da área da saúde têm sido amplamente investigadas no contexto da educação médica. Nosso objetivo foi avaliar a empatia do estudante de medicina e sua associação com qualidade de vida, esgotamento profissional e sonolência diurna. MÉTODOS: Estudo transversal randomizado de abrangência nacional, com a utilização de questionários de autorrelato validados para a avaliação de empatia (Escala Multidimensional de Reatividade Interpessoal de Davis - EMRI), qualidade de vida (The Whoqol Quality of Life Assessment - WHOQOL-BREF e Questionário para avaliar a qualidade de vida do estudante e residente da área da saúde Veras-q), esgotamento profissional (Maslach Burnout Inventory - MBI) e sonolência diurna excessiva (Escala de Sonolência Diurna de Epworth - ESS) em uma plataforma eletrônica desenvolvida para o estudo - a plataforma VERAS. RESULTADOS: Dos 1.650 estudantes randomizados, 1.350 (81,8\%) completaram todos os questionários da plataforma VERAS. Observamos importantes diferenças de gênero nos domínios consideração empática e angústia pessoal da EMRI, com maiores escores para o grupo do sexo feminino $(p<0,05 ; d \geq 0,5)$. Estudantes dos diversos ciclos do curso de medicina apresentaram diferenças pouco expressivas das disposições empáticas $(p<0,05 ; f<0,25)$. A percepção de qualidade de vida no curso foi muito menor do que a percepção de qualidade de vida em geral entre os estudantes de medicina $(p<0,001 ; d>0,8)$. Estudantes do sexo feminino apresentaram menores escores de qualidade de vida nos domínios físico, psicológico e uso do tempo $(p<0,05 ; d<0,5)$. A percepção de qualidade de vida relacionada ao ambiente de ensino também foi discretamente menor entre estudantes dos últimos anos do curso $(p<0,001 ; f<0,25)$. Em relação aos escores de esgotamento profissional, estudantes do sexo feminino apresentaram maior exaustão emocional e menor despersonalização do que estudantes do sexo masculino $(p<0,001 ; d<0,5)$. Estudantes dos últimos anos do curso apresentaram escores discretamente maiores de exaustão emocional, despersonalização e realização pessoal $(p<0,05 ; f<0,25)$. Os escores de sonolência diurna foram discretamente maiores entre estudantes do sexo feminino $(p<0,001 ; d<0,5)$ e não diferiram entre os ciclos do curso. Aproximadamente $56 \%$ dos estudantes apresentaram sonolência diurna excessiva. Os escores de sonolência diurna apresentaram correlações fracas com os domínios da EMRI. Entre os estudantes do sexo masculino, realização pessoal $(\Omega=-0,22 ; p<0,001)$ e qualidade de vida no domínio psicológico $(ß=-$ $0,19 ; p<0,001)$ contribuíram para menor angústia pessoal. Entre o grupo do sexo feminino, realização pessoal contribuiu significativamente para maior consideração empática $(\Omega=0,23 ; p<0,001)$ e tomada de perspectiva $(B=0,30$; $p<0,001)$. Escores de despersonalização contribuíram para menor disposição empática nesses domínios $(~(=-0,29 ; p<0,001$ para consideração empática e 
$\beta=-0,17 ; p<0,001$ para tomada de perspectiva). CONCLUSÕES: Estudantes do sexo feminino apresentaram maior disposição para consideração empática e para angústia pessoal do que estudantes do sexo masculino. As diferenças das disposições empáticas dos estudantes de diferentes ciclos do curso de medicina foram inexpressivas. Dentre as variáveis estudadas, realização pessoal apresentou a maior contribuição para menor angústia pessoal entre estudantes do sexo masculino. Maior realização pessoal e menor despersonalização também contribuíram para maior disposição empática entre estudantes do sexo feminino.

Descritores: Empatia; Qualidade de Vida; Esgotamento Profissional; Distúrbios do Sono por Sonolência Excessiva; Estudantes de Medicina. 


\section{Abstract}

Paro HBMS. Empathy among medical students in Brazil: a multi-centric study [thesis]. São Paulo: "Faculdade de Medicina, Universidade de São Paulo"; 2013.

INTRODUCTION: Empathy is one of the main domains of social and communication skills. It is often associated to better diagnostic and therapeutic outcomes. For this reason, it has been extensively investigated among health professionals. We aimed to assess medical students' empathic disposition and its association with quality of life, burnout and daytime sleepiness. METHODS: Cross-sectional multi-centric randomized study with the use of validated selfreport questionnaires of empathy (the Interpersonal Reactivity Index - IRI), quality of life (The Whoqol Quality of Life Assessment - WHOQOL-BREF and the Health Professionals and Students' Life Questionnaire - Veras-q), burnout (the Maslach Burnout Inventory - MBI) and daytime sleepiness (the Epworth Excessive Sleepiness Scale - ESS). Questionnaires were available to students on an electronic platform designed for the study - the VERAS platform. RESULTS: From the total of 1,650 randomized students, 1,350 (81.8\%) completed all questionnaires. We observed important gender differences on students' dispositional empathic concern and personal distress. Female students had higher scores on these domains than their male counterparts $(p<0.05 ; d \geq 0.5)$. Students from different phases of medical training had minor differences on empathic dispositions $(p<0.05 ; f<0.25)$. Students' perception of quality of life related to medical school was quite lower than their perception of quality of life in general $(p<0.001 ; d>0.8)$. Female students had slightly lower scores on physical, psychological and time management domains of quality of life compared to male students $(p<0.05 ; d<0.5)$. Perceptions of quality of life on the learning environment were also slightly lower among students in the final years of medical school $(p<0.001 ; f<0.25)$. Female students had higher scores on emotional exhaustion and lower scores on depersonalization than their male counterparts $(p<0.001 ; d<0.5)$. Students at the final years of medical school had slightly higher scores on emotional exhaustion, depersonalization and personal accomplishment $(p<0.05 ; f<0.25)$. Daytime sleepiness scores were slightly higher among female students $(p<0.001 ; d<0.5)$. Sleepiness scores did not differ according to phases of medical school. Approximately $56 \%$ of students had suggestive scores of excessive daytime sleepiness. Daytime sleepiness scores yielded weak correlations with empathy domains. Among male students, personal accomplishment $(B=-0.22 ; p<0.001)$ and psychological quality of life $(ß=-0.19 ; p<0.001)$ contributed to lower personal distress. Among female students, personal accomplishment had a significant contribution to higher empathic concern $(B=0.23$ : $p<0.001)$ and perspective taking $(B=0.30$; $\mathrm{p}<0.001)$. Depersonalization scores contributed to lower empathic disposition on these domains $(B=-0.29$ : $p<0.001$ for empathic concern domain and $\beta=-$ 0.17 ; $p<0.001$ for perspective taking domain). CONCLUSIONS: Female students had higher disposition on empathic concern and personal distress than their male counterparts. Differences on students' empathic dispositions across phases of medical school were quite small. Among all study variables, personal accomplishment had higher contributions to lower personal distress among 
male students. Higher personal accomplishment and lower depersonalization also contributed to higher empathic disposition among female students.

Keywords: Empathy; Quality of Life; Burnout, Professional; Disorders of Excessive Somnolence; Students, Medical. 


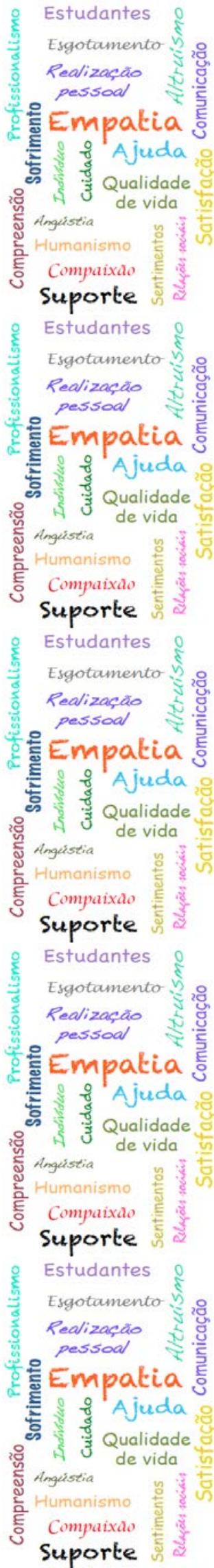

1 INTRODUÇÃO 
A empatia é uma habilidade multidimensional que permite perceber e entender o sentimento e a perspectiva do outro. É considerada uma virtude, mas também é vista como um processo intelectual e um comportamento a ser aprendido e aprimorado durante a vida. Como habilidade, representa um dos domínios centrais da inteligência emocional, das habilidades sociais e de comunicação (Davis, 1996; Rocha, 2010; Schutte et al., 2001).

O comportamento empático é um elemento importante do profissionalismo na área da saúde e envolve: escuta ativa, identificação de problemas e das emoções vinculadas a eles, linguagem corporal e expressão da empatia (Rogers, 1975; 1992; Stepien; Baernstein, 2006).

Além de ser uma das dimensões humanísticas mais mencionadas na medicina (Linn et al., 1987; Arnold, 2002; O'Sullivan et al., 2012), a empatia também está associada a melhores resultados diagnósticos e terapêuticos no contexto clínico (Stepien; Baernstein, 2006; Hojat, 2007). Por esse motivo, ganhou expressão na educação médica nas últimas décadas e tem sido objeto de estudo de várias pesquisas com estudantes, residentes e profissionais da área da saúde (Stepien; Baernstein, 2006).

No entanto, a habilidade empática nem sempre foi tão ressaltada no contexto da saúde. Os valores humanísticos da prática médica tiveram papel secundário por várias décadas do século XX. Os expressivos avanços da medicina desse século colocaram o tecnicismo em evidência, em detrimento das relações humanas. Apenas partir da década de 80, com o estímulo das mudanças científicas, econômicas e sociais, observamos um movimento de resgate desses valores humanísticos e éticos na medicina. Desde então, as habilidades humanísticas passaram a ser prioridade das associações médicas 
no contexto internacional (ABIM, 1983). Esse movimento, conhecido com Projeto Humanismo (Arnold, 2002), aborda o respeito, a compaixão e a integridade como características essenciais do profissional médico (ABIM, 1983; Arnold, 2002). Essas características estão intimamente relacionadas ao comportamento empático.

Tais características humanas e éticas foram incorporadas à agenda do profissionalismo (Medical Professionalism Project, 2002) no final da década de 90 pelas principais organizações e associações médicas ao redor do mundo: American Board of Internal Medicine, American College of Physicians, American Society of Internal Medicine, European Federation of Internal Medicine.

Embora apresentem visões singulares sobre 0 conceito de profissionalismo na medicina, as diferentes organizações apontam o altruísmo (um comportamento da orientação empática) como componente essencial da relação médico-paciente e primordial para o princípio da primacia pelo bem estar do paciente (Burks; Kobus, 2012; Medical Professionalism Project, 2002).

A preocupação com o bem estar do paciente, com a qualidade do cuidado na saúde e com o resgate dos valores éticos e humanísticos da profissão médica também é compartilhada pelas principais diretrizes de formação médica: Association of American Medical Colleges (Medical Schools Objectives Writing Group, 1999), Tomorrow's Doctors (General Medical Council, 2003), Global Standads in Medical Education for Better Health Care (World Federation for medical Education, 2003), Doctors in Society (Royal College of Physicians, 2005). 
Essas diretrizes delineiam competências técnicas, cognitivas e emocionais necessárias para a formação do profissional e enfatizam a importância do profissionalismo, das habilidades interpessoais e de comunicação (Epstein; Hundert, 2002).

No Brasil, as Diretrizes Curriculares Nacionais (DCN) para os cursos de graduação em medicina, homologadas em 2001 pelo Ministério da Educação (Brasil, 2001), trazem aspectos comuns à agenda do profissionalismo e apontam como competências gerais do egresso: atenção à saúde, tomada de decisões, comunicação, liderança, administração e gerenciamento, educação permanente. Essas competências dependem essencialmente do desenvolvimento e aprimoramento das competências emocionais do estudante, entre elas a empatia (Arora et al., 2010).

O conceito de competência é aqui admitido como "o uso habitual e sensato de habilidades de comunicação, conhecimento, habilidades técnicas, raciocínio clínico, emoções, valores e reflexão diária para benefício do paciente ou da comunidade" (Epstein; Hundert, 2002), e competência emocional emocional como "a habilidade de perceber, expressar e usar as emoções para facilitar interações sociais" (Salovey; Mayer, 1990; Bar-On, 1997; Goleman, 1998). A empatia é fundamental para o desenvolvimento dessas competências (Cherry et al., 2012), daí sua importância na educação médica (Harden et al., 1999).

Apesar das diretrizes de formação apontarem para a importância das competências emocionais dos estudantes, existem poucos estudos brasileiros nessa temática. Esses estudos trazem abordagens principalmente conceituais (Sampaio et al., 2009; Costa et al., 2010; Stock et al., 2012). Em publicações 
internacionais, observamos a avaliação de algumas iniciativas pedagógicas para o desenvolvimento da empatia (Bombeke et al., 2011) e a descrição das habilidades empáticas dos estudantes em trabalhos transversais (Bellini et al., 2002; Hojat et al., 2004; Newton et al., 2008) e longitudinais (Hojat et al., 2009). Os resultados desses estudos apontam que a empatia dos estudantes não sofre modificações ao longo do curso (Magalhães et al., 2012), ou ainda revelam uma deterioração das habilidades empáticas dos estudantes em anos mais avançados do curso (Bombeke et al., 2011; Hojat et al., 2009).

Em uma tentativa de compreender o contexto educacional em que se concebem esses resultados, pesquisadores buscam analisar a associação da empatia dos estudantes de medicina aos possíveis fatores estressores ligados à formação médica e à qualidade de vida do estudante (DiLalla; 2004; Neumann et al., 2011; Stratton et al., 2008; Thomas et al., 2007). São citados como fatores estressores do ambiente de ensino: carga horária excessiva (Guthrie et al., 1998), o contato com a doença e com a morte (MacLeod et al., 2003; Wear, 2002) e o próprio currículo (Hafferty, 1998; Kiessling et al., 2004; Moffat et al., 2004; Wilson et al., 1996). Somam-se a esses fatores aspectos relacionais dentro da escola médica, como o abuso moral e a competitividade (Neumann et al., 2011).

O grande interesse dos educadores em analisar essas associações reside no fato de que o ambiente de ensino pode atuar como um fator estressor e contribuir para a estagnação da empatia ou mesmo para sua perda.

Nosso estudo justifica-se pela necessidade de melhor compreender o desenvolvimento da empatia entre estudantes de medicina e os fatores determinantes desse processo. 
Portanto, avaliar a empatia dos estudantes de medicina e sua associação a fatores como sonolência e estresse, e de forma mais abrangente à sua qualidade de vida, responde a uma demanda no contexto da educação médica atual.

\subsection{Empatia: aspectos conceituais e questionários}

O termo empatia (do grego, empátheia - apreciação do sentimento do outro), em seu sentido mais amplo, pode ser definido como as reações cognitivas e emocionais de um indivíduo frente às experiências do outro. $\mathrm{O}$ conceito engloba um conjunto de construtos e atributos (Davis, 1983).

Historicamente, percebemos controvérsia e dualidade nos conceitos propostos para o termo empatia. As principais teorias contrastam os aspectos afetivos ou cognitivos do construto.

O termo "empatia" é um neologismo advindo da palavra alemã "Einfuhlung", usada pela primeira vez para descrever os sentimentos de um observador diante de obras de arte (Hojat, 2007) e a tendência de projetar-se emocionalmente para o objeto observado (Davis, 1996). Essa perspectiva do conceito aborda aspectos meramente afetivos.

Ainda na visão afetiva, Lipps (apud Davis, 1996) trouxe o termo para o campo da psicologia em 1903 para descrever o processo afetivo pelo qual as pessoas sentem-se no lugar do outro. Sigmund Freud também utilizou o termo "Einfuhlung" para descrever a psicodinâmica de colocar-se na posição do outro 
(apud Pigman, 1995). Percebemos aqui, apesar do predomínio da visão afetiva, o início de uma abordagem cognitiva para a definição de empatia.

A mudança para uma abordagem essencialmente cognitiva da empatia veio com Kohler, em 1923 (apud Davis, 1996). Esse teórico definiu empatia como a capacidade de compreender (mais do que compartilhar) as experiências do outro. Na mesma época, Mead e Piaget (apud Davis, 1996) trouxeram a importância da tomada de perspectiva e do abandono da visão egocêntrica para a efetivação das interações sociais.

Nas décadas de 40 e 50, o termo acurácia social (Chapin, 1942; Dymond, 1950; Kerr; Speroff, 1954) surge na definição de empatia e consagra a força da visão cognitiva do construto.

Não obstante, a empatia volta a ser um construto meramente afetivo na visão de teóricos contemporâneos, dos quais Stotland e Dunn (1963) são um dos primeiros representantes. Esses autores definem empatia como uma reação emocional à emoção do outro. Batson (1987) traz a ideia dos sentimentos de compaixão e preocupação para o construto.

O contraste das definições começa a ser atenuado com as propostas conceituais de Hoffman (1977): a empatia passa a ser uma "reposta afetiva mais apropriada à situação do outro do que à própria situação". Essa definição engloba tanto aspectos cognitivos - a tomada de perspectiva, como aspectos afetivos - sentimentos de angústia e preocupação (Davis, 1996).

Apesar de representar um avanço na definição da empatia, as visões contemporâneas de Hoffman ainda apresentam o problema de abordar os aspectos cognitivos e afetivos como dois fenômenos exclusivos (Davis, 1996). 
Em uma tentativa de formular um conceito inclusivo de empatia, Davis (1996) foi o primeiro a estabelecer uma definição mais ampla para o termo: "um conjunto de construtos relacionados às respostas de um indivíduo às experiências de outro". Sua proposta engloba tanto o processo cognitivo quanto as consequências intrapessoais e interpessoais advindas da empatia. $\mathrm{O}$ autor propõe um modelo organizacional que estabelece as conexões entre esses diferentes construtos (Davis, 1996).

Nesse modelo, o domínio dos antecedentes refere-se às características do observador, do alvo ou da situação. Os processos referem-se aos mecanismos pelos quais os resultados intrapessoais e interpessoais são produzidos. Os resultados intrapessoais relacionam-se às respostas cognitivas e afetivas produzidas no observador e os resultados interpessoais referem-se às respostas comportamentais direcionadas ao alvo (Figura 1) (Davis, 1996).

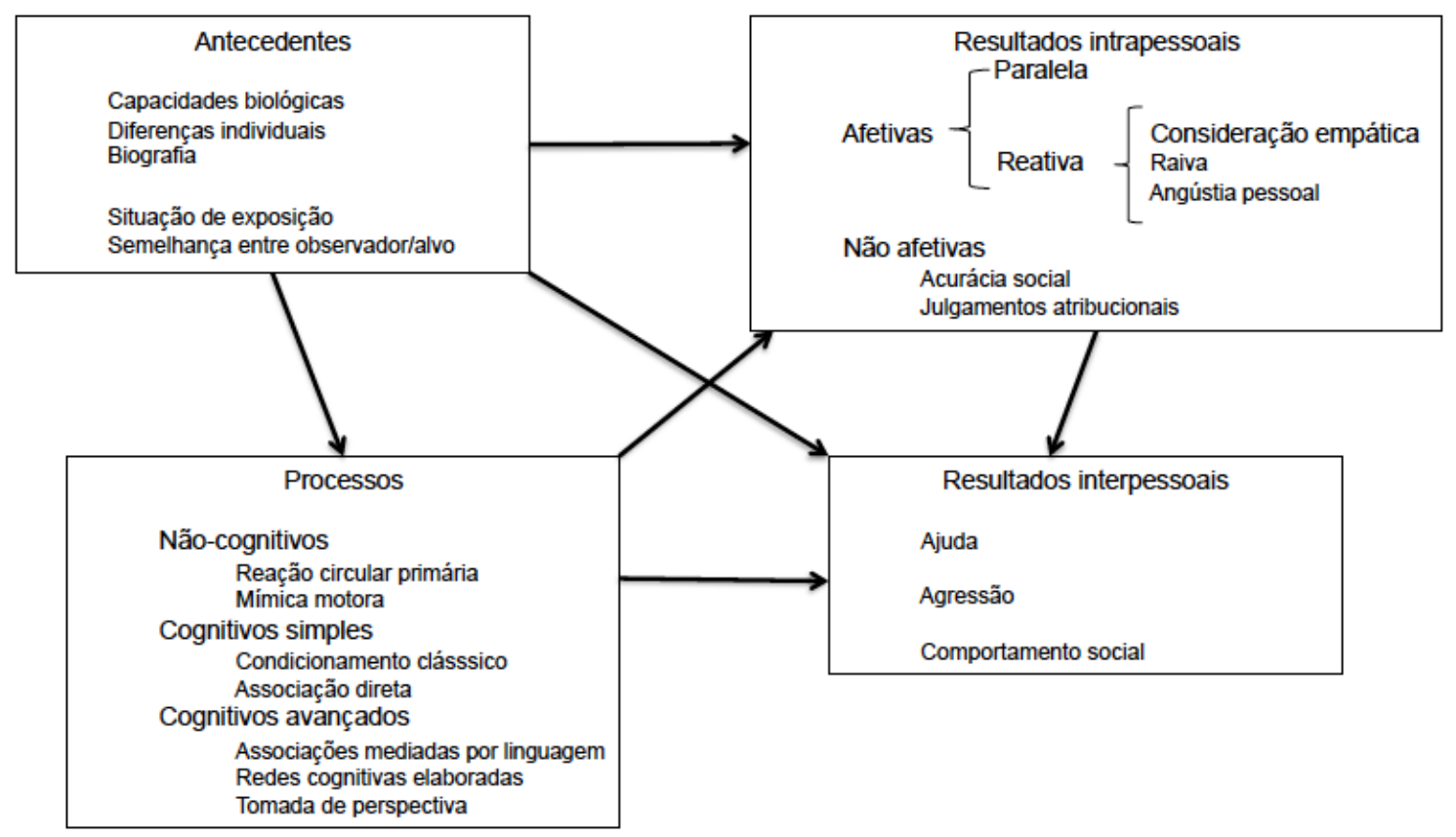

Figura 1 - O modelo organizacional de empatia de Davis 
Podemos comparar esses domínios àqueles abordados na definição de empatia para o contexto clínico (Stepien; Baernstein, 2006). Nesse contexto, empatia clínica inclui as dimensões moral, motivação interna do indivíduo para entender a perspectiva do paciente; cognitiva, capacidade intelectual para identificar e entender a perspectiva do paciente; emotiva habilidade de imaginar os sentimentos e perspectivas do paciente; e comportamental, capacidade de transmitir ao paciente a compreensão dos seus sentimentos e perspectivas (Stepien; Baernstein, 2006).

Como percebemos, a existência de diversos conceitos distintos de empatia e a multidimensionalidade inerente ao termo resultam em dificuldades para sua mensuração. Muitos instrumentos têm a característica de avaliar um construto relacionado ao conceito e excluir outras possíveis dimensões igualmente ligadas à empatia.

Em uma revisão sistemática dos testes de empatia utilizados na avaliação de estudantes de medicina e médicos, Hemmerdinger et al. (2007) relataram a existência de oito questionários com evidência de validade e confiabilidade. Entre eles, seis eram escalas de autorrelato e dois de observação do comportamento empático.

O autorrelato depende muito do autoconhecimento e apresenta a possibilidade do viés de resposta. O respondente tende a apresentar-se da forma mais positiva e socialmente aceita - social desirability (Hojat, 2007). Contudo, vários pesquisadores argumentam que essas escalas avaliam as disposições empáticas e são capazes de representar as habilidades medidas (Hojat, 2007; Falcone et al., 2008). De fato, percebemos que a maioria dos 
questionários de empatia empregados nas Ciências Humanas e da Saúde utilizam essa forma de medida (Quadro 1).

Quadro 1 - Questionários de avaliação de empatia validados

\begin{tabular}{|c|c|c|c|c|}
\hline Instrumento & Autores & $\begin{array}{l}\text { Dimensões } \\
\text { avaliadas } \\
\text { Número itens }\end{array}$ & Pessoa & $\begin{array}{l}\text { Versão } \\
\text { brasileira }\end{array}$ \\
\hline BEES & $\begin{array}{l}\text { Mehrabian; } \\
\text { Epstein, } 1972\end{array}$ & $\begin{array}{l}\text { Afetiva } \\
30 \text { itens }\end{array}$ & $\begin{array}{l}1^{\mathrm{a}} \text { pessoa } \\
\text { Autorrelato }\end{array}$ & - \\
\hline EMRI & Davis, 1980; 1983 & $\begin{array}{l}\text { Afetiva } \\
\text { Cognitiva } \\
28 \text { itens }\end{array}$ & $\begin{array}{l}1^{\mathrm{a}} \text { pessoa } \\
\text { Autorrelato }\end{array}$ & $\begin{array}{l}\text { Koller et al, } 2005^{\star} \\
\text { Sampaio et al., } \\
2011^{\star \star}(49)\end{array}$ \\
\hline ECRS & LaMonica, 1981 & Afetiva & $\begin{array}{l}1^{\mathrm{a}} \text { pessoa } \\
\text { Autorrelato }\end{array}$ & - \\
\hline JSE & Hojat et al., 2001 & $\begin{array}{l}100 \text { itens } \\
\text { Cognitiva } \\
\text { Afetiva } \\
20 \text { itens }\end{array}$ & $\begin{array}{l}1^{\mathrm{a}} \text { pessoa } \\
\text { Autorrelato }\end{array}$ & Paro et al., 2012 \\
\hline CARE & Mercer et al., 2004 & $\begin{array}{l}\text { Comportamental } \\
\text { Cognitiva } \\
\text { Afetiva } \\
10 \text { itens }\end{array}$ & $\begin{array}{l}2^{a} \text { pessoa } \\
\text { Relato do } \\
\text { paciente }\end{array}$ & - \\
\hline FHCS & Krupat et al., 2006 & $\begin{array}{l}\text { Comportamental } \\
\text { Cognitiva } \\
23 \text { itens }\end{array}$ & $\begin{array}{l}3^{\mathrm{a}} \text { pessoa } \\
\text { Observador } \\
\text { externo }\end{array}$ & - \\
\hline IE & Falcone et al., 2008 & $\begin{array}{l}\text { Cognitiva } \\
\text { Afetiva } \\
40 \text { itens }\end{array}$ & $\begin{array}{l}1^{\mathrm{a}} \text { pessoa } \\
\text { Autorrelato }\end{array}$ & Versão original \\
\hline
\end{tabular}

*Versão com 21 itens ** Versão com 28 itens

BEES: Balanced Emotional Empathy Scale; EMRI: Escala Multidimensional de Reatividade Interpessoal de Davis; ECRS: Empathy Construct Rating Scale; JSE: Escala Jefferson de Empatia; CARE: Consultation and Relational Empathy; FHCS: The Four Habits Coding Scheme; IE: Inventário de Empatia

$\mathrm{Na}$ revisão de Hemmerdinger et al. (2007), dois questionários de empatia, o Consultation and Relational Empathy (CARE) e o The Four Habits Coding Scheme (FHCS), merecem destaque por dependerem da observação 
do comportamento empático, e não do autorrelato. O primeiro (CARE) refere-se a uma escala simples, composta por 10 itens, direcionada ao comportamento empático. O questionário utiliza a percepção do paciente acerca da atitude do médico na consulta (Mercer et al., 2004). O segundo (FHCS) avalia a entrevista médica por meio de quatro domínios principais, dois deles relacionados à empatia: "extração da perspectiva do paciente" e "demonstração de empatia" (Krupat et al., 2006). O questionário depende da codificação de um observador externo. Esses dois instrumentos têm a vantagem de diminuir a possibilidade do viés de resposta produzido pela tendência do indivíduo em responder de uma forma socialmente esperada. No entanto, até o momento, não existem versões validadas desses questionários para uso no Brasil.

Dentre os questionários de avaliação de empatia, percebemos que nem todos consideram a sua natureza multidimensional e abordam apenas uma dimensão do construto. Como exemplo, citamos a Balanced Emotional Empathy Scale (BEES) e a Empathy Construct Rating Scale (ECRS), que avaliam exclusivamente a dimensão afetiva. Destacamos a importância da Escala Multidimensional de Reatividade Interpessoal de Davis (EMRI) (Davis, 1980; Davis, 1983) e da Escala Jefferson de Empatia (JSE) (Hojat et al., 2001) por abrangerem domínios tanto afetivos quanto cognitivos. A EMRI abrange os domínios afetivos e cognitivos em uma abordagem ampla e inclusiva do construto. Já a Escala Jefferson de Empatia (JSE) (Hojat et al., 2001), específica para o contexto clínico, avalia predominantemente o domínio cognitivo da empatia, mas também aborda alguns aspectos afetivos (Quadro 1). 
1.2 Qualidade de vida: aspectos conceituais e questionários

Conceitos mais contemporâneos de qualidade de vida levam em consideração alguns modelos teóricos do construto. A teoria da satisfação de desejos ou preferências traz a ideia de qualidade de vida como o alcance daquilo que o indivíduo considera importante para sua vida, e, dessa forma, ressalta a autonomia e a subjetividade do conceito (Sandøe, 1999). Segundo essa teoria, uma boa qualidade de vida é atingida quando os desejos individuais alcançados satisfazem as expectativas, ou seja, quando há a menor distância entre os objetivos alcançados e os almejados (de Leval, 1999; Moore et al., 2005; Sandøe, 1999).

Essa teoria embasa o conceito atual de qualidade de vida formulado pela Organização Mundial de Saúde (OMS): "a percepção do indivíduo de sua posição na vida no contexto cultural e no sistema de valores em que ele vive e em relação a seus objetivos, expectativas, preocupações e desejos". Tal definição realça a subjetividade e multidimensionalidade do conceito, bem como a sua bipolaridade por incluir dimensões tanto positivas quanto negativas (The WHOQOL Group, 1995). Nesse sentido, esse conceito contempla uma visão holística do ser humano e contribui para a mudança do paradigma mecanicista da saúde.

Embora a construção de modelos teóricos tenha contribuído para o progresso conceitual e metodológico do termo qualidade de vida, em termos práticos, essa definição ainda enfrenta desafios.

O primeiro desafio está relacionado à abrangência dos múltiplos domínios relacionados ao termo. Algumas dimensões parecem incluir os 
aspectos mais relevantes do conceito de qualidade de vida, como as dimensões físicas, psicológicas, sociais e funcionais (Bullinger, 2002; The WHOQOL Group, 1995).

Outros domínios também podem ser incluídos para determinar esta multidimensionalidade: ambiente, espiritualidade, religiosidade, crenças pessoais e autonomia (The WHOQOL Group, 1995).

Além do aspecto multidimensional que mencionamos, a subjetividade que acompanha esses conceitos pode justificar a teoria de alguns autores de que qualidade de vida não pode ser bem definida e, consequentemente, não permite mensuração (Bullinger, 2002). Nesse sentido, podemos afirmar que o caráter individual atribuído a esse construto representa uma complexidade para as medidas de qualidade de vida (Carr; Higginson, 2001).

Dentro do aspecto individual do conceito, a percepção de qualidade de vida também é considerada temporal e circunstancial, uma vez que muda ao longo da vida e de acordo com as circunstâncias vividas (Petrone, 1994; Tempski-Fiedler, 2008).

Diante desses aspectos individuais, os questionários de qualidade de vida baseiam-se essencialmente na autopercepção. Não podemos negar o fato de que o julgamento de valores necessário ao conceito de qualidade de vida depende do autoconhecimento (Petrone, 1994), outra dificuldade inerente à avaliação da qualidade de vida entre os estudos.

Apesar das dificuldades de definição e mensuração da qualidade de vida, esforços têm sido direcionados à tentativa de transformar esses julgamentos subjetivos em escalas numéricas passíveis de análise e interpretação. Desse modo, a mensuração da qualidade de vida tem sido 
realizada por meio de questionários construídos a partir de vários itens ou perguntas que são agrupados nas diferentes dimensões ou domínios correspondentes às áreas do comportamento ou às experiências que se pretende medir (Guyatt et al, 1993).

Os questionários de qualidade de vida podem ser classificados em genéricos ou específicos. Os primeiros foram desenvolvidos com a finalidade de descrever e comparar qualidade de vida em diversas populações, permitir o amplo uso em diferentes situações e possibilitar a identificação de repercussões inesperadas de uma determinada condição ou intervenção (Berlim; Fleck, 2005; Garratt et al., 2002; Guyatt et al., 1993).

Os instrumentos específicos abordam aspectos relevantes para uma determinada população, dimensão ou condição. Por essa razão, apresentam maior sensibilidade (Berlim; Fleck, 2005; Garrat et al., 2002; Guyatt et al., 1993).

O desenvolvimento de medidas de qualidade de vida específicas para estudantes de medicina surgiu da importância de promover o bem-estar dessa população durante sua trajetória de formação. Até o momento, identificamos iniciativas de dois grupos de pesquisa na educação médica nessa direção.

O grupo de Dyrbye et al. (2010b) desenvolveu e validou o Medical Student Well-Being Index (MSWBI) em uma amostra de 2.248 estudantes provenientes de sete escolas médicas nos Estados Unidos da América. $O$ instrumento possui sete itens que abrangem os seguintes domínios: esgotamento profissional (exaustão emocional e despersonalização), depressão, fadiga, estresse e qualidade de vida (física e mental) (Dyrbye et al., 2010b). Os itens foram retirados ou adaptados de questionários de validade e 
confiabilidade consagradas como Maslach Burnout Inventory (MBI), Primary Care Evaluation of Mental Disorder (PRIME-MD), escala de sonolência diurna de Epworth (ESS), Perceived Stress Scale (PSS) e Medical Outcomes Survey - Short Form (SF-8).

O instrumento apresenta boa confiabilidade e demonstrou-se capaz de rastrear os principais problemas emocionais dos estudantes de medicina (Dyrbye et al., 2010b; 2011b). Apesar de ter sido concebido como um índice para avaliar o bem estar dos estudantes, percebemos que o instrumento aborda aspectos meramente negativos relacionados ao desgaste emocional dessa população.

Já o grupo de Tempski et al. (2009) concebeu um questionário para a avaliação da qualidade de vida do estudante de medicina a partir das concepções dessa população acerca do construto. Para isso, os pesquisadores conduziram grupos focais com estudantes de diversas escolas brasileiras. Nos grupos focais, Tempski et al. (2009) analisaram o conteúdo das entrevistas em busca de aspectos conceituais e fatores determinantes da qualidade de vida desse grupo de estudantes (Tempski et al., 2012). O questionário contém 45 itens, distribuídos em quatro domínios: uso do tempo, psicológico, físico e ambiente de ensino (Tempski et al., 2009). É um instrumento robusto, com boa confiabilidade e validade (Tempski et al., 2009). Esse questionário abrange aspectos positivos e negativos da qualidade de vida dos estudantes de medicina, ou seja, é capaz de englobar a bipolaridade inerente ao construto. Ainda, dá conta dos atributos da multidimensionalidade e subjetividade do termo. 
Em um estudo sobre a qualidade de vida do estudante de medicina com avaliação por meio do Veras-q, Tempski-Fiedler (2008) observou pior percepção de qualidade de vida entre estudantes do sexo feminino e entre estudantes do terceiro e quarto anos do curso - o que a autora denominou de "crise do meio". Ainda nesse estudo, a autora avaliou a sonolência dos estudantes e constatou que aproximadamente metade da sua amostra apresentava sonolência diurna excessiva, provavelmente atribuída à privação do sono (Tempski-Fiedler, 2008).

1.3 Empatia, qualidade de vida, sono e outras variáveis

Sabemos que a privação do sono pode estar relacionada a problemas como ansiedade, depressão e estresse (Rosal et al., 1997; Eller et al., 2006). A privação do sono ainda pode associar-se com dificuldades na transmissão e fluidez de ideias e levar a um prejuízo das habilidades de comunicação e das interações sociais (Harrison; Horne, 2000).

Sendo a empatia uma característica essencial da comunicação e do estabelecimento de vínculos sociais, poderíamos aventar a hipótese de que a privação do sono associa-se a piores habilidades empáticas. Essas associações ainda devem ser melhor exploradas em estudos com desenhos epidemiológicos apropriados.

Observamos algumas iniciativas nas pesquisas em educação médica com o intuito de estabelecer essas associações teóricas. Os principais estudos com enfoque na associação entre variáveis relacionadas ao desgaste 
emocional, empatia, qualidade de vida e sono dos estudantes de medicina apontam para uma correlação direta entre competências emocionais, desempenho acadêmico e profissionalismo.

Resultados de algumas dessas iniciativas demonstram que estudantes com baixa qualidade de vida e alto esgotamento profissional ("burnout") têm maior risco de envolverem-se em atividades antiéticas (Dyrbye et al., 2010a), além de apresentarem um prejuízo de suas disposições empáticas (Thomas et al., 2007).

Podemos observar que as principais iniciativas em explorar a relação entre qualidade de vida e desempenho profissional advêm de estudos norteamericanos multicêntricos (Dyrbye et al., 2006a; 2008; 2009; 2010a; 2012; Reed et al., 2011; Thomas et al., 2007). O desenho multicêntrico tem a vantagem de ampliar a amostra e a generalização dos resultados. No entanto, apesar do grande número de estudantes avaliados nessas iniciativas, os resultados devem ser interpretados com cautela. A seleção de estudantes por conveniência pode trazer vieses às conclusões, limitação frequente dos principais trabalhos publicados nessa área. Para dados adicionais sobre estudos multicêntricos em educação médica e suas limitações, ver Apêndice A.

Em uma tentativa de minimizar os possíveis vieses advindos de uma amostra de conveniência, conduzimos um estudo multicêntrico com uma amostra randomizada de estudantes de medicina brasileiros. Nossa hipótese é que há uma associação entre melhores percepções de qualidade de vida, sono, menor esgotamento profissional e maior disposição empática entre os estudantes de medicina. 

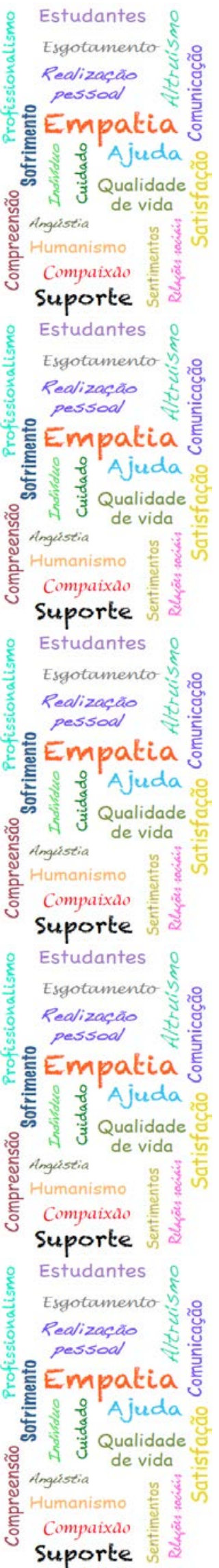

2 OBJETIVOS 


\subsection{Objetivo geral}

Avaliar a empatia do estudante de medicina e sua associação com qualidade de vida, esgotamento profissional e sonolência diurna.

\subsection{Objetivos específicos}

- Avaliar se há diferença de gênero na empatia, qualidade de vida, esgotamento profissional e sonolência diurna do estudante de medicina;

- Avaliar se empatia, qualidade de vida, esgotamento profissional e sonolência diurna do estudante de medicina diferem entre os ciclos do curso;

- Testar se há associação entre empatia do estudante de medicina e qualidade de vida, esgotamento profissional e sonolência diurna. 


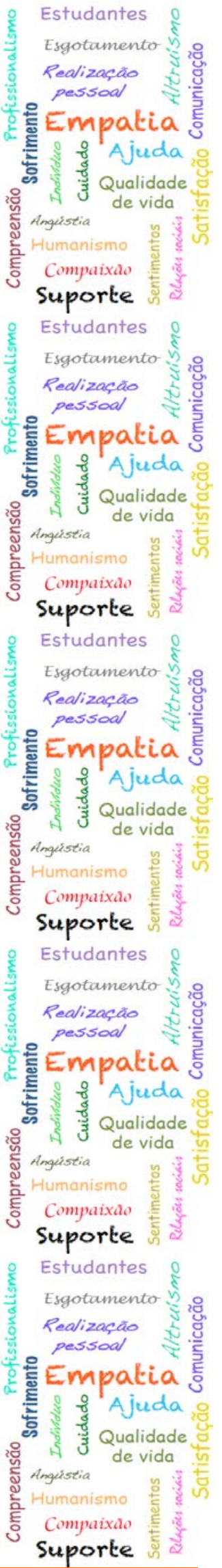

3 MÉTODOS 
O presente estudo foi aprovado pelo Comitê de Ética em Pesquisa da Faculdade de Medicina da Universidade de São Paulo (CEP-FMUSP), protocolo de pesquisa número 485/11 (Anexo A). Essa pesquisa é parte integrante do projeto VERAS (Vida do Estudante e Residente da Área da Saúde), aprovação CEP-FMUSP $n^{\circ}$ 181/11. O projeto VERAS tem financiamento a partir de recursos da CAPES, dentro do projeto aprovado no Edital 24/2010 - Pró-Ensino na Saúde.

\subsection{Instituições de ensino superior participantes}

Trata-se de um estudo multicêntrico nacional, com a participação de 22 escolas médicas de todas as regiões do Brasil (Quadro 2; Figura 2) e 38 pesquisadores locais. As escolas foram escolhidas de maneira a representar a diversidade das escolas médicas brasileiras quanto à localização (regiões do país, escolas de capitais e do interior), tempo de funcionamento (ano de abertura), tamanho (número de vagas), natureza jurídica (pública ou privada) e método de ensino (tradicional e aprendizado baseado em problemas - ABP). Definimos como critérios de inclusão das instituições participantes: ter estudantes cursando o sexto ano do curso e pesquisadores locais com linhas de pesquisa ou interesse na temática estudada, além de aprovação da Direção da Instituição de Ensino Superior. 
Quadro 2 - Caracterização das Instituições de Ensino Superior participantes do Projeto VERAS

\begin{tabular}{|c|c|c|c|c|}
\hline $\begin{array}{l}\text { Nome da Instituição de Ensino } \\
\text { Superior }\end{array}$ & Cidade/UF & $\begin{array}{l}\text { Natureza } \\
\text { jurídica }\end{array}$ & $\begin{array}{l}\text { Ano de } \\
\text { abertura }\end{array}$ & $\begin{array}{l}\text { Vagas } \\
\text { / ano }\end{array}$ \\
\hline $\begin{array}{l}\text { Escola Bahiana de Medicina e } \\
\text { Saúde Pública (EBMSP) }\end{array}$ & Salvador/BA & Privada & 1953 & 190 \\
\hline $\begin{array}{l}\text { Faculdade de Medicina de Marília } \\
\text { (FAMEMA) }\end{array}$ & Marília/SP & Pública & 1966 & 80 \\
\hline $\begin{array}{l}\text { Faculdade de Medicina de São } \\
\text { José do Rio Preto (FAMERP) }\end{array}$ & $\begin{array}{l}\text { São José Rio } \\
\text { Preto/SP }\end{array}$ & Pública & 1968 & 64 \\
\hline $\begin{array}{l}\text { Faculdade de Ciências Médicas da } \\
\text { Paraíba (FCMPB) }\end{array}$ & $\begin{array}{l}\text { João } \\
\text { Pessoa/PB }\end{array}$ & Privada & 2004 & 100 \\
\hline $\begin{array}{l}\text { Faculdade Evangélica do Paraná } \\
\text { (FEPAR) }\end{array}$ & Curitiba/PR & Privada & 1969 & 100 \\
\hline $\begin{array}{l}\text { Faculdade de Medicina do ABC } \\
\text { (FMABC) }\end{array}$ & $\begin{array}{l}\text { Santo } \\
\text { André/SP }\end{array}$ & Privada & 1969 & 100 \\
\hline $\begin{array}{l}\text { Fundação Universidade Federal de } \\
\text { Rondônia (UNIR) }\end{array}$ & $\begin{array}{l}\text { Porto } \\
\text { Velho/RO }\end{array}$ & Pública & 2002 & 40 \\
\hline $\begin{array}{l}\text { Pontifícia Universidade Católica do } \\
\text { Rio Grande do Sul (PUC-RS) }\end{array}$ & $\begin{array}{l}\text { Porto } \\
\text { Alegre/RS }\end{array}$ & Privada & 1970 & 74 \\
\hline $\begin{array}{l}\text { Pontifícia Universidade Católica de } \\
\text { São Paulo (PUC-SP-Sorocaba) }\end{array}$ & Sorocaba/SP & Privada & 1950 & 100 \\
\hline $\begin{array}{l}\text { Universidade de São Paulo (USP- } \\
\text { SP) }\end{array}$ & São Paulo/SP & Pública & 1912 & 175 \\
\hline $\begin{array}{l}\text { Universidade Estadual do Piauí } \\
\text { (UESPI) }\end{array}$ & Teresina/PI & Pública & 1998 & 84 \\
\hline $\begin{array}{l}\text { Universidade Federal do Ceará } \\
\text { (UFC-Sobral) }\end{array}$ & Sobral/CE & Pública & 2000 & 80 \\
\hline $\begin{array}{l}\text { Universidade Federal de Ciências } \\
\text { da Saúde de Porto Alegre } \\
\text { (UFCSPA) }\end{array}$ & $\begin{array}{l}\text { Porto } \\
\text { Alegre/RS }\end{array}$ & Pública & 1961 & 88 \\
\hline $\begin{array}{l}\text { Universidade Federal de Goiás } \\
\text { (UFG) }\end{array}$ & Goiânia/GO & Pública & 1960 & 110 \\
\hline $\begin{array}{l}\text { Universidade Federal de Mato } \\
\text { Grosso do Sul (UFMS) }\end{array}$ & $\begin{array}{l}\text { Campo } \\
\text { Grande/MS }\end{array}$ & Pública & 1967 & 80 \\
\hline $\begin{array}{l}\text { Universidade Federal do Rio de } \\
\text { Janeiro (UFRJ) }\end{array}$ & $\begin{array}{l}\text { Rio de } \\
\text { Janeiro/RJ }\end{array}$ & Pública & 1808 & 192 \\
\hline $\begin{array}{l}\text { Universidade Federal do Tocantins } \\
\text { (UFT) }\end{array}$ & Palmas/TO & Pública & 2007 & 80 \\
\hline $\begin{array}{l}\text { Universidade Federal de Uberlândia } \\
\text { (UFU) }\end{array}$ & Uberlândia/MG & Pública & 1968 & 80 \\
\hline $\begin{array}{l}\text { Universidade Estadual Paulista } \\
\text { Júlio de Mesquita Filho (UNESP) }\end{array}$ & Botucatu/SP & Pública & 1962 & 90 \\
\hline $\begin{array}{l}\text { Centro Universitário Serra dos } \\
\text { Órgãos (UNIFESO) }\end{array}$ & Teresópolis/RJ & Privada & 1970 & 144 \\
\hline $\begin{array}{l}\text { Universidade de Fortaleza } \\
\text { (UNIFOR) }\end{array}$ & Fortaleza/CE & Privada & 2006 & 120 \\
\hline $\begin{array}{l}\text { Universidade de Passo Fundo } \\
\text { (UPF) }\end{array}$ & $\begin{array}{l}\text { Passo } \\
\text { Fundo/RS }\end{array}$ & Privada & 1969 & 80 \\
\hline
\end{tabular}

Fonte: www.escolasmedicas.com.br 


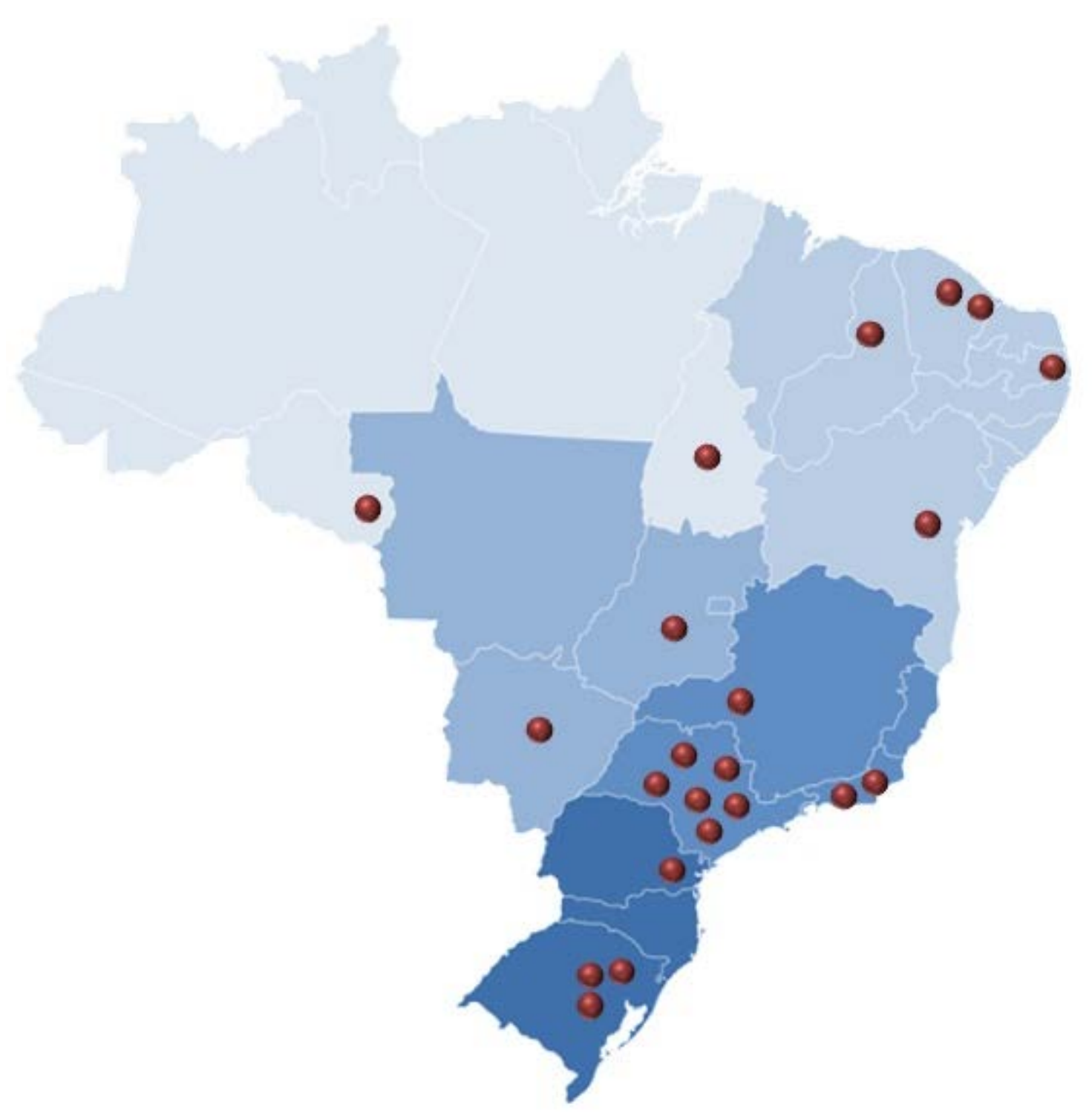

Figura 2 - Distribuição geográfica das Instituições de Ensino Superior participantes do Projeto VERAS 


\subsection{Sujeitos da pesquisa}

Esse estudo teve como sujeitos os estudantes de medicina do Brasil. No Brasil existem atualmente 201 escolas médicas que compreendem um universo aproximado de 110.000 estudantes.

O tamanho da amostra para esse universo, com uma margem de erro máximo de $5 \%$, e poder estatístico de $80 \%$ seria de pelo menos 384 estudantes (Cochran, 1996). Estimamos uma amostra desejada de 1.152 estudantes para possibilitar análises de acordo com o gênero e anos do curso.

Durante as análises, os anos do curso foram agrupados nos três ciclos de aprendizagem tradicionalmente observados na maioria das escolas médicas brasileiras: ciclo básico (primeiro e segundo anos), ciclo intermediário (terceiro e quarto anos) e profissionalizante (quinto e sexto anos) (Lampert et al., 2009).

Optamos por recrutar uma amostra randomizada por meio de tabela de números aleatórios gerada por computador. Pesquisadores locais das escolas participantes foram orientados a randomizar o mínimo de 60 estudantes, 10 estudantes por ano de curso, em igual proporção entre sexo feminino e masculino.

\subsection{Plataforma veras}

O Projeto VERAS idealizou o uso de um sistema eletrônico desenvolvido pelos próprios pesquisadores como forma de coleta de dados. O sistema da plataforma VERAS é acessível a qualquer público através da Internet e utiliza 
páginas dinâmicas construídas com HTML e línguas PERL, com suporte de banco de dados MySQL, escolhidos pela gratuidade do uso ("freeware"). O sistema Web destinado à coleta dos dados da pesquisa foi desenvolvido de maneira a garantir a confidencialidade e o anonimato das respostas dos participantes. Esse sistema foi denominado Plataforma VERAS, acessada no endereço eletrônico www.veras.logicamix.com.

Após o preenchimento "online" do Termo de Consentimento Livre e Esclarecido (Anexo B), os estudantes tinham acesso ao questionário sóciodemográfico por meio de "login" e senha gerados automaticamente pelo sistema e enviados ao e-mail cadastrado do respondente. Os demais questionários da pesquisa eram disponibilizados em ordem aleatória. A disponibilização de um novo questionário somente era possível após a finalização do questionário anterior, como forma de evitar a perda de dados relacionadas aos itens.

Os estudantes tinham um prazo de 10 dias para completarem suas respostas na plataforma e recebiam uma comunicação eletrônica a cada dois dias caso houvessem questionários incompletos durante esse prazo. Após completarem todos os questionários, os estudantes tinham acesso a um relatório individual gerado automaticamente pelo sistema com a interpretação dos seus escores. A equipe de pesquisa disponibilizou um espaço de contato direto caso o estudante desejasse discutir seus resultados. Os respondentes também foram orientados quanto à possibilidade de buscar auxílio junto ao pesquisador local. 


\subsubsection{Instrumentos}

A plataforma VERAS utiliza questionários validados para o estudo das variáveis: qualidade de vida, empatia, resiliência, sono, ansiedade e depressão, esgotamento profissional e ambiente de ensino. Optamos por utilizar escalas consagradas pelo amplo uso em estudos internacionais com versões brasileiras validadas de maneira a permitir comparações com dados publicados em estudos transculturais. Apresentamos uma breve descrição dos instrumentos utilizados na plataforma VERAS no Quadro 3. 
Quadro 3 - Questionários utilizados na Plataforma VERAS

\begin{tabular}{|c|c|c|c|c|}
\hline Variáveis & Questionário & Validação Brasil & Itens & Características \\
\hline Dados Gerais & $\begin{array}{l}\text { Sócio- } \\
\text { demográfico }\end{array}$ & - & 11 & $\begin{array}{l}\text { Investiga: idade, sexo, ano do curso, IES, } \\
\text { cidade de origem, tipo de matrículas } \\
\text { (bolsista, cotas, FIES), especialidade } \\
\text { pretendida e atividade física. }\end{array}$ \\
\hline \multirow[t]{3}{*}{ Qualidade de vida } & WHOQOL-bref & Fleck et al., 2000 & 26 & $\begin{array}{l}\text { Versão abreviada, com } 4 \text { domínios: Saúde } \\
\text { física, Psicológico, Relações sociais e } \\
\text { Ambiente. Respostas obtidas em escala } \\
\text { Likert de } 5 \text { pontos e escores por domínios } \\
\text { transformados em escala de } 0 \text { (pior } \\
\text { qualidade de vida) a } 100 \text { (melhor qualidade } \\
\text { de vida). }\end{array}$ \\
\hline & VERAS-q & Tempski et al., 2009 & 45 & $\begin{array}{l}\text { Questionário específico para avaliação da } \\
\text { qualidade de vida do estudante de medicina, } \\
\text { com } 4 \text { domínios: Uso do tempo, Psicológico, } \\
\text { Físico e Ambiente de Ensino. Respostas } \\
\text { obtidas em escala Likert de } 5 \text { pontos e } \\
\text { escores transformados em escala de } 0 \text { (pior } \\
\text { qualidade de vida) a } 100 \text { (melhor qualidade } \\
\text { de vida). }\end{array}$ \\
\hline & $\begin{array}{l}\text { Autoavaliação } \\
\text { da Qualidade de } \\
\text { Vida }\end{array}$ & - & 2 & $\begin{array}{l}\text { Avalia a percepção do estudante quanto a } \\
\text { sua qualidade de vida geral e no curso de } \\
\text { medicina, em uma escala de } 0 \text { a } 10 .\end{array}$ \\
\hline Empatia & EMRI & Koller et al., 2001 & 21 & $\begin{array}{l}\text { Versão brasileira com } 3 \text { subescalas: } \\
\text { Consideração empática, Tomada de } \\
\text { perspectiva e Angústia pessoal. Respostas } \\
\text { obtidas em escala Likert de } 5 \text { pontos. }\end{array}$ \\
\hline Resiliência & RS-14 & Pesce et al., 2005 & 14 & $\begin{array}{l}\text { Versão abreviada com respostas em escala } \\
\text { Likert de } 7 \text { pontos. Os escores variam de } 14 \\
\text { (alta resiliência) a } 98 \text { (baixa resiliência). }\end{array}$ \\
\hline Depressão & IDB & $\begin{array}{c}\text { Gorenstein; } \\
\text { Andrade, } 1996\end{array}$ & 21 & $\begin{array}{l}\text { São atribuídos valores } 0 \text { a } 3 \text { para cada } \\
\text { questão. Calcula-se escore global que varia } \\
0 \text { a } 63 \text {. Escore }>9 \text { indica sintomas } \\
\text { depressivos. }\end{array}$ \\
\hline \multirow[t]{3}{*}{ Sono } & PSQI-BR & $\begin{array}{l}\text { Bertolazi et al., } \\
\qquad 2011\end{array}$ & 19 & $\begin{array}{l}\text { Apresenta } 7 \text { domínios: Qualidade subjetiva } \\
\text { do sono, Latência para o sono, Duração do } \\
\text { sono, Eficiência habitual do sono, } \\
\text { Transtornos do sono, Uso de medicamentos } \\
\text { para dormir e Disfunção diurna. São } \\
\text { atribuídos valores de } 0 \text { a } 3 \text {, com escore } \\
\text { global que varia de } 0 \text { a } 21 \text {. Quanto maior a } \\
\text { pontuação, pior a qualidade do sono. Escore } \\
\text { global > } 5 \text { indica má qualidade do sono. }\end{array}$ \\
\hline & EPWORTH & $\begin{array}{l}\text { Bertolazi et al., } \\
2009\end{array}$ & 8 & $\begin{array}{l}\text { Escala desenvolvida para avaliar tendência } \\
\text { à sonolência em } 8 \text { situações cotidianas, com } \\
\text { respostas de } 0 \text { (nenhuma chance de } \\
\text { cochilar) a } 3 \text { (alta chance de cochilar). } \\
\text { Apresenta escores de } 0 \text { a } 24 \text {. Escore } \geq 10 \text { é } \\
\text { sugestivo de sonolência diurna patológica. }\end{array}$ \\
\hline & Autoavaliação & - & 6 & Avalia horas de sono e fatores relacionados \\
\hline Ansiedade & IDATE & $\begin{array}{c}\text { Biagio e Natalício, } \\
1979\end{array}$ & 40 & $\begin{array}{l}\text { Instrumento composto por } 2 \text { escalas com } 20 \\
\text { itens cada, destinadas à avaliação de } \\
\text { Ansiedade-traço e Ansiedade-estado. } \\
\text { Respostas em escala Likert de } 4 \text { pontos. } \\
\text { Quanto maior o escore maior a ansiedade. }\end{array}$ \\
\hline $\begin{array}{l}\text { Esgotamento } \\
\text { profissional }\end{array}$ & $\mathrm{MBI}$ & $\begin{array}{c}\text { Benevides-Pereira, } \\
2001\end{array}$ & 22 & $\begin{array}{l}\text { Instrumento com afirmações em } 3 \text { domínios: } \\
\text { Exaustão emocional, Despersonalização e } \\
\text { Realização pessoal. Respostas em escala } \\
\text { Likert de } 7 \text { pontos. Maior o esgotamento } \\
\text { quanto maior os escores em exaustão } \\
\text { emocional e despersonalização e menor em } \\
\text { realização profissional. }\end{array}$ \\
\hline \multirow[t]{2}{*}{$\begin{array}{l}\text { Ambiente de } \\
\text { ensino }\end{array}$} & DREEM & $\begin{array}{l}\text { Oliveira-Filho et al., } \\
2005\end{array}$ & 50 & $\begin{array}{l}\text { Questionário com } 5 \text { domínios: Ensino, } \\
\text { Professores, Aprendizado, Ambiente e } \\
\text { Social. Respostas em escala Likert de } 5 \\
\text { pontos. Os resultados globais permitem } \\
\text { comparação entre cursos, disciplinas e } \\
\text { instituições. Quanto maior os escores, } \\
\text { melhor o ambiente de ensino. }\end{array}$ \\
\hline & Total & 13 questionários & 285 & \\
\hline
\end{tabular}


Para o presente estudo, foram utilizados os dados obtidos por meio das respostas dos estudantes aos seguintes instrumentos: questionário sóciodemográfico, Escala Multidimensional de Reatividade Interpessoal de Davis (EMRI), The World Health Organization Quality of Life Assessment - Bref (WHOQOL-BREF), questionário para avaliar a qualidade de vida do estudante da área da saúde (Veras-q), Inventário de Burnout de Maslach (MBI) e Escala de Sonolência Diurna de Epworth (ESS) (Anexo C).

\subsubsection{Questionário sócio-demográfico}

Questionário desenvolvido especificamente para o projeto, com dados relativos à idade, sexo, ano do curso, nome da Instituição de Ensino Superior.

\subsubsection{Escala Multidimensional de Reatividade Interpessoal de Davis (EMRI)}

Esse instrumento foi concebido por Mark H. Davis em 1980, a partir da necessidade de uma medida que refletisse o modelo multidimensional da empatia e permitisse uma avaliação independente dos domínios cognitivo, afetivo e comportamental. Os instrumentos existentes até então representavam o construto da empatia de maneira unidimensional (cognitiva ou afetiva) ou abordavam as duas dimensões em um escore global único (Davis, 1980; 1983).

Com o intuito de obter uma escala capaz de capturar separadamente variações individuais das disposições cognitivas, afetivas e reações 
emocionais, Davis propôs o desenvolvimento do instrumento em três etapas. Na primeira etapa, 50 itens (alguns provenientes de escalas existentes, mas a maioria escrita especificamente para a escala) foram reunidos na primeira versão do instrumento. Essa primeira versão foi testada em 452 indivíduos, que responderam as questões por meio de uma escala Likert de cinco pontos com variação de 0 (não me descreve bem) a 4 (descreve-me muito bem).

A análise fatorial da primeira etapa revelou a presença de 4 fatores principais: fantasia, que representa a tendência do respondente a identificar-se com personagens fictícios de livros, filmes ou teatro; tomada de perspectiva, que reflete a tendência ou disposição do respondente em adotar a perspectiva ou o ponto de vista do outro; consideração empática, que avalia a tendência do respondente a vivenciar sentimentos de cordialidade, compaixão e preocupação em relação ao outro indivíduo em experiências negativas; angústia pessoal, que indica a vivência de sentimentos de desconforto e ansiedade pelo respondente diante da experiência negativa de outros (Davis, 1980; 1983).

Após a análise preliminar dos resultados da primeira etapa de desenvolvimento da escala, a segunda versão do instrumento foi elaborada a partir da adaptação e elaboração dos itens em conformidade com os quatro fatores emergidos na análise inicial. A segunda versão, com 45 itens, foi testada em uma amostra com 427 estudantes universitários. A análise fatorial dessa versão confirmou a presença dos quatro fatores provenientes da análise inicial. 
A terceira etapa do desenvolvimento da escala teve o objetivo de produzir um instrumento robusto e confiável. Para isso, os itens com as maiores cargas fatoriais foram mantidos na versão final da escala, composta por 28 proposições igualmente distribuídas entre 4 subescalas: consideração empática (CE), tomada de perspectiva (TP), angústia pessoal (AP) e fantasia (Davis, 1980; 1983).

A versão final foi então testada quanto à validade e confiabilidade em uma terceira amostra independente com 1079 estudantes do curso de psicologia da Universidade do Texas. A análise fatorial confirmou a adequabilidade do uso dos 4 fatores e seus respectivos itens nos grupos masculino e feminino. O coeficiente de confiabilidade da consistência interna (alfa de Cronbach) foi analisado para cada subescala dentro dos grupos masculino e feminino. Essa análise demostrou valores entre 0,70 e 0,78. A confiabilidade do teste-reteste foi analisada em um subgrupo de 109 estudantes, que responderam novamente ao instrumento em um período de 60 a 75 dias. Essa análise também foi realizada para cada subescala dentro dos grupos masculino e feminino e demonstrou valores de coeficientes entre 0,61 e 0,81 .

A versão final da escala também foi testada quanto à intercorrelação entre as subescalas. Essa análise, apesar de demonstrar uma fraca correlação entre as subescalas tomada de perspectiva e consideração empática, ou seja, entre as dimensões cognitiva e emocional respectivamente, revelou uma independência relativa dos seus quatro fatores: as duas subescalas "emocionais" (consideração empática e angústia pessoal) apresentaram um padrão de correlação praticamente ortogonal e a subescala fantasia não 
apresentou correlação com a subescala tomada de perspectiva. Esses dados indicam que os domínios da escala devem ser analisados separadamente.

A Escala Multidimensional de Reatividade Interpessoal (EMRI) de Davis provou-se um instrumento robusto, confiável, capaz de detectar independentemente as variações individuais dos diversos conceitos relacionados ao construto multidimensional da empatia e produzir uma variedade de "constelações de empatia" (Davis, 1980; 1983; 1996).

Durante o estudo de tradução e validação da versão brasileira utilizada nesse estudo, a subescala fantasia foi excluída. De acordo com os autores do estudo, a subescala fantasia foi originalmente elaborada de acordo com aspectos culturais específicos do país de origem e tem sido abandonada por inadequações culturais em diversos estudos, inclusive na cultura norteamericana (Koller et al., 2001). Dessa maneira, essa versão brasileira contempla 3 subescalas (tomada de perspectiva, consideração empática e angústia pessoal), com respostas obtidas em escala Likert de cinco pontos (Quadro 4). 
Quadro 4 - Subescalas e itens da Escala Multidimensional de Reatividade Interpessoal de Davis (EMRI)

\begin{tabular}{|c|c|}
\hline Item & Consideração empática \\
\hline 1 & $\begin{array}{l}\text { Eu frequentemente tenho sentimentos de ternura e preocupação por } \\
\text { pessoas menos afortunadas do que eu. }\end{array}$ \\
\hline 3 & $\begin{array}{l}\text { Às vezes, eu não me lamento muito por outras pessoas que estão tendo } \\
\text { problemas. * }\end{array}$ \\
\hline 6 & Quando eu vejo alguém sendo logrado eu sinto vontade de protege-lo. \\
\hline 10 & $\begin{array}{l}\text { As desgraças e os problemas dos outros em geral não me perturbam } \\
\text { muito. * }\end{array}$ \\
\hline 13 & $\begin{array}{l}\text { Quando eu vejo alguém sendo injustiçado, eu às vezes não sinto muita } \\
\text { pena dele. * }\end{array}$ \\
\hline 15 & Frequentemente eu fico emocionado com coisas que eu vejo acontecer. \\
\hline \multirow[t]{2}{*}{17} & Eu descreveria a mim mesmo como uma pessoa de coração mole. \\
\hline & Tomada de perspectiva \\
\hline 2 & $\begin{array}{l}\text { Às vezes, eu tenho dificuldade de ver as coisas do ponto de vista dos } \\
\text { outros. * }\end{array}$ \\
\hline 5 & $\begin{array}{l}\text { Eu tento considerar os argumentos de todas as pessoas em uma } \\
\text { discussão antes de tomar uma decisão. }\end{array}$ \\
\hline 8 & $\begin{array}{l}\text { Às vezes, eu tento entender melhor meus amigos, imaginando como as } \\
\text { coisas são vistas da perspectiva deles. }\end{array}$ \\
\hline 11 & $\begin{array}{l}\text { Se eu tenho certeza de que estou correto sobre alguma coisa, eu não } \\
\text { desperdiço muito tempo ouvindo os argumentos das outras pessoas. * }\end{array}$ \\
\hline 16 & $\begin{array}{l}\text { Eu acredito que existem dois lados para cada questão e tento olhar para } \\
\text { ambos. }\end{array}$ \\
\hline 19 & $\begin{array}{l}\text { Quando eu estou incomodado com alguém, geralmente eu tento me } \\
\text { colocar em seu lugar por um momento. }\end{array}$ \\
\hline \multirow[t]{2}{*}{21} & $\begin{array}{l}\text { Antes de criticar alguém, eu tento imaginar como eu me sentiria, se } \\
\text { estivesse em seu lugar. }\end{array}$ \\
\hline & Angústia pessoal \\
\hline 4 & Em situações de emergência, eu me sinto ansioso e desconfortável. \\
\hline 7 & $\begin{array}{l}\text { Às vezes, eu me sinto desconfortável quando estou no meio de uma } \\
\text { situação muito emotiva. }\end{array}$ \\
\hline 9 & Quando eu vejo alguém se ferir, eu tendo a permanecer calmo. * \\
\hline 12 & Estar em uma situação emocional tensa assusta-me. \\
\hline 14 & Geralmente eu sou muito efetivo para lidar com emergências. * \\
\hline 18 & Eu tendo a perder o controle durante emergências. \\
\hline 20 & $\begin{array}{l}\text { Quando eu vejo alguém que tem grande necessidade de ajuda em uma } \\
\text { emergência, eu fico desesperado. }\end{array}$ \\
\hline
\end{tabular}

* Item com valor de escala Likert invertido: escores variam de 5 ("não me descreve bem") a 1 ("descreve-me muito bem") 
Ainda, no estudo de tradução e adaptação da escala para o Brasil, os autores consideram o escore global (somatória dos escores das subescalas) (Koller et al., 2001), apesar de orientações em contrário nos estudos originais da escala (Davis, 1980; 1983). Por entendermos que as subescalas da EMRI estão relacionadas a conceitos diferentes porém relacionados ao construto empatia, os escores das subescalas foram analisados separadamente nesse estudo.

\subsubsection{Autoavaliação da qualidade de vida}

Com o objetivo de avaliar a percepção subjetiva da qualidade de vida do estudante, incluímos dois itens de autoavaliação global. Os estudantes foram solicitados a atribuir um valor a sua qualidade de vida geral e a sua qualidade de vida no curso de medicina por meio de uma escala com variação de 0 a 10.

\subsubsection{The World Health Organization Quality of Life Assessment - Bref (WHOQOL-BREF)}

Com o intuito de reafirmar o seu compromisso com a abordagem holística da promoção e das ações em saúde, a Organização Mundial da Saúde (OMS) liderou um estudo multicêntrico que resultou no instrumento de avaliação de qualidade de vida - o WHOQOL (The WHOQOL Group, 1995).

Essa iniciativa utilizou uma abordagem colaborativa e simultânea entre 15 centros de pesquisa, incluídos no estudo por representarem culturas em 
diversos níveis de industrialização e de acesso a serviços de saúde. Revisões iterativas entre pacientes, pesquisadores e profissionais de saúde dos diversos centros participantes e a metodologia de tradução e retro-tradução foram importantes para que o instrumento refletisse o conceito multidimensional de qualidade de vida entre as diversas culturas.

As amplas revisões do conceito de qualidade de vida entre os pesquisadores internacionais resultaram em seis domínios a serem abordados pelo instrumento: 1. Físico, 2. Psicológico, 3. Nível de independência, 4. Relações sociais, 5. Ambiente, 6. Espiritualidade/religião/crenças pessoais (The WHOQOL Group, 1995).

A partir da definição dos domínios de qualidade de vida, um estudo qualitativo foi conduzido com o objetivo de formar um banco de itens para o instrumento. Grupos focais compostos de pacientes e profissionais de saúde dos 15 centros participantes redigiram aproximadamente 1800 itens. A análise de conteúdo quanto à equivalência semântica resultou em uma redução do banco para 1000 itens. Pesquisadores dos centros de pesquisa participantes selecionaram um total de 235 itens desse banco de acordo com sua relevância cultural.

O instrumento com 235 itens foi submetido a teste piloto quantitativo nos 15 centros de pesquisa, com a participação de 4500 sujeitos. Essa etapa de desenvolvimento do instrumento teve o objetivo de testar as validades de construto e discriminante, e selecionar os melhores itens para representar as diversas facetas do conceito de qualidade de vida. Desse teste, foram selecionados 100 itens para o WHOQOL-100, um instrumento composto por 
seis domínios, 24 facetas - cada faceta com 4 itens - e 4 itens representativos da medida de qualidade de vida geral (The WHOQOL Group, 1995).

Os itens do WHOQOL-100 são respondidos em uma escala do tipo Likert de cinco pontos. Desse modo, cada afirmação pode ter um valor atribuído de um a cinco, cada faceta tem um escore que varia de 4 a 20 . Maiores escores denotam melhor qualidade de vida (The WHOQOL Group, 1998a). Os escores dos domínios são calculados pela média da somatória dos escores de cada faceta relacionada ao domínio. Os escores dos domínios são então transformados em uma escala de zero a 100 (WHO, 1998).

Ainda durante o estudo piloto, o instrumento com 100 itens foi novamente submetido à análise de validade discriminante e de construto. Observou-se que o WHOQOL-100 foi capaz de discriminar a qualidade de vida entre pessoas saudáveis e doentes (validade de grupos conhecidos) em todos os seus domínios (The WHOQOL Group, 1998a). A análise fatorial resultou em um modelo de quatro fatores/domínios: 1. Capacidade física (domínios físico e nível de independência), 2. Ambiente, 3. Psicológico (domínios psicológico e espiritualidade) e 4. Relações sociais (domínio relações sociais e faceta relacionada à imagem corporal e aparência). Porém, optou-se por manter a estrutura de seis domínios para o WHOQOL-100 e adotar o modelo de quatro domínios para a versão abreviada do instrumento - o WHOQOL-BREF (The WHOQOL Group, 1998b).

O WHOQOL-BREF surgiu da necessidade de um instrumento mais curto para uso em grandes estudos epidemiológicos em que a qualidade de vida é uma das variáveis estudadas (The WHOQOL Group, 1998a). O grupo da OMS optou por manter a estrutura do instrumento original, com a escolha de um item 
para cada uma das 24 facetas, distribuídas em quatro domínios, e dois itens para a avaliação da qualidade de vida geral (Quadro 5). A versão abreviada do WHOQOL consiste, então, de 26 itens, com respostas obtidas em escala do tipo Likert de cinco pontos. Para permitir comparações com os escores obtidos com o WHOQOL-100, os escores dos domínios são multiplicados por quatro e transformados em uma escala de zero (pior qualidade de vida) a 100 (melhor qualidade de vida) (The WHOQOL Group, 1998b; WHO, 1998). 
Quadro 5 - Domínios e facetas do WHOQOL-BREF

\begin{tabular}{|c|c|c|}
\hline Domínio & Faceta & Item \\
\hline \multirow{2}{*}{$\begin{array}{l}\text { Questões } \\
\text { Gerais }\end{array}$} & Qualidade de vida geral & 1 \\
\hline & Saúde geral & 2 \\
\hline \multicolumn{3}{|l|}{ Domínio 1} \\
\hline \multirow[t]{7}{*}{ Físico } & Dor e desconforto * & 3 \\
\hline & Dependência de medicação ou de tratamento * & 4 \\
\hline & Energia e fadiga & 10 \\
\hline & Mobilidade & 15 \\
\hline & Sono e repouso & 16 \\
\hline & Atividades da vida cotidiana & 17 \\
\hline & Capacidade de trabalho & 18 \\
\hline \multicolumn{3}{|l|}{ Domínio 2} \\
\hline \multirow[t]{6}{*}{ Psicológico } & Sentimentos positivos & 5 \\
\hline & Espiritualidade/religião/crenças pessoais & 6 \\
\hline & Pensar, aprender, memória e concentração & 7 \\
\hline & Imagem corporal e aparência & 11 \\
\hline & Autoestima & 19 \\
\hline & Sentimentos negativos * & 26 \\
\hline \multicolumn{3}{|l|}{ Domínio 3} \\
\hline \multirow{3}{*}{$\begin{array}{l}\text { Relações } \\
\text { sociais }\end{array}$} & Relações pessoais & 20 \\
\hline & Atividade sexual & 21 \\
\hline & Suporte (apoio) social & 22 \\
\hline \multicolumn{3}{|l|}{ Domínio 4} \\
\hline \multirow[t]{8}{*}{ Meio Ambiente } & Segurança física e proteção & 8 \\
\hline & Ambiente físico (poluição/ruído/trânsito/clima) & 9 \\
\hline & Recursos financeiros & 12 \\
\hline & Oportunidades de adquirir novas informações e habilidades & 13 \\
\hline & Participação e oportunidades de recreação/lazer & 14 \\
\hline & Ambiente no lar & 23 \\
\hline & Cuidados de saúde e sociais: disponibilidade e qualidade & 24 \\
\hline & Transporte & 25 \\
\hline
\end{tabular}

* Item com valor de escala Likert invertido

Fonte: WHO, 1998; The Whoqol Group, 1998b; Fleck et al., 2000

O WHOQOL-BREF foi avaliado quanto sua confiabilidade (consistência interna e teste-reteste) e validade (discriminante e de construto) (The WHOQOL Group, 1998b). Nos estudos originais do instrumento, os coeficientes de confiabilidade de Cronbach variaram de 0,66 (domínio 3 relações sociais) a 0,84 (domínio 1 - físico). As comparações das médias dos 
respondentes saudáveis obtidas em aplicações com intervalos entre duas a oito semanas não revelaram diferenças significativas. O WHOQOL-BREF foi capaz de discriminar as diferenças entre indivíduos saudáveis e doentes em todos os quatro domínios. O modelo de quatro fatores mostrou-se aceitável na análise fatorial confirmatória (The WHOQOL Group, 1998b).

Diante das propriedades psicométricas do instrumento, o WHOQOLBREF tem sido utilizado em diversas culturas e cenários de pesquisa. No Brasil, o instrumento foi traduzido e adaptado por Fleck et al. (2000) e validado em diversas situações (Fleck et al., 2000; Berlim et al., 2005; Castro et al., 2007; Rocha; Fleck, 2009). O WHOQOL-BREF também tem sido utilizado como instrumento genérico para avaliar a qualidade de vida em vários estudos na área da educação médica (Tempski-Fiedler, 2008; Hassed et al., 2009; Krägeloh et al., 2011; Dias et al., 2012; Zhang et al., 2012).

\subsubsection{VERAS-q: questionário para avaliar a qualidade de vida do estudante e residente da área da saúde}

O VERAS-q foi concebido por Tempski-Fiedler (2008) a partir da necessidade de um instrumento de avaliação de qualidade de vida específico para estudantes de medicina, capaz de abranger aspectos conceituais e determinantes dessa população. O desenvolvimento do instrumento deu-se em três etapas distintas. A primeira etapa consistiu de grupos focais realizados com 56 estudantes de medicina dos diferentes anos de curso, provenientes de seis escolas brasileiras. As escolas médicas incluídas nessa fase 
representavam a diversidade das escolas brasileiras quanto ao modelo curricular (tradicional ou ABP), a natureza jurídica (pública ou privada) e a localização (capital e interior) (Tempski-Fiedler, 2008; Tempski et al., 2012).

A análise de conteúdo das entrevistas semiestruturadas dos grupos focais resultou em várias categorias relacionadas ao conceito de qualidade de vida e a seus fatores determinantes: satisfação com a vida, capacidade funcional, comportamento emocional, hábitos saudáveis, relações sociais e afetivas, manejo do tempo, aspectos didático-pedagógicos, ambiente físico de ensino, crenças e expectativas quanto ao futuro profissional (Tempski-Fiedler, 2008; Tempski et al., 2012).

Tais categorias nortearam a redação dos 90 itens que compuseram a versão inicial do VERAS-q, com respostas em uma escala do tipo Likert de cinco pontos. Os escores do questionário variam de um ("discordo totalmente") a cinco ("concordo totalmente") (Tempski-Fiedler, 2008).

Durante a segunda etapa de desenvolvimento do VERAS-q, a versão inicial do questionário foi submetida a teste piloto com um grupo de estudantes. A confiabilidade da consistência interna da versão inicial do VERAS-q revelou coeficiente de alfa Cronbach de 0,94 (Tempski-Fiedler, 2008).

O instrumento foi, então, aplicado a uma amostra de 800 estudantes de medicina de 75 escolas brasileiras (terceira etapa). Essa etapa teve o objetivo de selecionar os melhores itens para representar os diversos domínios da qualidade de vida para os estudantes de medicina e testar a confiabilidade da consistência interna e a validade de construto do questionário (Tempski et al., 2009). 
Os itens com coeficientes de alfa Cronbach menores do que 0,3 foram eliminados (total de 38 itens). Análises semânticas resultaram na eliminação de mais dois itens. Dessa maneira, a versão da terceira etapa do VERAS-q resultou em um questionário com 50 itens. O coeficiente de alfa Cronbach para o questionário global foi igual a 0,78. A análise fatorial revelou a presença de 13 domínios, que explicaram 56,8\% da variância (Tempski et al., 2009). Agrupamentos dos domínios de acordo com a similaridade de temas resultaram em um questionário com cinco domínios: qualidade de vida geral, saúde física, uso do tempo, ambiente de ensino e psicológico.

Em uma quarta etapa, o questionário foi novamente avaliado quanto a sua validade e confiabilidade em uma amostra de 1979 estudantes de medicina. Cinco itens foram excluídos de acordo com os resultados da análise fatorial e a versão final do questionário ficou constituída por 45 itens, distribuídos em quatro domínios: uso do tempo, psicológico, físico e ambiente de ensino (Quadro 6). A confiabilidade da consistência interna da versão final do Veras-q revelou coeficientes entre 0,77 e 0,82

Os domínios têm escores calculados por meio da somatória dos escores de seus respectivos itens (Tempski-Fiedler, 2008). Os escores são transformados em valores de zero a 100. Maiores escores denotam melhor qualidade de vida. Assim como em outros instrumentos de avaliação de qualidade de vida (The WHOQOL Group, 1998b), o VERAS-q não possui uma nota de corte para determinação da boa qualidade de vida. Os resultados são analisados por meio de comparações entre grupos. 
Quadro 6 - Definição dos domínios do VERAS-q e respectivos itens

\begin{tabular}{|lll|}
\hline Domínio & Definição & Itens \\
\hline Uso do & Avalia o gerenciamento do tempo do aluno e se & $4,9,10^{\star}$, \\
tempo & consegue se dedicar a outras atividades além do & $15^{\star}, 16^{\star}, 18,19^{\star}$, \\
11 itens & curso. & $21,28^{\star}, 31,33$ \\
Psicológico & Avalia sentimentos positivos e negativos, & $11,12,25$, \\
12 itens & concentração, suporte, nível de cobrança e & $29^{\star}, 36^{\star}, 37^{\star}, 39$, \\
& autoestima. & $40^{\star}, 41,43^{*}$, \\
& & $46^{\star}, 47^{\star}$ \\
Físico & Avalia cuidados com saúde, sono, lazer, atividade & $1,2^{\star}, 17^{\star}, 26$, \\
8 itens & física e autocuidado. & $34^{\star}, 44,45,49$ \\
Ambiente de & Avalia a percepção do estudante sobre ambiente & $3,6^{\star}, 7,8$, \\
ensino & de ensino, organização do curso, relações com & $13,14,22,23^{\star}$, \\
14 itens & colegas, professores e instituição. & $24,27,30,32$, \\
& & $38^{\star}, 50^{*}$ \\
\hline
\end{tabular}

* Item com valor de escala Likert invertido: 1 ("concordo totalmente") a 5 ("discordo totalmente")

\subsubsection{Inventário de Burnout de Maslach (MBI)}

A concepção do Inventário de Burnout de Maslach (MBI) emergiu das pesquisas iniciais sobre os fatores estressores das relações interpessoais no ambiente de trabalho (Freudenberger, 1975). Esses estudos pioneiros, com enfoque predominantemente descritivo e qualitativo, possibilitaram a conceituação do termo "burnout" - ou esgotamento profissional - como uma "síndrome psicológica em resposta aos estressores interpessoais crônicos relacionados ao trabalho" (Maslach; Jackson, 1981; Maslach et al., 2001). O construto abrange três dimensões: exaustão emocional, despersonalização e falta de realização pessoal.

Diante da concepção multidimensional do esgotamento profissional, Maslach e Jackson (1981) procuraram desenvolver um inventário com itens 
relativos aos sentimentos pessoais e às atitudes do trabalhador. A versão preliminar do questionário apresentava 47 itens, com escalas de avaliação de frequência - com valores que variam de zero (nunca) a seis (todos os dias) - e intensidade - com valores que variam de 1 (muito leve) a 7 (muito forte) (Maslach; Jackson, 1981).

A versão preliminar foi testada em um grupo de 605 profissionais de diversas áreas (policiais, professores, enfermeiros, assistentes sociais, psiquiatras, psicólogos, advogados, médicos e administradores). Da análise fatorial, resultaram quatro fatores principais que explicavam grande parte da variância. Os autores reduziram o número de itens do inventário para 25, escolhidos de acordo com carga fatorial, validade discriminante do item e correlação item-total (Maslach; Jackson, 1981).

A segunda versão do inventário, com 25 itens, foi testada em um grupo de 420 pessoas e submetida a nova análise fatorial. Dessa análise, os autores excluíram três itens do inventário e a versão final do MBI permaneceu composta por 22 itens, distribuídos em três subescalas: exaustão emocional (9 itens), despersonalização (5 itens) e realização pessoal (8 itens) (Maslach; Jackson, 1981).

A subescala exaustão emocional refere-se ao estresse individual (Maslach et al., 2001) e contempla sentimentos de esgotamento emocional e exaustão pelo trabalho (Maslach; Jackson, 1981). A dimensão da despersonalização (ou cinismo) traz referência ao domínio relacional do construto (Maslach et al., 2001) e contém itens referentes à postura impessoal e de distanciamento em relação ao contexto do trabalho e às pessoas (clientes, pacientes, equipe). Essas duas subescalas apresentam correlação moderada e 
seus itens têm cargas fatoriais comuns. Em ambas subescalas, maiores escores representam maior vivência de esgotamento profissional (Maslach; Jackson, 1981).

Já a subescala realização pessoal refere-se a uma dimensão de autoavaliação (Maslach et al., 2001) e contém itens relativos aos sentimentos de competência e realização no trabalho. Em contraste com as outras duas subescalas, maiores escores em realização pessoal denotam menor esgotamento profissional (Maslach; Jackson, 1981).

Nos estudos originais do MBI (Maslach; Jackson, 1981), estimou-se um valor de alfa de Cronbach global de 0,83. O coeficiente de confiabilidade testereteste, calculado a partir da reaplicação do teste em uma amostra de 53 estudantes, variou de 0,60 (para a subescala despersonalização) a 0,82 (para a subescala exaustão emocional).

O inventário foi ainda validado por meio de observação externa, correlação com outros questionários e variáveis sócio-demográficas. Os autores (Maslach; Jackson, 1981) observaram que maiores escores de esgotamento profissional estavam relacionados a maior frequência de insônia, uso de álcool e drogas. Mulheres apresentaram maiores escores de exaustão emocional e menores escores de despersonalização e realização pessoal do que homens nos estudos originais do inventário (Maslach; Jackson, 1981). Ainda a partir desses estudos, indivíduos mais jovens apresentaram maiores escores de despersonalização e menores escores de realização pessoal do que indivíduos mais velhos, o que levou os autores à hipótese de que a síndrome do esgotamento profissional deve ser mais provável nos primeiros anos da carreira (Maslach; Jackson, 1981). 
Os autores do inventário têm argumentado que a síndrome de esgotamento profissional deve ser considerada uma variável contínua, e não deve ser vista como uma variável dicotômica (ausente ou presente) (Maslach et al., 1996). Nesse sentido, os escores do inventário devem ser interpretados como um contínuo que varia entre baixo grau de esgotamento profissional (baixos escores nas subescalas exaustão emocional e despersonalização e altos escores na subescala realização pessoal) a alto grau de esgotamento profissional (altos escores nas subescalas exaustão emocional e despersonalização e baixos escores na subescala realização pessoal) (Maslach et al., 1996).

Os escores são considerados altos quando situados no terço superior da distribuição normativa, calculados a partir de estudos norte-americanos (Maslach et al., 1996). Os pontos de corte para a interpretação dos resultados em populações na área da medicina são demonstrados no Quadro 7.

Desde o desenvolvimento do inventário e do estabelecimento de suas propriedades psicométricas na década de 80 (Maslach; Jackson, 1981), a pesquisa em esgotamento profissional começou a ter um enfoque quantitativo, com o aparecimento de estudos com amostras mais robustas (Maslach et al., 2001). A partir da tradução, adaptação e validação do MBI para outras culturas, o inventário passou a ser utilizado em diversos países (Maslach et al., 2001).

A partir da década de 90, houve uma expansão do conceito de esgotamento profissional para diversas áreas profissionais, inclusive para a população de estudantes, com o desenvolvimento de uma versão do questionário específica para essa população - o MBI - Student Survey (MBISS) (Schaufeli et al., 2002; Carlotto; Câmara, 2006). 
No presente estudo, optamos por utilizar a versão original da escala - o MBI - Human Services Survey (MBI-HSS). Essa versão tem a vantagem de apresentar uma padronização dos escores sugestivos da síndrome de esgotamento profissional (notas de corte) e de ser amplamente utilizada nos estudos em educação médica.

Quadro 7 - Categorização dos escores do Inventário de Burnout de Maslach (MBI) para amostra geral e para área de medicina

\begin{tabular}{|c|c|c|c|}
\hline \multicolumn{4}{|c|}{ Graus de esgotamento profissional } \\
\hline MBI - Subescalas & Baixo & Moderado & Alto \\
\hline \multicolumn{4}{|l|}{ Amostra geral } \\
\hline $\begin{array}{l}\text { Exaustão } \\
\text { Emocional }\end{array}$ & $\leq 16$ & $17-26$ & $\geq 27$ \\
\hline Despersonalização & $\leq 6$ & $7-12$ & $\geq 13$ \\
\hline $\begin{array}{l}\text { Realização } \\
\text { Pessoal }\end{array}$ & $\geq 39$ & $38-22$ & $\leq 31$ \\
\hline Medicina & & & \\
\hline $\begin{array}{l}\text { Exaustão } \\
\text { Emocional }\end{array}$ & $\leq 18$ & $17-27$ & $\geq 27$ \\
\hline Despersonalização & $\leq 5$ & $6-9$ & $\geq 10$ \\
\hline $\begin{array}{l}\text { Realização } \\
\text { Pessoal }\end{array}$ & $\geq 40$ & $39-34$ & $\leq 33$ \\
\hline
\end{tabular}

Fonte: Maslach et al., 1986

\subsubsection{Escala de sonolência diurna de Epworth (ESS)}

A Escala de sonolência diurna de Epworth (ESS) surgiu da necessidade de um instrumento autoaplicável, de utilização mais simples do que as medidas tradicionais de sonolência. 
A ESS avalia a tendência à sonolência em situações cotidianas. Durante o desenvolvimento da escala, o autor procurou englobar tanto situações sabidamente soporíferas, em que a chance de cochilar é grande até mesmo entre os indivíduos não sonolentos, como situações em que apenas os indivíduos sonolentos cochilariam (Johns, 1991). A escala compreende oito situações (itens), com respostas que variam de zero (nenhuma chance de cochilar) a três (alta chance de cochilar) (Quadro 8).

Quadro 8 - Itens da Escala de Sonolência Diurna de Epworth (ESS)

\begin{tabular}{|c|c|}
\hline Item & Situações mais soporíferas* \\
\hline 1 & Sentado e lendo. \\
\hline 4 & Andando de carro por uma hora sem parar, como passageiro. \\
\hline \multirow[t]{2}{*}{5} & $\begin{array}{l}\text { Deitado para descansar à tarde, quando as circunstâncias } \\
\text { permitem. }\end{array}$ \\
\hline & Situações intermediárias* \\
\hline 2 & Assistindo TV. \\
\hline 3 & $\begin{array}{l}\text { Sentado, quieto, em um lugar público (por exemplo, em um teatro, } \\
\text { reunião ou palestra). }\end{array}$ \\
\hline \multirow[t]{2}{*}{7} & Sentado quieto após o almoço sem bebida de álcool. \\
\hline & Situações menos soporíferas* \\
\hline 6 & Sentado e conversando com alguém. \\
\hline 8 & Em um carro parado no trânsito por alguns minutos. \\
\hline
\end{tabular}

* Classificação para o grupo de estudantes de medicina (Johns, 1994)

Ao avaliar a chance (e não a frequência) de cochilar, a escala diminui o viés de respostas nos itens que são infrequentes para o respondente (Johns, 1991).

Os itens da ESS foram originalmente avaliados em um estudo de validação com uma amostra composta por 150 pacientes com diversos distúrbios do sono (120 homens e 30 mulheres) e 30 controles (14 homens e 
16 mulheres). Nesse estudo, 96\% dos pacientes com narcolepsia ou hipersônia idiopática relataram chance de cochilar em situações pouco soporíferas e 94\% dos controles relataram chance de cochilar em situações muito soporíferas (Johns, 1994). A escala demonstrou-se capaz de distinguir o grupo dos indivíduos com diagnóstico de apneia obstrutiva do sono, narcolepsia e hipersônia do grupo dos indivíduos controles e com insônia primária (validade de grupos conhecidos). A ESS apresentou correlação negativa com a latência do sono medida por polissonografia (validade divergente) e correlação positiva com o "Multiple Sleep Latency Test", teste consagrado para a avaliação de sonolência (validade convergente). Escores da ESS maiores ou iguais a 16 foram encontrados apenas em pacientes com diagnóstico de narcolepsia, hipersônia idiopática e apneia obstrutiva do sono moderada e severa (Johns, 1991).

Análises posteriores confirmaram a validade e a confiabilidade da ESS em uma amostra composta por dois grupos de estudo, um deles composto por 87 estudantes de medicina saudáveis e outro por 54 pacientes com apneia obstrutiva do sono (Johns,1992). O grupo de estudantes de medicina (46 homens e 41 mulheres) respondeu a ESS em dois períodos distintos em um intervalo de cinco meses. O grupo de pacientes com apneia obstrutiva do sono respondeu a ESS antes e após o tratamento com pressão positiva contínua das vias aéreas. Nesse estudo, a ESS demonstrou-se precisa, com valores de coeficientes de alfa Cronbach de 0,73 para a amostra de estudantes e de 0,88 para a amostra de pacientes. A escala ainda revelou-se estável, com médias semelhantes entre as duas avaliações dos estudantes de medicina, como esperado; e sensível a mudanças, com alteração dos escores dos pacientes 
após o tratamento. A análise fatorial confirmou a presença de um fator único sonolência diurna, o que permite a avaliação da escala por meio de um escore global, a somatória dos itens, com variação de zero a 24.

A interpretação dos escores da ESS foi posteriormente confirmada em um estudo com 331 trabalhadores australianos (267 homens e 64 mulheres) (Johns; Hocking, 1997), com idade entre 22 e 59 anos. Escores maiores do que dez foram relacionados à sonolência diurna excessiva em homens e mulheres.

Desde os estudos originais, a ESS foi traduzida e validada em vários países (Bloch et al., 1999; Chiner et al., 1999; Chen et al., 2002; Tsara et al., 2004; Izci et al., 2008; Chica-Urzola et al., 2007; Heaton et al., 2007; Beiske et al., 2009; Kaminska et al., 2009; Banhiran et al., 2011; Kopitovic et al., 2011), inclusive no Brasil (Bertolazi et al., 2009).

A ESS tem sido extensivamente utilizada na área da educação médica para avaliação da sonolência diurna entre estudantes (Aloé, 1997; Rodrigues et al., 2002; Tempski-Fiedler, 2008; Zailinawati et al., 2009; Abdulghani et al., 2012) e residentes (West et al., 2009).

\subsection{Formação da rede multicêntrica de pesquisa}

Em uma iniciativa inédita no país quanto ao número de instituições e pesquisadores envolvidos, a coordenação do Projeto VERAS formou o Grupo de Pesquisa VERAS ou Rede Multicêntrica VERAS. Participam desse grupo 
pesquisadores, professores, gestores de ensino, pós-graduandos e estudantes, provenientes de 22 escolas médicas brasileiras.

A Rede VERAS foi formada a partir de convites emitidos pela coordenação do projeto a pesquisadores de reconhecida competência na área de pesquisa da educação médica. A proposta do Projeto VERAS foi apresentada no Congresso Brasileiro de Educação Médica em Goiânia/2010. Nesse evento, novos pesquisadores somaram-se ao grupo inicial de pesquisadores, por apresentarem interesse na temática do estudo.

A composição dos pesquisadores da Rede VERAS representa a diversidade das escolas médicas brasileiras e a característica inclusiva que define a Rede.

A consolidação da Rede VERAS deu-se por meio de algumas estratégias desenvolvidas pela coordenação do projeto. Tais estratégias tiveram o objetivo de capacitar os pesquisadores, melhorar o recrutamento e taxas de respostas, orientar e acompanhar os resultados parciais da coleta, discutir aspectos éticos da pesquisa, elaborar as perguntas do estudo e definir questões de publicação da produção científica do grupo. Descreveremos essas estratégias a seguir.

\subsubsection{Oficina da Rede VERAS}

Após estabelecer contato com os pesquisadores locais durante 0 congresso de educação médica, a coordenação do Projeto VERAS organizou a primeira oficina da Rede VERAS, em maio de 2011, em São Paulo (SP). 
Estiveram presentes 45 pesquisadores de 40 escolas médicas. Os objetivos do encontro foram: estabelecer o vínculo entre os pesquisadores do grupo, apresentar e testar a plataforma VERAS, discutir as questões iniciais da pesquisa e as necessidades do grupo, discutir questões éticas relacionadas à condução das pesquisas e publicações do grupo, capacitar os pesquisadores com as técnicas de randomização, solicitar os termos de adesão, autorização das escolas para a participação na pesquisa, pactuar o cronograma de trabalho do grupo e delinear as perguntas do estudo.

\subsubsection{VERAS News}

Após o primeiro encontro com os pesquisadores da Rede VERAS de pesquisa, estabeleceu-se a necessidade de criação de um meio de comunicação efetivo para orientação e atualização dos pesquisadores locais quanto ao andamento da pesquisa nacional. Diante dessa necessidade, surgiu, em agosto de 2011, o VERAS News, um boletim informativo mensal, em formato eletrônico (Anexo D), enviado aos e-mails dos pesquisadores locais.

\subsubsection{Reuniões com pesquisadores locais}

Os pesquisadores locais foram convidados para reunião presencial durante o $49^{\circ}$ Congresso Brasileiro de Educação Médica (COBEM), realizado em novembro de 2011, em Belo Horizonte (MG). A reunião teve o objetivo de 
discutir e propor soluções para as dificuldades encontradas nas etapas de randomização e recrutamento dos estudantes.

Em outubro de 2012, durante o $50^{\circ}$ COBEM em São Paulo (SP), outro encontro com os pesquisadores locais foi realizado, com o propósito de compartilhar experiências e expectativas entre os pesquisadores da rede quanto às publicações e a continuidade da pesquisa. $\mathrm{O}$ encontro teve ainda os objetivos de apresentar os números iniciais da pesquisa, formar grupos de interesse entre os pesquisadores da rede para o fomento de publicações, pactuar um cronograma de publicações e traçar novas metas da rede de pesquisadores. Entre as novas metas de pesquisa, firmou-se o desafio do seguimento dos estudantes em um estudo longitudinal.

\subsubsection{A estratégia "Adote uma escola"}

Durante a coleta de dados, observamos que a distância entre os pesquisadores locais e o grupo coordenador do projeto dificultava a adesão dos pesquisadores e dos estudantes à pesquisa. Como resposta a essa demanda, foi criada a estratégia "Adote uma escola", em abril de 2012. Nessa estratégia, cada pós-graduando ligado ao projeto foi responsabilizado por gerenciar os processos de randomização e coleta de dados e enviar relatórios semanais acerca da situação dos respondentes em cada escola. Os contatos dos pós-graduandos com as escolas participantes eram feitos por e-mail, telefone ou visita à instituição de ensino. 


\subsection{Coleta de dados}

A coleta de dados desse estudo ocorreu no período de agosto de 2011 a agosto de 2012. O processo de randomização dos respondentes deu-se a partir tabelas de números aleatórios, elaboradas de modo singular para cada IES, de acordo com a frequência de entrada de estudantes (semestral ou anual) e o número de estudantes matriculados (Anexo E).

Os estudantes randomizados foram recrutados por meio de estratégias padronizadas, para as quais os pesquisadores locais foram capacitados previamente em oficina presencial. O recrutamento aconteceu nas seguintes etapas: 1. reunião presencial para apresentação do Projeto VERAS aos estudantes, 2. convite pessoal por e-mail, carta, contato telefônico, redes sociais na Internet, 3. reunião com estudantes randomizados e 4. reunião com representantes de turma.

Durante o período de coleta de dados, os pós-graduandos responsáveis por cada IES enviaram relatórios semanais com a situação dos respondentes aos pesquisadores locais. Os relatórios permitiam a verificação do cadastro dos estudantes randomizados na plataforma de pesquisa e o diagnóstico da recusa do estudante.

Os estudantes de uma determinada IES que se recusavam a participar do estudo eram substituídos pelo próximo estudante do mesmo sexo na tabela de números aleatórios da respectiva IES. 


\subsection{Análise estatística}

Utilizamos a estatística descritiva para determinar a distribuição dos respondentes de acordo com sexo e ano de curso (frequências), os escores das respostas dos estudantes aos diversos questionários (médias, desvios padrões, percentis 25 e 75) e a distribuição dos escores nos domínios de cada questionário (frequências). Para determinarmos a distribuição das respostas a cada item da EMRI, utilizamos a estatística não-paramétrica (mediana, percentis 25 e 75), já que o îtem tipo Likert deve ser tratado como uma variável ordinal (Carifio; Perla, 2007; 2008; Pell, 2005).

Para avaliarmos a qualidade dos dados dos questionários, determinamos a ocorrência dos efeitos piso (porcentagem dos respondentes no escore mínimo do questionário) e teto (porcentagem dos respondentes no escore máximo do questionário). Apesar de não haver consenso sobre os valores aceitáveis na distribuição das respostas (Holmes et al., 1996; Gandek et al., 1998), estabelecemos a ocorrência dos efeitos piso e teto quando mais de $10 \%$ dos respondentes apresentaram escore mínimo ou máximo no domínio (Smith et al., 2005).

Analisamos a confiabilidade dos questionários utilizados na pesquisa por meio dos coeficientes de alfa Cronbach (Cronbach, 1951) de cada domínio estudado. Valores maiores ou iguais a 0,7 são considerados satisfatórios para estudos de grupos (Cramer, 2002; Aaronson et al., 2002).

Utilizamos o teste t de Student para comparar as médias dos escores dos domínios analisados de acordo com o sexo e a análise de variância 
(ANOVA) para as comparações entre os ciclos do curso. Ainda, realizamos as comparações dos escores atribuídos à autoavaliação da qualidade de vida geral e no curso por meio do teste t pareado.

Calculamos a magnitude das diferenças estatisticamente significativas (tamanho do efeito) a partir da determinação do $d$ de Cohen (razão entre a diferença das médias e o desvio padrão combinado para as comparações entre dois grupos independentes; razão entre a diferença das médias e o desvio padrão médio para as comparações entre dois grupos dependentes) (Cohen, 1988; Cumming, 2012) e do $f$ de Cohen (coeficiente que leva em consideração a razão entre a soma dos quadrados entre grupos e a soma dos quadrados totais) para as comparações entre mais de dois grupos independentes (Cohen, 1988; Ellis, 2010). Interpretamos como efeito pequeno, médio ou grande os seguintes valores: para o $d$ de Cohen: 0,$2 ; 0,5$ e 0,8; para o $f$ de Cohen: 0,1 ; 0,25; 0,40 (Cohen, 1988). Tamanhos de efeito médios geralmente são considerados clinicamente importantes (Sloan; Dueck, 2004). Para uma compreensão dos cálculos e interpretação do tamanho do efeito, ver Apêndice B.

Determinamos as correlações entre os domínios dos questionários analisados por meio do coeficiente de correlação de Pearson. Os valores de 0,1; 0,3 e 0,5 foram considerados para a interpretação de correlações fracas, moderadas e fortes, respectivamente (Cohen, 1988).

Selecionamos os estudantes com os menores e maiores escores $(P \leq 25$ e $P \geq 75$, respectivamente) dos questionários que apresentaram coeficiente de correlação maior ou igual a 0,3 com os domínios da EMRI. Os escores de empatia desses estudantes foram comparados por meio do teste t de Student. 
Para determinarmos o valor preditivo das variáveis estudadas para os domínios da EMRI, realizamos a análise por regressão múltipla. Primeiramente, realizamos regressão linear simples entre as variáveis do estudo para selecionarmos somente aquelas com valor preditivo significativo. As variáveis independentes também foram selecionadas de modo a evitarmos a multicolinearidade dos dados (domínios com correlações maiores ou iguais a 0,5 foram eliminados da regressão) (Hair Jr et al., 2009).

Nas análises de regressão múltipla, interpretamos como tamanho de efeito pequeno, médio e grande os seguintes valores de $R^{2}: 0,02 ; 0,13 ; 0,26$ (Cohen, 1988).

Estabelecemos o nível de significância estatística a 0,05. 


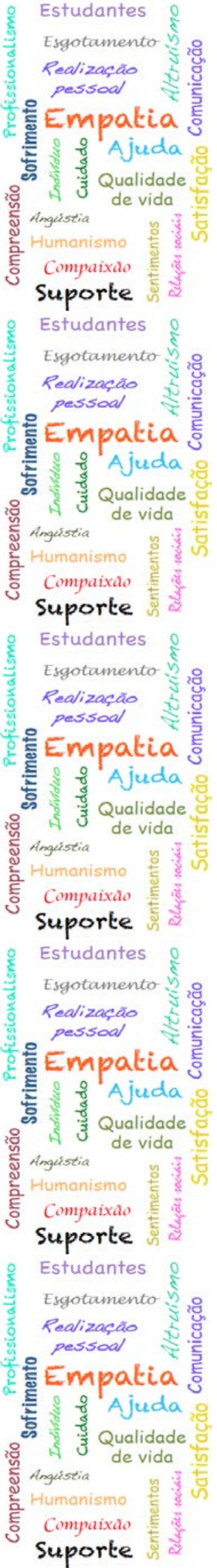




\subsection{Sujeitos da pesquisa}

De acordo com o cálculo do tamanho da amostra de 1.152 estudantes, para admitirmos uma perda máxima de 20\%, o número necessário de randomizados foi de 1.440 estudantes. Assim, optamos por randomizar 1.650 estudantes para esse estudo. Desses, 274 (16,6\%) não aceitaram participar do estudo (não acessaram a plataforma em até 30 dias após o convite) e 13 estudantes $(0,8 \%)$ não terminaram todos os questionários da plataforma - o que denominamos perda por exaustão. Por motivos técnicos inerentes da plataforma, dados de 13 estudantes $(0,8 \%)$ foram excluídos. As perdas do estudo totalizaram 18,2\% (Figura 3).

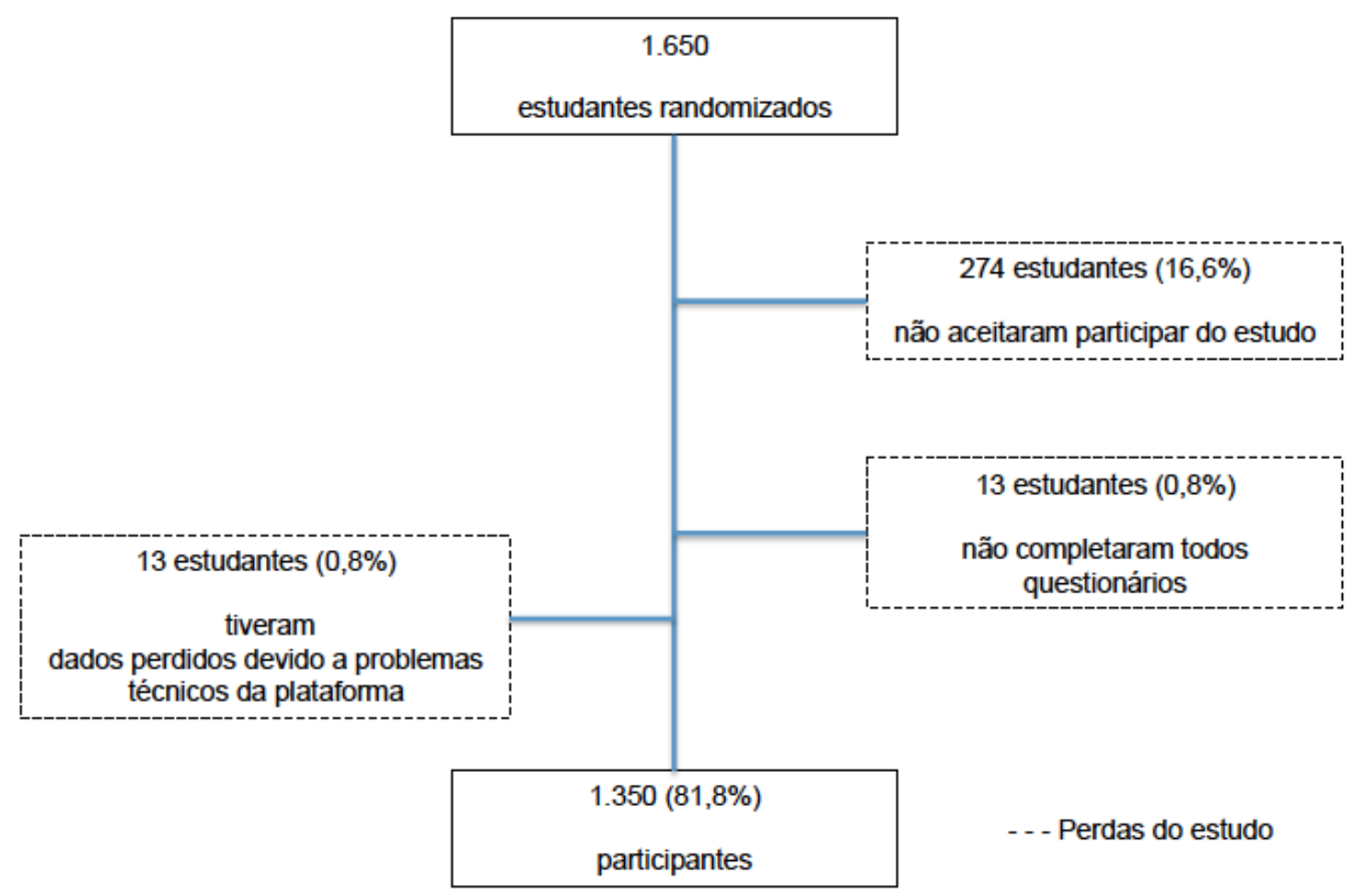

Figura 3- Fluxograma de perdas e número de participantes do projeto Veras 
O número de respondentes que acessaram a plataforma Veras durante o período de coleta está demonstrado na Figura 4. Observamos picos de respostas nos seguintes períodos: de setembro a novembro de 2011 , maio e junho de 2012 e agosto de 2012. As respostas visualizadas nos meses de junho e julho de 2011 correspondem aos testes da plataforma e à capacitação dos pesquisadores para o uso da plataforma Veras. Essas respostas foram excluídas da análise dos dados.

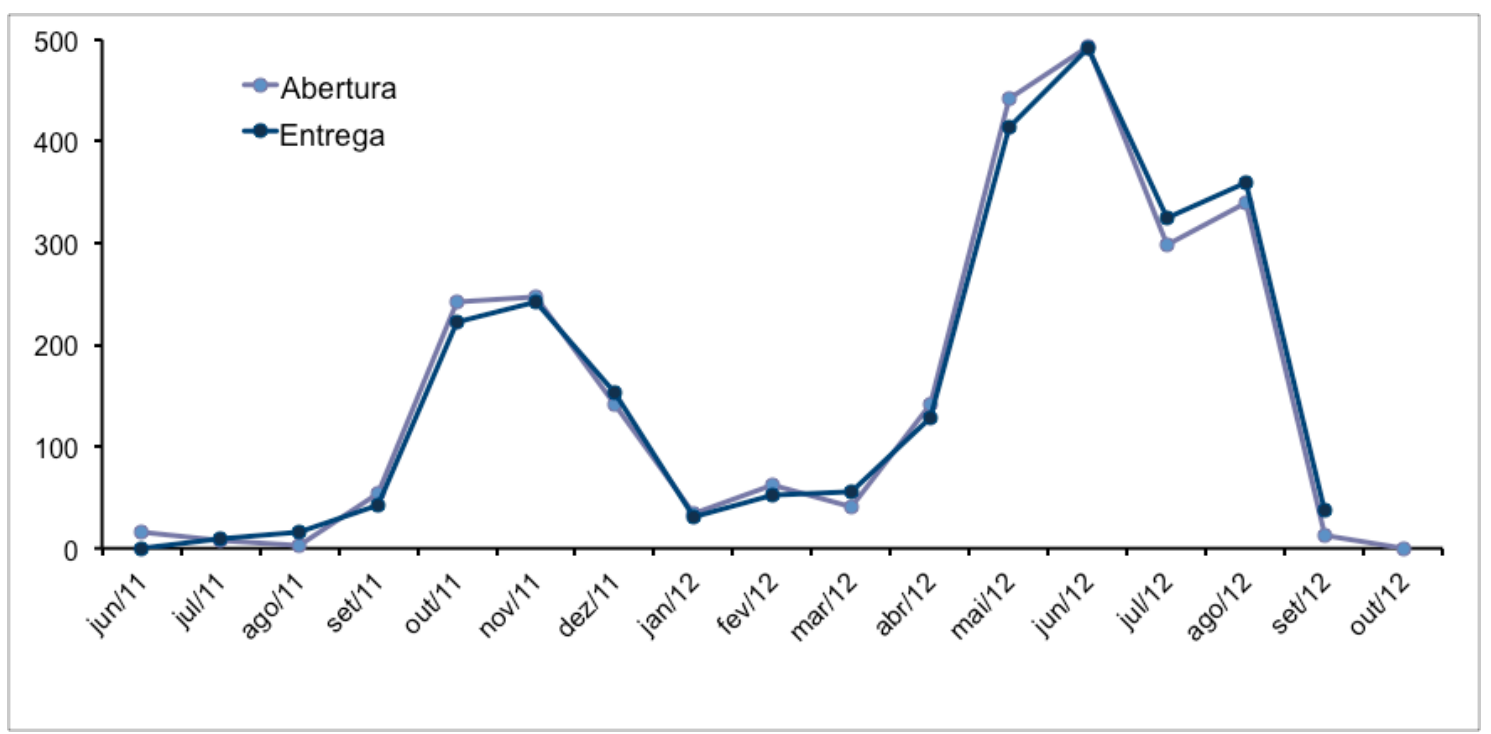

Figura 4 - Número de respondentes na plataforma Veras de acordo com mês e ano de início e término dos questionários

Do total de respondentes, 714 (52,9\%) eram do sexo feminino. Quanto à distribuição nos anos do curso, 459 (34,0\%) cursavam o ciclo básico (primeiro e segundo anos do curso), 491 (36,4\%) cursavam o ciclo intermediário (terceiro e quarto anos) e $400(29,6 \%)$ cursavam o ciclo profissionalizante (quinto e sexto anos). Não houve diferença entre a proporção de respondentes nos diferentes anos do curso (Tabela 1). 
Tabela 1 - Idade média (desvio padrão) e distribuição dos respondentes de acordo com sexo e ano do curso

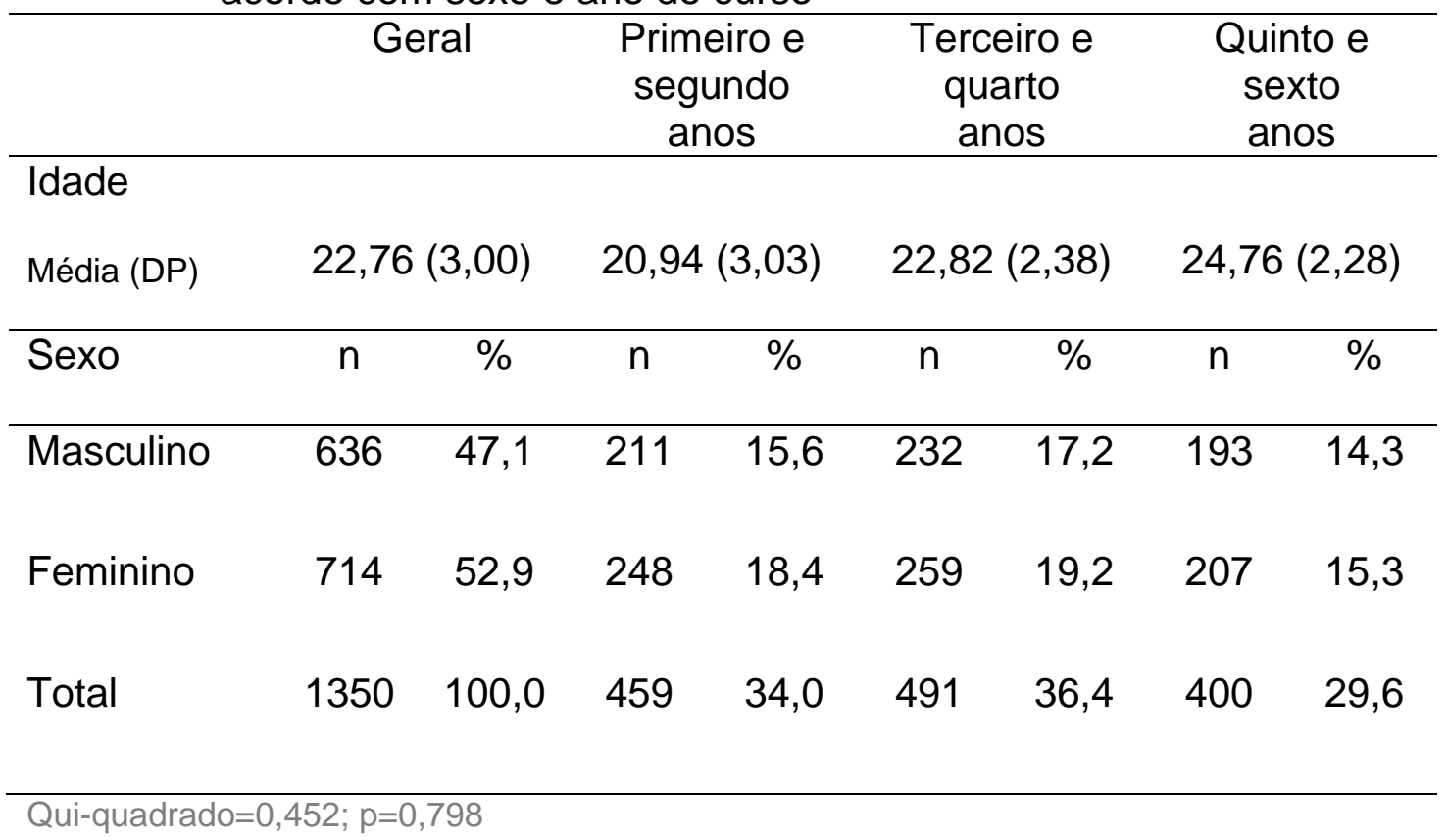

\subsection{Empatia}

Ao analisarmos a qualidade dos dados das respostas obtidas por meio da EMRI, não observamos a ocorrência dos efeitos piso e teto. Os coeficientes de confiabilidade de alfa Cronbach foram maiores do que 0,7 nos domínios consideração empática e tomada de perspectiva (Tabela 2).

Tabela 2 - Qualidade dos dados (efeitos piso e teto) ${ }^{\star}$ e confiabilidade da EMRI

\begin{tabular}{lccc}
\hline \multirow{2}{*}{ Domínios } & \multicolumn{2}{c}{ Qualidade dos dados } & Confiabilidade \\
\cline { 2 - 4 } & $\begin{array}{c}\text { Escore mínimo } \\
\mathrm{n}(\%)\end{array}$ & $\begin{array}{c}\text { Escore máximo } \\
\mathrm{n}(\%)\end{array}$ & Cronbach \\
\hline $\begin{array}{l}\text { Consideração } \\
\text { empática }\end{array}$ & $0(0)$ & $25(1,9)$ & 0,731 \\
$\begin{array}{l}\text { Tomada de } \\
\text { perspectiva }\end{array}$ & $0(0)$ & $19(1,4)$ & 0,776 \\
$\begin{array}{l}\text { Angústia pessoal } \\
\text { "Efeito piso: porcentagem de respondentes com escore mínimo }\end{array}$ & $\geq 10 \%$. Efeito teto: \\
$\begin{array}{l}\text { porcentagem de respondentes com escore máximo } \geq 10 \% . \\
\text { EMRI: Escala Multidimensional de Reatividade Interpessoal de Davis }\end{array}$ &
\end{tabular}


A análise por item da EMRI permite-nos observar que a média e a mediana das respostas dos estudantes variou entre 3 e 4 nos itens 01 (" $E u$ frequentemente tenho sentimentos de ternura e preocupação por pessoas menos afortunadas do que eu"), 06 ("Quando eu vejo alguém sendo logrado eu sinto vontade de protege-lo") e 13 ("Quando eu vejo alguém sendo injustiçado, eu às vezes não sinto muita pena dele") do domínio consideração empática (Figura 5). As respostas aos itens do domínio tomada de perspectiva foram relativamente mais variadas (Figura 6). No domínio angústia pessoal, salientamos que a maioria dos estudantes tiveram respostas entre 0 e 2 nos itens 09 ("Quando eu vejo alguém se ferir, eu tendo a permanecer calmo"), 18 ("Eu tendo a perder o controle durante emergências") e 20 ("Quando eu vejo alguém que tem grande necessidade de ajuda em uma emergência, eu fico desesperado") (Figura 7). 


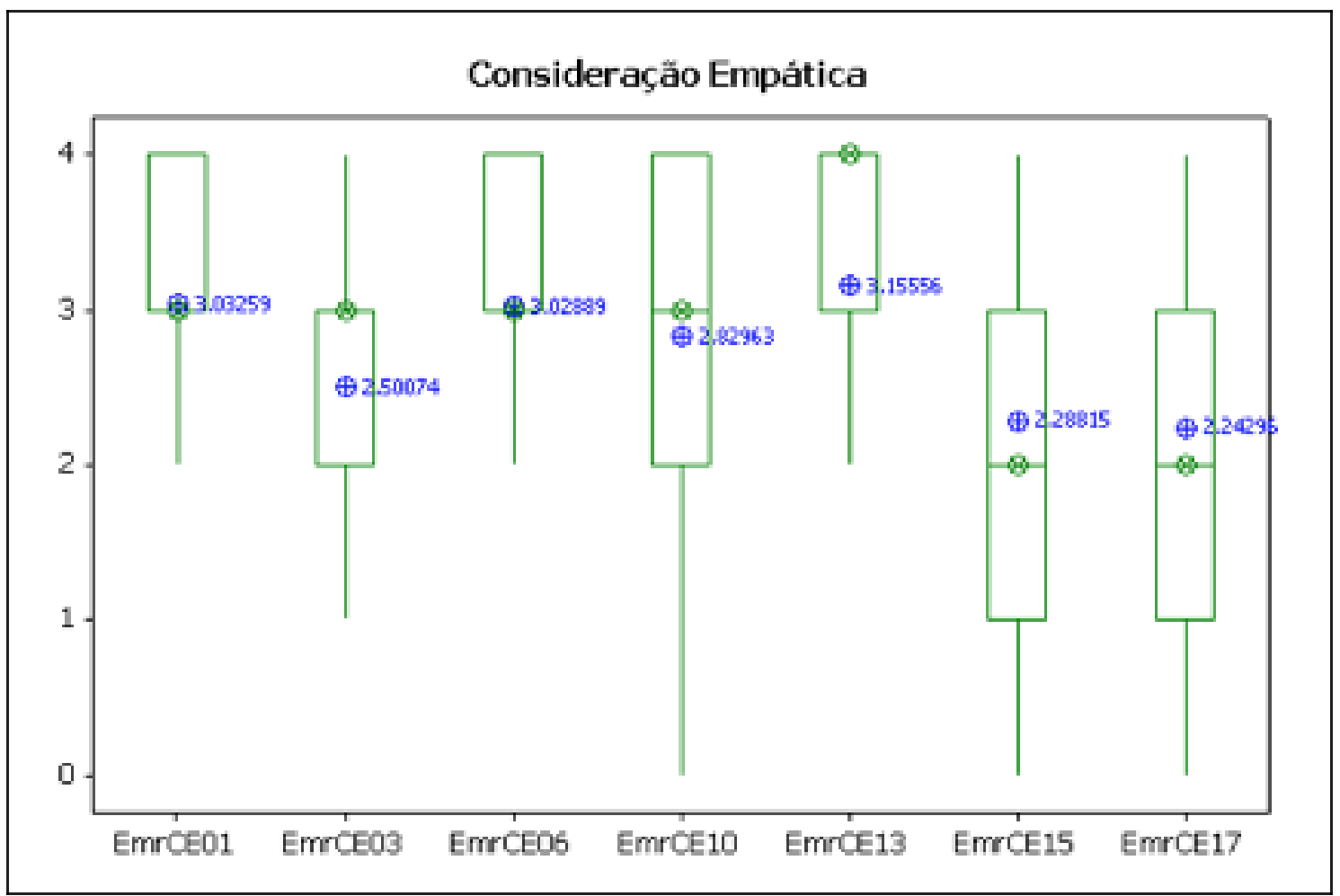

Figura 5 - Análise por item das respostas à Escala Multidimensional de Reatividade Interpessoal de Davis (EMRI) da população geral do estudo ( $n=1350)$, domínio consideração empática (EmrCE)

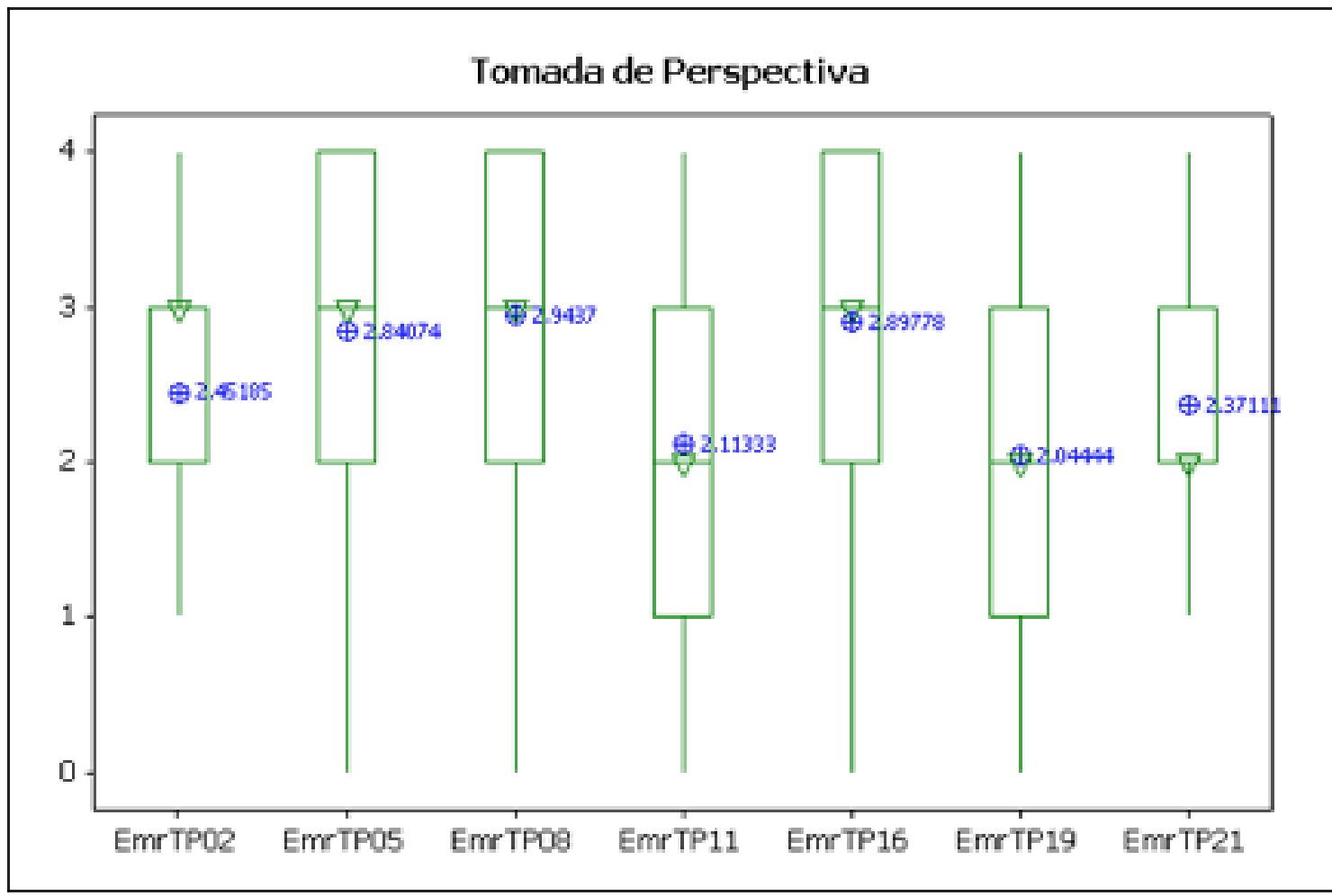

Figura 6 - Análise por item das respostas à Escala Multidimensional de Reatividade Interpessoal de Davis (EMRI) da população geral do estudo (n=1350), domínio tomada de perspectiva (EmrTP) 


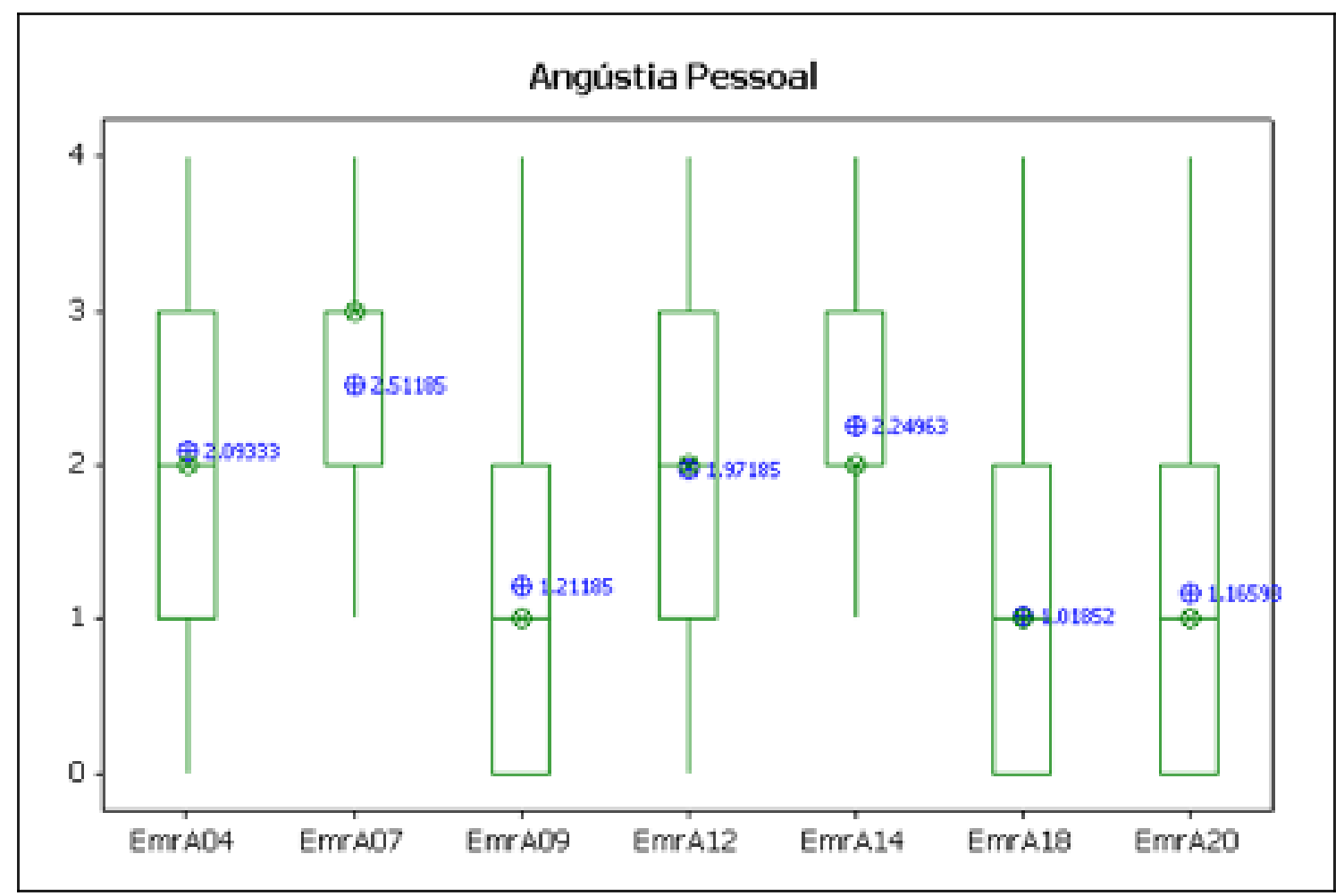

Figura 7 - Análise por item das respostas à Escala Multidimensional de Reatividade Interpessoal de Davis (EMRI) da população geral do estudo ( $n=1350)$, domínio angústia pessoal (EmrA)

A comparação dos escores de empatia obtidos por meio da EMRI revelou diferenças significativas entre os sexos. Os escores do grupo feminino no domínio consideração empática foram moderadamente maiores do que os escores do grupo masculino ( $p<0,001 ; d=0,63)$. No domínio angústia pessoal, estudantes do sexo feminino apresentaram escores ligeiramente maiores do que os estudantes do grupo masculino $(p<0,001 ; d=0,35)$ (Tabela 3). Essa diferença manteve-se nos diferentes anos do curso (Tabela 4). Não observamos diferença nos escores do domínio tomada de perspectiva entre homens e mulheres (Tabela 3) e entre os anos do curso (Tabela 4). 
Tabela 3 - Escores de empatia obtidos por meio da EMRI de acordo com sexo

\begin{tabular}{|c|c|c|c|c|c|}
\hline \multirow[t]{2}{*}{ Domínio } & Geral & Masculino & Feminino & \multirow[b]{2}{*}{$p^{*}$} & \multirow[b]{2}{*}{$d^{\dagger}$} \\
\hline & Média (DP) & Média (DP) & Média (DP) & & \\
\hline Consideração empática & $19,08(4,82)$ & $17,54(4,51)$ & $20,45(4,66)$ & $<0,001$ & 0,63 \\
\hline Tomada de perspectiva & $17,66(5,04)$ & $17,47(5,11)$ & $17,83(4,99)$ & 0,192 & - \\
\hline Angústia pessoal & $12,22(4,22)$ & $11,46(3,93)$ & $12,91(4,36)$ & $<0,001$ & 0,35 \\
\hline
\end{tabular}

Tabela 4 - Escores de empatia obtidos por meio da EMRI de acordo com sexo nos diferentes anos do curso

\begin{tabular}{|c|c|c|c|c|c|}
\hline \multirow[t]{2}{*}{ Anos do curso } & Geral & Masculino & Feminino & \multirow{2}{*}{$p^{*}$} & \multirow{2}{*}{$d^{\dagger}$} \\
\hline & Média (DP) & Média (DP) & Média (DP) & & \\
\hline \multicolumn{6}{|l|}{$1^{\circ}$ e $2^{\circ}$ anos } \\
\hline $\begin{array}{l}\text { Consideração } \\
\text { empática }\end{array}$ & $19,61(4,84)$ & $17,99(4,67)$ & $20,98(4,55)$ & $<0,001$ & 0,65 \\
\hline $\begin{array}{l}\text { Tomada de } \\
\text { perspectiva }\end{array}$ & $17,94(4,97)$ & $17,48(5,11)$ & $18,33(4,83)$ & 0,069 & - \\
\hline Angústia pessoal & $12,71(4,28)$ & $12,05(3,91)$ & $13,28(4,51)$ & 0,002 & 0,29 \\
\hline \multicolumn{6}{|l|}{$3^{\circ}$ e $4^{\circ}$ anos } \\
\hline $\begin{array}{l}\text { Consideração } \\
\text { empática }\end{array}$ & $18,99(4,65)$ & $17,52(4,35)$ & $20,31(4,52)$ & $<0,001$ & 0,63 \\
\hline $\begin{array}{l}\text { Tomada de } \\
\text { perspectiva }\end{array}$ & $17,84(5,01)$ & $17,65(5,08)$ & $18,01(4,95)$ & 0,426 & - \\
\hline Angústia pessoal & $12,28(4,18)$ & $11,30(3,90)$ & $13,16(4,23)$ & $<0,001$ & 0,46 \\
\hline \multicolumn{6}{|l|}{$5^{\circ}$ e $6^{\circ}$ anos } \\
\hline $\begin{array}{l}\text { Consideração } \\
\text { empática }\end{array}$ & $18,58(4,94)$ & $17,08(4,51)$ & $19,98(4,92)$ & $<0,001$ & 0,61 \\
\hline $\begin{array}{l}\text { Tomada de } \\
\text { perspectiva }\end{array}$ & $17,13(5,14)$ & $17,25(5,16)$ & $17,01(5,13)$ & 0,642 & - \\
\hline Angústia pessoal & $11,59(4,13)$ & $11,00(3,92)$ & $12,14(4,25)$ & 0,006 & 0,28 \\
\hline
\end{tabular}


$\mathrm{Na}$ população geral do estudo (incluindo homens e mulheres), os escores de empatia nos domínios consideração empática e tomada de perspectiva dos estudantes do ciclo profissionalizante foram menores do que os escores dos estudantes do ciclo básico $(p<0,05 ; f<0,10)$. Os estudantes do ciclo profissionalizante também obtiveram escores ligeiramente menores no domínio angústia pessoal do que os estudantes dos ciclos básico e intermediário $(p<0,01 ; f=0,11)$ (Tabela 5).

As análises para os estudantes do sexo masculino demonstraram não haver diferença significativa para os escores dos domínios consideração empática e tomada de perspectiva nos diferentes anos do curso $(p>0,05)$. Os estudantes do ciclo profissionalizante apresentaram escores menores no domínio angústia pessoal do que os estudantes do ciclo básico $(p=0,02 ; f=$ 0,11) (Tabela 5).

Para o grupo de estudantes do sexo feminino, os escores dos domínios consideração empática não diferiram entre os anos do curso $(p=0,06)$. Os escores do domínio tomada de perspectiva das estudantes do ciclo profissionalizante foram ligeiramente menores do que os escores do grupo do ciclo básico $(p=0,01 ; f=0,11)$. As estudantes do ciclo profissionalizante também apresentaram menores escores no domínio angústia pessoal quando comparadas com as estudantes dos ciclos básico e intermediário $(p<0,01 ; f=$ 0,11) (Tabela 5). 
Tabela 5 - Escores de empatia obtidos por meio da EMRI de acordo com ano do curso

\begin{tabular}{|c|c|c|c|c|c|}
\hline Domínios EMRI & $\begin{array}{c}\text { Primeiro e } \\
\text { segundo anos } \\
\text { Média (DP) }\end{array}$ & $\begin{array}{c}\text { Terceiro e } \\
\text { quarto anos } \\
\text { Média (DP) }\end{array}$ & $\begin{array}{c}\text { Quinto e sexto } \\
\text { anos } \\
\text { Média (DP) }\end{array}$ & $p^{*}$ & $f^{\dagger}$ \\
\hline $\begin{array}{l}\text { Geral } \\
\text { Consideração } \\
\text { empática }\end{array}$ & $19,61^{\mathrm{a}}(4,84)$ & $18,99^{a, b}(4,65)$ & $18,58^{\mathrm{b}}(4,94)$ & 0,007 & 0,09 \\
\hline $\begin{array}{l}\text { Tomada de } \\
\text { perspectiva }\end{array}$ & $17,94^{\mathrm{a}}(4,97)$ & $17,84^{a, b}(5,01)$ & $17,13^{\mathrm{b}}(5,14)$ & 0,040 & 0,07 \\
\hline Angústia pessoal & $12,71^{\mathrm{a}}(4,28)$ & $12,28^{\mathrm{a}}(4,18)$ & $11,59^{\mathrm{b}}(4,13)$ & $<0,001$ & 0,11 \\
\hline $\begin{array}{l}\text { Masculino } \\
\text { Consideração } \\
\text { empática }\end{array}$ & $17,99(4,67)$ & $17,52(4,35)$ & $17,08(4,51)$ & 0,132 & - \\
\hline $\begin{array}{l}\text { Tomada de } \\
\text { perspectiva }\end{array}$ & $17,48(5,11)$ & $17,65(5,08)$ & $17,25(5,16)$ & 0,728 & - \\
\hline Angústia pessoal & $12,05^{\mathrm{a}}(3,91)$ & $11,30^{a, b}(3,90)$ & $11,00^{\mathrm{b}}(3,92)$ & 0,020 & 0,11 \\
\hline $\begin{array}{l}\text { Feminino } \\
\text { Consideração } \\
\text { empática }\end{array}$ & $20,98(4,55)$ & $20,31(4,52)$ & $19,98(4,92)$ & 0,061 & - \\
\hline $\begin{array}{l}\text { Tomada de } \\
\text { perspectiva }\end{array}$ & $18,33^{\mathrm{a}}(4,83)$ & $18,01^{a, b}(4,95)$ & $17,01^{b}(5,13)$ & 0,015 & 0,11 \\
\hline Angústia pessoal & $13,28^{\mathrm{a}}(4,51)$ & $13,16^{\mathrm{a}}(4,23)$ & $12,14^{\mathrm{b}}(4,25)$ & 0,010 & 0,11 \\
\hline
\end{tabular}

\subsection{Qualidade de vida}

As análises da qualidade dos dados relacionados às respostas obtidas por meio da autoavaliação da qualidade de vida geral e no curso, do WHOQOL-BREF e do Veras-q não demonstraram a ocorrência de efeitos piso ou teto. Os coeficientes de alfa Cronbach foram maiores do que 0,7 na maioria 
dos domínios do WHOQOL-BREF (exceto no domínio relações sociais, alfa=0,657) e em todos os domínios do Veras-q (Tabela 6).

Tabela 6 - Qualidade dos dados obtidos (efeitos piso e teto) ${ }^{*}$ e confiabilidade da autoavaliação da qualidade de vida, WHOQOL-BREF e Veras-q

\begin{tabular}{|c|c|c|c|}
\hline \multirow[b]{2}{*}{ Domínios } & \multicolumn{2}{|c|}{ Qualidade dos dados } & \multirow{2}{*}{$\begin{array}{c}\text { Confiabilidad } € \\
\text { Cronbach }\end{array}$} \\
\hline & $\begin{array}{c}\text { Escore mínimo } \\
\mathrm{n}(\%)\end{array}$ & $\begin{array}{c}\text { Escore máximo } \\
\mathrm{n}(\%)\end{array}$ & \\
\hline \multicolumn{4}{|l|}{ Auto-avaliacão } \\
\hline $\begin{array}{l}\text { Qualidade de vida } \\
\text { geral }\end{array}$ & $0(0,0)$ & $92(6,8)$ & - \\
\hline $\begin{array}{l}\text { Qualidade de vida } \\
\text { no curso }\end{array}$ & $1(0,1)$ & $17(1,3)$ & - \\
\hline \multicolumn{4}{|l|}{ WHOQOL-BREF } \\
\hline Físico & $0(0,0)$ & $7(0,5)$ & 0,752 \\
\hline Psicológico & $1(0,1)$ & $2(0,1)$ & 0,788 \\
\hline Relações sociais & $4(0,3)$ & $51(3,8)$ & 0,657 \\
\hline Meio Ambiente & $0(0,0)$ & $2(0,1)$ & 0,732 \\
\hline \multicolumn{4}{|l|}{ Veras-q } \\
\hline Uso do tempo & $2(0,1)$ & $0(0,0)$ & 0,821 \\
\hline Psicológico & $0(0,0)$ & $1(0,1)$ & 0,819 \\
\hline Físico & $0(0,0)$ & $2(0,1)$ & 0,788 \\
\hline Ambiente de ensino & $0(0,0)$ & $0(0,0)$ & 0,768 \\
\hline
\end{tabular}

Os escores obtidos por meio de autoavaliação da qualidade de vida em geral (QVG) e da qualidade de vida no curso (QVC) não foram diferentes entre os estudantes do sexo masculino e feminino $(p>0,05)$ (Tabela 7). Os escores da qualidade de vida no curso de medicina foram significativamente menores do que os escores da qualidade de vida geral entre os estudantes de medicina em todas as comparações realizadas (população geral, sexo masculino, sexo feminino, diferentes anos do curso) ( $p<0,001 ; d>0,80)$ (Tabelas 7 e 8). 
Tabela 7 - Escores obtidos por meio da autoavaliação da qualidade de vida geral e da qualidade de vida no curso de acordo com sexo

\begin{tabular}{lccccc}
\hline População & $\begin{array}{c}\text { Qualidade de vida } \\
\text { geral }\end{array}$ & $\begin{array}{c}\text { Qualidade de vida } \\
\text { no curso }\end{array}$ & \multirow{2}{*}{$\mathrm{p}^{*}$} & $d^{\S}$ \\
\cline { 2 - 3 } & Média (DP) & Média (DP) & & \\
\hline Geral & $7,86(1,27)$ & $6,51(1,56)$ & $<0,001$ & 0,95 \\
Masculino & $7,93(1,26)$ & $6,53(1,66)$ & $<0,001$ & 0,95 \\
Feminino & $7,81(1,28)$ & $6,50(1,46)$ & $<0,001$ & 0,95 \\
\hline $\mathrm{p}^{\dagger}$ & 0,09 & 0,72 & & \\
\hline
\end{tabular}

*Teste t-pareado

${ }^{\dagger}$ Teste t-student (comparação de acordo com sexo)

${ }^{\S} d$ de Cohen

Tabela 8 - Comparação dos escores obtidos por meio da autoavaliação da qualidade de vida geral e da qualidade de vida no curso de acordo com ano do curso

\begin{tabular}{|c|c|c|c|c|}
\hline Ano do curso & $\begin{array}{c}\text { Qualidade de } \\
\text { vida geral } \\
\text { Média (DP) }\end{array}$ & $\begin{array}{l}\text { Qualidade de } \\
\text { vida no curso } \\
\text { Média (DP) }\end{array}$ & $p^{\star}$ & $d^{\dagger}$ \\
\hline \multicolumn{5}{|l|}{$1^{\circ}$ e $2^{\circ}$ anos } \\
\hline Geral & $7,88(1,21)$ & $6,62(1,56)$ & $<0,001$ & 0,90 \\
\hline Masculino & $7,84(1,25)$ & $6,64(1,68)$ & $<0,001$ & 0,81 \\
\hline Feminino & $7,90(1,18)$ & $6,61(1,45)$ & $<0,001$ & 0,97 \\
\hline \multicolumn{5}{|l|}{$3^{\circ}$ e $4^{\circ}$ anos } \\
\hline Geral & $7,91(1,25)$ & $6,53(1,50)$ & $<0,001$ & 0,99 \\
\hline Masculino & $8,00(1,17)$ & $6,59(1,51)$ & $<0,001$ & 1,04 \\
\hline Feminino & $7,83(1,31)$ & $6,47(1,49)$ & $<0,001$ & 0,97 \\
\hline \multicolumn{5}{|l|}{$5^{\circ}$ e $6^{\circ}$ anos } \\
\hline Geral & $7,80(1,37)$ & $6,36(1,61)$ & $<0,001$ & 0,96 \\
\hline Masculino & $7,93(1,38)$ & $6,32(1,80)$ & $<0,001$ & 1,00 \\
\hline Feminino & $7,68(1,35)$ & $6,40(1,43)$ & $<0,001$ & 0,92 \\
\hline
\end{tabular}

*Teste t-pareado

${ }^{\dagger} d$ de Cohen

Os estudantes do ciclo profissionalizante atribuíram escores ligeiramente menores para a qualidade de vida no curso do que os estudantes do ciclo básico $(p=0,04 ; f=0,07)$ (Tabela 9). 
Tabela 9 - Escores obtidos por meio da autoavaliação da qualidade de vida (geral e no curso) de acordo com ano do curso

\begin{tabular}{|c|c|c|c|c|c|}
\hline Autoavaliação & $\begin{array}{l}\text { Primeiro e } \\
\text { segundo } \\
\text { anos } \\
\text { Média (DP) }\end{array}$ & $\begin{array}{c}\text { Terceiro e } \\
\text { quarto anos } \\
\text { Média (DP) }\end{array}$ & $\begin{array}{c}\text { Quinto e } \\
\text { sexto } \\
\text { anos } \\
\text { Média (DP) }\end{array}$ & $p^{*}$ & $f^{\dagger}$ \\
\hline Geral & & & & & \\
\hline Qualidade de vida geral & $7,88(1,21)$ & $7,91(1,25)$ & $7,80(1,38)$ & 0,45 & - \\
\hline $\begin{array}{l}\text { Qualidade de vida no } \\
\text { curso }\end{array}$ & $6,62^{a}(1,56)$ & $6,53^{\mathrm{a}, \mathrm{b}}(1,50)$ & $6,36^{\mathrm{b}}(1,62)$ & 0,04 & 0,07 \\
\hline Masculino & & & & & \\
\hline Qualidade de vida geral & $7,84(1,25)$ & $8,00(1,18)$ & $7,93(1,38)$ & 0,45 & - \\
\hline $\begin{array}{l}\text { Qualidade de vida no } \\
\text { curso }\end{array}$ & $6,64(1,68)$ & $6,59(1,51)$ & $6,32(1,80)$ & 0,12 & - \\
\hline $\begin{array}{l}\text { Feminino } \\
\text { Qualidade de vida geral }\end{array}$ & $7,90(1,18)$ & $7,83(1,31)$ & $7,68(1,35)$ & 0,16 & - \\
\hline $\begin{array}{l}\text { Qualidade de vida no } \\
\text { curso }\end{array}$ & $6,61(1,45)$ & $6,47(1,49)$ & $6,40(1,43)$ & 0,28 & - \\
\hline
\end{tabular}

As comparações dos escores de qualidade de vida obtidos por meio do WHOQOL-BREF revelaram diferenças significativas entre os sexos nos domínios físico e psicológico, com escores ligeiramente menores para estudantes do sexo feminino $(p<0,001 ; d \leq 0,30)$ (Tabela 10). Também observamos essa diferença entre os sexos nos diferentes anos do curso $(p<0,05 ; d<0,40)$ (Tabela 11).

Tabela 10 - Escores de qualidade de vida obtidos por meio do WHOQOLBREF de acordo com sexo

\begin{tabular}{lccccc}
\hline Domínio & Geral & Masculino & Feminino & \multirow{2}{*}{ p $^{*}$} & \multirow{2}{*}{$d^{\dagger}$} \\
\cline { 2 - 4 } & Média (DP) & Média (DP) & Média (DP) & & \\
\hline Físico & $65,22(14,70)$ & $67,31(14,38)$ & $63,36(14,75)$ & $<0,001$ & 0,27 \\
Psicológico & $61,72(15,69)$ & $64,16(15,03)$ & $59,54(15,96)$ & $<0,001$ & 0,30 \\
Relações sociais & $65,56(19,89)$ & $63,76(20,32)$ & $63,39(19,51)$ & 0,733 & - \\
Meio Ambiente & $63,82(14,08)$ & $63,97(14,19)$ & $63,69(14,00)$ & 0,712 & - \\
\hline
\end{tabular}

*Teste t-student

${ }^{\dagger} d$ de Cohen

WHOQOL-BREF: The World Health Organization Quality of Life Assessment 
Tabela 11 - Escores de qualidade de vida obtidos por meio do WHOQOLBREF de acordo com sexo nos diferentes anos do curso

\begin{tabular}{|c|c|c|c|c|c|}
\hline \multirow[t]{3}{*}{ Anos do curso } & Geral & Masculino & Feminino & \multirow{3}{*}{$p^{*}$} & \multirow{3}{*}{$d^{\dagger}$} \\
\hline & & & & & \\
\hline & Média (DP) & Média (DP) & Média (DP) & & \\
\hline \multicolumn{6}{|l|}{$1^{\circ}$ e $2^{\circ}$ anos } \\
\hline Físico & $63,66(15,62)$ & $65,89(15,08)$ & $61,77(15,84)$ & 0,005 & 0,27 \\
\hline Psicológico & $62,01(16,02)$ & $64,59(15,59)$ & $59,81(16,09)$ & 0,001 & 0,30 \\
\hline $\begin{array}{l}\text { Relações } \\
\text { sociais }\end{array}$ & $64,85(18,89)$ & $64,10(19,56)$ & $65,49(18,32)$ & 0,432 & - \\
\hline Meio Ambiente & $62,81(14,49)$ & $62,75(14,44)$ & $62,87(14,75)$ & 0,934 & - \\
\hline \multicolumn{6}{|l|}{$3^{\circ}$ e $4^{\circ}$ anos } \\
\hline Físico & $65,82(14,30)$ & $67,30(13,76)$ & $64,49(14,67)$ & 0,030 & 0,20 \\
\hline Psicológico & $62,18(15,21)$ & $63,94(13,68)$ & $60,60(16,32)$ & 0,015 & 0,22 \\
\hline $\begin{array}{l}\text { Relações } \\
\text { sociais }\end{array}$ & $63,80(20,08)$ & $64,19(20,24)$ & $63,45(19,97)$ & 0,684 & - \\
\hline Meio Ambiente & $64,70(13,94)$ & $64,12(14,25)$ & $65,23(13,67)$ & 0,379 & - \\
\hline \multicolumn{6}{|l|}{$5^{\circ}$ e $6^{\circ}$ anos } \\
\hline Físico & $66,28(13,98)$ & $68,87(14,24)$ & $63,85(13,31)$ & $<0,001$ & 0,36 \\
\hline Psicológico & $60,82(15,90)$ & $63,97(16,00)$ & $57,89(15,27)$ & $<0,001$ & 0,39 \\
\hline $\begin{array}{l}\text { Relações } \\
\text { sociais }\end{array}$ & $61,79(20,67)$ & $62,87(21,28)$ & $60,79(20,09)$ & 0,316 & - \\
\hline Meio Ambiente & $63,91(13,61)$ & $65,14(13,79)$ & $62,76(13,37)$ & 0,080 & - \\
\hline
\end{tabular}

Na população geral do estudo, os escores do WHOQOL-BREF não diferiram entre os diferentes anos do curso, exceto no domínio físico. Nesse domínio, os escores dos estudantes do ciclo profissionalizante foram ligeiramente maiores do que os escores dos estudantes do ciclo básico $(p=0,02 ; f=0,08)($ Tabela 12$)$.

Entre os estudantes do sexo masculino, não houve diferença dos escores do WHOQOL-BREF nos diferentes anos do curso ( $p>0,05)$. No grupo do sexo feminino, as estudantes do ciclo profissionalizante apresentaram 
escores no domínio relações sociais ligeiramente menores do que as estudantes do ciclo básico $(p=0,03 ; f=0,10)$ (Tabela 12).

Tabela 12 - Escores de qualidade de vida obtidos por meio do WHOQOLBREF de acordo com ano do curso

\begin{tabular}{|c|c|c|c|c|c|}
\hline & $\begin{array}{c}\text { Primeiro e } \\
\text { segundo anos }\end{array}$ & $\begin{array}{c}\text { Terceiro e } \\
\text { quarto anos }\end{array}$ & $\begin{array}{l}\text { Quinto e sexto } \\
\text { anos }\end{array}$ & $p^{*}$ & $f^{\dagger}$ \\
\hline Domínios & Média (DP) & Média (DP) & Média (DP) & & \\
\hline \multicolumn{6}{|l|}{ Geral } \\
\hline Físico & $63,66^{a}(15,62)$ & $65,82^{a, b}(14,30)$ & $66,28^{\mathrm{b}}(13,98)$ & 0,02 & 0,08 \\
\hline Psicológico & $62,01(16,02)$ & $62,18(15,21)$ & $60,82(15,90)$ & 0,39 & - \\
\hline Relações sociais & $64,85(18,89)$ & $63,80(20,08)$ & $61,79(20,67)$ & 0,07 & - \\
\hline Meio Ambiente & $62,81(14,59)$ & $64,70(13,94)$ & $63,91(13,61)$ & 0,12 & - \\
\hline \multicolumn{6}{|l|}{ Masculino } \\
\hline Físico & $65,89(15,08)$ & $67,30(13,76)$ & $68,87(14,24)$ & 0,12 & - \\
\hline Psicológico & $64,59(15,59)$ & $63,94(13,68)$ & $63,97(16,00)$ & 0,88 & - \\
\hline Relações sociais & $64,10(19,56)$ & $64,19(20,24)$ & $62,87(21,28)$ & 0,77 & - \\
\hline Meio Ambiente & $62,75(14,44)$ & $64,12(14,25)$ & $65,14(13,79)$ & 0,24 & - \\
\hline \multicolumn{6}{|l|}{ Feminino } \\
\hline Físico & $61,77(15,84)$ & $64,49(14,67)$ & $63,85(13,31)$ & 0,10 & - \\
\hline Psicológico & $59,81(16,09)$ & $60,60(16,32)$ & $57,89(15,27)$ & 0,18 & - \\
\hline Relações sociais & $65,49^{\mathrm{a}}(18,32)$ & $63,45^{\mathrm{a}, \mathrm{b}}(19,97)$ & $60,79^{b}(20,09)$ & 0,04 & 0,10 \\
\hline Meio Ambiente & $62,87(14,75)$ & $65,23(13,67)$ & $62,76(13,37)$ & 0,09 & - \\
\hline
\end{tabular}

Em relação à avaliação da qualidade de vida obtida por meio do Verasq, as estudantes do sexo feminino apresentaram médias ligeiramente menores do que o grupo do sexo masculino em todos os domínios do questionário $(p<0,01 ; d \leq 0,23)$, exceto no domínio ambiente de ensino $(p=0,111)$ (Tabela 13). 
Tabela 13 - Escores de qualidade de vida obtidos por meio do Veras-q de acordo com sexo

\begin{tabular}{lccccc}
\hline Domínio & Geral & Masculino & Feminino & \multirow{2}{*}{$\mathrm{p}^{*}$} & \multirow{2}{*}{$\mathbf{d}^{\dagger}$} \\
\cline { 2 - 4 } & Média (DP) & Média (DP) & Média (DP) & & \\
\hline Uso do tempo & $37,37(15,47)$ & $39,04(15,53)$ & $35,88(15,26)$ & $<\mathbf{0 , 0 0 1}$ & 0,20 \\
Psicológico & $51,02(16,10)$ & $52,84(16,11)$ & $49,40(15,94)$ & $<0,001$ & 0,21 \\
Físico & $54,47(18,28)$ & $56,70(18,65)$ & $52,48(17,71)$ & $<0,001$ & 0,23 \\
Ambiente de ensino & $57,23(13,12)$ & $57,83(13,14)$ & $56,69(13,09)$ & 0,111 & - \\
\hline
\end{tabular}

*Teste t-student

${ }^{\dagger} d$ de Cohen

A comparação das médias obtidas por meio do Veras-q de acordo com o sexo variou nos diferentes anos do curso. Entre os estudantes do ciclo básico, as estudantes do sexo feminino apresentaram escores ligeiramente menores do que os estudantes do sexo masculino nos domínios uso do tempo, psicológico e físico $(p<0,01 ; d<0,30)$. Entre os estudantes do ciclo profissionalizante, observamos escores ligeiramente menores entre as mulheres para todos domínios do Veras-q $(p<0,05 ; d \leq 0,31)$, exceto para 0 domínio uso do tempo $(p>0,05)$ (Tabela 14). 
Tabela 14 - Escores de qualidade de vida obtidos por meio do Veras-q de acordo com sexo nos difentes anos do curso

\begin{tabular}{|c|c|c|c|c|c|}
\hline \multirow[t]{2}{*}{ Anos do curso } & Geral & Masculino & Feminino & \multirow{2}{*}{$p^{*}$} & \multirow{2}{*}{$d^{\dagger}$} \\
\hline & Média (DP) & Média (DP) & Média (DP) & & \\
\hline \multicolumn{6}{|l|}{$1^{\circ}$ e $2^{\circ}$ anos } \\
\hline Uso do tempo & $38,19(16,51)$ & $40,82(16,26)$ & $36,08(16,51)$ & 0,002 & 0,29 \\
\hline Psicológico & $51,86(16,59)$ & $54,10(15,94)$ & $50,08(17,19)$ & 0,010 & 0,24 \\
\hline Físico & $54,45(18,15)$ & $56,93(18,78)$ & $52,27(17,45)$ & 0,006 & 0,26 \\
\hline $\begin{array}{l}\text { Ambiente de } \\
\text { ensino }\end{array}$ & $60,24(12,92)$ & $60,92(13,12)$ & $59,83(12,56)$ & 0,365 & - \\
\hline \multicolumn{6}{|l|}{$3^{\circ}$ e $4^{\circ}$ anos } \\
\hline Uso do tempo & $37,36(14,95)$ & $38,70(14,96)$ & $36,50(15,17)$ & 0,108 & - \\
\hline Psicológico & $50,71(15,40)$ & $52,01(15,35)$ & $50,27(15,38)$ & 0,209 & - \\
\hline Físico & $55,17(18,27)$ & $56,98(17,76)$ & $53,98(18,71)$ & 0,070 & - \\
\hline $\begin{array}{l}\text { Ambiente de } \\
\text { ensino }\end{array}$ & $56,56(12,91)$ & $57,08(12,52)$ & $56,85(13,43)$ & 0,842 & - \\
\hline \multicolumn{6}{|l|}{$5^{\circ}$ e $6^{\circ}$ anos } \\
\hline Uso do tempo & $36,40(14,73)$ & $37,53(15,28)$ & $34,87(13,77)$ & 0,068 & - \\
\hline Psicológico & $50,37(16,34)$ & $52,46(17,16)$ & $47,50(14,96)$ & 0,002 & 0,31 \\
\hline Físico & $53,67(18,46)$ & $56,12(19,62)$ & $50,88(16,65)$ & 0,004 & 0,29 \\
\hline $\begin{array}{l}\text { Ambiente de } \\
\text { ensino }\end{array}$ & $54,39(12,90)$ & $55,36(13,30)$ & $52,73(12,28)$ & 0,041 & 0,20 \\
\hline
\end{tabular}

*Teste t-student

${ }^{\dagger} d$ de Cohen

$\mathrm{Na}$ população geral do estudo (incluindo homens e mulheres), os escores do domínio ambiente de ensino foram ligeiramente menores entre os estudantes dos anos mais avançados do curso ( $p<0,001 ; f=0,20)$ (Tabela 15).

Entre os estudantes do sexo masculino, também observamos escores significativamente menores no domínio ambiente de ensino nos anos mais avançados do curso $(p<0,001 ; f=0,18)$. As médias do grupo do ciclo profissionalizante e do ciclo intermediário foram menores do que as médias do ciclo básico (Tabela 15). 
Entre as estudantes do sexo feminino, também observamos diferença significativa nos diferentes anos do curso apenas no domínio ambiente de ensino do Veras-q. Nesse domínio, as médias foram ligeiramente menores nos anos mais avançados do curso $(p<0,001 ; f=0,22)$ (Tabela 15).

Tabela 15 - Escores de qualidade de vida obtidos por meio do Veras-q de acordo com ano do curso

\begin{tabular}{|c|c|c|c|c|c|}
\hline \multirow[b]{2}{*}{ Domínios } & $\begin{array}{c}\text { Primeiro e } \\
\text { segundo anos }\end{array}$ & $\begin{array}{c}\text { Terceiro e } \\
\text { quarto anos }\end{array}$ & $\begin{array}{l}\text { Quinto e } \\
\text { sexto anos }\end{array}$ & \multirow[t]{2}{*}{$p^{*}$} & \multirow[t]{2}{*}{$f^{\dagger}$} \\
\hline & Média (DP) & Média (DP) & Média (DP) & & \\
\hline \multicolumn{6}{|l|}{ Geral } \\
\hline Uso do tempo & $38,26(15,55)$ & $37,54(15,10)$ & $36,15(14,56)$ & 0,132 & - \\
\hline Psicológico & $51,93(16,73)$ & $51,09(15,38)$ & $49,90(16,23)$ & 0,181 & - \\
\hline Físico & $54,41(18,20)$ & $55,40(18,31)$ & $53,41(18,31)$ & 0,270 & - \\
\hline Ambiente de ensino & $60,33^{a}(12,81)$ & $56,96^{\mathrm{b}}(12,99)$ & $54,00^{\mathrm{c}}(12,84)$ & $<0,001$ & 0,20 \\
\hline \multicolumn{6}{|l|}{ Masculino } \\
\hline Uso do tempo & $40,82(16,26)$ & $38,70(14,96)$ & $37,53(15,28)$ & 0,094 & - \\
\hline Psicológico & $54,10(15,94)$ & $52,01(15,35)$ & $52,46(17,16)$ & 0,368 & - \\
\hline Físico & $56,93(18,78)$ & $56,98(17,76)$ & $56,12(19,62)$ & 0,874 & - \\
\hline Ambiente de ensino & $60,92^{a}(13,12)$ & $57,08^{\mathrm{b}}(12,52)$ & $55,36^{\mathrm{b}}(13,30)$ & $<0,001$ & 0,18 \\
\hline \multicolumn{6}{|l|}{ Feminino } \\
\hline Uso do tempo & $36,08(16,51)$ & $36,50(15,17)$ & $34,87(13,77)$ & 0,502 & - \\
\hline Psicológico & $50,08(17,19)$ & $50,27(15,38)$ & $47,50(14,96)$ & 0,126 & - \\
\hline Físico & $52,27(17,45)$ & $53,98(18,71)$ & $50,88(16,65)$ & 0,166 & - \\
\hline Ambiente de ensino & $59,83^{\mathrm{a}}(12,56)$ & $56,85^{\mathrm{b}}(14,43)$ & $52,73^{\mathrm{c}}(12,28)$ & $<0,001$ & 0,22 \\
\hline
\end{tabular}

\subsection{Esgotamento profissional}

Ao analisarmos a qualidade das respostas do $\mathrm{MBI}$, não observamos a ocorrência de efeito piso ou teto. Os coeficientes de alfa Cronbach foram 
maiores do que 0,7 nos domínios exaustão emocional e realização pessoal (Tabela 16).

Tabela 16 - Qualidade dos dados (efeitos piso e teto) ${ }^{*}$ e confiabilidade do MBI

\begin{tabular}{lccc}
\hline \multirow{2}{*}{ Domínios } & \multicolumn{2}{c}{ Qualidade dos dados } & Confiabilidade \\
\cline { 2 - 4 } & $\begin{array}{c}\text { Escore mínimo } \\
\mathrm{n}(\%)\end{array}$ & $\begin{array}{c}\text { Escore máximo } \\
\mathrm{n}(\%)\end{array}$ & Cronbach \\
\hline Exaustão emocional & $4(0,3)$ & $1(0,1)$ & 0,850 \\
Despersonalização & $87(6,4)$ & $0(0,0)$ & 0,680 \\
Realização pessoal & $3(0,2)$ & $7(0,5)$ & 0,811 \\
\hline Efeito piso: porcentagem de respondentes com escore mínimo & $\geq 10 \%$. Efeito teto: \\
porcentagem de respondentes com escore máximo $\geq 10 \%$. &
\end{tabular}

A comparação dos escores relacionados ao esgotamento profissional revelou diferenças significativas entre homens e mulheres nos domínios exaustão emocional e despersonalização. Na população geral do estudo, observamos que os escores de exaustão emocional são ligeiramente maiores entre estudantes do sexo feminino $(p<0,001 ; d=0,21)$ e os escores de despersonalização são maiores entre os estudantes do sexo masculino $(p<0,001 ; d=0,20)$ (Tabela 17).

Ao analisarmos as médias da população geral do estudo, observamos que tanto homens quanto mulheres apresentaram escores médios indicativos de esgotamento profissional no domínio exaustão emocional (escores $\geq 27$ ). No entanto, nos domínos despersonalização e realização pessoal, as médias da população geral desse estudo não denotam a presença da síndrome de esgotamento profissional (Tabela 17). 
Tabela 17 - Escores de esgotamento profissional obtidos por meio do MBI de acordo com sexo

\begin{tabular}{lcccccc}
\hline \multirow{2}{*}{ Domínio } & Geral & Masculino & Feminino & \multirow{2}{*}{$\mathrm{p}^{\star}$} & \multirow{2}{*}{$d^{\dagger}$} \\
\cline { 2 - 4 } & Média (DP) & Média (DP) & Média (DP) & & \\
\hline Exaustão emocional & $26,73(9,80)$ & $25,67(9,90)$ & $27,68(9,61)$ & $<0,001$ & 0,21 \\
Despersonalização & $8,55(5,74)$ & $9,16(5,90)$ & $8,00(5,53)$ & $<0,001$ & 0,20 \\
Realização pessoal & $33,75(7,61)$ & $33,93(7,67)$ & $33,59(7,56)$ & 0,407 & - \\
\hline
\end{tabular}

*Teste t-student

${ }^{\dagger} d$ de Cohen

MBI: Inventário de Burnout de Maslach

Entre a população geral do estudo, mais de $50 \%$ dos estudantes apresentaram escores indicativos de esgotamento profissional no domínio exaustão emocional. A proporção de mulheres com escores nesse domínio sugestivos de esgotamento profissional foi maior do que a proporção de homens $(p<0,001)$ (Tabela 18).

Em relação ao domínio despersonalização, aproximadamente $40 \%$ dos estudantes apresentaram escores maiores ou iguais a 10. A proporção de homens com escores sugestivos de esgotamento profissional foi significativamente maior do que a proporção de mulheres $(p<0,001)($ Tabela 18).

Tabela 18 - Frequência de esgotamento profissional nos domínios do MBI

\begin{tabular}{lcccc}
\hline Domínio & Geral & Masculino & Feminino & $\mathrm{p}^{*}$ \\
\cline { 2 - 5 } & $\mathrm{n}(\%)$ & $\mathrm{n}(\%)$ & $\mathrm{n}(\%)$ & \\
\hline${ }^{\top}$ Exaustão emocional $\geq 27$ & $697(51,6)$ & $299(47,0)$ & $398(55,7)$ & $\mathbf{0 , 0 0 1}$ \\
${ }^{\dagger}$ Despersonalização $\geq 10$ & $546(40,4)$ & $287(45,1)$ & $259(36,3)$ & $\mathbf{0 , 0 0 1}$ \\
${ }^{\dagger}$ Realização pessoal $\leq 33$ & $599(44,4)$ & $279(43,9)$ & $320(44,8)$ & 0,726
\end{tabular}

*Qui-quadrado

${ }^{\dagger}$ Escore sugestivo de esgotamento profissional

MBI: Inventário de Burnout de Maslach 
A comparações dos escores de esgotamento profissional entre homens e mulheres diferiu nos anos do curso. Entre os estudantes do ciclo básico, as mulheres apresentaram escores de exaustão emocional ligeiramente maiores do que os homens $(p=0,008 ; d=0,25)$. No ciclo intermediário, estudantes do sexo masculino apresentaram escores de despersonalização estatisticamente maiores do que estudantes do sexo feminino $(p=0,030 ; d=0,20)$. Entre os estudantes do ciclo profissionalizante, as mulheres obtiveram escores ligeiramente maiores no domínio exaustão emocional e menores nos domínios despersonalização e realização profissional quando comparadas com colegas do sexo masculino $(p<0,05 ; d \leq 0,25)$ (Tabela 19).

Tabela 19 - Escores de esgotamento profissional obtidos por meio do $\mathrm{MBI}$ de acordo com sexo nos diferentes anos do curso

\begin{tabular}{|c|c|c|c|c|c|}
\hline \multirow[t]{2}{*}{ Anos do curso } & Geral & Masculino & Feminino & \multirow[b]{2}{*}{$p^{*}$} & \multirow[b]{2}{*}{$d^{\dagger}$} \\
\hline & Média (DP) & Média (DP) & Média (DP) & & \\
\hline \multicolumn{6}{|l|}{$1^{\circ}$ e $2^{\circ}$ anos } \\
\hline Exaustão & $25,85(10,11)$ & $24,50(10,02)$ & $27,00(10,06)$ & 0,008 & 0,25 \\
\hline \multicolumn{6}{|l|}{ emocional } \\
\hline Despersonalização & $7,30(5,32)$ & $7,79(5,39)$ & $6,88(5,24)$ & 0,068 & - \\
\hline Realização pessoal & $33,35(7,91)$ & $32,82(8,07)$ & $33,80(7,76)$ & 0,189 & - \\
\hline \multicolumn{6}{|l|}{$3^{\circ}$ e $4^{\circ}$ anos } \\
\hline Exaustão & $26,20(9,44)$ & $25,48(9,38)$ & $26,85(9,47)$ & 0,109 & - \\
\hline \multicolumn{6}{|l|}{ emocional } \\
\hline Despersonalização & $8,26(5,61)$ & $8,84(5,66)$ & $7,74(5,51)$ & 0,030 & 0,20 \\
\hline Realização pessoal & $33,27(7,78)$ & $33,60(7,90)$ & $32,98(7,68)$ & 0,383 & - \\
\hline \multicolumn{6}{|l|}{$5^{\circ}$ e $6^{\circ}$ anos } \\
\hline Exaustão & $28,40(9,68)$ & $27,16(10,24)$ & $29,55(8,99)$ & 0,013 & 0,25 \\
\hline \multicolumn{6}{|l|}{ emocional } \\
\hline Despersonalização & $10,34(5,92)$ & $11,05(6,26)$ & $9,68(5,51)$ & 0,020 & 0,23 \\
\hline Realização pessoal & $34,80(6,95)$ & $35,55(6,65)$ & $34,10(7,15)$ & 0,036 & 0,21 \\
\hline
\end{tabular}


Na população geral do estudo (homens e mulheres), estudantes do ciclo profissionalizante apresentaram escores ligeiramente maiores nos domínios exaustão emocional e realização pessoal do que estudantes dos ciclos básico e intermediário $(p<0,01 ; f \leq 0,11)$. As médias do domínio despersonalização foram maiores nos anos mais avançados do curso $(p<0,001 ; f=0,22)$ (Tabela 20).

Entre os estudantes do sexo masculino, os escores de exaustão emocional foram ligeiramente maiores entre os estudantes do ciclo profissionalizante quando comparados com os escores dos estudantes do ciclo básico $(p=0,025 ; f=0,11)$. Estudantes do ciclo profissionalizante também apresentaram maiores escores de despersonalização e realização pessoal do que estudantes dos ciclos básico e intermediário $(p \leq 0,001 ; f \leq 0,23)$ (Tabela 20).

As estudantes do ciclo profissionalizante apresentaram escores ligeiramente maiores de exaustão emocional e de despersonalização do que as estudantes dos ciclos básico e intermediário $(p<0,01 ; f \leq 0,21)$ (Tabela 20). 
Tabela 20 - Escores de esgotamento profissional obtidos por meio do $\mathrm{MBI}$ de acordo com ano do curso

\begin{tabular}{|c|c|c|c|c|c|}
\hline Domínios MBI & $\begin{array}{c}\text { Primeiro e } \\
\text { segundo anos } \\
\text { Média (DP) }\end{array}$ & $\begin{array}{c}\text { Terceiro e } \\
\text { quarto anos } \\
\text { Média (DP) } \\
\end{array}$ & $\begin{array}{c}\text { Quinto e sexto } \\
\text { anos } \\
\text { Média (DP) }\end{array}$ & $p^{*}$ & $f^{\dagger}$ \\
\hline $\begin{array}{l}\text { Geral } \\
\text { Exaustão emocional }\end{array}$ & $25,85^{a}(10,11)$ & $26,20^{\mathrm{a}}(9,44)$ & $28,40^{\mathrm{b}}(9,68)$ & $<0,001$ & 0,11 \\
\hline Despersonalização & $7,30^{a}(5,32)$ & $8,26^{\mathrm{b}}(5,61)$ & $10,34^{\mathrm{C}}(5,92)$ & $<0,001$ & 0,22 \\
\hline Realização pessoal & $33,35^{\mathrm{a}}(7,91)$ & $33,27^{\mathrm{a}}(7,78)$ & $34,80^{\mathrm{b}}(6,95)$ & 0,005 & 0,09 \\
\hline $\begin{array}{l}\text { Masculino } \\
\text { Exaustão emocional }\end{array}$ & $24,50^{\mathrm{a}}(10,02)$ & $25,48^{a, b}(9,38)$ & $27,16^{\mathrm{b}}(10,24)$ & 0,025 & 0,11 \\
\hline Despersonalização & $7,79^{a}(5,39)$ & $8,84^{a}(5,66)$ & $11,05^{\mathrm{b}}(6,26)$ & $<0,001$ & 0,23 \\
\hline Realização pessoal & $32,82^{\mathrm{a}}(8,07)$ & $33,60^{\mathrm{a}}(7,90)$ & $35,55^{\mathrm{b}}(6,65)$ & 0,001 & 0,15 \\
\hline $\begin{array}{l}\text { Feminino } \\
\text { Exaustão emocional }\end{array}$ & $27,00^{\mathrm{a}}(10,06)$ & $26,85^{\mathrm{a}}(9,47)$ & $29,55^{\mathrm{b}}(8,99)$ & 0,004 & 0,12 \\
\hline Despersonalização & $6,88^{\mathrm{a}}(5,24)$ & $7,74^{a}(5,51)$ & $9,68^{\mathrm{b}}(5,51)$ & $<0,001$ & 0,21 \\
\hline Realização pessoal & $33,80(7,76)$ & $32,98(7,68)$ & $34,10(7,15)$ & 0,250 & - \\
\hline
\end{tabular}

*ANOVA. Médias seguidas da mesma letra não diferem estatisticamente entre si pelo teste de Tukey

${ }^{\dagger} f$ de Cohen

MBI: Inventário de Burnout de Maslach

\subsection{Sonolência diurna}

Não observamos efeito piso ou teto nas respostas dos estudantes a Escala de Sonolência Diurna Epworth. O coeficiente alfa Cronbach da escala foi maior do que 0,7 (Tabela 21).

Tabela 21 - Qualidade dos dados (efeitos piso e teto) ${ }^{*}$ e confiabilidade da Escala de Sonolência Diurna de Epworth

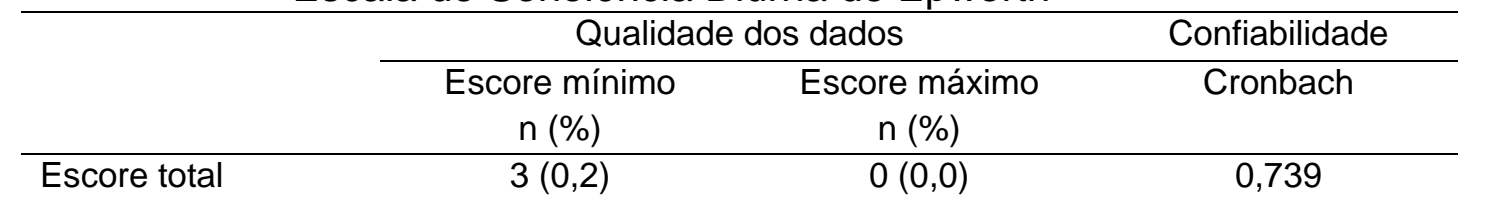

"Efeito piso: porcentagem de respondentes com escore mínimo $\geq 10 \%$. Efeito teto: porcentagem de respondentes com escore máximo $\geq 10 \%$. 
A comparação dos escores de sonolência diurna obtidos por meio da Escala de Sonolência Diurna de Epworth revelou diferenças estatisticamente significativas entre estudantes do sexo masculino e feminino, com escores ligeiramente maiores entre as mulheres $(p<0,001 ; d \leq 0,32)$. Essa diferença persistiu nos diferentes anos do curso (Tabela 22).

Os escores de sonolência diurna não mudaram nos diferentes anos do curso ( $p>0,05$ ). As médias dos estudantes variaram de 10,00 (estudantes do ciclo básico) a 10,27 (estudantes do ciclo profissionalizante) (Tabela 22).

Tabela 22 - Escores obtidos por meio da Escala de Sonolência Diurna de Epworth de acordo com sexo e ano de curso

\begin{tabular}{|c|c|c|c|c|c|}
\hline \multirow[t]{2}{*}{ Sexo } & Geral & $\begin{array}{l}\text { Primeiro e } \\
\text { segundo } \\
\text { anos }\end{array}$ & $\begin{array}{c}\text { Terceiro e } \\
\text { quarto anos }\end{array}$ & $\begin{array}{c}\text { Quinto e } \\
\text { sexto } \\
\text { anos }\end{array}$ & \multirow[t]{2}{*}{$\mathrm{p}^{*}$} \\
\hline & Média (DP) & Média (DP) & Média (DP) & Média (DP) & \\
\hline Geral & $10,26(3,90)$ & $10,53(4,00)$ & $10,00(3,85)$ & $10,27(3,83)$ & 0,090 \\
\hline Masculino & $9,54(3,86)$ & $9,74(4,05)$ & $9,29(3,63)$ & $9,64(3,90)$ & 0,434 \\
\hline Feminino & $10,89(3,83)$ & $11,20(3,85)$ & $10,63(3,93)$ & $10,86(3,67)$ & 0,246 \\
\hline$p^{\dagger}$ & $<0,001$ & $<0,001$ & $<0,001$ & $<0,001$ & \\
\hline$d^{\S}$ & 0,35 & 0,37 & 0,35 & 0,32 & \\
\hline
\end{tabular}

$\mathrm{Na}$ população geral do estudo, aproximadamente $56 \%$ dos estudantes apresentaram escores patológicos de sonolência diurna. A proporção de estudantes com escores maiores ou iguais a 10 foi maior entre estudantes do sexo feminino $(p<0,05)$ e não diferiu nos diversos anos do curso $(p>0,05)$ (Tabela 23). 
Tabela 23 - Percentual de estudantes com escores patológicos* de sonolência diurna

\begin{tabular}{lccccc}
\hline Sexo & Geral & $\begin{array}{c}\text { Primeiro e } \\
\text { segundo } \\
\text { anos }\end{array}$ & $\begin{array}{c}\text { Terceiro e } \\
\text { quarto anos }\end{array}$ & $\begin{array}{c}\text { Quinto } \mathrm{e} \\
\text { sexto } \\
\text { anos }\end{array}$ & $\mathrm{p}^{\dagger}$ \\
\cline { 2 - 5 } & $\mathrm{n}(\%)$ & $\mathrm{n}(\%)$ & $\mathrm{n}(\%)$ & $\mathrm{n}(\%)$ & \\
\hline Geral & $759(56,2)$ & $272(59,3)$ & $264(53,8)$ & $223(55,8)$ & 0,23 \\
Masculino & $317(49,8)$ & $110(52,1)$ & $113(48,7)$ & $94(48,7)$ & 0,72 \\
Feminino & $442(61,9)$ & $162(65,3)$ & $151(58,3)$ & $129(62,3)$ & 0,26 \\
\hline $\mathrm{p}^{\dagger}$ & $<\mathbf{0 , 0 0 1}$ & $\mathbf{0 , 0 0 4}$ & $\mathbf{0 , 0 3 3}$ & $\mathbf{0 , 0 0 6}$ & \\
\hline
\end{tabular}

Escores $\geq 10$

${ }^{\dagger}$ Qui-quadrado

4.6 Empatia, qualidade de vida, esgotamento profissional e sonolência diurna

Em geral, os escores dos domínios da EMRI apresentaram correlações fracas com os domínios dos instrumentos de qualidade de vida, esgotamento profissional e sonolência diurna $(r<0,30)$. Observamos correlações moderamente negativas entre o domínio angústia pessoal da EMRI e os domínios psicológicos do WHOQOL-BREF $(p<0,001 ; r=-0,30)$ e do Veras-q $(p<0,001 ; r=-0,34)$ e o domínio realização pessoal do $\mathrm{MBI}(p<0,001 ; r=-0,32)$. Notamos ainda correlação moderada entre o domínio tomada de perspectiva e o domínio realização pessoal $(p<0,001 ; r=0,30)$ para a população geral do estudo. Observamos correlações fracas entre os escores da ESS e os domínios da EMRI $(r<0,10)$ (Tabela 24). 
Tabela 24 - Coeficientes de correlação de Pearson entre os domínios das variáveis do estudo (empatia, qualidade de vida, esgotamento profissional e sonolência diurna) para a população geral do estudo

\begin{tabular}{|c|c|c|c|c|c|c|c|c|c|c|c|c|c|c|c|c|c|}
\hline & QVG & QVC & Exau & Desp & Real & CE & TP & $\mathrm{AP}$ & EpwT & VerasT & - VerasP & VerasF & VerasA & WhoF & WhoP & Whos & WhoA \\
\hline QVG & $\overline{1}$ & & & & & & & & & & & & & & & & \\
\hline QVC & $0,57^{* *}$ & 1 & & & & & & & & & & & & & & & \\
\hline BurE &,$- 28^{\star *}$ & $-0,44^{* \star}$ & 1 & & & & & & & & & & & & & & \\
\hline BurD & $-0,18^{\star *}$ & $-0,25^{\star \star}$ & $0,52^{* *}$ & 1 & & & & & & & & & & & & & \\
\hline BurR & $0,19^{* *}$ & $0,21^{* *}$ & $-0,27^{\star \star}$ & $-0,26^{* *}$ & 1 & & & & & & & & & & & & \\
\hline CE & $-0,01$ & $-0,01$ & $-0,03$ & $-0,29^{\star *}$ & $0,20^{* *}$ & 1 & & & & & & & & & & & \\
\hline TP & 0,05 & $0,08^{* *}$ & $-0,16^{\star *}$ & $-0,27^{* *}$ & $0,30^{* *}$ & $0,36^{* *}$ & 1 & & & & & & & & & & \\
\hline$A P$ & $-0,13^{\star \star}$ & $-0,11^{\star *}$ & $0,26^{* *}$ & $0,14^{* \star}$ & $-0,32^{* *}$ & $0,16^{\star \star}$ & $-0,11^{\star \star}$ & 1 & & & & & & & & & \\
\hline EpwT & $-0,09^{* \star}$ & $-0,21^{\star \star}$ & $0,26^{* *}$ & $0,11^{* *}$ & $-0,09^{* *}$ & $0,08^{\star *}$ & $-0,09^{*}$ & $0,08^{*}$ & 1 & & & & & & & & \\
\hline VerasT & $0,26^{\star *}$ & $0,49^{* *}$ & $-0,51^{\star \star}$ & $-0,24^{\star \star}$ & $0,20^{* *}$ & $-0,07^{*}$ & $0,08^{*}$ & $-0,28^{\star \star}$ & $-0,28^{\star \star}$ & 1 & & & & & & & \\
\hline VerasP & $0,37^{* *}$ & $0,46^{* *}$ & $-0,57^{* *}$ & $-0,41^{* *}$ & $0,50^{* *}$ & 0,03 & $0,21^{* *}$ & $-0,27^{\star *}$ & $-0,27^{* *}$ & $-0,48^{\star *}$ & 1 & & & & & & \\
\hline VerasF & $0,50^{* *}$ & $0,51^{\star \star}$ & $-0,42^{\star \star}$ & $-0,27^{* \star}$ & $0,31^{\star *}$ & $-0,06^{*}$ & $0,12^{* *}$ & $-0,24^{\star \star}$ & $-0,24^{* \star}$ & $0,54^{\star *}$ & $0,58^{* *}$ & 1 & & & & & \\
\hline VerasA & $0,34^{* *}$ & $0,49^{* *}$ & $-0,48^{\star \star}$ & $-0,42^{\star *}$ & $0,38^{* *}$ & $0,07^{*}$ & $0,18^{* *}$ & $-0,19^{\star \star}$ & $-0,19^{\star *}$ & $0,46^{* *}$ & $0,59^{* *}$ & $0,51^{\star \star}$ & & & & & \\
\hline WhoF & $0,34^{* *}$ & $0,44^{* *}$ &,$- 048^{* \star}$ & $-0,25^{* *}$ & $0,39^{* *}$ & $-0,03$ & $0,12^{* *}$ & $-0,33^{* *}$ & $-0,33^{* *}$ & $0,45^{* *}$ & $0,63^{* *}$ & $0,55^{* *}$ & $0,43^{* *}$ & 1 & & & \\
\hline WhoP & $0,45^{* *}$ & $0,48^{* *}$ & $-0,51^{* *}$ & $-0,34^{* *}$ & $0,46^{\star *}$ & 0,01 & $0,17^{* *}$ & $-0,21^{\star *}$ & $-0,21^{* *}$ & $0,42^{* *}$ & $0,76^{* *}$ & $0,62^{* \star}$ & $0,50^{* *}$ & $0,67^{* *}$ & 1 & & \\
\hline Whos & $0,37^{* *}$ & $0,33^{* \star}$ & $-0,34^{\star \star}$ & $-0,31^{* *}$ & $0,33^{* *}$ & 0,02 & $0,18^{\star *}$ & $-0,15^{\star \star}$ & $-0,15^{\star *}$ & $0,31^{\star *}$ & $0,51^{\star *}$ & $0,44^{* *}$ & $0,41^{* *}$ & $0,41^{* *}$ & $0,57^{* *}$ & 1 & \\
\hline WhoA & $0,42^{* *}$ & $0,42^{* *}$ & $-0,34^{* *}$ & $-0,25^{\star *}$ & $0,28^{* *}$ & 0,02 & $0,09^{*}$ & $-0,19^{* *}$ & $-0,19^{\star *}$ & $0,39^{* *}$ & $0,43^{* *}$ & $0,59^{* *}$ & $0,52^{* *}$ & $0,54^{* *}$ & $0,50^{* *}$ & $0,41^{* *}$ & 1 \\
\hline
\end{tabular}

Teste de correlação de Pearson

$\mathrm{p}<0,05$

$\mathrm{p}<0,001$

QVG: autoavaliação da qualidade de vida geral; QVC: autoavaliação da qualidade de vida no curso; Exau: Exaustão Emocional; Desp: Despersonalização; Real: Realização pessoal; CE: Consideração Empática; TP: Tomada de Perspectiva; AP: Angústia Pessoal; EpwT: Escore total Escala de Sonolência Diurna de Escala de Sonolência Diurna de Epworth; VerasT: Uso do tempo; VerasP: Psicológico; VerasF: Físico; VerasA Ambiente de Ensino; WhoF: Físico; WhoP: Psicológico; WhoS: Relações Sociais; WhoA: Ambiente 
Para o grupo de estudantes do sexo masculino, observamos moderadas correlações negativas entre o domínio angústia pessoal e os domínios psicológicos do WHOQOL-BREF $(p<0,001 ; r=-0,30)$ e do Veras-q $(p<0,001 ; r=$ $-0,34)$ e o domínio realização pessoal $(p<0,001 ; r=-0,32)$. Ainda, houve correlação moderada entre o domínio tomada de perspectiva e o domínio realização pessoal entre os estudantes do sexo masculino $(p<0,001 ; r=0,30)$. Observamos correlações fracas entre os escores da ESS e os domínios da EMRI $(r<0,10)$ (Tabela 25). 
Tabela 25 - Coeficientes de correlação de Pearson entre os domínios d as variáveis do estudo (empatia, qualidade de vida, esgotamento profissional e sonolência diurna) para os estudantes do sexo masculino

\begin{tabular}{|c|c|c|c|c|c|c|c|c|c|c|c|c|c|c|c|c|c|}
\hline & QVG & QVC & Exau & Desp & Real & CE & TP & $\mathrm{AP}$ & EpwT & VerT & VerPs & VerFi & VerAE & WhoF & WhoP & Whos & WhoA \\
\hline QVG & 1 & & & & & & & & & & & & & & & & \\
\hline QVC & $0,56^{* *}$ & 1 & & & & & & & & & & & & & & & \\
\hline Exau & $-0,30^{* *}$ & $-0,43^{* *}$ & 1 & & & & & & & & & & & & & & \\
\hline Desp & $-0,23^{\star \star}$ & $-0,28^{\star \star}$ & $0,55^{* *}$ & 1 & & & & & & & & & & & & & \\
\hline Real & $0,24^{* *}$ & $0,22^{* *}$ & $-0,24^{* *}$ & $-0,22^{\star \star}$ & 1 & & & & & & & & & & & & \\
\hline CE & $-0,03$ & $-0,02$ & $-0,03$ & $-0,23^{\star *}$ & $0,15^{\star *}$ & 1 & & & & & & & & & & & \\
\hline TP & $0,11^{* *}$ & $0,10^{*}$ & $-0,16^{\star *}$ & $-0,26^{* *}$ & $0,23^{* *}$ & $0,35^{* *}$ & 1 & & & & & & & & & & \\
\hline$A P$ & $-0,16^{\star \star}$ & $-0,12^{\star \star}$ & $0,25^{* *}$ & $0,19^{\star *}$ & $-0,33^{* *}$ & $0,17^{* *}$ & $-0,11^{* *}$ & 1 & & & & & & & & & \\
\hline EpwT & $-0,06$ & $-0,17^{\star *}$ & $0,24^{\star *}$ & $0,14^{* *}$ & $-0,04$ & 0,06 & $-0,07$ & 0,04 & 1 & & & & & & & & \\
\hline VerT & $0,29^{\star *}$ & $0,48^{* *}$ & $-0,49^{* *}$ & $-0,24^{\star *}$ & $0,20^{\star *}$ & $-0,03$ & 0,07 & $-0,11^{\star *}$ & $-0,23^{\star *}$ & 1 & & & & & & & \\
\hline VerPs & $0,39^{* *}$ & $0,47^{* *}$ & $-0,56^{\star *}$ & $-0,41^{\star *}$ & $0,51^{* *}$ & 0,04 & $0,17^{* *}$ & $-0,37^{* *}$ & $-0,20^{* *}$ & $0,45^{* *}$ & 1 & & & & & & \\
\hline VerFi & $0,52^{\star *}$ & $0,52^{* *}$ & $-0,42^{* *}$ & $-0,31^{\star *}$ & $0,33^{\star *}$ & $-0,05$ & $0,13^{* *}$ & $-0,27^{* *}$ & $-0,23^{* *}$ & $0,51^{* *}$ & $0,56^{* *}$ & 1 & & & & & \\
\hline VerAE & $0,34^{\star \star}$ & $0,49^{\star *}$ & $-0,45^{\star *}$ & $-0,45^{\star \star}$ & $0,36^{\star \star}$ & 0,07 & $0,16^{\star *}$ & $-0,23^{* *}$ & $-0,16^{* *}$ & $0,44^{\star \star}$ & $0,60^{* *}$ & $0,51^{\star *}$ & 1 & & & & \\
\hline WhoF & $0,39^{\star *}$ & $0,46^{* *}$ & $-0,46^{\star *}$ & $-0,25^{\star \star}$ & $0,40^{* *}$ & $-0,04$ & $0,09^{*}$ & $-0,24^{* *}$ & $-0,31^{* *}$ & $0,43^{\star *}$ & $0,60^{* *}$ & $0,57^{\star *}$ & $0,41^{* *}$ & 1 & & & \\
\hline WhoP & $0,50^{\star *}$ & $0,49^{* *}$ & $-0,49^{\star *}$ & $-0,36^{\star \star}$ & $0,47^{* *}$ & 0,01 & $0,16^{\star *}$ & $-0,32^{\star *}$ & $-0,18^{\star *}$ & $0,39^{* *}$ & $0,76^{* *}$ & $0,62^{* *}$ & $0,51^{* *}$ & $0,65^{\star *}$ & 1 & & \\
\hline Whos & $0,43^{* *}$ & $0,37^{* *}$ & $-0,30^{* *}$ & $-0,28^{\star *}$ & $0,30^{\star *}$ & $-0,05$ & $0,14^{* *}$ & $-0,17^{* *}$ & $-0,17^{* *}$ & $0,28^{* *}$ & $0,49^{* *}$ & $0,46^{* *}$ & $0,40^{* *}$ & $0,40^{\star *}$ & $0,57^{\star *}$ & 1 & \\
\hline WhoA & $0,46^{* *}$ & $0,43^{* *}$ & $-0,33^{* *}$ & $-0,27^{* *}$ & $0,29^{* *}$ & $-0,06$ & 0,07 & $-0,18^{\star *}$ & $-0,20^{* *}$ & $0,39^{* *}$ & $0,40^{* *}$ & $0,62^{* *}$ & $0,52^{* *}$ & $0,55^{* *}$ & $0,51^{\star *}$ & $0,43^{* *}$ & 1 \\
\hline
\end{tabular}

Teste de correlação de Pearson

* $\mathrm{p}<0,05$

$\mathrm{p}<0,001$

QVG: autoavaliação da qualidade de vida geral; QVC: autoavaliação da qualidade de vida no curso; Exau: Exaustão Emocional; Desp: Despersonalização; Real: Realização pessoal; CE: Consideração Empática; TP: Tomada de Perspectiva; AP: Angústia Pessoal; EpwT: Escore total Escala de Sonolência Diurna de Escala de Sonolência Diurna de Epworth; VerasT: Uso do tempo; VerasP: Psicológico; VerasF: Físico; VerasA: Ambiente de Ensino; WhoF: Físico; WhoP: Psicológico; WhoS: Relações Sociais; WhoA: Ambiente 
Para o grupo de estudantes do sexo feminino, observamos correlações negativas entre o domínio consideração empática e despersonalização $(p<0,001 ; r=-0,30)$ e entre o domínio angústia pessoal e realização pessoal $(p<0,001 ; r=-0,31)$. Houve correlação positiva entre o domínio tomada de perspectiva e o domínio realização pessoal $(p<0,001 ; r=0,36)$ entre estudantes desse grupo. Observamos correlações fracas entre os escores da ESS e os domínios da EMRI $(r \leq 0,11)$ (Tabela 26). 
Tabela 26 - Coeficientes de correlação de Pearson entre os domínios das variáveis do estudo (empatia, qualidade de vida, esgotamento profissional e sonolência diurna) para os estudantes do sexo feminino

\begin{tabular}{|c|c|c|c|c|c|c|c|c|c|c|c|c|c|c|c|c|c|}
\hline & QVG & QVC & Exau & Desp & Real & CE & TP & AP & EpwT & VerT & VerP & VerF & VerAE & WhoF & WhoP & Whos & WhoA \\
\hline QVG & 1 & & & & & & & & & & & & & & & & \\
\hline QVC & $0,57^{* *}$ & 1 & & & & & & & & & & & & & & & \\
\hline Exau & $-0,26^{\star \star}$ & $-0,44^{\star *}$ & 1 & & & & & & & & & & & & & & \\
\hline Desp & $-0,15^{\star *}$ & $-0,22^{\star \star}$ & $0,52^{* \star}$ & 1 & & & & & & & & & & & & & \\
\hline Real & $0,15^{* *}$ & $0,21^{\star \star}$ & $-0,29^{\star \star}$ & $-0,31^{\star \star}$ & 1 & & & & & & & & & & & & \\
\hline CE & 0,04 & 0,01 & $-0,10^{\star *}$ & $-0,30^{* *}$ & $0,26^{\star *}$ & 1 & & & & & & & & & & & \\
\hline TP & 0,00 & 0,05 & $-0,17^{\star \star}$ & $-0,27^{\star \star}$ & $0,36^{\star *}$ & $0,37^{\star \star}$ & 1 & & & & & & & & & & \\
\hline AP & $-0,10^{\star \star}$ & $-0,10^{\star \star}$ & $0,25^{\star *}$ & $0,12^{\star *}$ & $-0,31^{\star \star}$ & 0,06 & $-0,13^{\star \star}$ & 1 & & & & & & & & & \\
\hline EpwT & $-0,11^{\star \star}$ & $-0,25^{\star *}$ & $0,25^{* *}$ & $0,12^{* *}$ & $-0,12^{\star \star}$ & 0,01 & $-0,11^{\star *}$ & 0,05 & 1 & & & & & & & & \\
\hline VerT & $0,23^{* *}$ & $0,50^{\star *}$ & $-0,53^{* *}$ & $-0,26^{\star \star}$ & $0,20^{* *}$ & $-0,04$ & $0,10^{* *}$ & $-0,13^{* *}$ & $-0,29^{\star *}$ & 1 & & & & & & & \\
\hline VerP & $0,34^{* *}$ & $0,48^{\star *}$ & $-0,58^{\star \star}$ & $-0,43^{\star \star}$ & $0,48^{* *}$ & $0,08^{*}$ & $0,26^{\star *}$ & $-0,29^{* *}$ & $-0,32^{\star \star}$ & $0,50^{* *}$ & 1 & & & & & & \\
\hline VerF & $0,48^{* *}$ & $0,52^{\star \star}$ & $-0,41^{\star *}$ & $-0,24^{\star \star}$ & $0,29^{\star *}$ & $-0,02$ & $0,11^{* *}$ & $-0,15^{\star \star}$ & $-0,22^{\star *}$ & $0,55^{* *}$ & $0,59^{* *}$ & 1 & & & & & \\
\hline VerAE & $0,40^{* *}$ & $0,50^{* *}$ & $-0,49^{\star *}$ & $-0,41^{\star *}$ & $0,38^{\star *}$ & $0,11^{* *}$ & $0,20^{* *}$ & $-0,18^{\star \star}$ & $-0,21^{\star *}$ & $0,48^{* *}$ & $0,58^{* *}$ & $0,50^{* *}$ & 1 & & & & \\
\hline WhoF & $0,30^{* *}$ & $0,44^{* *}$ & $-0,49^{\star *}$ & $-0,28^{\star \star}$ & $0,38^{\star *}$ & 0,06 & $0,15^{* *}$ & $-0,16^{\star \star}$ & $-0,32^{\star *}$ & $0,45^{\star \star}$ & $0,64^{* *}$ & $0,52^{* *}$ & $0,44^{* *}$ & 1 & & & \\
\hline WhoP & $0,40^{* *}$ & $0,47^{* *}$ & $-0,51^{\star \star}$ & $-0,36^{* *}$ & $0,46^{\star *}$ & $0,10^{\star *}$ & $0,20^{* *}$ & $-0,25^{\star \star}$ & $-0,20^{* *}$ & $0,43^{* *}$ & $0,76^{\star *}$ & $0,60^{\star *}$ & $0,49^{* *}$ & $0,68^{* *}$ & 1 & & \\
\hline Whos & $0,32^{* *}$ & $0,30^{* *}$ & $-0,37^{\star \star}$ & $-0,34^{\star \star}$ & $0,36^{\star *}$ & $0,09^{*}$ & $0,21^{\star *}$ & $-0,21^{\star *}$ & $-0,12^{\star \star}$ & $0,33^{* *}$ & $0,52^{* *}$ & $0,42^{* *}$ & $0,42^{\star *}$ & $0,43^{\star *}$ & $0,58^{\star *}$ & 1 & \\
\hline WhoA & $0,38^{* *}$ & $0,41^{\star *}$ & $-0,36^{\star \star}$ & $-0,24^{\star \star}$ & $0,26^{\star \star}$ & $0,09^{*}$ & $0,10^{* *}$ & $-0,08^{*}$ & $-0,18^{\star \star}$ & $0,39^{\star \star}$ & $0,45^{\star *}$ & $0,57^{* *}$ & $0,52^{\star *}$ & $0,54^{\star *}$ & $0,50^{\star \star}$ & $0,39^{\star *}$ & 1 \\
\hline
\end{tabular}

Teste de correlação de Pearson

* $\mathrm{p}<0,05$

$\mathrm{p}<0,001$

QVG: autoavaliação da qualidade de vida geral; QVC: autoavaliação da qualidade de vida no curso; Exau: Exaustão Emocional; Desp: Despersonalização; Real: Realização pessoal; CE: Consideração Empática; TP: Tomada de Perspectiva; AP: Angústia Pessoal; EpwT: Escore total Escala de Sonolência Diurna de Escala de Sonolência Diurna de Epworth; VerasT: Uso do tempo; VerasP: Psicológico; VerasF: Físico; VerasA: Ambiente de Ensino; WhoF: Físico; WhoP: Psicológico; WhoS: Relações Sociais; WhoA: Ambiente 
$\mathrm{Na}$ população geral do estudo, os estudantes com os maiores escores no domínio físico do WHOQOL-BREF (último percentil) tiveram escores moderamente menores no domínio angústia pessoal $(p<0,001 ; d=0,51)$. Essa diferença manteve-se para o grupo do sexo masculino e foi ligeiramente menor no grupo do sexo feminino (Tabela 27).

Tabela 27 - Comparação dos escores de empatia obtidos por meio da EMRI entre os estudantes com escores nos percentis 25 e 75 do domínio físico do WHOQOL-BREF

\begin{tabular}{|c|c|c|c|c|}
\hline \multirow{3}{*}{ Domínios } & \multicolumn{2}{|c|}{ WHOQOL - Físico } & \multirow{3}{*}{$p^{*}$} & \multirow{3}{*}{$d^{\dagger}$} \\
\hline & $\leq \mathrm{P} 25$ & $\geq$ P75 & & \\
\hline & Média (DP) & Média (DP) & & \\
\hline Geral & $n=242$ & $n=429$ & & \\
\hline $\begin{array}{l}\text { Consideração } \\
\text { empática }\end{array}$ & $19,29(4,98)$ & $18,76(4,86)$ & 0,180 & - \\
\hline $\begin{array}{l}\text { Tomada de } \\
\text { perspectiva }\end{array}$ & $17,00(5,28)$ & $18,51(5,02)$ & $<0,001$ & 0,29 \\
\hline $\begin{array}{l}\text { Angústia } \\
\text { pessoal }\end{array}$ & $13,39(4,37)$ & $11,29(3,98)$ & $<0,001$ & 0,51 \\
\hline Masculino & $n=134$ & $n=177$ & & \\
\hline $\begin{array}{l}\text { Consideração } \\
\text { empática }\end{array}$ & $18,09(4,66)$ & $17,25(4,66)$ & 0,116 & - \\
\hline $\begin{array}{l}\text { Tomada de } \\
\text { perspectiva }\end{array}$ & $17,24(5,26)$ & $18,03(5,19)$ & 0,184 & - \\
\hline $\begin{array}{l}\text { Angústia } \\
\text { pessoal }\end{array}$ & $12,46(4,13)$ & $10,58(3,46)$ & $<0,001$ & 0,50 \\
\hline Feminino & $n=149$ & $n=184$ & & \\
\hline $\begin{array}{l}\text { Consideração } \\
\text { empática }\end{array}$ & $20,02(4,83)$ & $20,53(4,78)$ & 0,334 & - \\
\hline $\begin{array}{l}\text { Tomada de } \\
\text { perspectiva }\end{array}$ & $17,03(5,16)$ & $18,93(4,94)$ & 0,001 & 0,38 \\
\hline $\begin{array}{l}\text { Angústia } \\
\text { pessoal }\end{array}$ & $13,79(4,49)$ & $12,35(4,24)$ & 0,003 & 0,33 \\
\hline $\begin{array}{l}{ }^{*} \text { Teste t de stu } \\
{ }^{\dagger} d \text { de Cohen } \\
\text { EMRI: Escala I I } \\
\text { WHOQOL: Wo }\end{array}$ & Oraanizat & of $/$ if & & \\
\hline
\end{tabular}


A comparação dos escores de empatia entre os estudantes com escores maiores (último percentil) e menores (primeiro percentil) no domínio psicológico do WHOQOL-BREF revelou diferenças importantes no domínio angústia pessoal. Observamos menores escores de angústia pessoal entre os estudantes com melhor percepção de qualidade de vida $(p \leq 0,001 ; d \geq 0,32)$. Essa diferença foi mais acentuada entre os estudantes do sexo masculino $(\mathrm{p}<0,001 ; d=0,82)$ (Tabela 28).

Tabela 28 - Comparação dos escores de empatia obtidos por meio da EMRI entre os estudantes com escores nos percentis 25 e 75 do domínio psicológico do WHOQOL-BREF

\begin{tabular}{|c|c|c|c|c|}
\hline \multirow{3}{*}{ Domínios } & \multicolumn{2}{|c|}{ WHOQOL - Psicológico } & \multirow{3}{*}{$p^{*}$} & \multirow{3}{*}{$d^{\dagger}$} \\
\hline & $\leq \mathrm{P} 25$ & $\geq \mathrm{P} 75$ & & \\
\hline & Média (DP) & Média (DP) & & \\
\hline Geral & $n=452$ & $n=348$ & & \\
\hline $\begin{array}{l}\text { Consideração } \\
\text { empática }\end{array}$ & $19,26(4,82)$ & $19,16(4,71)$ & 0,761 & - \\
\hline $\begin{array}{l}\text { Tomada de } \\
\text { perspectiva }\end{array}$ & $16,77(5,36)$ & $18,91(4,97)$ & $<0,001$ & 0,41 \\
\hline $\begin{array}{l}\text { Angústia } \\
\text { pessoal }\end{array}$ & $13,72(4,34)$ & $10,50(3,89)$ & $<0,001$ & 0,77 \\
\hline Masculino & $\mathrm{n}=177$ & $n=189$ & & \\
\hline $\begin{array}{l}\text { Consideração } \\
\text { empática }\end{array}$ & $17,75(4,60)$ & $17,79(4,28)$ & 0,937 & - \\
\hline $\begin{array}{l}\text { Tomada de } \\
\text { perspectiva }\end{array}$ & $16,56(5,49)$ & $18,43(4,95)$ & 0,001 & 0,32 \\
\hline $\begin{array}{l}\text { Angústia } \\
\text { pessoal }\end{array}$ & $13,13(4,07)$ & $9,97(3,64)$ & $<0,001$ & 0,82 \\
\hline Feminino & $n=197$ & $n=213$ & & \\
\hline $\begin{array}{l}\text { Consideração } \\
\text { empática }\end{array}$ & $20,1(4,84)$ & $20,64(4,66)$ & 0,253 & - \\
\hline $\begin{array}{l}\text { Tomada de } \\
\text { perspectiva }\end{array}$ & $16,73(5,34)$ & $19,09(4,91)$ & $<0,001$ & 0,46 \\
\hline $\begin{array}{l}\text { Angústia } \\
\text { pessoal }\end{array}$ & $14,21(4,45)$ & $11,58(4,08)$ & $<0,001$ & 0,62 \\
\hline
\end{tabular}

*Teste t de student

${ }^{\dagger} d$ de Cohen

EMRI: Escala Multidimensional de Reatividade Interpessoal de Davis WHOQOL: World Health Organization Quality of Life Assessment 
As diferenças encontradas na comparação dos escores de empatia entre estudantes com os escores no primeiro e último percentil do domínio relações sociais do WHOQOL-BREF foram de pequena magnitude $(p<0,05 ; d<$ 0,47) (Tabela 29).

Tabela 29 - Comparação dos escores de empatia obtidos por meio da EMRI entre os estudantes com escores nos percentis 25 e 75 do domínio relações sociais do WHOQOL-BREF

\begin{tabular}{|c|c|c|c|c|}
\hline \multirow{3}{*}{ Domínios } & \multicolumn{2}{|c|}{ WHOQOL - Relações Sociais } & \multirow{3}{*}{$p^{*}$} & \multirow{3}{*}{$d^{\dagger}$} \\
\hline & $\leq \mathrm{P} 25$ & $\geq$ P75 & & \\
\hline & Média (DP) & Média (DP) & & \\
\hline Geral & $n=399$ & $n=554$ & & \\
\hline $\begin{array}{l}\text { Consideração } \\
\text { empática }\end{array}$ & $19,02(4,66)$ & $19,08(4,93)$ & 0,839 & - \\
\hline $\begin{array}{l}\text { Tomada de } \\
\text { perspectiva }\end{array}$ & $16,74(5,38)$ & $18,46(4,90)$ & $<0,001$ & 0,34 \\
\hline $\begin{array}{l}\text { Angústia } \\
\text { pessoal }\end{array}$ & $13,19(4,31)$ & $11,43(4,04)$ & $<0,001$ & 0,42 \\
\hline Masculino & $n=182$ & $n=268$ & & \\
\hline $\begin{array}{l}\text { Consideração } \\
\text { empática }\end{array}$ & $17,86(4,56)$ & $17,33(4,46)$ & 0,217 & - \\
\hline $\begin{array}{l}\text { Tomada de } \\
\text { perspectiva }\end{array}$ & $16,70(5,51)$ & $18,00(5,00)$ & 0,009 & 0,25 \\
\hline $\begin{array}{l}\text { Angústia } \\
\text { pessoal }\end{array}$ & $12,29(4,00)$ & $10,91(3,81)$ & $<0,001$ & 0,35 \\
\hline Feminino & $n=217$ & $n=286$ & & \\
\hline $\begin{array}{l}\text { Consideração } \\
\text { empática }\end{array}$ & $19,98(4,53)$ & $20,72(4,79)$ & 0,080 & - \\
\hline $\begin{array}{l}\text { Tomada de } \\
\text { perspectiva }\end{array}$ & $16,78(5,29)$ & $18,89(4,77)$ & $<0,001$ & 0,42 \\
\hline $\begin{array}{l}\text { Angústia } \\
\text { pessoal }\end{array}$ & $13,94(4,43)$ & $11,92(4,19)$ & $<0,001$ & 0,47 \\
\hline $\begin{array}{l}{ }^{*} \text { Teste t de stu } \\
{ }^{\dagger} d \text { de Cohen } \\
\text { EMRI: Escala I } \\
\text { WHOQOL: Wo }\end{array}$ & $a_{r}$ & of iffo & & \\
\hline
\end{tabular}

As comparações dos escores de empatia entre estudantes com escores no primeiro e último percentil do domínio ambiente do WHOQOL-BREF também revelaram diferenças de pequena magnitude $(p<0,05 ; d \leq 0,38)($ Tabela 30). 
Tabela 30 - Comparação dos escores de empatia obtidos por meio da EMRI entre os estudantes com escores nos percentis 25 e 75 do domínio ambiente do WHOQOL-BREF

\begin{tabular}{|c|c|c|c|c|}
\hline \multirow{3}{*}{ Domínios } & \multicolumn{2}{|c|}{ WHOQOL - Ambiente } & \multirow{3}{*}{$p^{*}$} & \multirow{3}{*}{$d^{\dagger}$} \\
\hline & $\leq \mathrm{P} 25$ & $\geq P 75$ & & \\
\hline & Média (DP) & Média (DP) & & \\
\hline Geral & $n=259$ & $n=354$ & & \\
\hline $\begin{array}{l}\text { Consideração } \\
\text { empática }\end{array}$ & $18,92(4,87)$ & $19,31(4,80)$ & 0,318 & - \\
\hline $\begin{array}{l}\text { Tomada de } \\
\text { perspectiva }\end{array}$ & $17,29(5,30)$ & $18,47(4,88)$ & 0,004 & 0,23 \\
\hline $\begin{array}{l}\text { Angústia } \\
\text { pessoal }\end{array}$ & $12,92(4,39)$ & $11,67(3,73)$ & $<0,001$ & 0,31 \\
\hline Masculino & $n=118$ & $n=330$ & & \\
\hline $\begin{array}{l}\text { Consideração } \\
\text { empática }\end{array}$ & $18,15(4,80)$ & $17,34(4,51)$ & 0,116 & - \\
\hline $\begin{array}{l}\text { Tomada de } \\
\text { perspectiva }\end{array}$ & $17,33(5,08)$ & $17,66(5,06)$ & 0,184 & - \\
\hline $\begin{array}{l}\text { Angústia } \\
\text { pessoal }\end{array}$ & $12,53(3,89)$ & $11,05(3,85)$ & $<0,001$ & 0,38 \\
\hline Feminino & $n=141$ & $n=190$ & & \\
\hline $\begin{array}{l}\text { Consideração } \\
\text { empática }\end{array}$ & $19,56(4,86)$ & $21,02(4,60)$ & 0,006 & 0,31 \\
\hline $\begin{array}{l}\text { Tomada de } \\
\text { perspectiva }\end{array}$ & $17,26(5,49)$ & $18,64(4,50)$ & 0,013 & 0,28 \\
\hline $\begin{array}{l}\text { Angústia } \\
\text { pessoal }\end{array}$ & $13,25(4,76)$ & $12,55(3,73)$ & 0,134 & - \\
\hline $\begin{array}{l}{ }^{*} \text { Teste t de stu } \\
{ }^{\dagger} d \text { de Cohen } \\
\text { EMRI: Escala I I } \\
\text { WHOQOL: Wo }\end{array}$ & Orcannizati & the if $A c$ & & \\
\hline
\end{tabular}

$\mathrm{Na}$ população geral do estudo, observamos maiores escores nos domínios consideração empática e tomada de perspectiva e menores escores no domínio angústia pessoal entre os estudantes com escores acima do percentil 75 do domínio uso do tempo do Veras-q. Porém, essa diferença foi de pequena magnitude $(p<0,05 ; d \leq 0,32)$ (Tabela 31). 
Tabela 31 - Comparação dos escores de empatia obtidos por meio da EMRI entre os estudantes com escores nos percentis 25 e 75 do domínio uso do tempo do Veras-q

\begin{tabular}{|c|c|c|c|c|}
\hline \multirow{3}{*}{ Domínios } & \multicolumn{2}{|c|}{ Veras - Uso do tempo } & \multirow{3}{*}{$p^{*}$} & \multirow{3}{*}{$d^{\dagger}$} \\
\hline & $\leq \mathrm{P} 25$ & $\geq$ P75 & & \\
\hline & Média (DP) & Média (DP) & & \\
\hline Geral & $n=344$ & $n=303$ & & \\
\hline $\begin{array}{l}\text { Consideração } \\
\text { empática }\end{array}$ & $19,62(5,21)$ & $18,51(4,84)$ & 0,005 & 0,22 \\
\hline $\begin{array}{l}\text { Tomada de } \\
\text { perspectiva }\end{array}$ & $17,28(5,06)$ & $18,13(5,15)$ & 0,036 & 0,17 \\
\hline $\begin{array}{l}\text { Angústia } \\
\text { pessoal }\end{array}$ & $12,99(4,65)$ & $11,56(4,09)$ & $<0,001$ & 0,32 \\
\hline Masculino & $n=134$ & $n=163$ & & \\
\hline $\begin{array}{l}\text { Consideração } \\
\text { empática }\end{array}$ & $17,71(4,84)$ & $17,32(4,62)$ & 0,480 & - \\
\hline $\begin{array}{l}\text { Tomada de } \\
\text { perspectiva }\end{array}$ & $17,28(5,15)$ & $17,72(5,36)$ & 0,473 & - \\
\hline $\begin{array}{l}\text { Angústia } \\
\text { pessoal }\end{array}$ & $11,99(4,58)$ & $10,88(3,90)$ & 0,026 & 0,26 \\
\hline Feminino & $n=210$ & $n=202$ & & \\
\hline $\begin{array}{l}\text { Consideração } \\
\text { empática }\end{array}$ & $20,84(5,07)$ & $20,12(4,61)$ & 0,133 & - \\
\hline $\begin{array}{l}\text { Tomada de } \\
\text { perspectiva }\end{array}$ & $17,29(5,01)$ & $18,58(4,92)$ & 0,008 & 0,26 \\
\hline $\begin{array}{l}\text { Angústia } \\
\text { pessoal }\end{array}$ & $13,64(4,60)$ & $12,35(4,09)$ & 0,003 & 0,30 \\
\hline
\end{tabular}

Observamos grandes diferenças entre os escores de empatia no domínio angústia pessoal quando comparamos os estudantes de acordo com os escores no domínio psicológico do Veras-q. Os estudantes com os maiores escores de qualidade de vida apresentaram escores muito menores de angústia pessoal do que os estudantes com os menores escores de qualidade de vida $(p<0,001 ; d=0,84)$. A grande magnitude dessa diferença manteve-se entre os estudantes do sexo masculino $(p<0,001 ; d=1,08)$ e foi ligeiramente menor entre o grupo do sexo feminino $(p<0,001 ; d=0,70)$ (Tabela 32). 
Tabela 32 - Comparação dos escores de empatia obtidos por meio da EMRI entre os estudantes com escores nos percentis 25 e 75 do domínio psicológico do Veras-q

\begin{tabular}{|c|c|c|c|c|}
\hline \multirow{3}{*}{ Domínios } & \multicolumn{2}{|c|}{ Veras - Psicológico } & \multirow{3}{*}{$p^{*}$} & \multirow{3}{*}{$d^{\dagger}$} \\
\hline & $\leq \mathrm{P} 25$ & $\geq P 75$ & & \\
\hline & Média (DP) & Média (DP) & & \\
\hline Geral & $n=295$ & $n=354$ & & \\
\hline $\begin{array}{l}\text { Consideração } \\
\text { empática }\end{array}$ & $18,93(5,20)$ & $19,23(4,74)$ & 0,438 & - \\
\hline $\begin{array}{l}\text { Tomada de } \\
\text { perspectiva }\end{array}$ & $16,41(5,49)$ & $19,19(4,85)$ & $<0,001$ & 0,54 \\
\hline $\begin{array}{l}\text { Angústia } \\
\text { pessoal }\end{array}$ & $13,98(4,49)$ & $10,48(3,92)$ & $<0,001$ & 0,84 \\
\hline Masculino & $n=168$ & $n=138$ & & \\
\hline $\begin{array}{l}\text { Consideração } \\
\text { empática }\end{array}$ & $17,47(4,66)$ & $17,99(4,53)$ & 0,331 & - \\
\hline $\begin{array}{l}\text { Tomada de } \\
\text { perspectiva }\end{array}$ & $16,45(5,56)$ & $19,02(4,89)$ & $<0,001$ & 0,49 \\
\hline $\begin{array}{l}\text { Angústia } \\
\text { pessoal }\end{array}$ & $13,56(3,95)$ & $9,43(3,64)$ & $<0,001$ & 1,08 \\
\hline Feminino & $n=175$ & $n=191$ & & \\
\hline $\begin{array}{l}\text { Consideração } \\
\text { empática }\end{array}$ & $20,13(5,19)$ & $20,85(4,66)$ & 0,162 & - \\
\hline $\begin{array}{l}\text { Tomada de } \\
\text { perspectiva }\end{array}$ & $16,39(5,37)$ & $19,34(4,81)$ & $<0,001$ & 0,58 \\
\hline $\begin{array}{l}\text { Angústia } \\
\text { pessoal }\end{array}$ & $14,28(4,69)$ & $11,17(4,17)$ & $<0,001$ & 0,70 \\
\hline
\end{tabular}

*Teste t de student

${ }^{\dagger} d$ de Cohen

EMRI: Escala Multidimensional de Reatividade Interpessoal de Davis

Veras-q: questionário para avaliar a qualidade de vida do estudante de medicina

$\mathrm{Na}$ população geral do estudo, estudantes com escores no último percentil do domínio físico do Veras-q apresentaram escores moderamente menores no domínio angústia pessoal $(p<0,001 ; d=0,57)$. Observamos a mesma magnitude dessa diferença entre os estudantes do grupo masculino $(p<0,001 ; d=0,74)$ (Tabela 33). 
Tabela 33 - Comparação dos escores de empatia obtidos por meio da EMRI entre os estudantes com escores nos percentis 25 e 75 do domínio físico do Veras-q

\begin{tabular}{|c|c|c|c|c|}
\hline \multirow{3}{*}{ Domínios } & \multicolumn{2}{|c|}{ Veras - Físico } & \multirow{3}{*}{$p^{*}$} & \multirow{3}{*}{$d^{\dagger}$} \\
\hline & $\leq \mathrm{P} 25$ & $\geq$ P75 & & \\
\hline & Média (DP) & Média (DP) & & \\
\hline Geral & $n=279$ & $n=254$ & & \\
\hline $\begin{array}{l}\text { Consideração } \\
\text { empática }\end{array}$ & $19,44(4,89)$ & $18,68(4,88)$ & 0,050 & 0,15 \\
\hline $\begin{array}{l}\text { Tomada de } \\
\text { perspectiva }\end{array}$ & $17,00(5,34)$ & $18,40(4,77)$ & 0,001 & 0,28 \\
\hline $\begin{array}{l}\text { Angústia } \\
\text { pessoal }\end{array}$ & $13,27(4,61)$ & $10,86(3,83)$ & $<0,001$ & 0,57 \\
\hline Masculino & $n=190$ & $n=136$ & & \\
\hline $\begin{array}{l}\text { Consideração } \\
\text { empática }\end{array}$ & $17,61(4,88)$ & $17,38(4,53)$ & 0,668 & - \\
\hline $\begin{array}{l}\text { Tomada de } \\
\text { perspectiva }\end{array}$ & $16,85(5,44)$ & $18,65(4,98)$ & 0,002 & 0,34 \\
\hline $\begin{array}{l}\text { Angústia } \\
\text { pessoal }\end{array}$ & $12,53(4,05)$ & $9,69(3,57)$ & $<0,001$ & 0,74 \\
\hline Feminino & $n=166$ & $n=195$ & & \\
\hline $\begin{array}{l}\text { Consideração } \\
\text { empática }\end{array}$ & $20,27(4,81)$ & $20,46(4,69)$ & 0,695 & - \\
\hline $\begin{array}{l}\text { Tomada de } \\
\text { perspectiva }\end{array}$ & $17,23(5,20)$ & $18,52(4,80)$ & 0,015 & 0,26 \\
\hline $\begin{array}{l}\text { Angústia } \\
\text { pessoal }\end{array}$ & $13,54(4,65)$ & $12,01(4,04)$ & 0,001 & 0,35 \\
\hline
\end{tabular}

$\mathrm{Na}$ população geral do estudo, observamos escores moderamente menores de angústia pessoal entre os estudantes com escores no percentil 75 do domínio ambiente de ensino do Veras-q $(p<0,001 ; d=0,51)$. Entre o grupo do sexo feminino, notamos escores no domínio tomada de perspectiva moderamente maiores entre as estudantes com os maiores escores (último percentil) de qualidade de vida no domínio ambiente de ensino $(p<0,001 ; d=$ 0,50) (Tabela 34). 
Tabela 34 - Comparação dos escores de empatia obtidos por meio da EMRI entre os estudantes com escores nos percentis 25 e 75 do domínio ambiente de ensino do Veras-q

\begin{tabular}{|c|c|c|c|c|}
\hline \multirow{3}{*}{ Domínios } & \multicolumn{2}{|c|}{ Veras - Ambiente de Ensino } & \multirow{3}{*}{$p^{*}$} & \multirow{3}{*}{$d^{\dagger}$} \\
\hline & $\leq$ P25 & $\geq \mathrm{P} 75$ & & \\
\hline & Média (DP) & Média (DP) & & \\
\hline Geral & $n=298$ & $n=360$ & & \\
\hline $\begin{array}{l}\text { Consideração } \\
\text { empática }\end{array}$ & $18,90(4,88)$ & $19,55(4,82)$ & 0,086 & - \\
\hline $\begin{array}{l}\text { Tomada de } \\
\text { perspectiva }\end{array}$ & $16,57(5,37)$ & $18,90(4,84)$ & $<0,001$ & 0,46 \\
\hline $\begin{array}{l}\text { Angústia } \\
\text { pessoal }\end{array}$ & $13,50(4,56)$ & $11,29(4,11)$ & $<0,001$ & 0,51 \\
\hline Masculino & $n=194$ & $n=175$ & & \\
\hline $\begin{array}{l}\text { Consideração } \\
\text { empática }\end{array}$ & $17,18(4,63)$ & $18,05(4,34)$ & 0,062 & - \\
\hline $\begin{array}{l}\text { Tomada de } \\
\text { perspectiva }\end{array}$ & $16,87(5,35)$ & $18,57(4,86)$ & 0,002 & 0,33 \\
\hline $\begin{array}{l}\text { Angústia } \\
\text { pessoal }\end{array}$ & $12,46(4,28)$ & $10,57(3,53)$ & $<0,001$ & 0,48 \\
\hline Feminino & $n=167$ & $n=185$ & & \\
\hline $\begin{array}{l}\text { Consideração } \\
\text { empática }\end{array}$ & $20,07(4,70)$ & $20,97(4,84)$ & 0,078 & - \\
\hline $\begin{array}{l}\text { Tomada de } \\
\text { perspectiva }\end{array}$ & $16,69(5,33)$ & $19,22(4,80)$ & $<0,001$ & 0,50 \\
\hline $\begin{array}{l}\text { Angústia } \\
\text { pessoal }\end{array}$ & $14,04(4,59)$ & $11,96(4,50)$ & $<0,001$ & 0,46 \\
\hline
\end{tabular}

*Teste t de student

${ }^{\dagger} d$ de Cohen

EMRI: Escala Multidimensional de Reatividade Interpessoal de Davis

Veras-q: questionário para avaliar a qualidade de vida do estudante de medicina

As diferenças nos escores de empatia de acordo com a presença de exaustão emocional foram de pequena magnitude $(p<0,001 ; d \leq 0,44)$ (Tabela 35). 
Tabela 35 - Escores de empatia obtidos por meio da EMRI de acordo com a presença de esgotamento profissional no domínio exaustão emocional do MBI

\begin{tabular}{|c|c|c|c|c|}
\hline \multirow{3}{*}{ Domínios } & \multicolumn{2}{|c|}{ Exaustão Emocional } & \multirow{3}{*}{$p^{*}$} & \multirow{3}{*}{$d^{\dagger}$} \\
\hline & $<27$ & $\geq 27$ & & \\
\hline & Média (DP) & Média (DP) & & \\
\hline Geral & $n=653$ & $n=697$ & & \\
\hline $\begin{array}{l}\text { Consideração } \\
\text { empática }\end{array}$ & $19,21(4,63)$ & $18,96(4,99)$ & 0,332 & - \\
\hline $\begin{array}{l}\text { Tomada de } \\
\text { perspectiva }\end{array}$ & $18,45(4,88)$ & $16,92(5,09)$ & $<0,001$ & 0,31 \\
\hline $\begin{array}{l}\text { Angústia } \\
\text { pessoal }\end{array}$ & $11,32(3,87)$ & $13,06(4,36)$ & $<0,001$ & 0,42 \\
\hline Masculino & $n=337$ & $n=299$ & & \\
\hline $\begin{array}{l}\text { Consideração } \\
\text { empática }\end{array}$ & $17,71(4,35)$ & $17,35(4,69)$ & 0,327 & - \\
\hline $\begin{array}{l}\text { Tomada de } \\
\text { perspectiva }\end{array}$ & $18,16(4,80)$ & $16,70(5,33)$ & $<0,001$ & 0,29 \\
\hline $\begin{array}{l}\text { Angústia } \\
\text { pessoal }\end{array}$ & $10,82(3,66)$ & $12,17(4,10)$ & $<0,001$ & 0,35 \\
\hline Feminino & $n=316$ & $n=398$ & & \\
\hline $\begin{array}{l}\text { Consideração } \\
\text { empática }\end{array}$ & $20,81(4,37)$ & $20,16(4,86)$ & 0,062 & - \\
\hline $\begin{array}{l}\text { Tomada de } \\
\text { perspectiva }\end{array}$ & $18,76(4,95)$ & $17,09(4,89)$ & $<0,001$ & 0,34 \\
\hline $\begin{array}{l}\text { Angústia } \\
\text { pessoal }\end{array}$ & $11,86(4,01)$ & $13,73(4,44)$ & $<0,001$ & 0,44 \\
\hline
\end{tabular}

*Teste t de student

EMRI: Escala Multidimensional de Reatividade Interpessoal de Davis

$\mathrm{MBI}$ : Inventário de Burnout de Maslach

As diferenças encontradas nos escores de empatia de acordo com a presença de escores sugestivos despersonalização também foram de pequena magnitude $(p<0,05 ; d \leq 0,46)$ (Tabela 36). 
Tabela 36 - Escores de empatia obtidos por meio da EMRI de acordo com a presença de esgotamento profissional no domínio despersonalização do MBI

\begin{tabular}{|c|c|c|c|c|}
\hline \multirow{3}{*}{ Domínios } & \multicolumn{2}{|c|}{ Despersonalização } & \multirow{3}{*}{$\mathrm{p}$} & \multirow{3}{*}{$d^{\dagger}$} \\
\hline & $<10$ & $\geq 10$ & & \\
\hline & Média (DP) & Média (DP) & & \\
\hline Geral & $n=804$ & $n=546$ & & \\
\hline $\begin{array}{l}\text { Consideração } \\
\text { empática }\end{array}$ & $19,91(4,62)$ & $17,86(4,84)$ & $<0,001$ & 0,43 \\
\hline $\begin{array}{l}\text { Tomada de } \\
\text { perspectiva }\end{array}$ & $18,44(4,90)$ & $16,53(5,04)$ & $<0,001$ & 0,38 \\
\hline $\begin{array}{l}\text { Angústia } \\
\text { pessoal }\end{array}$ & $11,87(4,18)$ & $12,74(4,23)$ & $<0,001$ & 0,21 \\
\hline Masculino & $n=349$ & $n=287$ & & \\
\hline $\begin{array}{l}\text { Consideração } \\
\text { empática }\end{array}$ & $18,21(4,43)$ & $16,73(4,49)$ & $<0,001$ & 0,33 \\
\hline $\begin{array}{l}\text { Tomada de } \\
\text { perspectiva }\end{array}$ & $18,40(4,86)$ & $16,35(5,18)$ & $<0,001$ & 0,41 \\
\hline $\begin{array}{l}\text { Angústia } \\
\text { pessoal }\end{array}$ & $10,89(3,72)$ & $12,14(4,07)$ & $<0,001$ & 0,32 \\
\hline Feminino & $n=455$ & $n=259$ & & \\
\hline $\begin{array}{l}\text { Consideração } \\
\text { empática }\end{array}$ & $21,21(4,33)$ & $19,11(4,92)$ & $<0,001$ & 0,46 \\
\hline $\begin{array}{l}\text { Tomada de } \\
\text { perspectiva }\end{array}$ & $18,47(4,94)$ & $16,72(4,88)$ & $<0,001$ & 0,35 \\
\hline $\begin{array}{l}\text { Angústia } \\
\text { pessoal }\end{array}$ & $12,62(4,37)$ & $13,41(4,30)$ & 0,021 & 0,18 \\
\hline
\end{tabular}

Na população geral do estudo, observamos escores no domínio tomada de perspectiva moderamente maiores entre os estudantes com escores sugestivos de realização pessoal $(p<0,001 ; d=0,55)$. Esses estudantes também apresentaram escores moderamente menores no domínio angústia pessoal $(p<0,001 ; d=0,52)$. Entre os estudantes do sexo masculino, observamos escores moderamente menores de angústia pessoal entre os estudantes com os maiores escores de realização pessoal $(p<0,001 ; d=0,57)$. Entre o grupo do sexo feminino, notamos escores moderamente maiores no 
domínio tomada de perspectiva entre as estudantes com os maiores escores de realização pessoal ( $p<0,001 ; d=0,70)$ (Tabela 37).

Tabela 37 - Escores de empatia obtidos por meio da EMRI de acordo com a presença de esgotamento profissional no domínio realização pessoal do MBI

\begin{tabular}{|c|c|c|c|c|}
\hline \multirow{3}{*}{ Domínios } & \multicolumn{2}{|c|}{ Realização pessoal } & \multirow{3}{*}{$p^{*}$} & \multirow{3}{*}{$d^{\dagger}$} \\
\hline & $>33$ & $\leq 33$ & & \\
\hline & Média (DP) & Média (DP) & & \\
\hline Geral & $n=751$ & $n=599$ & & \\
\hline $\begin{array}{l}\text { Consideração } \\
\text { empática }\end{array}$ & $19,76(4,74)$ & $18,23(4,78)$ & $<0,001$ & 0,32 \\
\hline $\begin{array}{l}\text { Tomada de } \\
\text { perspectiva }\end{array}$ & $18,86(4,84)$ & $16,16(4,89)$ & $<0,001$ & 0,55 \\
\hline Angústia pessoal & $11,28(4,15)$ & $13,40(4,01)$ & $<0,001$ & 0,52 \\
\hline Masculino & $n=279$ & $n=357$ & & \\
\hline $\begin{array}{l}\text { Consideração } \\
\text { empática }\end{array}$ & $18,11(4,50)$ & $16,81(4,43)$ & $<0,001$ & 0,29 \\
\hline $\begin{array}{l}\text { Tomada de } \\
\text { perspectiva }\end{array}$ & $18,37(5,09)$ & $16,33(4,90)$ & $<0,001$ & 0,41 \\
\hline $\begin{array}{l}\text { Angústia } \\
\text { pessoal }\end{array}$ & $10,51(3,81)$ & $12,67(3,75)$ & $<0,001$ & 0,57 \\
\hline Feminino & $n=394$ & $n=320$ & & \\
\hline $\begin{array}{l}\text { Consideração } \\
\text { empática }\end{array}$ & $21,25(4,46)$ & $19,46(4,73)$ & $<0,001$ & 0,39 \\
\hline $\begin{array}{l}\text { Tomada de } \\
\text { perspectiva }\end{array}$ & $19,31(4,57)$ & $16,02(4,89)$ & $<0,001$ & 0,70 \\
\hline $\begin{array}{l}\text { Angústia } \\
\text { pessoal }\end{array}$ & $11,98(4,32)$ & $14,04(4,13)$ & $<0,001$ & 0,49 \\
\hline
\end{tabular}

*Teste t de student

${ }^{\dagger} d$ de Cohen

EMRI: Escala Multidimensional de Reatividade Interpessoal de Davis

$\mathrm{MBI}$ : Inventário de Burnout de Maslach

Nas análises multivariadas do grupo masculino, excluímos os domínios físico e psicológico do Veras-q, bem com os domínios exaustão emocional do MBI e ambiente do WHOQOL-BREF para evitarmos a multicolinearidade entre as variáveis estudadas. Esses domínios apresentaram fortes correlações com os demais domínios de qualidade de vida $(r \geq 0,50 ; p<0,001)$ (Tabela 25). 
Nas análises de regressão linear simples para o grupo do sexo masculino, observamos os domínios cujos escores foram preditores dos escores da EMRI: despersonalização, realização pessoal, domínios físico, psicológico e relações sociais do WHOQOL-BREF, domínios uso do tempo e ambiente de ensino do Veras-q $(p<0,05)$ (Tabela 38).

Tabela 38 - Análise de regressão simples entre os domínios da EMRI e os domínios dos questionários de qualidade de vida e esgotamento profissional no grupo do sexo masculino

\begin{tabular}{|c|c|c|c|c|c|c|}
\hline Domínios & $\begin{array}{l}\text { Consideração } \\
\text { empática }\end{array}$ & $\mathrm{p}^{\circ}$ & $\begin{array}{l}\text { Tomada de } \\
\text { perspectiva }\end{array}$ & $\mathrm{p}^{\circ}$ & $\begin{array}{c}\text { Angústia } \\
\text { pessoal }\end{array}$ & $\mathrm{p}^{\circ}$ \\
\hline $\begin{array}{l}\text { Despersonaliza- } \\
\text { ção }\end{array}$ & & & & & & \\
\hline $\mathrm{R}^{2}$ ajustado & 0,05 & \multirow{2}{*}{$<0,001$} & 0,07 & \multirow{2}{*}{$<0,001$} & 0,04 & \multirow{2}{*}{$<0,001$} \\
\hline B & $-0,23$ & & $-0,26$ & & 0,19 & \\
\hline $\begin{array}{l}\text { Realização } \\
\text { pessoal }\end{array}$ & & & & & & \\
\hline $\begin{array}{l}\mathrm{R}^{2} \text { ajustado } \\
\mathrm{B}\end{array}$ & $\begin{array}{l}0,02 \\
0,15\end{array}$ & $<0,001$ & $\begin{array}{l}0,05 \\
0,23\end{array}$ & $<0,001$ & $\begin{array}{r}0,11 \\
-0,33\end{array}$ & $<0,001$ \\
\hline Whoqol - Físico & & & & & & \\
\hline $\begin{array}{l}R^{2} \text { ajustado } \\
B\end{array}$ & $\begin{array}{r}0,00 \\
-0,04\end{array}$ & 0,284 & $\begin{array}{l}0,01 \\
0,09\end{array}$ & 0,022 & $\begin{array}{r}0,05 \\
-0,24\end{array}$ & $<0,001$ \\
\hline $\begin{array}{l}\text { Whoqol - } \\
\text { Psicológico }\end{array}$ & & & & & & \\
\hline $\begin{array}{l}\mathrm{R}^{2} \text { ajustado } \\
\mathrm{B}\end{array}$ & $\begin{array}{l}0,00 \\
0,00\end{array}$ & 0,902 & $\begin{array}{l}0,02 \\
0,16\end{array}$ & $<0,001$ & $\begin{array}{r}0,10 \\
-0,32\end{array}$ & $<0,001$ \\
\hline $\begin{array}{l}\text { Whoqol - } \\
\text { Relações Sociais }\end{array}$ & & & & & & \\
\hline $\begin{array}{l}\mathrm{R}^{2} \text { ajustado } \\
\mathrm{B}\end{array}$ & $\begin{array}{r}0,00 \\
-0,05\end{array}$ & 0,201 & $\begin{array}{l}0,02 \\
0,14\end{array}$ & 0,001 & $\begin{array}{r}0,03 \\
-0,17\end{array}$ & $<0,001$ \\
\hline Veras - Tempo & & & & & & \\
\hline $\begin{array}{l}R^{2} \text { ajustado } \\
B\end{array}$ & $\begin{array}{r}0,00 \\
-0,03\end{array}$ & 0,411 & $\begin{array}{l}0,00 \\
0,06\end{array}$ & 0,098 & $\begin{array}{r}0,01 \\
-0,11\end{array}$ & 0,004 \\
\hline $\begin{array}{l}\text { Veras - Ambiente } \\
\text { de ensino }\end{array}$ & & & & & & \\
\hline $\begin{array}{l}\mathrm{R}^{2} \text { ajustado } \\
\mathrm{B}\end{array}$ & $\begin{array}{l}0,00 \\
0,06\end{array}$ & 0,093 & $\begin{array}{l}0,02 \\
0,16\end{array}$ & $<0,001$ & $\begin{array}{r}0,05 \\
-0,23 \\
\end{array}$ & $<0,001$ \\
\hline
\end{tabular}

ANOVA

EMRI: Escala Multidimensional de Reatividade Interpessoal de Davis

ß: coeficiente beta padronizado 
Ao utilizarmos os escores dos domínios que apresentaram resultados significativos na regressão linear simples como variáveis independentes na análise de regressão múltipla, observamos resultados significativos para todos os domínios da EMRI. Porém, apenas o domínio angústia pessoal apresentou resultados com explicação moderada da variância dos escores pelo modelo proposto $\left(R^{2}=0,15 ; \mathrm{p}<0,001\right)$. Nesse domínio, a variável com maior contribuição para a explicação do modelo foi o domínio realização pessoal (ß= $-0,22 ; p<0,001)$ (Tabela 39, Figura 8).

Tabela 39 - Análise de regressão múltipla entre os domínios da EMRI e os domínios dos questionários de qualidade de vida e esgotamento profissional no grupo do sexo masculino

\begin{tabular}{|c|c|c|c|c|c|c|}
\hline Domínios & \multicolumn{2}{|c|}{$\begin{array}{l}\text { Consideração } \\
\text { empática }\end{array}$} & \multicolumn{2}{|c|}{$\begin{array}{l}\text { Tomada de } \\
\text { perspectiva }\end{array}$} & \multicolumn{2}{|c|}{ Angústia pessoal } \\
\hline $\mathrm{R}^{2}$ & \multicolumn{2}{|c|}{0,08} & \multicolumn{2}{|c|}{0,11} & \multicolumn{2}{|c|}{0,15} \\
\hline $\mathrm{R}^{2}$ ajustado & \multicolumn{2}{|c|}{0,07} & \multicolumn{2}{|c|}{0,10} & \multicolumn{2}{|c|}{0,14} \\
\hline $\mathrm{p}$ & \multicolumn{2}{|c|}{$<0,001$} & \multicolumn{2}{|c|}{$<0,001$} & \multicolumn{2}{|c|}{$<0,001$} \\
\hline & B & $p^{*}$ & $B$ & $p^{*}$ & $B$ & $p^{*}$ \\
\hline $\begin{array}{l}\text { Despersonaliza- } \\
\text { ção }\end{array}$ & $-0,23$ & $<0,001$ & $-0,23$ & $<0,001$ & 0,07 & 0,088 \\
\hline $\begin{array}{l}\text { Realização } \\
\text { pessoal }\end{array}$ & 0,13 & 0,001 & 0,20 & 0,001 & $-0,22$ & $<0,001$ \\
\hline Whoqol - Físico & - & - & $-0,06$ & 0,232 & $-0,02$ & 0,674 \\
\hline $\begin{array}{l}\text { Whoqol - } \\
\text { Psicológico }\end{array}$ & - & - & 0,00 & 0,993 & $-0,19$ & 0,001 \\
\hline $\begin{array}{l}\text { Whoqol - } \\
\text { Relações Sociais }\end{array}$ & - & - & 0,04 & 0,380 & 0,04 & 0,386 \\
\hline Veras - Tempo & $-0,11$ & 0,005 & - & - & 0,04 & 0,302 \\
\hline $\begin{array}{l}\text { Veras - Ambiente } \\
\text { de ensino }\end{array}$ & - & - & $-0,01$ & 0,875 & $-0,05$ & 0,312 \\
\hline
\end{tabular}

ANOVA

EMRI: Escala Multidimensional de Reatividade Interpessoal de Davis

ß: coeficiente beta padronizado 

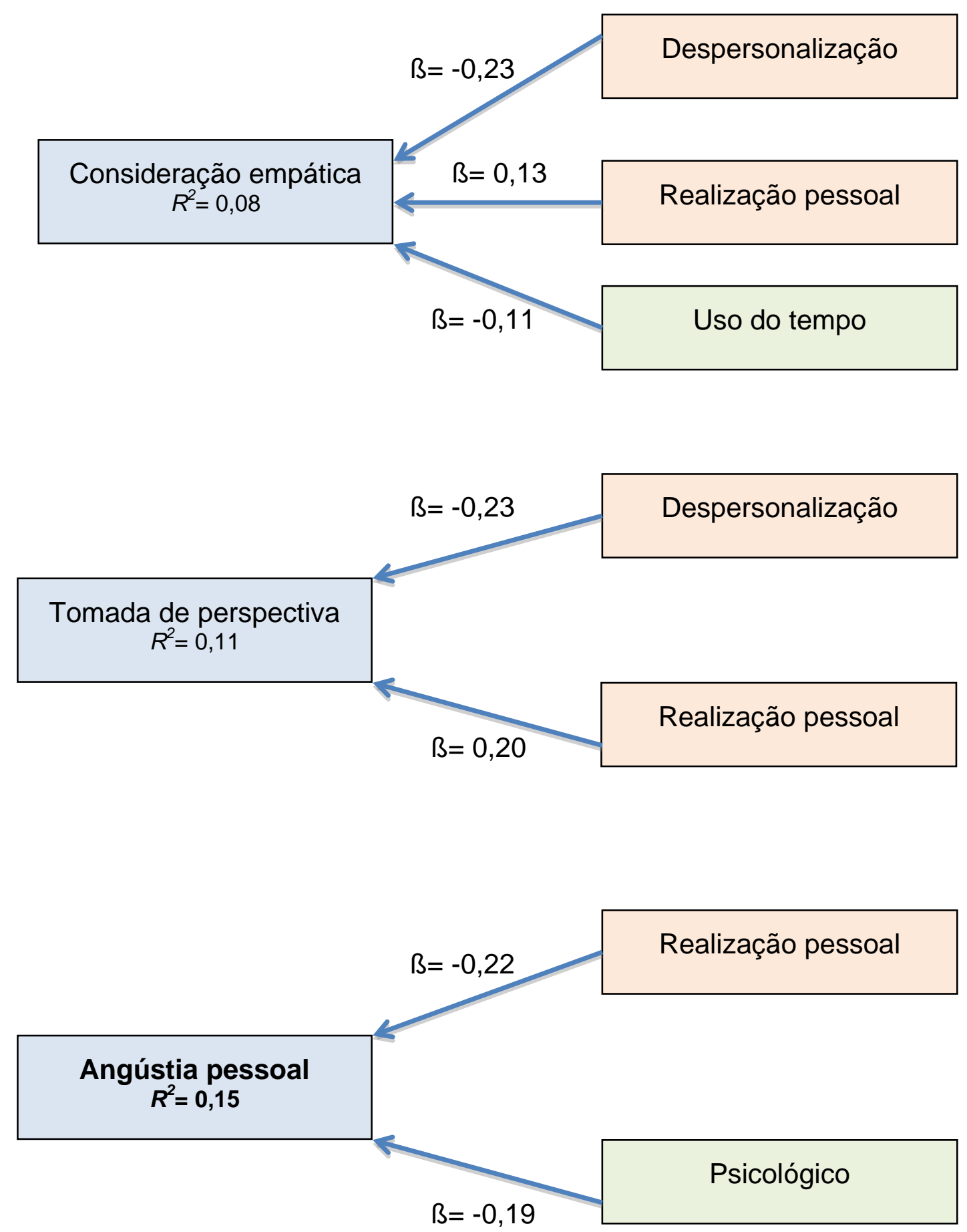

Figura 8 - Modelo de regressão linear múltipla para os domínios da EMRI entre o grupo do sexo masculino 
Nas análises multivariadas do grupo feminino excluímos os domínios físico e psicológico do Veras-q, bem com os domínios exaustão emocional do MBI e ambiente do WHOQOL-BREF para evitarmos a multicolinearidade entre as variáveis estudadas. Esses domínios apresentaram fortes correlações com os demais domínios de qualidade de vida $(r \geq 0,50 ; p<0,001)$ (Tabela 26).

Nas análises de regressão linear simples para o grupo do sexo feminino, observamos os domínios cujos escores foram preditores dos escores da EMRI: despersonalização, realização pessoal, domínios físico, psicológico e relações sociais do WHOQOL-BREF, domínios uso do tempo e ambiente de ensino do Veras- $q(p<0,05)($ Tabela 40$)$ 
Tabela 40 - Análise de regressão simples entre os domínios da EMRI e os domínios dos questionários de qualidade de vida e esgotamento profissional no grupo do sexo feminino

\begin{tabular}{|c|c|c|c|c|c|c|}
\hline Domínios & $\begin{array}{l}\text { Consideração } \\
\text { empática }\end{array}$ & $p^{\circ}$ & $\begin{array}{l}\text { Tomada de } \\
\text { perspectiva }\end{array}$ & $\mathrm{p}^{\circ}$ & $\begin{array}{l}\text { Angústia } \\
\text { pessoal }\end{array}$ & $p^{\circ}$ \\
\hline \multicolumn{7}{|l|}{$\begin{array}{l}\text { Despersonaliza- } \\
\text { ção }\end{array}$} \\
\hline $\begin{array}{l}R^{2} \text { ajustado } \\
\beta\end{array}$ & 0,09 & $<0,001$ & 0,07 & $<0,001$ & 0,01 & 0,001 \\
\hline \multirow{2}{*}{\multicolumn{7}{|c|}{$\begin{array}{l}\text { Realização } \\
\text { pessoal }\end{array}$}} \\
\hline & & & & & & \\
\hline B & $\begin{array}{l}0,01 \\
0,26\end{array}$ & $<0,001$ & $\begin{array}{l}0,13 \\
036\end{array}$ & $<0,001$ & $\begin{array}{r}0,09 \\
-0,31\end{array}$ & $<0,001$ \\
\hline \multicolumn{7}{|l|}{ Whoqol - Físico } \\
\hline $\begin{array}{l}\mathrm{R}^{2} \text { ajustado } \\
\mathrm{B}\end{array}$ & $\begin{array}{l}0,00 \\
0,06\end{array}$ & 0,960 & $\begin{array}{l}0,02 \\
0,15\end{array}$ & $<0,001$ & $\begin{array}{c}0,02 \\
-0,16\end{array}$ & $<0,001$ \\
\hline \multicolumn{7}{|l|}{$\begin{array}{l}\text { Whoqol - } \\
\text { Psicológico }\end{array}$} \\
\hline $\begin{array}{l}R^{2} \text { ajustado } \\
B\end{array}$ & $\begin{array}{l}0,01 \\
0,10\end{array}$ & 0,006 & $\begin{array}{l}0,04 \\
0,20\end{array}$ & $<0,001$ & $\begin{array}{r}0,06 \\
-0,25\end{array}$ & $<0,001$ \\
\hline \multicolumn{7}{|l|}{$\begin{array}{l}\text { Whoqol - } \\
\text { Relações Sociais }\end{array}$} \\
\hline $\begin{array}{l}\mathrm{R}^{2} \text { ajustado } \\
\mathrm{B}\end{array}$ & $\begin{array}{l}0,01 \\
0,09\end{array}$ & 0,020 & $\begin{array}{l}0,04 \\
0,21\end{array}$ & $<0,001$ & $\begin{array}{c}0,04 \\
-0,21\end{array}$ & $<0,001$ \\
\hline \multicolumn{7}{|l|}{ Veras - Tempo } \\
\hline $\begin{array}{l}\mathrm{R}^{2} \text { ajustado } \\
\mathrm{B}\end{array}$ & $\begin{array}{c}0,00 \\
-0,04\end{array}$ & 0,276 & $\begin{array}{l}0,01 \\
0,10\end{array}$ & 0,009 & $\begin{array}{c}0,01 \\
-0,13\end{array}$ & 0,001 \\
\hline \multicolumn{7}{|l|}{$\begin{array}{l}\text { Veras - Ambiente } \\
\text { de ensino }\end{array}$} \\
\hline $\begin{array}{l}\mathrm{R}^{2} \text { ajustado } \\
\mathrm{B}\end{array}$ & $\begin{array}{l}0,01 \\
0,11\end{array}$ & 0,003 & $\begin{array}{l}0,04 \\
0,20\end{array}$ & $<0,001$ & $\begin{array}{r}0,03 \\
-0,18\end{array}$ & $<0,001$ \\
\hline
\end{tabular}

ANOVA

EMRI: Escala Multidimensional de Reatividade Interpessoal de Davis

ß: coeficiente beta padronizado

Ao utilizarmos os escores dos domínios que apresentaram resultados significativos na regressão linear simples como variáveis independentes na análise de regressão múltipla, observamos resultados significativos para todos os domínios da EMRI, com moderada explicação da variância para os domínios consideração empática $\left(R^{2}=0,13 ; \mathrm{p}<0,001\right)$ e tomada de perspectiva $\left(R^{2}=0,16\right.$; $p<0,001)$. Para o domínio consideração empática, a variável que mais contribuiu para a variância dos resultados foi o domínio despersonalização ( $(=$ 
-0,29; $p<0,001)$. Para o domínio tomada de perspectiva, a variável de maior contribuição para a explicação do modelo foi o domínio realização pessoal (ß= 0,30; $p<0,001)$ (Tabela 41, Figura 9).

Tabela 41 - Análise de regressão múltipla entre os domínios da EMRI e os domínios dos questionários de qualidade de vida e esgotamento profissional no grupo do sexo feminino

\begin{tabular}{|c|c|c|c|c|c|c|}
\hline Domínios & \multicolumn{2}{|c|}{$\begin{array}{c}\text { Consideração } \\
\text { empática }\end{array}$} & \multicolumn{2}{|c|}{$\begin{array}{l}\text { Tomada de } \\
\text { perspectiva }\end{array}$} & \multicolumn{2}{|c|}{ Angústia pessoal } \\
\hline & \multicolumn{2}{|c|}{0,13} & \multicolumn{2}{|c|}{0,16} & \multicolumn{2}{|c|}{0,12} \\
\hline $\mathrm{R}^{2}$ ajustado & \multicolumn{2}{|c|}{0,13} & \multicolumn{2}{|c|}{0,15} & \multicolumn{2}{|c|}{0,11} \\
\hline $\mathrm{p}$ & \multicolumn{2}{|c|}{$<0,001$} & \multicolumn{2}{|c|}{$<0,001$} & \multicolumn{2}{|c|}{$<0,001$} \\
\hline & $B$ & $\mathrm{p}^{*}$ & $\beta$ & $\mathrm{p}^{*}$ & $\beta$ & $\mathrm{p}^{*}$ \\
\hline $\begin{array}{l}\text { Despersonaliza- } \\
\text { cão }\end{array}$ & $-0,29$ & $<0,001$ & $-0,17$ & $<0,001$ & $-0,16$ & 0,685 \\
\hline $\begin{array}{l}\text { Realização } \\
\text { pessoal }\end{array}$ & 0,23 & $<0,001$ & 0,30 & $<0,001$ & $-0,24$ & $<0,001$ \\
\hline Whoqol - Físico & - & - & $-0,04$ & 0,379 & 0,04 & 0,483 \\
\hline $\begin{array}{l}\text { Whoqol - } \\
\text { Psicológico }\end{array}$ & $-0,06$ & 0,064 & - & - & $-0,17$ & 0,001 \\
\hline $\begin{array}{l}\text { Whoqol - } \\
\text { Relações Sociais }\end{array}$ & - & - & 0,07 & 0,101 & - & - \\
\hline Veras - Tempo & - & - & $-0,02$ & 0,703 & 0,09 & 0,040 \\
\hline $\begin{array}{l}\text { Veras - Ambiente } \\
\text { de ensino }\end{array}$ & $-0,06$ & 0,180 & 0,01 & 0,794 & $-0,06$ & 0,188 \\
\hline
\end{tabular}

*ANOVA

EMRI: Escala Multidimensional de Reatividade Interpessoal de Davis

ß: coeficiente beta padronizado 



Figura 9 - Modelo de regressão linear múltipla para os domínios da EMRI entre o grupo do sexo feminino 


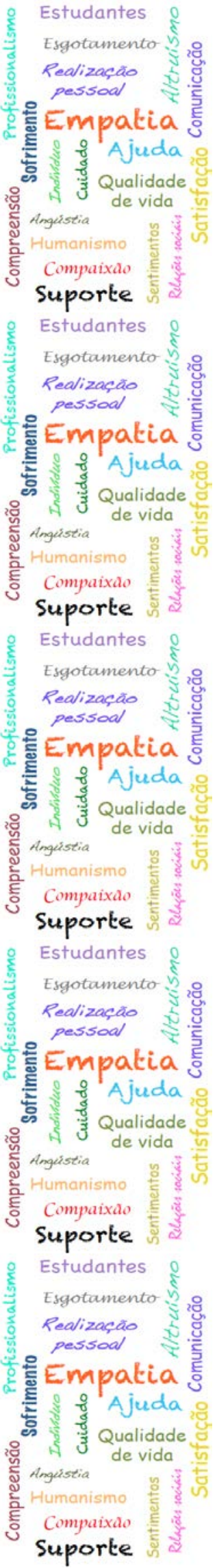

5 DISCUSSÃO 
O presente estudo apresentou inovações em diversas dimensões. Primeiro, ao fornecer dados que avaliam a associação da empatia, qualidade de vida, esgotamento profissional e sonolência, inexistentes até o momento no país. Segundo, inovou no desenho da pesquisa, ao articular 22 instituições de ensino em um projeto de pesquisa multicêntrico. E terceiro, ao utilizar uma amostra randomizada que corresponde a um dos maiores bancos de dados aleatorizados para pesquisa em educação médica no Brasil e no mundo.

A originalidade do estudo também reside na combinação de vários instrumentos vallidados para avaliação de empatia, sonolência diurna, estresse e qualidade de vida. A seleção dos instrumentos e a forma de correlacioná-los também representa um avanço de caráter metodológico. Outro fator inovador foi a construção de uma plataforma eletrônica específica para a coleta de dados desse estudo. A plataforma permitiu a garantia do sigilo e o conforto dos respondentes durante as respostas e devolutivas dos resultados individuais. O meio eletrônico de coleta de dados também permitiu maior abrangência territorial ao estudo, além de minimizar custos de impressão e oferecer sustentabilidade ecológica.

Em geral, os estudos de empatia, sono, estresse e qualidade de vida apresentam limitações intrínsecas de avaliação, no que se refere tanto à abrangência do construto pelo instrumento de avaliação, quanto à forma autorreferida de apreensão das percepções dos entrevistados. Resultados assim obtidos dependem do estado cognitivo, do autoconhecimento do entrevistado e do padrão de valorização dos eventos que o entrevistado detém.

Nosso estudo apresenta a limitação de não permitir inferências de causa e efeito por ter sido concebido em formato transversal. Contudo, podemos 
afirmar que conseguimos alcançar os objetivos do estudo e avançamos no sentido de possibilitar generalizações dos nossos resultados ao analisarmos uma amostra aleatorizada de estudantes.

Optamos por randomizar a amostra do estudo para minimizarmos a possibilidade do viés de seleção, limitação comum entre estudos que contam com amostras de conveniência (Dyrbye et al., 2006b; 2008; 2009; 2010a; 2012; Hillis et al., 2010; Reed et al., 2011; Roh et al., 2009; 2010; Sen et al., 2010; Thomas et al., 2007). Nesse sentido, em uma tentativa de preservar o caráter randômico da amostra, tivemos o cuidado de evitar grandes perdas.

Dentre as perdas do nosso estudo (18,2\%), atribuímos uma pequena parcela $(0,8 \%)$ aos estudantes que não completaram suas respostas na plataforma, ou seja, perdas por desinteresse ou exaustão. A exaustão dos respondentes foi outra preocupação do desenho do estudo, principalmente devido ao fato de incluirmos diversos questionários com um total de 285 itens na plataforma VERAS. Sabemos que estudos com uso de questionários com mais de 50 itens podem apresentar perdas maiores do que $10 \%$ e as respostas dos indivíduos podem ser erráticas (Smith; Huntington, 2006).

Surpreendentemente, observamos uma alta taxa de resposta em nosso estudo. Atribuímos o sucesso na taxa de resposta ao prazo de 10 dias para o término dos questionários da plataforma. A possibilidade de completar os questionários de acordo com a conveniência do estudante pode ter minimizado nossas perdas por exaustão. Ainda, conseguimos minimizar possíveis erros sistemáticos de respostas e garantir a qualidade dos dados do estudo por meio da disposição aleatória dos questionários na plataforma eletrônica. Com essa estratégia, conseguimos evitar o viés da exaustão do respondente ao final de 
apenas um dos questionários, o que prejudicaria a qualidade de resposta aos últimos instrumentos apresentados.

Algumas dificuldades inerentes ao recrutamento dos estudantes estiveram presentes ao longo do período de coleta de dados. As principais estratégias do grupo de pesquisa para aumentar a participação dos estudantes podem ser observadas em coincidência com os picos de respostas na plataforma.

O primeiro pico corresponde ao início da pesquisa, no qual a adesão dos pesquisadores e participantes era maior, por se tratar do início do período de recrutamento. O segundo pico coincide com a estratégia "Adote uma escola", com envio semanal dos relatórios numéricos dos respondentes aos pesquisadores locais. Atribuímos o terceiro pico de respondentes à melhoria da representação gráfica dos relatórios semanais, que facilitou o reconhecimento do número de estudantes necessários para atingir a meta do estudo. O último pico corresponde ao período final de coleta dos dados. Durante todas as etapas do estudo foram oferecidos estímulos e orientações ao recrutamento dos estudantes por meio do boletim eletrônico "Veras News".

Nossa interpretação para esses picos é que o acompanhamento dos núcleos de pesquisa e dos pesquisadores locais foi o fator de maior impacto para o sucesso da coleta de dados. Percebemos que o contato individual e frequente ofereceu apoio e suporte necessários para que a meta de recrutamento fosse atingida.

Outra questão que consideramos importante para a coleta de dados foi a garantia do sigilo e a devolutiva individual aos participantes. O estudante respondeu aos instrumentos da plataforma em um ambiente livre de medos e 
julgamentos, e ao final pôde comparar seus resultados com escores esperados ou médias provenientes de outros estudos em cada domínio avaliado. Sabemos que um estudo como esse não é isento de risco e por esse motivo disponibilizamos uma via de contato para explicações, orientações e suporte, caso o respondente solicitasse.

As estratégias de recrutamento utilizadas foram eficientes para garantir uma amostra equilibrada de estudantes do sexo feminino e masculino, e entre os anos do curso.

A mesma preocupação do grupo de pesquisa em garantir aspectos éticos, oferecer suporte aos respondentes e pesquisadores locais e atingir as metas para o número de estudantes randomizados estendeu-se para a qualidade dos dados coletados. Não observamos efeitos piso ou teto em nenhum dos domínios estudados, ou seja, os questionários utilizados foram capazes de discriminar entre os estudantes com os menores e maiores escores. Além disso, asseguramos a confiabilidade dos questionários uma vez que os coeficientes de alfa Cronbach foram satisfatórios para todos os domínios analisados.

A análise das disposições empáticas desse estudo demonstrou que estudantes do sexo feminino têm maior consideração empática (tendência em vivenciar sentimentos de compaixão, cordialidade e preocupação em relação aos outros) do que estudantes do sexo masculino. A angústia pessoal (tendência em sentir desconforto e ansiedade frente à dificuldade dos outros), também foi maior entre as estudantes do sexo feminino. Essas diferenças se mantiveram nos diferentes anos do curso. Não houve diferença de gênero no domínio tomada de perspectiva (dimensão cognitiva do construto empatia que 
envolve a disposição em adotar o ponto de vista do outro). Esses resultados demonstram que estudantes do sexo feminino apresentaram maior disposição empática nas dimensões emocionais (consideração empática e angústia pessoal) do que seus colegas do sexo masculino. Nossos resultados são consistentes com achados de vários estudos que também utilizaram medidas de empatia de autorrelato (Hojat et al., 2002; Kataoka et al., 2009; Quince et al., 2011; Stratton et al., 2008).

No entanto, a diferença de gênero para as habilidades empáticas ainda é assunto controverso na literatura. Contrariamente às evidências anteriores, alguns estudos com medidas de autorrelato não encontraram diferenças entre sexo nas disposições empáticas dos estudantes de medicina (Di Lillo et al., 2009; Rahimi-Madiseh et al., 2010; Roh et al., 2010).

As inconsistências dos achados acerca das diferenças de gênero para as habilidades ou disposições empáticas foram analisadas por Eisenberg e Lennon (1983) em uma extensa revisão de literatura. Os autores concluem que os resultados dependem das diferentes medidas utilizadas entre os estudos. As maiores diferenças de gênero foram encontradas em trabalhos que utilizaram as medidas de autorrelato para avaliar as disposições empáticas. Já os estudos que avaliaram a habilidade empática (ou o comportamento empático) por meio observações externas (Blanch-Hartigan et al., 2010) ou pela acurácia empática (capacidade de prever adequadamente o pensamento ou sentimento do outro) não evidenciaram diferenças de gênero (Decety; Ickes, 2009; Eisenberg; Lennon, 1983; Ickes et al., 2000). Dessa maneira, podemos pensar que homens e mulheres apresentam-se diferentemente em avaliações 
que contam com sua autopercepção, mas devem ter a mesma capacidade para demonstrar o comportamento empático.

A diferença de gênero parece ocorrer em maior magnitude quando o instrumento de medida oferece pistas sobre a atitude avaliada, ou seja, traz em si a obviedade da medida (Eisenberg; Lennon, 1983). Instrumentos com essa característica podem evocar respostas de acordo com estereótipos culturais, como o da maior sensibilidade interpessoal das mulheres (Ickes et al., 2000).

Nesse sentido, os dados obtidos com a avaliação da disposição empática dos estudantes por autorrelato podem ser resultado de respostas socialmente desejáveis - fenômeno denominado de viés da expectativa social, traduzido da expressão em inglês "social desirability". O viés da expectativa social não parece não ter influencia na medida da dimensão cognitiva da empatia (tomada de perspectiva), uma vez que nossos resultados não apontaram diferenças de gênero na disposição dos estudantes em adotarem a perspectiva do outro. Estudos anteriores utilizando a EMRI apresentaram diferenças pouco expressivas (Quince et al., 2011) ou revelaram ausência de diferenças de gênero nesse domínio (Stratton et al., 2008).

Nossos resultados forçam-nos a refletir sobre o papel dos estereótipos culturais referentes ao gênero nas escolas de medicina. Com o aumento do número de mulheres nos cursos e na profissão médica, atualmente o sexo feminino representa a maioria na medicina - fenômeno denominado de "feminilização da medicina" (Bleakly, 2013; Lambert et al., 2003; McKinstry, 2008). Por esse motivo, vários estudos têm avaliado o impacto das diferenças de gênero na atenção à saúde. Alguns desses estudos demonstram que as mulheres dispensam maior tempo conversando com seus pacientes do que 
seus colegas do sexo masculino (Roter et al., 2002). Outros estudos constatam que mulheres seguem carreiras de perfis diferentes quando comparadas aos homens (Carr et al., 1998). No entanto, esses estudos demonstram que não há diferença de gênero na aptidão para as diversas carreiras na medicina. Essas diferenças parecem estar relacionadas à inequidade de oportunidades em uma profissão que durante séculos foi tradicionalmente masculina (Carr et al., 1998; Kilminster et al., 2007; McKinstry, 2008).

Outra reflexão que podemos levantar é se as diferenças de empatia encontradas em nosso estudo poderiam ser refletidas nas práticas assistenciais a favor do bem estar do paciente. Se isso for comprovado, as escolas médicas precisariam construir em seus currículos estratégias educacionais que contemplassem tanto as potencialidades como as fragilidades femininas e masculinas relacionadas ao comportamento empático.

Por outro lado, ressaltar as diferenças de gênero nas disposições empáticas dos estudantes e em outras dimensões pode estimular o sexismo ${ }^{(*)}$ dentro do meio acadêmico e a inequidade nas oportunidades de aprendizado e desenvolvimento pessoal e profissional (Bickel, 2001; Risberg et al., 2008). O contraponto é que ao minimizarmos o reforço da diferença entre homens e mulheres relacionadas ao comportamento empático, podemos potencializar as habilidades empáticas a serem desenvolvidas nos estudantes do sexo masculino.

(*) Preconceito ou discriminação baseado no gênero, comportamento ou atitudes que promovem papeis sociais estereotipados baseados no gênero. Termo indexado no Medical Subject Headings (MeSH) em 2013. 
Quanto ao desenvolvimento da empatia no curso médico, é preocupante observarmos que nossos resultados não demonstraram diferenças nas disposições empáticas dos estudantes nos diversos anos do curso. Além de não observamos uma maior empatia nos últimos anos do curso, notamos que estudantes do sexo feminino apresentaram disposição discretamente menor para tomada de perspectiva nesse período.

Esses dados são intrigantes e contrários às nossas expectativas. Esperávamos que as vivências no curso médico favorecessem a aquisição e o aprimoramento das competências emocionais e da empatia do estudante. Sabemos que apesar dessas competências serem enfatizadas nas Diretrizes Curriculares Nacionais (DCN), elas nem sempre estão estabelecidas como objetivos pedagógicos dos cursos de medicina. No entanto, as competências emocionais são estruturantes da prática médica, e certamente estão presentes nas atividades práticas do curso e podem ser reforçadas nos currículos oculto e paralelo dos cursos. Nesse caso, se nossos dados revelam que um estudante do último ano do curso tem a mesma disposição empática de um estudante do primeiro ano, poderíamos inferir que a escola médica não contribui para o desenvolvimento dessa competência. Poderíamos ainda pensar que talvez a competência empática reflita um conjunto de virtudes inatas e imutáveis.

Outra explicação possível é que o instrumento utilizado reflita mais o senso comum acerca da empatia do que a real disposição empática dos estudantes. Essa explicação levantaria a hipótese de que a EMRI seja pouco discriminativa para a população desse estudo. No entanto, estudos que utilizaram escalas específicas para o contexto da saúde também demonstraram 
uma estagnação da empatia nos anos do curso (Bombeke et al., 2011; Costa et al., 2012b; Rahimi-Madiseh et al., 2010).

De maneira semelhante, estudos prévios com formatos transversais (Rahimi-Madiseh et al., 2010; Thomas et al., 2007) e longitudinais (Costa et al., 2012b; Quince et al., 2011) também não observaram diferenças da empatia durante o curso de medicina. Esses resultados permitem a interpretação de que a educação médica parece não influenciar o desenvolvimento das habilidades cognitivas e emocionais da empatia (Handford et al., 2013).

Um fato ainda mais intrigante e contraditório é que existem vários estudos que relatam uma deterioração das habilidades empáticas ao longo do curso (Bombeke et al., 2011; Chen et al., 2007; Hojat et al., 2004; 2009; Neumann et al., 2011; Newton et al., 2008; Stratton et al., 2008). No entanto, é importante salientar que diferenças estatísticas nem sempre refletem diferenças relevantes no que se refere a comportamentos, principalmente em estudos com grandes amostras. Daí a importância de também interpretarmos e discutirmos esses achados sob a perspectiva do tamanho do efeito. Nesse contexto, o declínio da empatia registrado em alguns estudos tem sido amplamente criticado devido à ausência de significância prática dos resultados (Colliver et al., 2010).

Independentemente de haver um declínio da empatia ou não no curso de medicina, é desapontador constatarmos que não houve diferença na disposição empática entre os ingressantes e os concluintes do curso médico. Apesar da empatia ser uma competência central do profissionalismo e estruturante das competências gerais das nossas DCN, notamos que em grande parte das escolas médicas brasileiras o desenvolvimento dessas 
habilidades fica restrito a momentos isolados do currículo, geralmente relacionados às áreas das humanidades (Paro et al., 2012).

A análise da empatia do estudante de medicina brasileiro nesse estudo não se restringiu aos três domínios da EMRI. A análise também foi aprofundada para os itens da escala e posteriormente para a correlação com os demais questionários aplicados.

No que se refere à análise dos itens, percebemos que alguns deles apresentaram respostas desviadas para os escores mais altos ou mais baixos da escala. Esses itens refletem conceitos do senso comum e foram pouco discriminativos para a população estudada. Por exemplo, o item 01 da EMRI relacionado aos termos "preocupação" e "ternura", demonstrou desvio das respostas para os escores mais altos da escala. Esse item parece representar a ideia comum da empatia como uma atitude emocional relacionada ao compartilhamento de sentimentos e atitudes de benevolência (Gelhaus, 2012). O caráter benevolente do construto também está representado no termo "pena" do item 13, que também apresentou um desvio das respostas para os escores mais altos da escala. Os termos "pena" e "compaixão", embora representem conceitos distintos, são frequentemente utilizados como sinônimos e apresentam relação com o senso comum da visão do homem como um ser essencialmente vulnerável, solidário e benevolente (Boleyn-Fitzgerald, 2003, Gelhaus, 2012). Talvez essa seja uma possível explicação para que a maioria dos respondentes do nosso estudo tenha obtido escore máximo nesses itens.

Uma grande parcela dos estudantes também apresentou escore máximo no item 06, que nos remete a disposições protetoras ou paternalistas. No 
Brasil, o paternalismo médico ${ }^{(*)}$ vem sendo questionado apenas recentemente, após reformas no Código de Ética Médica iniciadas na década de 90 (Almeida; Schramm, 1999; Siqueira, 2008). Desde então, discussões bioéticas sobre a autonomia do paciente têm se tornado mais comuns no cenário da educação médica brasileira (Siqueira, 2008; Paro et al., 2012). No entanto, o padrão de resposta ao item 06 demonstra que o comportamento paternalista ainda é muito comum entre os estudantes de medicina no nosso país.

Outros itens que parecem apresentar pouco poder discriminativo entre os estudantes de medicina são aqueles relacionados a situações de emergência (itens 09, 18 e 20). Não surpreendentemente, esses itens apresentaram desvio para os escores mais baixos da escala. A análise desses itens demonstra que os estudantes parecem apresentar uma estabilidade emocional em situações de emergências. Esse comportamento pode ser atribuído ao contato com essas situações em graus variados de complexidade desde as fases mais iniciais do curso. Podemos ainda atribuir essa observação ao desenvolvimento do autocontrole para situações de emergência ou de crises durante o curso.

Com essas considerações, alguns autores argumentam que o domínio da angústia pessoal pode representar um atributo da empatia para a população geral, mas não representa o construto para o contexto da saúde (Hojat et al., 2005). O sofrimento excessivo com a situação do outro pode revelar-se prejudicial ao desempenho profissional no contexto da medicina. Nesse

\footnotetext{
( * ) Paternalismo: interferência na liberdade ou autonomia pessoal de outra pessoal, com justificativas relacionadas à promoção do bem ou da prevenção do dano à pessoa, geralmente, não permitindo que uma pessoa tome decisões por conta própria. Termo indexado no Medical Subject Headings (MeSH) em 2002.
} 
sentido, esperamos que mesmo com alto índice de angústia pessoal, o estudante consiga agir frente ao sofrimento compartilhado, de modo a expressar as competências técnicas e humanísticas nas mais variadas situações de atenção à saúde. Nessas situações, a expressão da competência depende essencialmente do desenvolvimento do autocontrole.

Em contrapartida, o autocontrole pode ser excessivamente reforçado pelos modelos na formação e desencadear estratégias de enfrentamento que tornem o estudante menos suscetível a emoções e determinem seu embrutecimento ou frieza. Desenvolver o autocontrole e ao mesmo tempo as competências emocionais constitui um desafio para os educadores médicos, que precisam orientar o jovem em formação a lidar com a dor e sofrimento, sem perder a capacidade de colocar-se no lugar do outro.

Tal desafio remete-nos à expressão do revolucionário Ernesto Che Guevara: "Endurecer é necessário, mas sem jamais perder a ternura”"(*). Apesar de construída em outro contexto social, histórico e político, essa expressão traz a ideia de que as vivências estressantes a que somos submetidos podem endurecer-nos, porém manter a serenidade e os valores humanísticos são desafios a serem conquistados de forma consciente. Acreditamos que essa conquista dependa da criação de espaços de discussão nas escolas médicas e de avaliações formativas com devolutivas constantes que contribuam para o autoconhecimento e desenvolvimento pessoal dos estudantes de medicina, e, em última análise, para sua prática profissional futura e qualidade de vida.

\footnotetext{
(*) "Hay que endurecerse, pero sin perder la ternura jamás." - Che Guevara, 1967 (tradução nossa). Epígrafe do livro: Rojo R. Mi amigo el Che. Buenos Aires: Editorial Sudamericana S.A.; 1996.p.25.
} 
Por compreendermos que a qualidade de vida está relacionada ao autocontrole e autoconhecimento do indivíduo, avaliar a qualidade de vida do estudante foi outra preocupação do nosso estudo.

Se por um lado observamos problemas na forma de autorrelato das medidas de empatia, por outro, podemos dizer que essa deve ser a metodologia de escolha para a avaliação da qualidade de vida dos estudantes. O construto da qualidade de vida deve contemplar as percepções subjetivas e individuais em várias dimensões da vida (The Whoqol Group, 1995), sendo a autopercepção recomendada.

As medidas de qualidade de vida em itens únicos são validadas para uma avaliação geral da população analisada (Sloan et al., 1998). Dessa maneira, empregamos os itens de autoavaliação da qualidade de vida geral e no curso de medicina nesse estudo. Essa análise revelou grandes diferenças na percepção dos estudantes acerca de sua qualidade de vida geral e no curso médico. A qualidade de vida relacionada ao curso de medicina foi muito menor do que a qualidade de vida geral. Essa autoavaliação pode ser um reflexo das dificuldades enfrentadas durante o curso. A carga horária excessiva (Guthrie et al., 1998), o contato com a doença e com a morte (Macleod et al., 2003; Wear, 2002) e o próprio currículo (Hafferty, 1998; Kiessling et al., 2004; Moffat et al., 2004; Wilson et al., 1996) constituem alguns dos fatores que contribuem para a pior percepção de qualidade de vida no curso entre os estudantes. Como demonstram esses estudos, a insatisfação do estudante pode estar relacionada às condições gerais, à estrutura e ao projeto pedagógico do curso.

Também acreditamos que essa insatisfação deva-se à visão que os estudantes possam ter da escola médica como um local de "deveres" ou de 
"trabalho". Esses deveres, os estudos e os compromissos relativos ao curso médico podem ser entendidos como um "tempo roubado", sobre o qual o estudante não detém nenhuma autonomia (Tempski-Fiedler, 2008; Schraiber, 1993). O viver intensamente estaria fora do curso, pois a vida na faculdade é o roubo do seu tempo de lazer, que se concretiza nas muitas renúncias que a vida acadêmica impõe. Essa forma de ver o trabalho e o estudo é uma característica da sociedade atual, pós-industrialização, na qual o produzir não significa mais felicidade, mas sim roubo do tempo. Dessa maneira, a retomada do tempo e da autonomia de utilizá-lo dá-se fora do contexto do trabalho (Bosi, 1994).

Não observamos diferenças quando comparamos a percepção da qualidade de vida geral e no curso de medicina entre gêneros e entre os anos do curso. Esse resultado é diferente daquele encontrado no estudo de Tempski-Fiedler (2008), que também analisou essa comparação em uma amostra de conveniência de estudantes de medicina. No referido estudo, os estudantes matriculados no terceiro e quarto anos do curso e as estudantes do sexo feminino atribuíram menores escores a sua qualidade de vida geral e no curso (Tempski-Fiedler, 2008). Acreditamos que essa diferença deva-se ao fato de que amostras aleatorizadas podem resultar em dados diferentes daqueles coletados por conveniência. No entanto, nos dois estudos a percepção da qualidade de vida no curso foi significativamente menor do que a percepção da qualidade de vida geral.

As comparações que realizamos entre os estudantes do sexo feminino e masculino acerca da qualidade de vida por meio do WHOQOL-BREF revelaram que as mulheres têm pior percepção nos domínios físico e psicológico. 
Também observamos piores escores entre as mulheres nos domínios físico, psicológico e uso do tempo do VERAS-q. Trabalhos prévios observaram resultados semelhantes e também trazem diferenças de gênero referentes à qualidade de vida dos estudantes (Dyrbye et al., 2011a; Henning et al., 2012; Paro et al., 2010; Tempski-Fiedler, 2008; Zhang et al., 2012). Da perspectiva do gênero, estudos demostram que os homens, em comparação com as mulheres, apresentam diversos comportamentos de risco e atribuem menor importância aos cuidados com a saúde. Os homens também valorizam menos seus sintomas físicos e psicológicos do que as mulheres (Schraiber et al., 2005). A partir dessas considerações, esperávamos que as mulheres respondessem de forma mais crítica aos instrumentos de avaliação de qualidade de vida e dessa forma apresentassem pior qualidade de vida nos domínios avaliados.

Já foi demonstrado que as mulheres podem apresentar maior ansiedade e sofrimento em situações estressantes quando comparadas a colegas do sexo masculino (Hojat et al., 1999) e que estudantes do sexo feminino também têm pior percepção do seu desempenho acadêmico (Chandavarkar et al., 2007). Essa percepção mais crítica das mulheres pode ser consequência da persistência de inequidades de gênero nas escolas (Bickel, 2001; Risberg et al., 2008). Em consequência das inequidades, estudantes do sexo feminino sentem-se constantemente pressionadas a comprovar suas capacidades e habilidades, principalmente em ambientes tradicionalmente "masculinos", como nos estágios hospitalares (Bickel, 2001; Barbaria et al., 2009, Risberg et al., 2008). 
A visão do estágio hospitalar como um ambiente culturalmente tido como "masculino" pode explicar a percepção discretamente menor das estudantes sobre suas relações sociais durante o ciclo profissionalizante, durante o qual o cenário de aprendizado predominante é o hospital. Outro fator que explica esse achado diz respeito ao isolamento social resultante das altas demandas acadêmicas direcionadas às estudantes dos últimos anos do curso (Barbaria et al., 2009; Risberg et al., 2009).

Não observamos diferenças da qualidade de vida avaliada por meio do WHOQOL-BREF entre os estudantes dos diversos anos do curso. As únicas diferenças encontradas foram no domínio físico (maior nos últimos anos do curso) e no domínio relações sociais (menor entre as estudantes do ciclo profissionalizante). No entanto, esses resultados parecem não ter uma representação importante na prática, tendo em vista os baixos tamanhos de efeito a eles associados. Portanto, a denominada "crise do meio", expressão utilizada para denotar piores escores de qualidade de vida entre os estudantes do meio do curso em trabalhos prévios com estudantes de medicina (Dyrbye et al., 2006a; Paro et al., 2010; Tempski-Fiedler, 2008; Zhang et al., 2012), não foi confirmada em nossos dados. Poderíamos inferir que nosso resultado seja reflexo de um recente movimento observado na comunidade acadêmica em direção à valorização da saúde mental positiva (autocuidado, bem estar, autonomia, resiliência) como estratégia para a formação de profissionais mais humanos e altruístas (Dyrbye et al., 2012; General Medical Council, 2009; Royal College of Physicians, 2005). Outra possível interpretação para esses resultados contrastantes é que as respostas de uma amostra aleatorizada 
sejam diferentes daquelas oriunda de uma amostra de conveniência, como já abordamos anteriormente.

Ainda em relação à qualidade de vida no curso de medicina, observamos que no domínio ambiente de ensino do VERAS-q os estudantes do ciclo profissionalizante apresentaram pior qualidade de vida quando comparados aos seus colegas do ciclo básico. Esse dado demonstra que a satisfação e o bem estar do estudante em relação ao seu ambiente de ensino é menor ao final do curso. Entre os estudantes brasileiros, esse resultado pode estar relacionado às demandas acadêmicas do ciclo profissionalizante e ao estresse inerente ao processo de seleção para uma vaga de residência médica.

Sabemos ainda que o curso médico representa um ambiente de toxicidade psicológica para o estudante (Nogueira-Martins, 1991; Wolf, 1994). Apesar de evidenciarmos estratégias que promovem o bem estar discente nas escolas, a prevalência de esgotamento profissional ainda é alta entre os estudantes de medicina. A exaustão emocional esteve presente em $50 \%$ dos respondentes nesse estudo, com maior prevalência de exaustão emocional entre mulheres $(55,7 \%)$ e despersonalização entre homens $(45,1 \%)$. A realização pessoal não apresentou diferenças de gênero. A literatura traz resultados controversos relativos ao esgotamento profissional entre estudantes de medicina. Alguns estudos apontam para maior despersonalização (Willcock et al., 2004) e esgotamento (Costa et al., 2012a) entre estudantes do sexo masculino, enquanto outros relatam maior esgotamento profissional entre estudantes do sexo feminino (Dyrbye et al., 2011a). Há ainda alguns resultados que demonstram não haver diferença de gênero para a síndrome de 
esgotamento profissional (Dahlin; Runeson, 2007; Galán et al., 2011; Guthrie et al., 1998).

Essas divergências devem acontecer devido aos diferentes critérios admitidos em cada um desses estudos para a definição da síndrome de esgotamento profissional ou ao uso de diferentes versões do MBI para a avaliação dessa síndrome entre estudantes de medicina. Realmente, alguns autores questionam o uso do MBI - HSS para a população de estudantes, já que o questionário foi construído para trabalhadores (Costa et al., 2012a; Galán et al., 2011; Guthrie et al., 1998). No entanto, outros argumentam que a versão para estudantes (MBI - SS) pode não refletir a realidade da vivência prática dos estudantes de medicina, que estão inseridos em um contexto real de prática profissional e interagem com pacientes desde os anos iniciais do curso (Galán et al., 2011).

A diferença de gênero no esgotamento profissional também pode acontecer devido às diferentes estratégias de enfrentamento ao estresse mobilizadas por homens e mulheres. Tradicionalmente, reconhecemos que homens tendem a reagir de maneira mais operacional ao estresse e mulheres tendem a expressar-se mais emocionalmente (Freud, 1933). Apesar de alguns estudos não demonstrarem diferenças de gênero nos mecanismos de enfrentamento ao estresse (Hamilton; Fagot, 1988), não podemos negar que esse comportamento é amplamente reproduzido pelos estereótipos culturais (Dressler, 1985). Dessa maneira, seria esperado encontrarmos maior exaustão emocional entre mulheres e maior despersonalização entre homens diante das situações estressantes do curso de medicina. 
Semelhantemente aos nossos resultados, entre os estudos que avaliaram a síndrome de esgotamento profissional nos diferentes anos do curso, observamos maior prevalência de exaustão emocional (Galán et al., 2011; Willcok et al., 2004), despersonalização (Dyrbye et al., 2006a; Willcok et al., 2004) e realização pessoal (Dyrbye et al., 2006a) entre estudantes das fases mais avançadas. Parece natural observarmos maior exaustão e realização pessoal nesse período. Nos últimos anos do curso, os estudantes têm maior carga horária prática, maior contato e maior responsabilidade pelo cuidado dos pacientes.

No entanto, consideramos a maior prevalência de despersonalização um achado preocupante. O contato frio, impessoal e indiferente às experiências do outro que caracteriza a despersonalização pode afetar negativamente a relação do estudante com o paciente (Benevides-Pereira, 2010; Maslach et al., 1996). A despersonalização pode ser consequência de mecanismos de enfrentamento do estresse relacionado ao período intenso de atividades práticas do ciclo profissionalizante, mas também pode ser resultante de inseguranças quanto ao futuro profissional e à seleção para os programas de residência médica.

Ao constatarmos maior despersonalização e exaustão emocional nos anos mais avançados do curso, esperaríamos também encontrar maior sonolência diurna entre esses estudantes. No entanto, não evidenciamos diferenças na prevalência de sonolência diurna entre os estudantes dos diversos anos do curso de medicina. Esse dado pode ser explicado pela alta proporção de estudantes com sonolência excessiva em todos os anos do curso, já que 56\% da população estudada apresentou escores patológicos. 
Sabemos que na população jovem a principal causa de sonolência é a privação do sono (Aloé et al., 1997). No entanto, também devemos considerar fatores de estresse transitórios, como as avaliações (Eller et al., 2006).

Provavelmente, a alta prevalência de sonolência diurna também tem relação com questões contemporâneas próprias dos adultos jovens, não exclusiva dos estudantes de medicina (Aloé et al., 1997). As interações eletrônicas em redes sociais e o volume excessivo de informação na Internet podem contribuir para a diminuição do período de sono entre os jovens (Tempski-Fiedler, 2008). Esse aspecto é reforçado pelo fato de que as primeiras avaliações de sonolência diurna em estudantes de medicina australianos na década de 90 por meio da Escala de Epworth tinham como média escores próximos a 7 (Johns, 1992). Essa média é inferior àquelas encontradas nos estudos mais contemporâneos, inclusive no nosso. Atualmente, os estudos têm relatado médias com interpretação patológica, superiores a 10 (Aloé et al., 1997; Rodrigues et al., 2002; Tempski-Fiedler, 2008).

As consequências da privação do sono para a saúde física e mental dos estudantes podem ser importantes. A literatura aponta que privação do sono causa progressiva deterioração mental, psicológica e física, com evidências de mudanças de humor, diminuição da coordenação motora e da capacidade de raciocínio, problemas de memória, de aprendizado e da fala (Coren, 1998).

As comparações que realizamos acerca da prevalência de sonolência diurna revelaram pequenas diferenças de gênero, com maior proporção de sonolência entre as mulheres. Poucos estudos confirmam diferenças de gênero na sonolência dos estudantes de medicina (Abdulghani et al., 2012, Tempski- 
Fiedler, 2008). Relações entre sonolência e sintomas de ansiedade e depressão entre mulheres poderiam explicar essa diferença (Eller et al., 2006).

Outra explicação para as diferenças de gênero na prevalência de sonolência diurna poderia ser a utilização de uma medida de autorrelato para a avaliação dessa variável. Nessas medidas, mulheres tendem a comportar-se de maneira mais crítica e relatam sintomas físicos e psicológicos com mais frequência do que homens (Verbrugge, 1985).

Nossa hipótese de que estudantes sonolentos teriam dificuldades em adotar a perspectiva do outro e engajar interações sociais mais efetivas (Harrison; Horne, 2000) não foi confirmada, uma vez que as correlações entre sonolência e os domínios da empatia foram baixas.

No entanto, confirmamos a hipótese de que as diferentes dimensões disposições empáticas têm relação tanto com aspectos positivos de qualidade de vida e realização pessoal quanto com aspectos negativos de esgotamento profissional. Comparamos as disposições empáticas dos estudantes com escores acima do percentil 75 e abaixo do percentil 25 nos domínios do WHOQOL-BREF e observamos que os estudantes com melhor qualidade de vida apresentaram menor angústia pessoal e maior disposição para tomada de perspectiva. Nessa análise, a relação mais importante foi aquela entre o domínio psicológico e a angústia pessoal.

A análise comparativa entre estudantes com os escores nos quartis superior e inferior dos domínios do Veras-q também demonstrou que indivíduos com melhor qualidade de vida (principalmente nos domínios psicológico e ambiente de ensino) têm maior disposição empática. Esses resultados foram ainda mais importantes do que os resultados obtidos por meio do WHOQOL- 
BREF, provavelmente pelo fato do Veras-q ser um questionário específico de qualidade de vida para o estudante de medicina. Nossos resultados permitemnos afirmar que o bem estar físico, mental e social parece contribuir para a disposição individual em colocar-se no lugar do outro.

A análise dos grupos de estudantes com exaustão emocional e despersonalização demonstrou que esses estudantes apresentaram menor disposição para a tomada de perspectiva e maior angústia pessoal. Nossos achados reforçam a importância de programas educacionais que promovam saúde e bem estar e que minimizem o desgaste emocional dos estudantes como alternativa para aprimorar suas habilidades empáticas e profissionais (Shanafelt et al., 2005; Thomas et al., 2007).

Estudantes com maior realização pessoal apresentaram mais disposição para a tomada de perspectiva e menor angústia pessoal. Estudos anteriores relatam que a satisfação (Gleichgerrcht; Decety, 2013; Grühn et al., 2008) e o crescimento profissional (Grühn et al., 2008) têm relação com as disposições empáticas de adultos e com a satisfação dos pacientes com o cuidado médico (Haas et al., 2000). Essa relação também não parece carregar diferenças de gênero (Haas et al., 2000; Grühn et al., 2008).

Em uma tentativa de compreendermos melhor as relações entre os aspectos positivos e negativos do bem estar dos estudantes e suas disposições empáticas, procuramos interpretar nossos resultados a partir de análises multivariadas. Uma vez que detectamos diferenças de gênero importantes nas disposições empáticas dos estudantes, desenvolvemos modelos distintos para as relações entre empatia, qualidade de vida e esgotamento profissional para homens e mulheres. 
Nas análises de regressão múltipla, obtivemos um modelo com moderada explicação da variância do domínio angústia pessoal entre os estudantes do sexo masculino. Nesse domínio, confirmamos a importância da realização profissional e da percepção de qualidade de vida no domínio psicológico. A associação entre realização pessoal, qualidade de vida mental e empatia também foi encontrada em estudos prévios (Shanafelt et al., 2005; Thomas et al., 2007).

No grupo do sexo feminino, observamos explicação moderada da variância dos domínios consideração empática e tomada de perspectiva pelos escores de despersonalização e realização pessoal. Estudos anteriores confirmaram a importância das correlações entre empatia, realização pessoal e despersonalização entre estudantes de medicina (Brazeau et al., 2010; Thomas et al., 2007).

O comportamento de distanciamento e impessoalidade característico da despersonalização justifica sua correlação negativa com as disposições empáticas das estudantes. Se entendermos a disposição empática como uma característica importante na ampliação e fortalecimento das relações sociais (Grühn et al., 2008), essa relação parece-nos justificada.

O distanciamento social pode ser consequência de estratégias passivas de enfretamento e isolamento desencadeadas por situações estressantes (Lazarus, 1993). Estratégias passivas de enfrentamento, focadas em emoções, também estão relacionadas à menor satisfação dos estudantes de medicina com o curso (Alimoglu et al., 2011; Kjeldstadli et al., 2006).

A satisfação ou realização pessoal dos estudantes de medicina é uma variável que deve ser explorada na educação médica. A realização pessoal 
apresentou relação importante com todos os domínios da empatia avaliados em nosso estudo. Alguns trabalhos indicam que a realização pessoal dos estudantes de medicina relaciona-se a percepções de menor interferência do curso na vida pessoal e social (Kjeldstadli et al., 2006), à presença de fortes laços sociais (Parkerson et al., 1990) e ao suporte social (Tyssen et al., 2009).

A satisfação pessoal também pode estar relacionada a fatores curriculares, como a utilização de metodologias ativas de aprendizagem (Gurpinar et al., 2010) e prática clínica desde as fases mais iniciais do curso (Johnson; Scott, 1998; Tempski et al., 2012).

Reforçamos, dessa maneira, a necessidade de desenharmos estratégias educacionais que promovam o sentimento de realização pessoal entre os estudantes como maneira de potencializar suas habilidades empáticas.

Devemos considerar algumas limitações advindas do uso de um questionário de autorrelato das disposições empáticas nesse estudo. O questionário pode não refletir o real comportamento dos estudantes no contexto da prática profissional. No entanto, alguns autores referem que a orientação empática pode desencadear um comportamento empático (Hojat, 2007). Dessa maneira, podemos considerar que o questionário de tendência empática levou-nos a uma boa aproximação do nosso objeto de estudo em um estudo multicêntrico como esse.

A utilização do questionário autorrelato poderia ainda ser questionada quanto à obviedade de sua medida, que pode levar ao reforço dos estereótipos culturais nas diferenças de gênero. Esse questionamento obriga-nos a considerar que as diferenças de gênero que encontramos em nosso estudo 
possam também ser resultantes da expectativa social de maior desempenho das mulheres nas habilidades empáticas.

A continuidade do projeto VERAS em um desenho longitudinal poderá trazer algumas respostas de causa e efeito aqui hipotetizadas. Da mesma forma, análises qualitativas futuras para o aprofundamento da compreensão dos resultados aqui encontrados também contribuirão para elucidar os fatores determinantes da empatia entre os estudantes de medicina.

Apesar de algumas limitações aqui mencionadas, alguns pontos fortes do nosso estudo devem ser ressaltados. Um deles refere-se ao rigor na análise estatística, representado pelo cálculo do tamanho do efeito a que todos os resultados foram submetidos. Devido ao tamanho da amostra do estudo, esperávamos que muitas comparações apresentassem significância estatística. Porém, o cálculo do tamanho do efeito permitiu-nos demonstrar que algumas das diferenças encontradas não correspondiam a uma relevância prática. Análises semelhantes têm sido incentivadas principalmente em estudos das áreas das ciências comportamentais (American Psychological Association, 2010). Dessa maneira, acreditamos que pesquisadores em educação médica deveriam ser estimulados a incluírem o tamanho do efeito na análise de seus resultados.

O rigor estatístico admitido nesse estudo permitiu que nossas análises se aproximassem da realidade acerca da empatia, qualidade de vida e esgotamento profissional do estudante de medicina. Sabemos que nossas análises dão conta de parte dos fatores intrínsecos a cada uma das variáveis estudadas, tendo em vista suas naturezas multidimensionais. Empatia, qualidade de vida e esgotamento profissional são construtos que agregam 
relações complexas e dependem de diferentes aproximações e análises. Nesse caso, a escolha dos diferentes questionários e as análises uni e multivariadas conseguiram refletir parte dessa complexidade.

Considerações finais

A realização pessoal apresentou-se em importante relação com a disposição empática dos estudantes de medicina. Sabemos que a realização pessoal, de maneira analógica à qualidade de vida, pode representar um construto individual e complexo. Afinal, esse construto pode ter tantos significados quanto o número de sujeitos a quem isso for questionado. Para o indivíduo, a realização pessoal pode representar o conjunto dos seus valores. Poderíamos esperar que para o coletivo dos estudantes de medicina, a realização pessoal esteja associada à concretização do desejo de tornar-se médico, à sua aproximação com a prática médica ou ainda à percepção de que a sua prática de cuidado tem impacto na melhoria da vida do outro.

Contudo, os fatores determinantes da realização pessoal do estudante de medicina e como essa percepção traduz-se no seu comportamento empático são questões a serem melhor investigadas. Vemos essa investigação configurar-se como um dos próximos passos dessa pesquisa. $O$ uso de diferentes desenhos e metodologias permitirá obtermos conclusões sobre relações de causa e efeito e entendermos as dimensões qualitativas da temática em questão.

Se considerarmos que a empatia é uma competência importante dentro das diretrizes de formação médica e está intrinsicamente ligada à qualidade de 
vida e à realização pessoal do estudante, é papel da escola médica assumir sua corresponsabilidade pela manutenção da qualidade de vida e satisfação do estudante. 


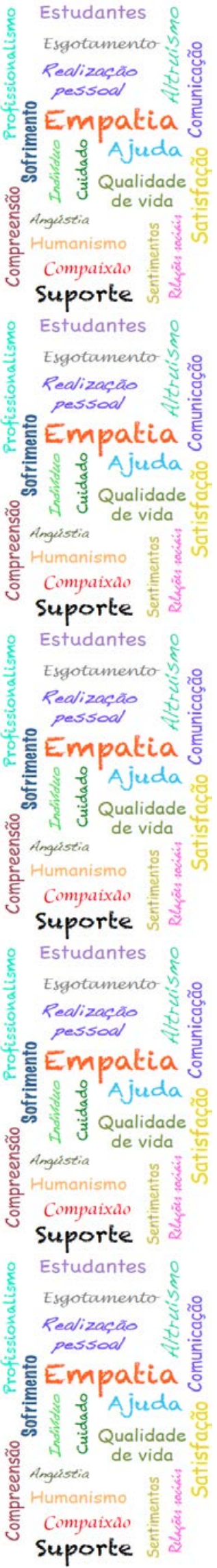

6 CONCLUSÕES 
A análise dos nossos resultados permite-nos concluir que estudantes do sexo feminino apresentaram maior disposição para a consideração empática e para a angústia pessoal do que estudantes do sexo masculino. As diferenças das disposições empáticas dos estudantes de diferentes ciclos do curso de medicina foram inexpressivas. A percepção do estudante sobre sua qualidade de vida no curso de medicina foi muito menor do que a percepção sobre sua qualidade de vida geral. As diferenças de qualidade de vida, esgotamento profissional e sonolência diurna entre gênero e ciclos do curso de medicina também foram de pequena relevância prática. Dentre as variáveis estudadas, realização pessoal parece ter a maior contribuição para a menor angústia pessoal entre estudantes do sexo masculino. Maior realização pessoal e menor despersonalização também parecem contribuir para maior disposição empática entre estudantes do sexo feminino. 


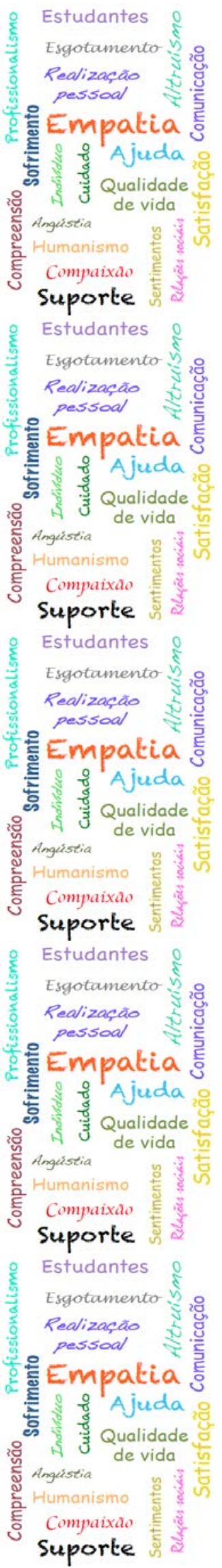

7 ANEXOS 
Anexo A - Aprovação do Comitê de Ética em Pesquisa da FMUSP

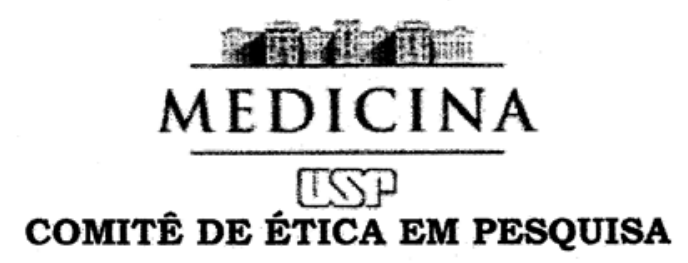

\section{APROVAÇÃo}

O Comitê de Ética em Pesquisa da Faculdade de Medicina da Universidade de São Paulo, em sessão de 14/12/2011, APROVOU o Protocolo de Pesquisa no 485/11 intitulado: "EMPATIA DO ESTUDANTE DE MEDICINA NO BRASIL: AVALIAÇÃO DA INFLUÊNCIA DO AMBIENTE DE ENSINO E DA QUALIDADE DE VIDA NOS DIFERENTES ANOS DO CURSO" apresentado pelo Departamento de Clínica Médica

Cabe ao pesquisador elaborar e apresentar ao CEPFMUSP, os relatórios parciais e final sobre a pesquisa (Resolução do Conselho Nacional de Saúde no 196, de 10/10/1996, inciso IX.2, letra "c").

Pesquisador (a) Responsável: Milton de Arruda Martins

Pesquisador (a) Executante: Helena Borges Martins da Silva Paro

CEP-FMUSP, 14 de Dezembro de 2011.



Prof. Dr. Paulo Eurípedes Marchiori

Vice-Coordenador interino

Comitê de Ética em Pesquisa 


\title{
Anexo B - Termo de Consentimento Livre e Esclarecido
}

\author{
Termo de Consentimento Livre Esclarecido \\ Projeto de Pesquisa VERAS \\ Vida de estudante e residente da área da saúde
}

\begin{abstract}
Este projeto será deservolvido jurio acs discerles matricuados em cursos de graduação em medicina em todo tentitório nacional. Tem por objetivo centıal conhecer a percepção do estıdante acerca da sua qualidade de vida no curso de medicira e identiticar talores irteırelacionados a uma melhor ou pior qualidade de vida. Buscando cortecer melhor a realidade dos estudantes, sua peıcepçäo da qualidade de vida, ambiente de ensinc, conlexto cultural, social e temporal, bem como os talcıes delermiramles de risco à sua saúde f sica e mental o pıcjeto VERAS elaborcu uma platatoıma eletıonica com instrumertos de avaliaçãa da qualidade de vida, sonclência, resiliêrcia, buırout, depressão, ansiedade e empatia, que seräo respondidos por estudarles em todo tertitório nacional. Cs estudarles que parliciparem de torma volırtária terão gaıantia de aronimaio e sigilo das sıas ıespostas.
\end{abstract}

A incısäo no estudo se dará de dıas tormas: por sorleic no grupo aleatorizado e por procura espontânea entre os alunos não selecionados para o estıdo. Nos dois grupos a participação é vcluntária. O convile para participação será teilo primeiramente de torma coletiva pelo pesquisador resporsável. Os aluncs includos no estudo por sorleio selão convidados individualmenle após o convile coletivo. A participaçäc do estudante implica na resposta aos instrumentos da pesquisa dispostos na Plalatorma Eletrônica VERAS, que pode ser acessada via Inlernet de qualquer local. $O$ lempo tolal de iesposta varia em média entre 45 e 60 mirutos. que podem sel divididos em 10 dias, nos quais a plalalorma se mantém ativa para aquele respondenle.

Esclaıecemos que o acesso ao sistema é protegido po nome de usuátic e senta, mas os dados são aımazenados no sistema ancrimamente, i.e., os pesquisadores ligados ao projelo rão lerão os dados de idertificação dos usuáaicios que respondem aos questionários. Aceitando participar, o sistema the enviaıa ım ou mais emails com irstruções que the permitiräo completal seu cadastro, conectar-se ao sistema, e dirigir-se à área de questionánios.

Aos participartes será olerecido acesso aos dados e devolutiva dos seus resuliados.

A adesäo dos alunos e da instituiçäo é gratuita e volıntária.

Caso concoıde em participar solicitamos que pıeercha os espaços a seguir.

Eᄂ,

(preencha в9u nome completo) 


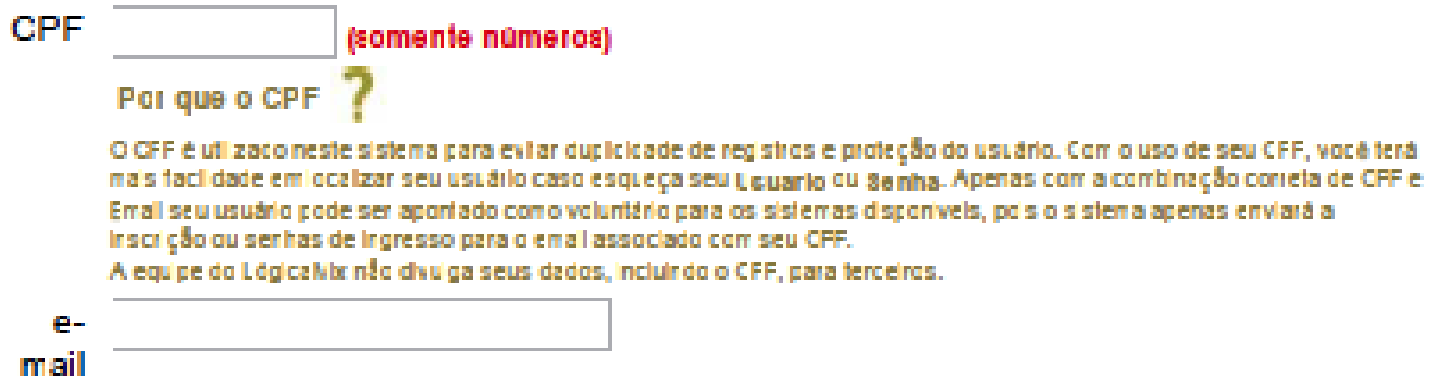

corcordo em participaı desse estudo scbre a qualidade de vida do estıdante de medicina, esiardo cierie de que:

- Este projeto näo implicará na utilização de métodos invasivos e não haverá risco significativo à sua integridade física e mental.

- Fica garantido o direito de confidencialidade dos participartes.

- O participante pode retirar seu consentimento e se abster de responder aos questionários aplicados, quando desejar.

- Fica garartido o acesso aos resultados do estudo.

- Näo haverá nenhum pagamento aos participantes.

Cadastrar

Caso você näo concorde com os termos acima, volte à tela inicial. Obrigado. 


\section{Anexo C - Questionários utilizados no estudo}

\section{Questionário sócio-demográfico}

1. Idade

2. Sexo (masculino/feminino)

3. Peso

4. Altura

5. Você participa de algum dos seguintes programas?(nenhum, FIES, PROUNI, bolsista, cotista ou proveniente de programa de inclusão social)

6. Com quem você reside?(pais, outros parentes, amigo, sozinho, outros)

7. Qual a Unidade da Federação / Faculdade de Medicina que você está cursando?

8. Como você se tornou voluntário?

9. Qual ano da graduação você está cursando?

10. Qual o ano de Residência Médica que você esta cursando?

11. Qual especialidade médica você pretende fazer (se está na gradução) ou está fazendo (se está na residência ou já é formado)?

12. Qual sua área de atuação?

13. Há quanto tempo você retornou de férias?

14. Gradue o quanto você achou difícil/fácil responder este questionário. 


\section{Escala Multidimensional de Reatividade Interpessoal de Davis (EMRI)}

\begin{tabular}{|c|c|c|c|c|c|}
\hline $\begin{array}{l}\text { 1. Eu frequentemente tenho sentimentos de } \\
\text { ternura e preocupação por pessoas menos } \\
\text { afortunadas do que eu. }\end{array}$ & 1 & 2 & 3 & 4 & 5 \\
\hline $\begin{array}{l}\text { 2. Às vezes, eu tenho dificuldade de ver as coisas } \\
\text { do ponto de vista dos outros. }\end{array}$ & 1 & 2 & 3 & 4 & 5 \\
\hline $\begin{array}{l}\text { 3. Às vezes, eu não me lamento muito por outras } \\
\text { pessoas que estão tendo problemas. }\end{array}$ & 1 & 2 & 3 & 4 & 5 \\
\hline $\begin{array}{l}\text { 4. Em situações de emergência, eu me sinto } \\
\text { ansioso e desconfortável. }\end{array}$ & 1 & 2 & 3 & 4 & 5 \\
\hline $\begin{array}{l}\text { 5. Eu tento considerar os argumentos de todas as } \\
\text { pessoas sem uma discussão antes de tomar } \\
\text { uma decisão. }\end{array}$ & 1 & 2 & 3 & 4 & 5 \\
\hline $\begin{array}{l}\text { 6. Quando eu vejo alguém sendo logrado eu sinto } \\
\text { vontade de protegê-lo. }\end{array}$ & 1 & 2 & 3 & 4 & 5 \\
\hline $\begin{array}{l}\text { 7. Às vezes, eu me sinto desconfortável quando } \\
\text { estou no meio de uma situação muito emotiva. }\end{array}$ & 1 & 2 & 3 & 4 & 5 \\
\hline $\begin{array}{l}\text { 8. Às vezes, eu tento entender melhor meus } \\
\text { amigos, imaginando como as coisas são vistas } \\
\text { da perspectiva deles. }\end{array}$ & 1 & 2 & 3 & 4 & 5 \\
\hline $\begin{array}{l}\text { 9. Quando eu vejo alguém se ferir, eu tendo a } \\
\text { permanecer calmo. }\end{array}$ & 1 & 2 & 3 & 4 & 5 \\
\hline $\begin{array}{l}\text { 10. As desgraças e os problemas dos outros em } \\
\text { geral não me perturbam muito. }\end{array}$ & 1 & 2 & 3 & 4 & 5 \\
\hline $\begin{array}{l}\text { 11. Se eu tenho certeza de que eu estou correto } \\
\text { sobre alguma coisa, eu não desperdiço muito } \\
\text { tempo ouvindo os argumentos das outras } \\
\text { pessoas. }\end{array}$ & 1 & 2 & 3 & 4 & 5 \\
\hline $\begin{array}{l}\text { 12. Estar em uma situação emocional tensa } \\
\text { assusta-me. }\end{array}$ & 1 & 2 & 3 & 4 & 5 \\
\hline $\begin{array}{l}\text { 13. Quando eu vejo alguém sendo injutiçado, eu às } \\
\text { vezes não sinto muita pena dele. }\end{array}$ & 1 & 2 & 3 & 4 & 5 \\
\hline $\begin{array}{l}\text { 14. Geralmente eu sou muito efetivo para lidar com } \\
\text { emergências. }\end{array}$ & 1 & 2 & 3 & 4 & 5 \\
\hline $\begin{array}{l}\text { 15. Frequentemente eu fico emocionado com } \\
\text { coisas que eu vejo acontecer. }\end{array}$ & 1 & 2 & 3 & 4 & 5 \\
\hline $\begin{array}{l}\text { 16. Eu acredito que existem dois lados para cada } \\
\text { questão e tento olhar para ambos. }\end{array}$ & 1 & 2 & 3 & 4 & 5 \\
\hline $\begin{array}{l}\text { 17. Eu descreveria a mim mesmo como uma } \\
\text { pessoa de coração mole. }\end{array}$ & 1 & 2 & 3 & 4 & 5 \\
\hline $\begin{array}{l}\text { 18. Eu tendo a perder o controle durante } \\
\text { emergências. }\end{array}$ & 1 & 2 & 3 & 4 & 5 \\
\hline $\begin{array}{l}\text { 19. Quando eu estou incomodado com alguém, } \\
\text { geralmente eu tento me colocar em seu lugar } \\
\text { por um momento. }\end{array}$ & 1 & 2 & 3 & 4 & 5 \\
\hline $\begin{array}{l}\text { 20. Quando eu vejo alguém que tem grande } \\
\text { necessidade de ajuda em uma emergência, eu } \\
\text { fico desesperado. }\end{array}$ & 1 & 2 & 3 & 4 & 5 \\
\hline $\begin{array}{l}\text { 21. Antes de criticar alguém, eu tento imaginar } \\
\text { como eu me sentiria, se eu estivesse em seu } \\
\text { lugar. }\end{array}$ & 1 & 2 & 3 & 4 & 5 \\
\hline
\end{tabular}




\section{Autoavaliação de qualidade de vida}

- Dê uma nota de o a 10 para sua qualidade de vida geral

- Dê uma nota de o a 10 para sua qualidade de vida no curso de medicina 


\section{The World Health Organization Quality of Life Assessment - Bref (WHOQOL-BREF)}

Este questionário é sobre como você se sente a respeito de sua qualidade de vida, saúde e outras áreas de sua vida. Por favor responda a todas as questões. Se você não tem certeza sobre que resposta dar em uma questão, por favor, escolha entre as alternativas a que lhe parece mais apropriada. Esta, muitas vezes, poderá ser sua primeira escolha.

Por favor, tenha em mente seus valores, aspirações, prazeres e preocupações. Nós estamos perguntando o que você acha de sua vida, tomando como referência as duas últimas semanas.

Por favor, leia cada questão, veja o que você acha e circule no número que lhe parece a melhor resposta.

\begin{tabular}{||l|l|c|c|c|c|c||}
\hline & & $\begin{array}{c}\text { muito } \\
\text { ruim }\end{array}$ & ruim & $\begin{array}{c}\text { nem ruim } \\
\text { nem boa }\end{array}$ & boa & $\begin{array}{c}\text { muito } \\
\text { boa }\end{array}$ \\
\hline 1 & $\begin{array}{l}\text { Como você avaliaria sua qualidade de } \\
\text { vida? }\end{array}$ & 1 & 2 & 3 & 4 & 5 \\
\hline
\end{tabular}

\begin{tabular}{||l|l|l|l|c|c|c||}
\hline \hline & $\begin{array}{l}\text { muito } \\
\text { insatisfeito }\end{array}$ & insatisfeito & $\begin{array}{c}\text { nem satisfeito } \\
\text { nem insatisfeito }\end{array}$ & satisfeito & $\begin{array}{c}\text { muito } \\
\text { satisfeit } \\
\text { o }\end{array}$ \\
\hline 2 & $\begin{array}{l}\text { Quão satisfeito(a) você está } \\
\text { com a sua saúde? }\end{array}$ & 1 & 2 & 3 & 4 & 5 \\
\hline
\end{tabular}

As questões seguintes são sobre o quanto você tem sentido algumas coisas nas últimas duas semanas.
\begin{tabular}{||l|l|c|c|c|c|c||}
\hline \hline 3 & nada & $\begin{array}{c}\text { muito } \\
\text { pouco }\end{array}$ & $\begin{array}{c}\text { mais ou } \\
\text { menos }\end{array}$ & $\begin{array}{l}\text { bastant } \\
\text { e }\end{array}$ & extremamente \\
\hline $\begin{array}{l}\text { Em que medida você acha que sua dor } \\
\text { fríca) impede você de fazer o que você } \\
\text { precisa? }\end{array}$ & 1 & 2 & 3 & 4 & 5 \\
\hline 4 & $\begin{array}{l}\text { O quanto você precisa de algum } \\
\text { tratamento médico para levar sua vida } \\
\text { diária? }\end{array}$ & 1 & 2 & 3 & 4 & 5 \\
\hline 5 & O quanto você aproveita a vida? & 1 & 2 & 3 & 4 & 5 \\
\hline 6 & $\begin{array}{l}\text { Em que medida você acha que a sua vida } \\
\text { tem sentido? }\end{array}$ & 1 & 2 & 3 & 4 & 5 \\
\hline 7 & O quanto você consegue se concentrar? & 1 & 2 & 3 & 4 & 5 \\
\hline 8 & $\begin{array}{l}\text { Quão seguro(a) você se sente em sua vida } \\
\text { diária? }\end{array}$ & 1 & 2 & 3 & 4 & 5 \\
\hline 9 & $\begin{array}{l}\text { Quão saudável é o seu ambiente físico } \\
\text { clima, barulho, poluição, atrativos)? }\end{array}$ & 1 & 2 & 3 & 4 & 5 \\
\hline
\end{tabular}

As questões seguintes perguntam sobre certas coisas nestas últimas duas semanas.

quão completamente você tem sentido ou é capaz de fazer

\begin{tabular}{||l|l|c|c|c|c|c||}
\hline \hline & & nada & $\begin{array}{l}\text { muito } \\
\text { pouco }\end{array}$ & médio & muito & completamente \\
\hline 10 & Você tem energia suficiente para seu dia-a-dia? & 1 & 2 & 3 & 4 & 5 \\
\hline 11 & Você é capaz de aceitar sua aparência física? & 1 & 2 & 3 & 4 & 5 \\
\hline 12 & $\begin{array}{l}\text { Você tem dinheiro suficiente para satisfazer suas } \\
\text { necessidades? }\end{array}$ & 1 & 2 & 3 & 4 & 5 \\
\hline 13 & $\begin{array}{l}\text { Quão disponíveis para você estão as } \\
\text { informações que precisa no seu dia-a-dia? }\end{array}$ & 1 & 2 & 3 & 4 & 5 \\
\hline 14 & $\begin{array}{l}\text { Em que medida você tem oportunidades de } \\
\text { atividade de lazer? }\end{array}$ & 1 & 2 & 3 & 4 & 5 \\
\hline \hline
\end{tabular}


As questões seguintes perguntam sobre quão bem ou satisfeito você se sentiu a respeito de vários aspectos de sua vida nas últimas duas semanas.

\begin{tabular}{||l|l|c|c|c|c|c||}
\hline \hline 15 & Quão bem você é capaz de se locomover? & $\begin{array}{c}\text { muito } \\
\text { ruim }\end{array}$ & ruim & $\begin{array}{c}\text { nem ruim } \\
\text { nem bom }\end{array}$ & bom & $\begin{array}{c}\text { muito } \\
\text { bom }\end{array}$ \\
\hline \hline
\end{tabular}

\begin{tabular}{|c|c|c|c|c|c|c|}
\hline & & $\begin{array}{c}\text { muito } \\
\text { insatisfeito }\end{array}$ & insatisfeito & $\begin{array}{c}\text { nem satisfeito } \\
\text { nem insatisfeito }\end{array}$ & satisfeito & $\begin{array}{r}\text { muito } \\
\text { satisfeito }\end{array}$ \\
\hline 16 & $\begin{array}{l}\text { Quão satisfeito(a) você está com o seu } \\
\text { sono? }\end{array}$ & 1 & 2 & 3 & 4 & 5 \\
\hline 17 & $\begin{array}{l}\text { Quão satisfeito(a) você está com sua } \\
\text { capacidade de desempenhar as atividades } \\
\text { do seu dia-a-dia? }\end{array}$ & 1 & 2 & 3 & 4 & 5 \\
\hline 18 & $\begin{array}{l}\text { Quão satisfeito(a) você está com sua } \\
\text { capacidade para o trabalho? }\end{array}$ & 1 & 2 & 3 & 4 & 5 \\
\hline 19 & $\begin{array}{l}\text { Quão satisfeito(a) você está consigo } \\
\text { mesmo? }\end{array}$ & 1 & 2 & 3 & 4 & 5 \\
\hline 20 & $\begin{array}{l}\text { Quão satisfeito(a) você está com suas } \\
\text { relações pessoais (amigos, parentes, } \\
\text { conhecidos, colegas)? }\end{array}$ & 1 & 2 & 3 & 4 & 5 \\
\hline 21 & $\begin{array}{l}\text { Quão satisfeito(a) você está com sua vida } \\
\text { sexual? }\end{array}$ & 1 & 2 & 3 & 4 & 5 \\
\hline 22 & $\begin{array}{l}\text { Quão satisfeito(a) você está com o apoio } \\
\text { que você recebe de seus amigos? }\end{array}$ & 1 & 2 & 3 & 4 & 5 \\
\hline 23 & $\begin{array}{l}\text { Quão satisfeito(a) você está com as } \\
\text { condições do local onde mora? }\end{array}$ & 1 & 2 & 3 & 4 & 5 \\
\hline 24 & $\begin{array}{l}\text { Quão satisfeito(a) você está com o seu } \\
\text { acesso aos serviços de saúde? }\end{array}$ & 1 & 2 & 3 & 4 & 5 \\
\hline 25 & $\begin{array}{l}\text { Quão satisfeito(a) você está com o seu } \\
\text { meio de transporte? }\end{array}$ & 1 & 2 & 3 & 4 & 5 \\
\hline
\end{tabular}

As questões seguintes referem-se a com que frequiência você sentiu ou experimentou certas coisas nas últimas duas semanas.

\begin{tabular}{||l|l|l|l|l|c|c||}
\hline \hline 26 & nunca & $\begin{array}{c}\text { algums } \\
\text { vers }\end{array}$ & fiequientemente & $\begin{array}{c}\text { muito } \\
\text { fiequientemente }\end{array}$ & sempe \\
\hline $\begin{array}{l}\text { Com que frequiência você tem } \\
\text { sentimentos negativos tais como mau } \\
\text { humor, desespero, ansiedade, } \\
\text { depressão? }\end{array}$ & 1 & 2 & 3 & 4 & 5 \\
\hline \hline
\end{tabular}

Alguém lhe ajudou a preencher este questionário?

Quanto tempo você levou para preencher este questionário?. 


\section{VERAS-q: questionário para avaliar a qualidade de vida do estudante de medicina}

Responda considerando seus valores, aspirações, prazeres e preocupações, nas duas (2) últimas semanas. Em cada uma das afirmações abaixo assinale uma das seguintes alternativas:

DT - discordo totalmente D-discordo I-indiferente C - concordo CT - concordo totalmente

\begin{tabular}{|c|c|c|c|c|c|}
\hline 01. Minha qualidade de vida é boa. & DT & $\mathrm{D}$ & I & C & CT \\
\hline 02. Não aproveito a vida como deveria. & DT & D & I & C & CT \\
\hline $\begin{array}{l}\text { 03. Recebo supervisão adequada em minhas } \\
\text { atividades práticas. }\end{array}$ & DT & D & I & C & CT \\
\hline 04. Tenho tempo para minha família. & DT & D & I & C & CT \\
\hline $\begin{array}{l}\text { 05. Em alguns momentos, sinto-me humilhado(a) } \\
\text { em atividades do meu curso de araduacão. }\end{array}$ & DT & D & $\mathrm{I}$ & C & CT \\
\hline $\begin{array}{l}\text { 06. O ambiente físico da minha faculdade é } \\
\text { saudável. }\end{array}$ & DT & D & $\mathrm{I}$ & C & CT \\
\hline $\begin{array}{l}\text { 07. Tenho uma boa relação com os colegas da } \\
\text { minha turma. }\end{array}$ & DT & D & $\mathrm{I}$ & C & CT \\
\hline 08. Tenho tempo para atividades extracurriculares. & DT & $\mathrm{D}$ & I & C & CT \\
\hline 09. Não tenho tempo livre suficiente. & DT & $\mathrm{D}$ & I & C & CT \\
\hline $\begin{array}{l}\text { 10. O suporte espiritual que tenho melhora minha } \\
\text { qualidade de vida. }\end{array}$ & DT & D & $\mathrm{I}$ & C & CT \\
\hline 11. Minha vida tem sentido. & DT & D & $\mathrm{I}$ & C & CT \\
\hline $\begin{array}{l}\text { 12. Meu relacionamento com os meus professores } \\
\text { é bom. }\end{array}$ & DT & D & $\mathrm{I}$ & $\mathrm{C}$ & CT \\
\hline $\begin{array}{l}\text { 13. O contato que tenho com pacientes aumenta } \\
\text { minha qualidade de vida. }\end{array}$ & DT & D & $\mathrm{I}$ & C & CT \\
\hline $\begin{array}{l}\text { 14. Cobro-me em excesso no meu curso de } \\
\text { araduacão. }\end{array}$ & DT & D & $\mathrm{I}$ & C & CT \\
\hline $\begin{array}{l}\text { 15. Sou cobrado(a) em excesso pelos } \\
\text { professores. }\end{array}$ & DT & D & $\mathrm{I}$ & C & CT \\
\hline 16. Não cuido bem de minha saúde. & DT & $\mathrm{D}$ & I & C & CT \\
\hline 17. Tenho tempo para atividades culturais. & DT & $\mathrm{D}$ & 1 & C & CT \\
\hline $\begin{array}{l}\text { 18. As atividades do meu curso de graduação são } \\
\text { excessivas para mim. }\end{array}$ & DT & D & $\mathrm{I}$ & C & CT \\
\hline 19. Tenho tempo suficiente para estudar. & DT & $\mathrm{D}$ & I & C & $\mathrm{CT}$ \\
\hline $\begin{array}{l}\text { 20. Tenho acesso adequado a atendimento } \\
\text { médico. }\end{array}$ & DT & D & $\mathrm{I}$ & C & CT \\
\hline 21. A maioria das aulas de meu curso é ruim. & DT & $\mathrm{D}$ & I & C & CT \\
\hline $\begin{array}{l}\text { 22. Minha relação com os colegas dos outros anos } \\
\text { é boa. }\end{array}$ & DT & $\mathrm{D}$ & $\mathrm{I}$ & C & $\mathrm{CT}$ \\
\hline
\end{tabular}


Responda considerando seus valores, aspirações, prazeres e preocupações, nas duas (2) últimas semanas. Em cada uma das afirmações abaixo assinale uma das seguintes alternativas:

DT - discordo totalmente D-discordo I-indiferente C-concordo CT-concordo totalmente

\begin{tabular}{|c|c|c|c|c|c|}
\hline 23. Consigo gerenciar bem o meu tempo. & DT & $\mathrm{D}$ & I & C & CT \\
\hline 24. Minha saúde é boa. & DT & D & I & C & CT \\
\hline $\begin{array}{l}\text { 25. Minha quali } \\
\text { araduacão é }\end{array}$ & DT & D & 1 & C & CT \\
\hline $\begin{array}{l}\text { 26. O meu curso de graduação me priva de alguns } \\
\text { compromissos pessoais. }\end{array}$ & DT & D & I & C & CT \\
\hline $\begin{array}{l}\text { 27. Tenho me sentido desanimado(a) } \\
\text { ultimamente. }\end{array}$ & DT & D & I & C & CT \\
\hline $\begin{array}{l}\text { 28. Tenho acesso adequado a atendimento } \\
\text { psicolóaico. }\end{array}$ & DT & D & I & C & CT \\
\hline 29. Tenho horas suficientes de sono. & DT & D & I & C & CT \\
\hline $\begin{array}{l}\text { 30. Estou satisfeito(a) com o meu curso de } \\
\text { araduacão. }\end{array}$ & DT & D & I & C & CT \\
\hline 31. Tenho tempo para meus amigos. & DT & $\mathrm{D}$ & I & C & CT \\
\hline 32. Não consigo cuidar da minha aparência. & DT & $\mathrm{D}$ & I & C & CT \\
\hline $\begin{array}{l}\text { 33. As expectativas que meus familiares têm } \\
\text { quanto ao meu desempenho no curso }\end{array}$ & DT & D & I & C & CT \\
\hline 34. Tenho me sentido ansioso(a) ultimamente. & DT & $\mathrm{D}$ & I & C & CT \\
\hline 35. O ambiente na minha faculdade é competitivo. & DT & $\mathrm{D}$ & I & C & CT \\
\hline 36. Estou satisfeito(a) com minha vida afetiva. & DT & $\mathrm{D}$ & I & C & CT \\
\hline $\begin{array}{l}\text { 37. As expectativas que tenho c } \\
\text { pioram minha qualidade de }\end{array}$ & DT & $\mathrm{D}$ & 1 & C & CT \\
\hline $\begin{array}{l}\text { italidade para desempenhar minhas } \\
\text { s de estudante. }\end{array}$ & DT & D & 1 & C & CT \\
\hline $\begin{array}{l}\text { 39. Não consigo assimilar } \\
\text { proaramático. }\end{array}$ & DT & D & I & C & CT \\
\hline 40. Consigo me alimentar adequadamente. & DT & $\mathrm{D}$ & I & C & CT \\
\hline 41. Pratico atividades físicas regularmente. & DT & $\mathrm{D}$ & I & C & CT \\
\hline $\begin{array}{l}\text { 42. Não tenho conseguido me concentrar direito } \\
\text { ultimamente. }\end{array}$ & DT & D & I & C & $c$ \\
\hline $\begin{array}{l}\text { 43. O meu curso de graduação me deixa } \\
\text { estressado(a). }\end{array}$ & DT & D & I & C & ( \\
\hline $\begin{array}{l}\text { 44. Estou satisfeito(a) com minhas condições de } \\
\text { moradia. }\end{array}$ & DT & D & I & C & CT \\
\hline $\begin{array}{l}\text { 45. Eu me sinto pressionado(a) por depender } \\
\text { financeiramente de minha família. }\end{array}$ & DT & $\mathrm{D}$ & I & C & CT \\
\hline
\end{tabular}




\section{mind garden}

\section{www. mindgarden.com}

To whom it may concem,

This letter is to grant permission for the above named person to use the following copright material;

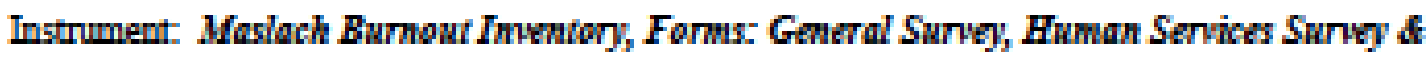
Educabrs Survy

\section{Anthors}

MBI-Genenal Survey, Wilmar B. Schaufeli, Michael P. Leiter, Christina Maslach $\boldsymbol{d}$ Susan E. Jackson

MBI-Human Services Survey: Christina Maslach o Susan E. Jackson

MRI-Educators Survey. Christina Maslach, Susan E. Jackson \& Richard L. Schwab

Copright: Copright 1986 by CPP, Inc. All rights resenved in all mediums

for his/her thesis resench.

Thre sample items from a single form of this instrument may be reproduced for inclusion in a proposal, thesis, or dissertation.

The entire instrument may not be included or reproduced at any time in any other published material.

Sincerely.



Robert Most

Mind Garden, Inc.

smw mindpredencur 
Utilize a escala apresentada a seguir para escolher o número mais apropriado para cada situação

$0-$ nunca

1 - uma vez ao ano ou menos

2 - uma vez ao mês ou menos

3 - algumas vezes ao mês

4 - uma vez por semana

5 - algumas vezes por semana

6 - todos os dias

\begin{tabular}{|c|c|c|c|c|c|c|c|}
\hline \multicolumn{8}{|c|}{ Exaustão Emocional } \\
\hline $\begin{array}{l}\text { 1. Sinto-me esgotado (a) emocionalmente } \\
\text { devido ao meu trabalho. }\end{array}$ & 0 & 1 & 2 & 3 & 4 & 5 & 6 \\
\hline \multicolumn{8}{|c|}{ Despersonalização } \\
\hline $\begin{array}{l}\text { 5. Creio que trato algumas pessoas como } \\
\text { se fossem objetos impessoais. }\end{array}$ & 0 & 1 & 2 & 3 & 4 & 5 & 6 \\
\hline \multicolumn{8}{|c|}{ Realização Pessoal } \\
\hline $\begin{array}{l}\text { 18. Sinto-me estimulado (a) depois de } \\
\text { trabalhar em contato com as pessoas. }\end{array}$ & 0 & 1 & 2 & 3 & 4 & 5 & 6 \\
\hline
\end{tabular}

\section{Escala de Sonolência Diurna de Epworth (ESS)}

Qual a probabilidade de você "cochilar" ou adormecer nas situações apresentadas a seguir? Procure separar da condição de se sentir simplesmente cansado(a).

Responda pensando no seu modo de vida nas últimas semanas. Mesmo que você não tenha passado por alguma dessas situações recentemente, tente avaliar como se portaria frente a elas.

Utilize a escala apresentada a seguir para escolher o número mais apropriado para cada situação.

0 - Nenhuma chance de cochilar

1 - Pequena chance de cochilar

2 - Moderada chance de cochilar

3 - Alta chance de cochilar

\begin{tabular}{|l|c|c|c|c|}
\hline 1. Sentado e lendo. & 0 & 1 & 2 & 3 \\
\hline 2. Assistindo TV. & 0 & 1 & 2 & 3 \\
\hline 3. $\begin{array}{l}\text { Sentado, quieto, em um lugar público (por exemplo, em um } \\
\text { teatro, reunião ou palestra). }\end{array}$ & 0 & 1 & 2 & 3 \\
\hline $\begin{array}{l}\text { 4. Andando de carro por uma hora sem parar, como } \\
\text { passageiro. }\end{array}$ & 0 & 1 & 2 & 3 \\
\hline $\begin{array}{l}\text { Deitado para descansar à tarde, quando as circunstâncias } \\
\text { permitem. }\end{array}$ & 0 & 1 & 2 & 3 \\
\hline 6. Sentado e conversando com alguém. & 0 & 1 & 2 & 3 \\
\hline 7. Sentado quieto após o almoço sem bebida de álcool. & 0 & 1 & 2 & 3 \\
\hline 8. Em um carro parado no trânsito por alguns minutos. & 0 & 1 & 2 & 3 \\
\hline
\end{tabular}


Anexo D - VERAS News

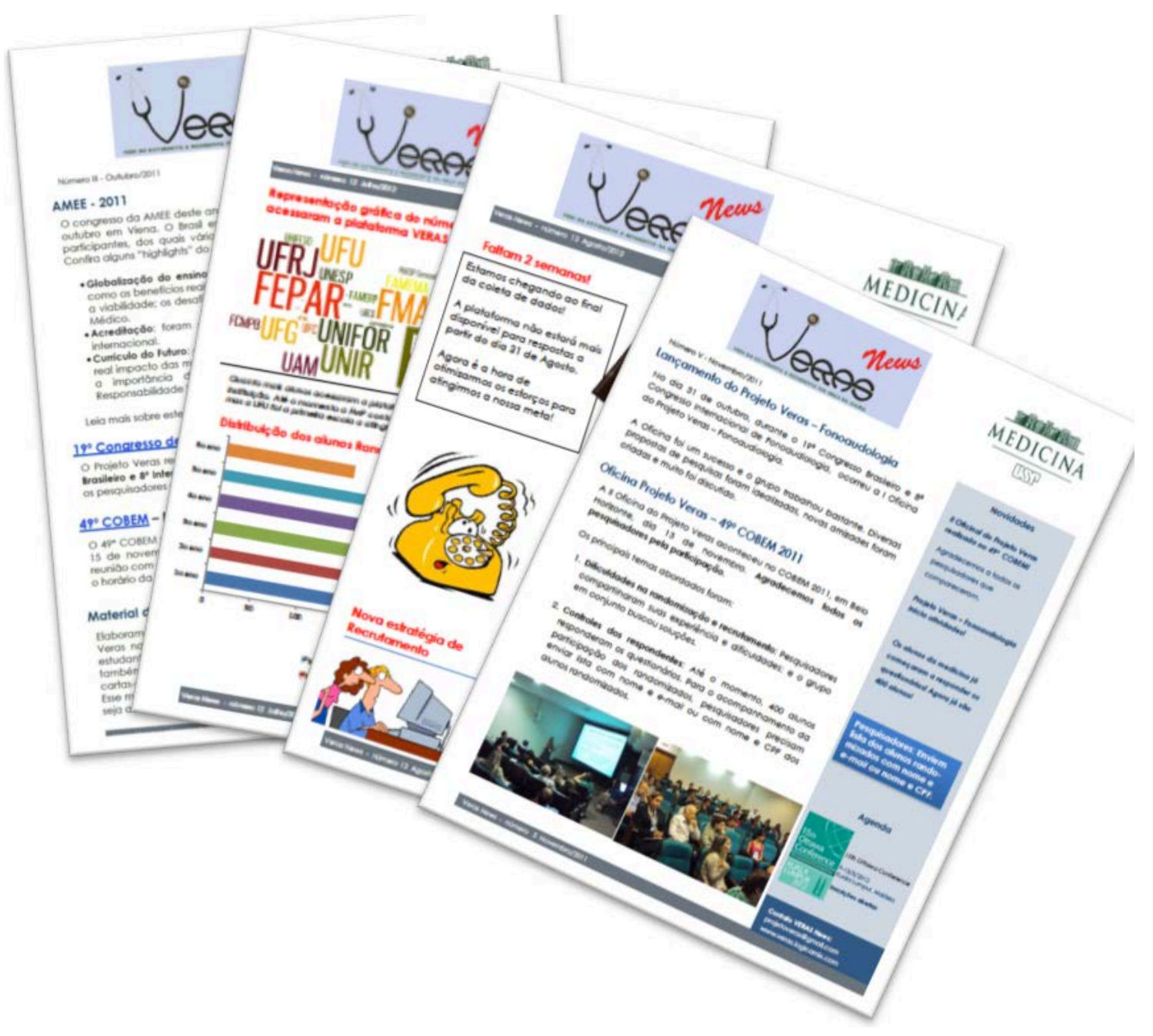


Anexo $\mathrm{E}$ - Modelo de tabela de números aleatórios utilizada para randomização dos respondentes

UFU

Semestre: 2a

\begin{tabular}{|c|c|c|c|c|c|c|c|c|c|}
\hline 32 & 49 & 17 & 41 & 45 & 3 & 43 & 14 & 20 & 38 \\
\hline 48 & 7 & 24 & 4 & 46 & 8 & 1 & 18 & 15 & 16 \\
\hline 6 & 29 & 42 & 12 & 34 & 28 & 13 & 40 & 50 & 23 \\
\hline 33 & 44 & 11 & 19 & 30 & 2 & 39 & 21 & 9 & 5 \\
\hline 37 & 36 & 10 & 35 & 22 & 27 & 25 & 26 & 31 & 47 \\
\hline
\end{tabular}

MEDICINA

TSSP

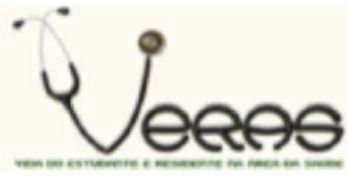

Projeto VERAS - Vida de Estudante e Residente na Area da Saúde

Instituição: $\quad$ FMABC

Randomização dos alunos do primeiro ano.

Número de alunos: 120

Números extras: 12

\begin{tabular}{|c|c|c|c|c|c|c|c|c|c|}
\hline 19 & 46 & 33 & 69 & 95 & 99 & 44 & 3 & 72 & 57 \\
\hline 17 & 94 & 52 & 35 & 73 & 105 & 119 & 21 & 49 & 111 \\
\hline 53 & 77 & 59 & 106 & 101 & 82 & 91 & 43 & 74 & 130 \\
\hline 125 & 22 & 63 & 118 & 121 & 98 & 6 & 129 & 114 & 26 \\
\hline 108 & 27 & 104 & 117 & 80 & 55 & 112 & 128 & 8 & 122 \\
\hline 116 & 25 & 12 & 54 & 66 & 90 & 60 & 124 & 75 & 68 \\
\hline 45 & 127 & 83 & 32 & 120 & 109 & 48 & 50 & 96 & 7 \\
\hline 88 & 61 & 89 & 14 & 93 & 16 & 78 & 9 & 67 & 81 \\
\hline 107 & 5 & 76 & 37 & 40 & 28 & 34 & 97 & 64 & 85 \\
\hline 86 & 87 & 13 & 41 & 1 & 4 & 123 & 70 & 10 & 84 \\
\hline 103 & 56 & 38 & 30 & 2 & 47 & 115 & 79 & 39 & 58 \\
\hline 110 & 51 & 42 & 24 & 113 & 100 & 92 & 62 & 29 & 132 \\
\hline 31 & 11 & 71 & 23 & 18 & 15 & 36 & 65 & 20 & 131 \\
\hline 126 & 102 & & & & & & &
\end{tabular}




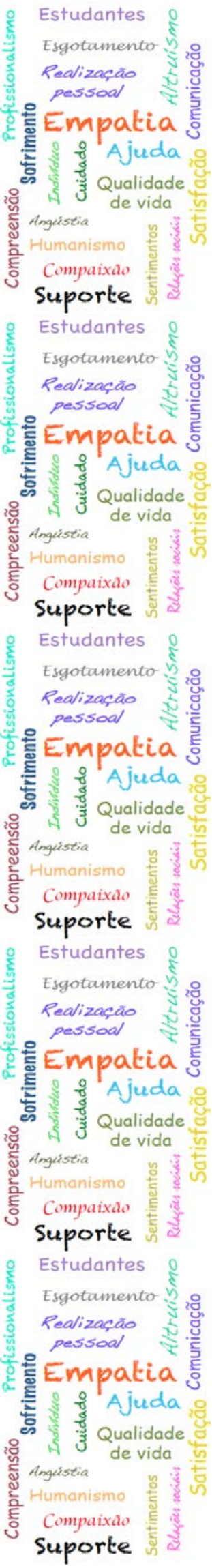

\section{REFERÊNCIAS}


Aaronson N, Alonso J, Burnam A, Lohr KN, Patrick DL, Perrin E, et al. Assessing health status and quality-of-life instruments: Attributes and review criteria. Qual Life Res. 2002;11(3):193-205.

Abdulghani HM, Alrowais NA, Bin-Saad NS, Al-Subaie NM, Haji AMA, Alhaqwi Al. Sleep disorder among medical students: Relationship to their academic performance. Med Teach. 2012;34(s1):S37-41.

Alimoglu MK, Gurpinar E, Mamakli S, Aktekin M. Ways of coping as predictors of satisfaction with curriculum and academic success in medical school. Adv Physiol Educ. 2011;35(1):33-8.

Almeida JL, Schramm FR. Paradigm shift, metamorphosis of medical ethics, and the rise of bioethics. Cad Saude Publica. 1999;15(Suppl 1):15-25.

Alóe F, Pedroso A, Tavares SM. Epworth Sleepiness Scale outcome in 616 Brazilian medical students. Arq Neuropsiquiatr. 1997;55(2):220-6.

American Board of Internal Medicine (ABIM). Subcommittee on Evaluation of humanistic qualities in the internist. Evaluation of humanistic qualities in the internist. Ann Intern Med. 1983;99(5):720-4.

American Psychological Association. Publication Manual of the American Psychological Association. 6th ed. Washington, DC: American Psycological Association; 2010.

Arnold L. Assessing professional behavior: yesterday, today, and tomorrow. Acad Med. 2002;77(6):502-15.

Arora S, Ashrafian H, Davis R, Athanasiou T, Darzi A, Sevdalis N. Emotional intelligence in medicine: a systematic review through the context of the ACGME competencies. Med Educ. 2010;44(8):749-64.

Babaria P, Abedin S, Nunez-Smith M. The effect of gender on the clinical clerkship experiences of female medical students: results from a qualitative study. Acad Med. 2009;84(7):859-66.

Banhiran W, Assanasen P, Nopmaneejumruslers C, Metheetrairut C. Epworth sleepiness scale in obstructive sleep disordered breathing: the reliability and validity of the Thai version. Sleep Breath. 2011;15(3):571-7.

Bar-On R. The Bar-On model of emotional-social intelligence (ESI). Psicothema. 2006;18 Suppl:13-25.

Batson CD, Fultz J, Schoenrade PA. Distress and empathy: two qualitatively distinct vicarious emotions with different motivational consequences. $J$ Pers. 1987;55(1):19-39.

Beiske KK, Kjelsberg FN, Ruud EA, Stavem K. Reliability and validity of a Norwegian version of the Epworth sleepiness scale. Sleep Breath. 2009;13(1):65-72. 
Bellini LM. Variation of Mood and Empathy During Internship. JAMA. 2002;287(23):3143-6.

Benevides-Pereira AMT. Burnout: O processo de adoecer pelo trabalho. In: Benevides-Pereira AMT, organizadora. Burnout: Quando o trabalho ameaça o bem-estar do trabalhador. $4^{\text {a }}$ ed. São Paulo: Casa do Psicólogo; 2010. p.21-91.

Benevides-Pereira AMT. Maslach Burnout Inventory e suas adaptações para o Brasil. In: XXXII Reunião Anual de Psicologia; 2001; Rio de Janeiro. Rio de Janeiro; 2001. v.1, p.84-5.

Berlim MT, Pavanello DP, Caldieraro MA, Fleck MP. Reliability and validity of the WHOQOL BREF in a sample of Brazilian outpatients with major depression. Qual Life Res. 2005;14(2):561-4.

Bertolazi AN, Fagondes SC, Hoff LS, Dartora EG, Miozzo IC, de Barba ME, et al. Validation of the Brazilian Portuguese version of the Pittsburgh Sleep Quality Index. Sleep Med. 2011;12(1):70-5.

Bertolazi AN, Fagondes SC, Hoff LS, Pedro VD, Menna Barreto SS, Johns MW. Portuguese-language version of the Epworth sleepiness scale: validation for use in Brazil. J Bras Pneumol. 2009;35(9):877-83.

Bickel J. Gender equity in undergraduate medical education: a status report. J Womens Health Gend Based Med. 2001;10(3):261-70.

Blanch-Hartigan D, Hall JA, Roter DL, Frankel RM. Gender bias in patients' perceptions of patient-centered behaviors. Patient Educ Couns. 2010;80(3):315-20.

Bleakley A. Gender matters in medical education. Med Educ. 2013;47(1):59-70.

Bloch KE, Schoch OD, Zhang JN, Russi EW. German version of the Epworth Sleepiness Scale. Respiration. 1999;66(5):440-7.

Boleyn-Fitzgerald P. Care and the problem of pity. Bioethics. 2003;17(1):1-20.

Bombeke K, Van Roosbroeck S, De Winter B, Debaene L, Schol S, Van Hal G, et al. Medical students trained in communication skills show a decline in patientcentred attitudes: an observational study comparing two cohorts during clinical clerkships. Patient Educ Couns. 2011;84(3):310-8.

Bosi E. Memória e sociedade: lembranças de velhos. 2a ed. São Paulo: Companhia das Letras; 1994.

Brasil. Conselho Nacional de Educação. Câmara de Educação Superior. RESOLUÇÃO CNE/CES No 4, DE 7 DE NOVEMBRO DE 2001. Institui Diretrizes Curriculares Nacionais do Curso de Graduação em Medicina. Brasília: 2001. 
Brazeau CM, Schroeder R, Rovi S, Boyd L. Relationships between medical student burnout, empathy, and professionalism climate. Acad Med. 2010;85(10 Suppl):S33-6.

Bullinger M. Assessing health related quality of life in medicine. An overview over concepts, methods and applications in international research. Restor Neurol Neurosci. 2002;20(3-4):93-101.

Burks DJ, Kobus AM. The legacy of altruism in health care: the promotion of empathy, prosociality and humanism. Med Educ. 2012;46(3):317-25.

Carifio J, Perla R. Resolving the 50-year debate around using and misusing Likert scales. Med Educ. 2008;42(12):1150-2.

Carifio J, Perla RJ. Ten Common Misunderstandings, Misconceptions, Persistent Myths and Urban Legends about Likert Scales and Likert Response Formats and their Antidotes. J. Social Sci. 2007;3(3):106-16.

Carlotto MS, Câmara SG. Características psicométricas do Maslach Burnout Inventory Student Survey (MBI-SS) em estudantes universitários brasileiros. Psico-USF. 2006;11(2):167-73.

Carr AJ, Higginson IJ. Are quality of life measures patient centred? BMJ. 2001;322(7298):1357-60.

Carr PL, Ash AS, Friedman RH, Scaramucci A, Barnett RC, Szalacha L, et al. Relation of family responsibilities and gender to the productivity and career satisfaction of medical faculty. Ann Intern Med. 1998;129(7):532-8.

Castro MAG, Oliveira MAS, Miguel AC, Araujo RB. WHOQOL-BREF psychometric properties in a sample of smokers. Rev Bras Psiquiatr. 2007;29(3):254-7.

Chandavarkar U, Azzam A, Mathews CA. Anxiety symptoms and perceived performance in medical students. Depress Anxiety. 2007;24(2):103-11.

Chapin FS. Preliminary standardization of a social insight scale. Am Sociol Rev. 1942;7(2):214-28.

Chen D, Lew R, Hershman W, Orlander J. A cross-sectional measurement of medical student empathy. J Gen Intern Med. 2007;22(10):1434-8.

Chen NH, Johns MW, Li HY, Chu CC, Liang SC, Shu YH, et al. Validation of a Chinese version of the Epworth sleepiness scale. Qual Life Res. 2002;11(8):817-21.

Cheng Y, Chou KH, Decety J, Chen IY, Hung D, Tzeng OJL, et al. Sex differences in the neuroanatomy of human mirror-neuron system: a voxel-based morphometric investigation. Neuroscience. 2009;158(2):713-20. 
Cherry MG, Fletcher I, O'Sullivan $\mathrm{H}$, Shaw N. What impact do structured educational sessions to increase emotional intelligence have on medical students? BEME Guide No. 17. Med Teach. 2012;34(1):11-9.

Chica-Urzola HL, Escobar-Cordoba F, Eslava-Schmalbach J. [Validating the Epworth sleepiness scale]. Rev Salud Publica (Bogota). 2007;9(4):558-67.

Chiner E, Arriero JM, Signes-Costa J, Marco J, Fuentes I. [Validation of the Spanish version of the Epworth Sleepiness Scale in patients. Arch Bronconeumol. 1999;35(9):422-7.

Cochran W. Sampling techniques. 3rd ed. New York: John Wiley \& Sons; 1986.

Cohen J. Statistical power analysis for the behavioral sciences. 2nd ed: Lawrence Erlbaum Associates; 1988.

Colliver Ja, Conlee MJ, Verhulst SJ, Dorsey JK. Reports of the decline of empathy during medical education are greatly exaggerated: a reexamination of the research. Acad Med. 2010;85(4):588-93.

Coren S. Ladrões de Sono. Tradução de Regina Gomes de Souza. São Paulo: Cultura Editores Associados; 1998.

Costa EF, Santos SA, Santos AT, Melo EV, Andrade TM. Burnout Syndrome and associated factors among medical students: a cross-sectional study. Clinics (Sao Paulo). 2012a;67(6):573-80.

Costa FD, Azevedo RCS. Empatia, Relação Médico-paciente e Formação em Medicina: um Olhar Qualitativo. Rev Bras Educ Med. 2010;34(2):261-9.

Costa $\mathrm{P}$, Magalhaes E, Costa MJ. A latent growth model suggests that empathy of medical students does not decline over time. Adv Health Sci Educ Theory Pract. 2012b Jul 4. [Epub ahead of print].

Cramer JA, ILAE Subcommission on Outcome Measurement in Epilepsy. Principles of health-related quality of life: Assessment in clinical trials. Epilepsia. 2002;43(9):1084-95.

Cronbach LJ. Coefficient alpha and the internal structure of tests. Psychometrika. 1951;16(3):297-334.

Cumming G. Understanding the new statistics: effect sizes, confidence intervals, and meta-analysis. New York: Routledge Taylor \& Francis Group; 2012.

Dahlin ME, Runeson B. Burnout and psychiatric morbidity among medical students entering clinical training: a three year prospective questionnaire and interview-based study. BMC Med Educ. 2007;7:6.

Davis $\mathrm{MH}$. A Multidimensional Approach to Individual Differences in Empathy. JSAS Catalog of Selected Documents in Psychology. 1980;10. 
Davis MH. Empathy: a social psychological approach. Madison: Brown \& Benchmark Publishers; 1996. (Social Psychological Series).

Davis $\mathrm{MH}$. Measuring individual differences in empathy: Evidence for a multidimensional approach. J Pers Soc Psychol. 1983;44(1):113-26.

de Leval N. Quality of life and depression: symmetry concepts. Qual Life Res. 1999;8(4):283-91.

Decety J, Ickes WJ, editores. The social neuroscience of empathy. Cambrigde, Massachusetts: The MIT Press; 2009. (Social Neuroscience Series).

Di Lillo M, Cicchetti A, Lo Scalzo A, Taroni F, Hojat M. The Jefferson Scale of Physician Empathy: preliminary psychometrics and group comparisons in Italian physicians. Acad Med. 2009;84(9):1198-202.

Dias M, Pagnin D, de Queiroz Pagnin V, Reis RL, Olej B. Effects of electroacupuncture on stress-related symptoms in medical students: a randomised controlled pilot study. Acupunct Med. 2012;30(2):89-95.

DiLalla LF, Hull SK, Dorsey JK. Effect of gender, age, and relevant course work on attitudes toward empathy, patient spirituality, and physician wellness. Teach Learn Med. 2004;16(2):165-70.

Dressler WW. The social and cultural context of coping: action, gender and symptoms in a southern black community. Soc Sci Med. 1985;21(5):499-506.

Dymond RF. Personality and empathy. J Consult Psychol. 1950;14(5):343-50.

Dyrbye LN, Harper W, Durning SJ, Moutier C, Thomas MR, Massie Jr FS, et al. Patterns of distress in US medical students. Med Teach. 2011a;33(10):834-9.

Dyrbye LN, Harper W, Moutier C, Durning SJ, Power DV, Massie FS, et al. A multi-institutional study exploring the impact of positive mental health on medical students' professionalism in an era of high burnout. Acad Med. 2012;87(8):1024-31.

Dyrbye LN, Massie FS, Eacker A, Harper W, Power D, Durning SJ, et al. Relationship between burnout and professional conduct and attitudes among US medical students. JAMA. 2010a;304(11):1173-80.

Dyrbye LN, Schwartz A, Downing SM, Szydlo DW, Sloan JA, Shanafelt TD. Efficacy of a brief screening tool to identify medical students in distress. Acad Med. 2011b;86(7):907-14.

Dyrbye LN, Szydlo DW, Downing SM, Sloan Ja, Shanafelt TD. Development and preliminary psychometric properties of a well-being index for medical students. BMC Med Educ. 2010b;10:8. 
Dyrbye LN, Thomas MR, Harper W, Massie FS, Jr., Power DV, Eacker A, et al. The learning environment and medical student burnout: a multicentre study. Med Educ. 2009;43(3):274-82.

Dyrbye LN, Thomas MR, Huntington JL, Lawson KL, Novotny PJ, Sloan JA, et al. Personal life events and medical student burnout: a multicenter study. Acad Med. 2006a;81(4):374-84.

Dyrbye LN, Thomas MR, Huschka MM, Lawson KL, Novotny PJ, Sloan JA, et al. A multicenter study of burnout, depression, and quality of life in minority and nonminority US medical students. Mayo Clin Proc. 2006b;81(11):1435-42.

Dyrbye LN, Thomas MR, Massie FS, Power DV, Eacker A, Harper W, et al. Burnout and suicidal ideation among U.S. medical students. Ann Intern Med. 2008;149(5):334-41.

Dyrbye LN, Thomas MR, Power DV, Durning S, Moutier C, Massie FS, Jr., et al. Burnout and serious thoughts of dropping out of medical school: a multiinstitutional study. Acad Med. 2010c;85(1):94-102.

Eisenberg N, Lennon R. Sex differences in empathy and related capacities. Psychol Bull. 1983;94(1):100-31.

Eller T, Aluoja A, Vasar V, Veldi M. Symptoms of anxiety and depression in Estonian medical students with sleep problems. Depress Anxiety. 2006;23(4):250-6.

Ellis PD. The essential guide to effect sizes: Statistical power, meta-analysis, and the interpretation of research results. Cambrigde: Cambrigde University Press; 2010.

Epstein RM, Hundert EM. Defining and assessing professional competence. JAMA. 2002;287(2):226-35.

Falcone EMO, Ferreira MC, Luz RCM, Fernandes CS, Faria CdA, D'Augustin JF, et al. Inventário de Empatia (I.E.): desenvolvimento e validação de uma medida brasileira. Aval. psicol. 2008;7(3):321-34.

Fleck MP, Louzada S, Xavier M, Chachamovich E, Vieira G, Santos L, et al. [Application of the Portuguese version of the abbreviated instrument of quality life WHOQOL-bref]. Rev Saude Publica. 2000;34(2):178-83.

Frenk J, Chen L, Bhutta ZA, Cohen J, Crisp N, Evans T, et al. Health professionals for a new century: transforming education to strengthen health systems in an interdependent world. Lancet. 2010;376(9756):1923-58.

Freud S. Lecture XXXIII: Femininity. In: Fiorini LG, Rose GA-S, editores. On Freud's Femininity. London: Karnac; 2010. (Contemporary Freud: Turning Points and Critical Issues). 
Freudenberger HJ. Staff burn-out syndrome in alternative institutions. Psychotherapy (Chic). 1975;12(1):73-82.

Galán F, Sanmartín A, Polo J, Giner L. Burnout risk in medical students in Spain using the Maslach Burnout Inventory-Student Survey. Int Arch Occup Environ Health. 2011;84(4):453-9.

Gandek B, Ware JE, Jr., Aaronson NK, Alonso J, Apolone G, Bjorner J, et al. Tests of data quality, scaling assumptions, and reliability of the SF-36 in eleven countries: results from the IQOLA Project. International Quality of Life Assessment. J Clin Epidemiol. 1998;51(11):1149-58.

Garratt A, Schmidt L, Mackintosh A, Fitzpatrick R. Quality of life measurement: bibliographic study of patient assessed health outcome measures. BMJ. 2002;324(7351):1417.

Gelhaus P. The desired moral attitude of the physician: (I) empathy. Med Health Care Philos. 2012;15(2):103-13.

General Medical Council. Tomorrow's Doctors: Outcomes and standards for undergraduate medical education. London: General Medical Council, 2009.

Gleichgerrcht E, Decety J. Empathy in clinical practice: how individual dispositions, gender, and experience moderate empathic concern, burnout, and emotional distress in physicians. PLoS One. 2013;8(4):e61526.

Goleman D. Inteligência emocional. Rio de Janeiro: Objetiva; 1995.

Gorenstein C, Andrade L. Validation of a Portuguese version of the Beck Depresion Inventory and the Sate-Trait Anxiety Inventory in Brazilian subjects. Braz J Med Biol Res. 1996;29(4):453-7.

Gruhn D, Rebucal K, Diehl M, Lumley M, Labouvie-Vief G. Empathy across the adult lifespan: Longitudinal and experience-sampling findings. Emotion. 2008;8(6):753-65.

Gurpinar E, Alimoglu MK, Mamakli S, Aktekin M. Can learning style predict student satisfaction with different instruction methods and academic achievement in medical education? Adv Physiol Educ. 2010;34(4):192-6.

Guthrie E, Black D, Bagalkote H, Shaw C, Campbell M, Creed F. Psychological stress and burnout in medical students: a five-year prospective longitudinal study. J R Soc Med. 1998;91(5):237-43.

Guyatt GH, Feeny DH, Patrick DL. Measuring health-related quality of life. Ann Intern Med. 1993;118(8):622-9.

Haas JS, Cook EF, Puopolo AL, Burstin HR, Cleary PD, Brennan TA. Is the professional satisfaction of general internists associated with patient satisfaction? J Gen Intern Med. 2000;15(2):122-8. 
Hafferty FW. Beyond curriculum reform: confronting medicine's hidden curriculum. Acad Med. 1998;73(4):403-7.

Hair Jr JF, Black WC, Babin BJ, Anderson RE, Tatham RL. Análise Multivariada de Dados. Tradução de Adonai Schlup Sant'Anna. 6a ed. São Paulo: Artmed; 2009.

Hamilton S, Fagot BI. Chronic stress and coping styles: a comparison of male and female undergraduates. J Pers Soc Psychol. 1988;55(5):819-23.

Handford C, Lemon J, Grimm MC, Vollmer-Conna U. Empathy as a function of clinical exposure - reading emotion in the eyes. PLoS One. 2013;8(6):e65159.

Harden RM, Crosby JR, Davis MH, Friedman M. AMEE Guide No. 14: Outcome-based education: Part 5-From competency to meta-competency: a model for the specification of learning outcomes. Med Teach. 1999;21(6):54652.

Harrison Y, Horne JA. The impact of sleep deprivation on decision making: a review. J Exp Psychol Appl. 2000;6(3):236-49.

Hassed C, de Lisle S, Sullivan G, Pier C. Enhancing the health of medical students: outcomes of an integrated mindfulness and lifestyle program. Adv Health Sci Educ Theory Pract. 2009;14(3):387-98.

Heaton K, Anderson D. A psychometric analysis of the Epworth Sleepiness Scale. J Nurs Meas. 2007;15(3):177-88.

Hemmerdinger JM, Stoddart SDR, Lilford RJ. A systematic review of tests of empathy in medicine. BMC Med Educ. 2007;7:24.

Henning MA, Krageloh CU, Hawken SJ, Zhao Y, Doherty I. The quality of life of medical students studying in New Zealand: a comparison with nonmedical students and a general population reference group. Teach Learn Med. 2012;24(4):334-40.

Hillis JM, Perry WR, Carroll EY, Hibble BA, Davies MJ, Yousef J. Painting the picture: Australasian medical student views on wellbeing teaching. Med J Aust. 2010;192(4):188-90.

Hoffman ML. Personality and social development. Annu Rev Psychol. 1977;28:295-321.

Hojat M, Glaser K, Xu G, Veloski JJ, Christian EB. Gender comparisons of medical students' psychosocial profiles. Med Educ. 1999;33(5):342-9.

Hojat M, Gonnella JS, Mangione S, Nasca TJ, Veloski JJ, Erdmann JB, et al. Empathy in medical students as related to academic performance, clinical competence and gender. Med Educ. 2002;36(6):522-7. 
Hojat M, Mangione S, Kane GC, Gonnella JS. Relationships between scores of the Jefferson Scale of Physician Empathy (JSPE) and the Interpersonal Reactivity Index (IRI). Med Teach. 2005;27(7):625-8.

Hojat M, Mangione S, Nasca TJ, Cohen MJM, Gonnella JS, Erdmann JB, et al. The Jefferson Scale of Physician Empathy: Development and Preliminary Psychometric Data. Educ Psychol Meas. 2001;61(2):349-65.

Hojat M, Mangione S, Nasca TJ, Rattner S, Erdmann JB, Gonnella JS, et al. An empirical study of decline in empathy in medical school. Med Educ. 2004;38(9):934-41.

Hojat M, Vergare MJ, Maxwell K, Brainard G, Herrine SK, Isenberg GA, et al. The devil is in the third year: a longitudinal study of erosion of empathy in medical school. Acad Med. 2009;84(9):1182-91.

Hojat M. Empathy in Patient Care: Antecedents, Development, Measurement, and Outcomes. New York: Springer; 2007.

Holmes W, Bix B, Shea J. SF-20 score and item distributions in a human immunodeficiency virus-seropositive sample. Med Care. 1996;34(6):562-9.

Ickes W, Gesn PR, Graham T. Gender differences in empathic accuracy: Differential ability or differential motivation? Pers Relatsh. 2000;7(1):95-110.

Izci B, Ardic S, Firat H, Sahin A, Altinors M, Karacan I. Reliability and validity studies of the Turkish version of the Epworth Sleepiness. Sleep Breath. 2008;12(2):161-8.

Johns M, Hocking B. Daytime sleepiness and sleep habits of Australian workers. Sleep. 1997;20(10):844-9.

Johns MW. A new method for measuring daytime sleepiness: the Epworth sleepiness scale. Sleep. 1991;14(6):540-5.

Johns MW. Reliability and factor analysis of the Epworth Sleepiness Scale. Sleep. 1992;15(4):376-81.

Johns MW. Sleepiness in different situations measured by the Epworth Sleepiness Scale. Sleep. 1994;17(8):703-10.

Johnson AK, Scott CS. Relationship between early clinical exposure and firstyear students' attitudes toward medical education. Acad Med. 1998;73(4):4302.

Kaminska M, Jobin V, Mayer P, Amyot R, Perraton-Brillon M, Bellemare F. The Epworth Sleepiness Scale: self-administration versus administration by the physician, and validation of a French version. Can Respir J. 2010;17(2):e27-34. 
Kataoka HU, Koide N, Ochi K, Hojat M, Gonnella JS. Measurement of empathy among Japanese medical students: psychometrics and score differences by gender and level of medical education. Acad Med. 2009;84(9):1192-7.

Kerr WA, Speroff BJ. Validation and evaluation of the empathy test. J Gen Psychol. 1954;50(2):269-76.

Kiessling C, Schubert B, Scheffner D, Burger W. First year medical students' perceptions of stress and support: a comparison between reformed and traditional track curricula. Med Educ. 2004;38(5):504-9.

Kilminster S, Downes J, Gough B, Murdoch-Eaton D, Roberts T. Women in medicine - is there a problem? A literature review of the changing gender composition, structures and occupational cultures in medicine. Med Educ. 2007;41(1):39-49.

Kjeldstadli K, Tyssen R, Finset A, Hem E, Gude T, Gronvold NT, et al. Life satisfaction and resilience in medical school--a six-year longitudinal, nationwide and comparative study. BMC Med Educ. 2006;6:48.

Koller SH, Camino C, Ribeiro J. Adaptação e validação interna de duas escalas de empatia para uso no Brasil. Estud. psicol. (Campinas). 2001;18(3):43-53.

Kopitovic I, Trajanovic N, Prodic S, Drvenica MJ, llic M, Kuruc V, et al. The Serbian version of the Epworth Sleepiness Scale. Sleep Breath. 2011;15(4):775-80.

Krägeloh CU, Henning MA, Hawken SJ, Zhao Y, Shepherd D, Billington R. Validation of the WHOQOL-BREF quality of life questionnaire for use with medical students. Educ Health (Abingdon). 2011;24(2):545.

Krupat E, Frankel R, Stein T, Irish J. The Four Habits Coding Scheme: validation of an instrument to assess clinicians' communication behavior. Patient Educ Couns. 2006;62(1):38-45.

Lambert TW, Goldacre MJ, Turner G. Career choices of United Kingdom medical graduates of 1999 and 2000: questionnaire surveys. BMJ. 2003;326(7382):194-5.

Lamonica EL. Construct-validity of an empathy instrument. Res Nurs Health. 1981;4(4):389-400.

Lampert JB, Costa NMdSC, Perim GL. Tendências de Mudanças em um Grupo de Escolas Médicas Brasileiras. Rev Bras Educ Med. 2009;33(1 Suppl 1):1934.

Lazarus RS. Coping theory and research: past, present, and future. Psychosom Med. 1993;55(3):234-47.

Linn LS, DiMatteo MR, Cope DW, Robbins A. Measuring physicians' humanistic attitudes, values, and behaviors. Med Care. 1987;25(6):504-15. 
MacLeod RD, Parkin C, Pullon S, Robertson G. Early clinical exposure to people who are dying: learning to care at the end of life. Med Educ. 2003;37(1):51-8.

Magalhaes E, Costa P, Costa MJ. Empathy of medical students and personality: evidence from the Five-Factor Model. Med Teach. 2012;34(10):807-12.

Maslach C, Jackson SE, Leiter MP. Maslach Burnout Inventory Manual. 3rd ed. Palo Alto, CA: Consulting Psychologists Press; 1996.

Maslach C, Jackson SE. The measurement of experienced burnout. J Organ Behav. 1981;2(2):99-113.

Maslach C, Schaufeli WB, Leiter MP. Job burnout. Annu Rev Psychol. 2001;52:397-422.

McKinstry B. Are there too many female medical graduates? Yes. BMJ. 2008;336(7647):748.

Medical Professionalism Project. Medical professionalism in the new millennium: a physicians' charter. Lancet. 2002;359(9305):520-2.

Mehrabian A, Epstein N. A measure of emotional empathy. $J$ Pers. 1972;40(4):525-43.

Mercer SW, Maxwell M, Heaney D, Watt GC. The consultation and relational empathy (CARE) measure: development and preliminary validation and reliability of an empathy-based consultation process measure. Fam Pract. 2004;21(6):699-705.

Moffat KJ, McConnachie A, Ross S, Morrison JM. First year medical student stress and coping in a problem-based learning medical curriculum. Med Educ. 2004;38(5):482-91.

Moore M, Hofer S, McGee H, Ring L. Can the concepts of depression and quality of life be integrated using a time perspective? Health Qual Life Outcomes. 2005;3:1.

Neumann M, Edelhäuser F, Tauschel D, Fischer MR, Wirtz M, Woopen C, et al. Empathy decline and its reasons: a systematic review of studies with medical students and residents. Acad Med. 2011;86(8):996-1009.

Newton BW, Barber L, Clardy J, Cleveland E, O'Sullivan P. Is there hardening of the heart during medical school? Acad Med. 2008;83(3):244-9.

Nogueira-Martins LA. Atividade médica: fatores de risco para a saúde mental do médico. Rev. bras. clín. ter. 1991;20(9):355-64.

O'Sullivan $\mathrm{H}$, van Mook W, Fewtrell $\mathrm{R}$, Wass V. Integrating professionalism into the curriculum: AMEE Guide No. 61. Med Teach. 2012;34(2):e64-77. 
Oliveira Filho GR, Vieira JE, Schonhorst L. Psychometric properties of the Dundee Ready Educational Environment Measure (DREEM) applied to medical residents. Med Teach. 2005;27(4):343-7.

Parkerson GR, Jr., Broadhead WE, Tse CK. The health status and life satisfaction of first-year medical students. Acad Med. 1990;65(9):586-8.

Paro HB, Daud-Gallotti RM, Pinto RM, Tiberio IF, Martins MA. Brazilian version of the Jefferson Scale of Empathy: psychometric properties and factor analysis. BMC Med Educ. 2012;12(1):73.

Paro HB, Morales NM, Silva CH, Rezende $\mathrm{CH}$, Pinto RM, Morales RR, et al. Health-related quality of life of medical students. Med Educ. 2010;44(3):227-35.

Peabody FW. Landmark article March 19, 1927: The care of the patient. By Francis W. Peabody. JAMA. 1984;252(6):813-8.

Pell G. Use and misuse of Likert scales. Med Educ. 2005;39(9):97.

Pesce RP, Assis SG, Avanci JQ, Santos NC, Malaquias JC, Carvalhaes R. Adaptação transcultural, confiabilidade e validade da escala de resiliência. Cad Saude Publica. 2005;21(2):436-48.

Petrone L. Qualidade de vida e doenças psicossomáticas. Tradução de Lúcia Malagnino Petrone. São Paulo: Lemos Editorial; 1994.

Pigman GW. Freud and the history of empathy. Int J Psychoanal. 1995;76(Pt 2):237-56.

Quince TA, Parker RA, Wood DF, Benson JA. Stability of empathy among undergraduate medical students: a longitudinal study at one UK medical school. BMC Med Educ. 2011;11:90.

Rahimi-Madiseh M, Tavakol M, Dennick R, Nasiri J. Empathy in Iranian medical students: A preliminary psychometric analysis and differences by gender and year of medical school. Med Teach. 2010;32(11):e471-8.

Reed DA, Shanafelt TD, Satele DW, Power DV, Eacker A, Harper W, et al. Relationship of pass/fail grading and curriculum structure with well-being among. Acad Med. 2011;86(11):1367-73.

Risberg G, Johansson EE, Hamberg K. 'Important... but of low status': male education leaders' views on gender in medicine. Med Educ. 2011;45(6):613-24.

Risberg G, Johansson EE, Westman G, Hamberg K. Attitudes toward and experiences of gender issues among physician teachers: a survey study conducted at a university teaching hospital in Sweden. BMC Med Educ. 2008;8:10. 
Rocha GVM. Empatia. In: Gomide PIC, organizadora. Comportamento moral: uma proposta para o desenvolvimento das virtudes. Curitiba: Juruá Editora; 2010. p.69-80.

Rocha NS, Fleck MP. Validity of the Brazilian version of WHOQOL-BREF in depressed patients using Rasch modelling. Rev Saude Publica. 2009;43(1):147-53.

Rodrigues RN, Viegas CA, Abreu ESAA, Tavares P. Daytime sleepiness and academic performance in medical students. Arq Neuropsiquiatr. 2002;60(1):611.

Rogers CR. Empathic - unappreciated way of being. Couns Psychol. 1975;5(2):2-10.

Rogers CR. The necessary and sufficient conditions of therapeutic personality change. 1957. J Consult Clin Psychol. 1992;60(6):827-32.

Roh M-S, Hahm B-J, Lee DH, Suh DH. Evaluation of empathy among Korean medical students: a cross-sectional study using the Korean Version of the Jefferson Scale of Physician Empathy. Teach Learn Med. 2010;22(3):167-71.

Roh MS, Jeon HJ, Kim H, Cho HJ, Han SK, Hahm BJ. Factors influencing treatment for depression among medical students: a nationwide cross-sectional study in South Korea. Med Educ. 2009;43(2):133-9.

Rosal MC, Ockene IS, Ockene JK, Barrett SV, Ma Y, Hebert JR. A longitudinal study of students' depression at one medical school. Acad Med. 1997;72(6):542-6.

Roter DL, Hall JA, Aoki Y. Physician gender effects in medical communication: a meta-analytic review. JAMA. 2002;288(6):756-64.

Royal College of Physicians. Doctors in society: medical professionalism in a changing world. Report of a Working Party of the Royal College of Physicians of London. London: RCP; 2005.

Salovey P, Mayer JD. Emotional intelligence. Imagin Cogn Pers. 1989;9(3):185211.

Sampaio LR, Camino CPDS, Roazzi A. Revisão de aspectos conceituais, teóricos e metodológicos da empatia. Psicol., Ciênc. Prof. 2009;29(2):212-27.

Sampaio LR, Guimarães PRB, Camino CPdS, Formiga NS, Menezes IG. Estudos sobre a dimensionalidade da empatia: tradução e adaptação do Interpersonal Reactivity Index (IRI) Psico. 2011;42(1):67-76.

Sandøe P. Quality of life - three competing views. Ethical Theory Moral Pract. 1999;2(1):11-23. 
Schaufeli WB, Martínez IM, Marques Pinto A, Salanova M, Bakker AB. Burnout and engagement in university students: A cross-national study. J Cross Cult Psychol. 2002;33(5):464-81.

Schraiber LB; Gomes R; Couto MT. Homens e saúde na pauta da saúde coletiva. Ciênc. saúde colet. 2005;10(1):7-17.

Schraiber LB. O médico e seu trabalho: limites da liberdade. São Paulo: HUCITEC; 1993.

Schutte NS, Malouff JM, Bobik C, Coston TD, Greeson C, Jedlicka C, et al. Emotional intelligence and interpersonal relations. $J$ Soc Psychol. 2001;141(4):523-36.

Sen S, Kranzler HR, Krystal JH, Speller H, Chan G, Gelernter J, et al. A prospective cohort study investigating factors associated with depression. Arch Gen Psychiatry. 2010;67(6):557-65.

Shanafelt TD, West C, Zhao X, Novotny P, Kolars J, Habermann T, et al. Relationship Between Increased Personal Well-Being and Enhanced Empathy Among Internal Medicine Residents. J Gen Intern Med. 2005;20(7):612-7.

Siqueira JE. A bioética e a revisão dos códigos de conduta moral dos médicos no Brasil. Rev. bioét. (Impr.). 2008;16(1):85-95.

Sloan JA, Dueck A. Issues for statisticians in conducting analyses and translating results for quality of life end points in clinical trials. J Biopharm Stat. 2004;14(1):73-96.

Sloan JA, Loprinzi CL, Kuross SA, Miser AW, O'Fallon JR, Mahoney MR, et al. Randomized comparison of four tools measuring overall quality of life in patients with advanced cancer. J Clin Oncol. 1998;16(11):3662-73.

Smith DJ, Huntington J. Choosing the "correct" assessment tool. Curr Probl Cancer. 2006;30(6):272-82.

Smith SC, Lamping DL, Banerjee S, Harwood R, Foley B, Smith P, et al. Measurement of health-related quality of life for people with dementia: development of a new instrument (DEMQOL) and an evaluation of current methodology. Health Technol Assess. 2005;9(10):1-93.

Spielberger C, Gorsich R, Lushene R. IDATE - Inventário de Ansiedade Traço. Rio de Janeiro: CEPA; 1979.

Stepien KA, Baernstein A. Educating for empathy. A review. J Gen Intern Med. 2006;21(5):524-30.

Stock FS, Sisson MC, Grosseman S. Percepção de Estudantes de Medicina sobre Aprendizagem da Relação Médico-Paciente após Mudança Curricular. Rev Bras Educ Med. 2012;36(1):5-13. 
Stotland E, Dunn RE. Empathy, self-esteem, and birth order. J Abnorm Soc Psychol. 1963;66(6):532-40.

Stratton TD, Saunders JA, Elam CL. Changes in medical students' emotional intelligence: an exploratory study. Teach Learn Med. 2008;20(3):279-84.

Tempski P, Bellodi PL, Paro HB, Enns SC, Martins MA, Schraiber LB. What do medical students think about their quality of life? A qualitative study. BMC Med Educ. 2012a;12(1):106.

Tempski P, Perotta B, Pose RA, Vieira JE. A questionnaire on the quality of life of medical student. Med Educ. 2009;43(11):1107-8.

Temspki-Fiedler P. Avaliação da qualidade de vida do estudante de medicina e da influência exercida pela formação acadêmica [tese]. São Paulo: Faculdade de Medicina, Universidade de São Paulo; 2008.

The Medical School Objectives Writing Group. Learning objectives for medical student education - guidelines for medical schools: report I of the Medical School Objectives Project. Acad Med. 1999;74(1):13-8.

The Whoqol Group. Development of the World Health Organization WHOQOLBREF quality of life assessment. The WHOQOL Group. Psychol Med. 1998a;28(3):551-8.

The Whoqol Group. The World Health Organization quality of life assessment (WHOQOL): Position paper from the World Health Organization. Soc Sci Med. 1995;41(10):1403-9.

The Whoqol Group. The World Health Organization quality of life assessment (WHOQOL): Development and general psychometric properties. Soc Sci Med. 1998b;46(12):1569-85.

Thomas MR, Dyrbye LN, Huntington JL, Lawson KL, Novotny PJ, Sloan JA, et al. How do distress and well-being relate to medical student empathy? A multicenter study. J Gen Intern Med. 2007;22(2):177-83.

Tsara V, Serasli E, Amfilochiou A, Constantinidis T, Christaki P. Greek version of the Epworth Sleepiness Scale. Sleep Breath. 2004;8(2):91-5.

Tyssen R, Hem E, Gude T, Gronvold NT, Ekeberg O, Vaglum P. Lower life satisfaction in physicians compared with a general population sample: a 10year longitudinal, nationwide study of course and predictors. Soc Psychiatry Psychiatr Epidemiol. 2009;44(1):47-54.

Verbrugge LM. Gender and health: an update on hypotheses and evidence. $J$ Health Soc Behav. 1985;26(3):156-82.

Wear D. "Face-to-face with It": medical students' narratives about their end-oflife education. Acad Med. 2002;77(4):271-7. 
West CP, Tan AD, Habermann TM, Sloan JA, Shanafelt TD. Association of resident fatigue and distress with perceived medical errors. JAMA. 2009;302(12):1294-300.

West CP. Empathy, distress and a new understanding of doctor professionalism. Med Educ. 2012;46(3):243-4.

Willcock SM, Daly MG, Tennant CC, Allard BJ. Burnout and psychiatric morbidity in new medical graduates. Med J Aust. 2004;181(7):357-60.

Wilson JF, Johnson MM, Studts JL, Elam CL. Students' quality of life after a major curriculum change. Acad Med. 1996;71(10 Suppl):S40-2.

Wolf TM. Stress, coping and health: enhancing well-being during medical school. Med Educ. 1994;28(1):8-17.

World Federation for Medical Education. Basic Medical Education: WFME Global Standards for Quality Improvement. Copenagen: World Federation for Medical Education, 2003.

World Health Organization (WHO). Division of Mental Health and Prevention of Substance Abuse. WHOQOL: User Manual. Geneva: World Health Organization; 1998.

Zailinawati AH, Teng CL, Chung YC, Teow TL, Lee PN, Jagmohni KS. Daytime sleepiness and sleep quality among Malaysian medical students. Med $\mathrm{J}$ Malaysia. 2009;64(2):108-10.

Zhang Y, Qu B, Lun S, Wang D, Guo Y, Liu J. Quality of Life of Medical Students in China: A Study Using the WHOQOL-BREF. PLoS One. 2012;7(11):e49714. 




APÊNDICE 


\section{Apêndice A - Estudos multicêntricos em Educação Médica}

Realizamos uma revisão da literatura na base de dados do PubMed com os seguintes unitermos: "multicentric studies" [publication type] AND "students, medical" AND ("quality of life" OR "educational environment" OR "resilience, psychological" OR empathy OR anxiety OR depression OR "burnout, professional" OR "disorders of excessive somnolence"). Também acessamos os artigos relacionados que eram relevantes às variáveis do nosso estudo. Os principais desfechos investigados foram:

- número de respondentes;

- técnicas de amostragem;

- taxas de resposta;

- meio de coleta de dados;

- limitações do estudo

Não limitamos a pesquisa por língua ou data de publicação. Excluímos os estudos cujos sujeitos de pesquisa não eram estudantes de medicina ou aqueles que envolviam menos de três centros de pesquisa.

\section{Resultados}

A pesquisa resultou em 23 artigos da base de dados PubMed. Desses, excluímos sete estudos: cinco por não envolverem estudantes de medicina e dois por envolverem apenas dois centros de pesquisa. Incluímos dois artigos relacionados devido à relevância para as variáveis do nosso estudo.

As tabelas a seguir apresentam os principais resultados dos artigos 
analisados na revisão. Identificamos dois importantes grupos de pesquisa em educação médica que merecem destaque pelo número de estudantes incluídos. O grupo asiático conseguiu a participação de 36 das 41 escolas médicas existentes na Coreia do Sul. A taxa de resposta dos estudos desse grupo foi de 52,2\%. O grupo norte-americano conta com a participação de sete centros de pesquisa em suas publicações e tem taxas de resposta que variam de $50 \%$ a $60 \%$. 


\begin{tabular}{|c|c|c|c|c|c|c|c|c|}
\hline \multicolumn{9}{|c|}{ América do Norte } \\
\hline Autores & $\begin{array}{c}\text { País } \\
\text { Número } \\
\text { Instituições }\end{array}$ & $\begin{array}{c}\text { Desenho } \\
\text { estudo } \\
\text { Tipo amostra }\end{array}$ & $\begin{array}{l}\text { Participan- } \\
\text { tes } \\
\text { (taxa de } \\
\text { resposta) }\end{array}$ & $\begin{array}{l}\text { Variáveis } \\
\text { estudadas }\end{array}$ & $\begin{array}{c}\text { Instrumentos } \\
\text { utilizados } \\
\text { (número de itens) }\end{array}$ & $\begin{array}{l}\text { Coleta de } \\
\text { dados } \\
\text { (ano) }\end{array}$ & Principais resultados & Limitações declaradas \\
\hline $\begin{array}{l}\text { Dyrbye et } \\
\text { al. }(2006 a) \\
\text { (1) }\end{array}$ & $\begin{array}{l}\text { EUA } \\
3 \text { instituições }\end{array}$ & $\begin{array}{l}\text { Transversal } \\
\text { População total }\end{array}$ & $\begin{array}{l}545 \\
\text { estudantes } \\
(50 \%)\end{array}$ & $\begin{array}{l}\text { Eventos } \\
\text { pessoais, } \\
\text { burnout, } \\
\text { qualidade de } \\
\text { vida, } \\
\text { depressão, uso } \\
\text { de álcool }\end{array}$ & $\begin{array}{l}\text { Sócio-demográfico- } \\
\text { inclui eventos } \\
\text { pessoais recentes, } \\
\text { MBI (22), PRIME-MD } \\
\text { (2), SF-8 (8), Alcohol } \\
\text { Users Disorders } \\
\text { Identification Test } \\
\text { (total itens = 118) }\end{array}$ & $\begin{array}{l}\text { Internet } \\
(2004)\end{array}$ & $\begin{array}{l}\text {-Maior prevalência de } \\
\text { depressão entre estudantes } \\
\text { do } 2^{\circ} \text { ano do curso } \\
\text {-Maior prevalência de burnout } \\
\text { nos anos mais avançados do } \\
\text { curso } \\
\text {-Eventos pessoais } \\
\text { importantes também } \\
\text { relacionam-se com burnout }\end{array}$ & $\begin{array}{l}\text { - Viés de resposta } \\
\text { - Desenho transversal } \\
\text {-Generalização dos resultados } \\
\text { - Não estudou possíveis eventos } \\
\text { pessoais }\end{array}$ \\
\hline $\begin{array}{l}\text { Dyrbye et } \\
\text { al. }(2006 \mathrm{~b}) \\
\text { (2) }\end{array}$ & $\begin{array}{l}\text { EUA } \\
3 \text { instituições }\end{array}$ & $\begin{array}{l}\text { Transversal } \\
\text { População total }\end{array}$ & $\begin{array}{l}545 \\
\text { estudantes } \\
(50 \%)\end{array}$ & $\begin{array}{l}\text { Burnout, } \\
\text { depressão, } \\
\text { qualidade de } \\
\text { vida, eventos } \\
\text { pessoais, } \\
\text { categorias } \\
\text { étnicas }\end{array}$ & $\begin{array}{l}\text { Sócio-demográfico } \\
\text { (inclui eventos } \\
\text { pessoais recentes, } \\
\text { satisfação com } \\
\text { carreira, relação com } \\
\text { colegas e estratégias } \\
\text { de enfrentamento), } \\
\text { MBI (22), PRIME-MD } \\
\text { (2), SF-8 (8), LASA } \\
\text { (10)(total itens = 118) }\end{array}$ & $\begin{array}{l}\text { Internet } \\
(2004)\end{array}$ & $\begin{array}{l}\text { Minoria não difere da maioria } \\
\text { quanto à depressão e } \\
\text { burnout, mas apresenta } \\
\text { menor realização pessoal e } \\
\text { pior qualidade de vida }\end{array}$ & $\begin{array}{l}\text {-Viés de resposta (maior \% de } \\
\text { não respondentes entre minoria) } \\
\text {-Minorias foram agrupadas em } \\
\text { categoria única } \\
\text {-Desenho transversal } \\
\text {-Generalização dos resultados }\end{array}$ \\
\hline $\begin{array}{l}\text { Thomas et } \\
\text { al. (2007) } \\
\text { (3) }\end{array}$ & $\begin{array}{l}\text { EUA } \\
3 \text { instituições }\end{array}$ & $\begin{array}{l}\text { Transversal } \\
\text { População total }\end{array}$ & $\begin{array}{l}545 \\
\text { estudantes } \\
(50 \%)\end{array}$ & $\begin{array}{l}\text { Empatia, } \\
\text { Burnout, } \\
\text { depressão, } \\
\text { qualidade de } \\
\text { vida }\end{array}$ & $\begin{array}{l}\text { Sócio-demográfico, } \\
\text { IRI (28), MBI (22), } \\
\text { PRIME-MD (2), LASA } \\
(10)(\text { total itens = 118) }\end{array}$ & $\begin{array}{l}\text { Internet } \\
\text { (2004) }\end{array}$ & $\begin{array}{l}\text {-Estudantes apresentam } \\
\text { maiores escores de empatia } \\
\text { cognitiva e emocional do que } \\
\text { população normativa } \\
\text {-Empatia está relacionada a } \\
\text { burnout e qualidade de vida }\end{array}$ & $\begin{array}{l}\text { - Viés de resposta } \\
\text { - Desenho transversal } \\
\text { - Pequena magnitude das } \\
\text { correlações } \\
\text {-Generalização dos resultados } \\
\text {-Uso de medidas de auto-relato } \\
\text { de empatia }\end{array}$ \\
\hline $\begin{array}{l}\text { Dyrbye et } \\
\text { al. }(2008) \\
(4)\end{array}$ & $\begin{array}{l}\text { EUA } \\
5 \text { Instituições } \\
\text { (2006-2007) } \\
7 \text { instituições } \\
\text { (2007) }\end{array}$ & $\begin{array}{l}\text { Coorte } \\
\text { longitudinal } \\
\text { (2006-2007) } \\
\text { Coorte } \\
\text { transversal } \\
(2007) \\
\text { População total } \\
\end{array}$ & $\begin{array}{l}1.321 \\
\text { estudantes } \\
(65 \%) \\
\\
2.248 \\
\text { estudantes } \\
(52,4 \%)\end{array}$ & $\begin{array}{l}\text { Ideação } \\
\text { suicida, } \\
\text { burnout, } \\
\text { depressão, } \\
\text { qualidade de } \\
\text { vida }\end{array}$ & $\begin{array}{l}\text { Sócio-demográfico } \\
\text { (inclui } 3 \text { itens sobre } \\
\text { ideação suicida), MBI } \\
\text { (22), PRIME-MD (2), } \\
\text { SF-8 (8) }\end{array}$ & $\begin{array}{l}\text { Internet } \\
(2006-2007)\end{array}$ & $\begin{array}{l}\text {-Burnout e pior qualidade de } \\
\text { vida estão relacionados a } \\
\text { maior risco de ideação suicida } \\
\text { - Nenhuma variável sócio- } \\
\text { demográfica relacionou-se } \\
\text { com ideação suicida } \\
\text { - Burnout crônico está } \\
\text { associado a maior risco de } \\
\text { ideação suicida }\end{array}$ & $\begin{array}{l}\text {-Viés de resposta } \\
\text { - Desenho transversal }\end{array}$ \\
\hline $\begin{array}{l}\text { Dyrbye et } \\
\text { al. (2009) } \\
\text { (5) }\end{array}$ & $\begin{array}{l}\text { EUA } \\
5 \text { instituições }\end{array}$ & $\begin{array}{l}\text { Transversal } \\
\text { População total }\end{array}$ & $\begin{array}{l}1.701 \\
\text { estudantes } \\
(55 \%)\end{array}$ & $\begin{array}{l}\text { Burnout, } \\
\text { ambiente de } \\
\text { ensino, eventos } \\
\text { pessoais }\end{array}$ & $\begin{array}{l}\text { Sócio-demográfico } \\
\text { (inclui itens sobre } \\
\text { eventos pessoais, } \\
\text { ambiente de ensino e } \\
\text { características dos } \\
\text { estágios), MBI (22) }\end{array}$ & $\begin{array}{l}\text { Internet } \\
\text { (2006) }\end{array}$ & $\begin{array}{l}\text {-Insatisfação com ambiente } \\
\text { de ensino e percepção de } \\
\text { apoio dos professores tem } \\
\text { forte associação com burnout } \\
\text { dos estudantes do } 1^{\circ} \text { e } 2^{\circ} \text { ano } \\
\text { do curso } \\
\text {-Entre os estudantes do } 3^{\circ} \text { e } \\
4^{\circ} \text { ano, insatisfação com }\end{array}$ & $\begin{array}{l}\text { - Viés de resposta } \\
\text { - Desenho transversal } \\
\text { - Não estudou possíveis fatores } \\
\text { relacionados }\end{array}$ \\
\hline
\end{tabular}




\begin{tabular}{|c|c|c|c|c|c|c|c|c|}
\hline \multicolumn{9}{|c|}{ América do Norte } \\
\hline Autores & $\begin{array}{c}\text { País } \\
\text { Número } \\
\text { Instituições }\end{array}$ & $\begin{array}{c}\text { Desenho } \\
\text { estudo } \\
\text { Tipo amostra }\end{array}$ & $\begin{array}{l}\text { Participan- } \\
\text { tes } \\
\text { (taxa de } \\
\text { resposta) }\end{array}$ & $\begin{array}{c}\text { Variáveis } \\
\text { estudadas }\end{array}$ & $\begin{array}{c}\text { Instrumentos } \\
\text { utilizados } \\
\text { (número de itens) }\end{array}$ & $\begin{array}{l}\text { Coleta de } \\
\text { dados } \\
\text { (ano) }\end{array}$ & Principais resultados & Limitações declaradas \\
\hline & & & & & & & $\begin{array}{l}\text { ambiente de ensino, } \\
\text { organização dos estágios e a } \\
\text { presença de ciniscmo entre } \\
\text { os residentes foram } \\
\text { associados com burnout }\end{array}$ & \\
\hline $\begin{array}{l}\text { Goebert et } \\
\text { al. (2009) } \\
\text { (6) }\end{array}$ & $\begin{array}{l}\text { EUA } \\
\text { Havaí } \\
6 \text { instituições }\end{array}$ & $\begin{array}{l}\text { Transversal } \\
\text { Amostra } \\
\text { conveniência }\end{array}$ & $\begin{array}{l}1.343 \\
\text { estudantes } \\
(95 \%) \\
\\
679 \\
\text { residentes } \\
(64 \%)\end{array}$ & $\begin{array}{l}\text { Sintomas } \\
\text { depressivos, } \\
\text { ideação suicida }\end{array}$ & $\begin{array}{l}\text { Sócio-demográfico } \\
\text { (inclui itens sobre } \\
\text { tratamento } \\
\text { psiquiátrico e história } \\
\text { familiar de } \\
\text { depressão), CES-D } \\
\text { (20), PRIME-MD (2) }\end{array}$ & $\begin{array}{l}\begin{array}{l}\text { Questionários } \\
\text { impressos }\end{array} \\
(2003-2004)\end{array}$ & $\begin{array}{l}\text {-Sintomas depressivos são } \\
\text { mais prevalentes entre } \\
\text { estudantes do que entre } \\
\text { residentes } \\
\text {-Sintomas depressivos são } \\
\text { mais prevalentes entre } \\
\text { estudantes do } 1^{\circ} \text { ao } 3^{\circ} \text { ano do } \\
\text { curso } \\
\text {-Maior ideação suicida entre } \\
\text { estudantes do } 4^{\mathrm{a}} \text { ano do } \\
\text { curso }\end{array}$ & $\begin{array}{l}\text { - Não avaliou o diagnóstico de } \\
\text { depressão } \\
\text { - Não investigou outras variáveis } \\
\text { relacionadas (álcool, drogas) } \\
\text { - Questionários de autorrelato } \\
\text { - Recall bias }\end{array}$ \\
\hline $\begin{array}{l}\text { Dyrbye et } \\
\text { al. }(2010) \\
(7)\end{array}$ & $\begin{array}{l}\text { EUA } \\
5 \text { Instituições } \\
\text { (2006-2007) } \\
7 \text { instituições } \\
\text { (2007) }\end{array}$ &  & $\begin{array}{l}2.248 \\
\text { estudantes } \\
(52,4 \%)\end{array}$ & $\begin{array}{l}\text { Pensamentos } \\
\text { de desistência } \\
\text { do curso, } \\
\text { burnout, } \\
\text { depressão, } \\
\text { qualidade de } \\
\text { vida, eventos } \\
\text { pessoais }\end{array}$ & $\begin{array}{l}\text { Sócio-demográfico } \\
\text { (inclui itens sobre } \\
\text { eventos pessoais } \\
\text { recentes e } \\
\text { pensamentos de } \\
\text { desistência do curso), } \\
\text { MBI (22), PRIME-MD } \\
\text { (2), SF-8 (8) }\end{array}$ & $\begin{array}{l}\text { Internet } \\
(2006-2007)\end{array}$ & $\begin{array}{l}\text {-Pensamentos de } \\
\text { desistência do curso tem } \\
\text { forte relação com medidas } \\
\text { de depressão, qualidade } \\
\text { de vida e burnout }\end{array}$ & $\begin{array}{l}\text { - Viés de resposta } \\
\text { - Desenho transversal }\end{array}$ \\
\hline $\begin{array}{l}\text { Dyrbye at } \\
\text { al. (2010) }\end{array}$ & $\begin{array}{l}\text { EUA } \\
7 \text { instituições }\end{array}$ & $\begin{array}{l}\text { Transversal } \\
\text { População total }\end{array}$ & $\begin{array}{l}2.682 \\
\text { estudantes } \\
(61 \%)\end{array}$ & $\begin{array}{l}\text { Atitudes } \\
\text { desonestas ou } \\
\text { anti-éticas } \\
\text { entre } \\
\text { estudantes, } \\
\text { burnout, } \\
\text { qualidade de } \\
\text { vida, } \\
\text { depressão }\end{array}$ & $\begin{array}{l}\text { Sócio-demográfico, } \\
\text { MBI (22), PRIME-MD } \\
\text { (2), SF-8 (8), itens } \\
\text { sobre condutas anti- } \\
\text { éticas (auto-relato) }\end{array}$ & $\begin{array}{l}\text { Internet } \\
\text { (2009) }\end{array}$ & $\begin{array}{l}\text { - Burnout está associado } \\
\text { ao auto-relato de pelo } \\
\text { menos um } \\
\text { comportamento anti-ético }\end{array}$ & $\begin{array}{l}\text { - Número limitado de atitudes } \\
\text { anti-éticas estudadas } \\
\text { - Uso de auto-relato para o } \\
\text { estudo das atitudes anti-éticas } \\
\text { (recall bias) } \\
\text { - Desenho transversal } \\
\text { - Viés de resposta }\end{array}$ \\
\hline $\begin{array}{l}\text { Sen et al. } \\
(2010)(8)\end{array}$ & $\begin{array}{l}\text { EUA } \\
13 \text { hospitais }\end{array}$ & $\begin{array}{l}\text { Longitudinal, } \\
\text { prospectivo } \\
\text { Amostra } \\
\text { conveniência }\end{array}$ & $\begin{array}{l}740 \\
\text { residentes } \\
\text { do } 1^{\circ} \text { ano } \\
(58 \%)\end{array}$ & $\begin{array}{l}\text { Depressão, } \\
\text { residentes, } \\
\text { personalidade, } \\
\text { stress, suporte } \\
\text { social, } \\
\text { resiliência, } \\
\text { ambiente } \\
\text { familiar e } \\
\text { estilos } \\
\text { cognitivos }\end{array}$ & $\begin{array}{l}\text { Sócio-demográfico, } \\
\text { PHQ-9 (9), NEO-Five } \\
\text { Factor Inventory, } \\
\text { Connor-Davidson } \\
\text { Resilience Scale, } \\
\text { PSS, Sarason Social } \\
\text { Support } \\
\text { Questionnaire, Risky } \\
\text { Families } \\
\text { Questionnaire, }\end{array}$ & $\begin{array}{l}\text { Internet } \\
(2007-2008) \\
(2008-2009)\end{array}$ & $\begin{array}{l}\text {-Incidência de depressão } \\
\text { aumentou drasticamente } \\
\text { no primeiro ano de } \\
\text { residência } \\
\text {-Erro médico está } \\
\text { associado à depressão } \\
\text {-Presença de sintomas } \\
\text { depressivos prediz erro } \\
\text { médico } \\
\text {-Erro médico também }\end{array}$ & $\begin{array}{l}\text { - Viés de resposta } \\
\text {-Variáveis importantes e não } \\
\text { estudadas } \\
\text {-Depressão e erro médico foram } \\
\text { avaliados por auto-relato } \\
\text {-Generalização (estudo restrito a } \\
\text { residentes do } 1^{\circ} \text { ano) }\end{array}$ \\
\hline
\end{tabular}




\begin{tabular}{|c|c|c|c|c|c|c|c|c|}
\hline \multicolumn{9}{|c|}{ América do Norte } \\
\hline Autores & $\begin{array}{c}\text { País } \\
\text { Número } \\
\text { Instituições }\end{array}$ & $\begin{array}{c}\text { Desenho } \\
\text { estudo } \\
\text { Tipo amostra }\end{array}$ & $\begin{array}{l}\text { Participan- } \\
\text { tes } \\
\text { (taxa de } \\
\text { resposta) } \\
\end{array}$ & $\begin{array}{l}\text { Variáveis } \\
\text { estudadas }\end{array}$ & $\begin{array}{c}\text { Instrumentos } \\
\text { utilizados } \\
\text { (número de itens) }\end{array}$ & $\begin{array}{l}\text { Coleta de } \\
\text { dados } \\
\text { (ano) }\end{array}$ & Principais resultados & Limitações declaradas \\
\hline & & & & & $\begin{array}{l}\text { Sociotropy-Autonomy } \\
\text { Scale }\end{array}$ & & prediz depressão & \\
\hline $\begin{array}{l}\text { Dyrbye et } \\
\text { al. (2011) } \\
\text { (9) }\end{array}$ & $\begin{array}{l}\text { EUA } \\
7 \text { instituições }\end{array}$ & $\begin{array}{l}\text { Transversal } \\
\text { População total }\end{array}$ & $\begin{array}{l}2.248 \\
\text { estudantes } \\
(52,4 \%) \\
(2007) \\
\\
2.682 \\
\text { estudantes } \\
(61 \%) \\
(2009)\end{array}$ & $\begin{array}{l}\text { Instrumento de } \\
\text { bem estar do } \\
\text { estudante de } \\
\text { medicina }\end{array}$ & $\begin{array}{l}\text { Sócio-demográfico } \\
\text { (inclui itens sobre } \\
\text { ideação suicida e } \\
\text { pensamentos de } \\
\text { desistência do curso), } \\
\text { MSWBI (7), MBI (22), } \\
\text { PRIME-MD (2), SF-8 } \\
\text { (8), [Epworth (8), PSS } \\
\text { (10) (2007)] }\end{array}$ & $\begin{array}{l}\text { Internet } \\
\text { (2007 / 2009) }\end{array}$ & $\begin{array}{l}\text { - O instrumento foi capaz } \\
\text { de identificar estudantes } \\
\text { com baixos escores de } \\
\text { qualidade de vida mental, } \\
\text { ideação suicida e com } \\
\text { pensamentos de } \\
\text { desistência do curso }\end{array}$ & $\begin{array}{l}\text { - O instrumento avalia um } \\
\text { construto multidimensional, não } \\
\text { há medida padrão-ouro } \\
\text { - O instrumento pode não } \\
\text { identificar estudantes em risco } \\
\text { para outras variáveis } \\
\text { importantes } \\
\text { - Generalização dos resultados }\end{array}$ \\
\hline $\begin{array}{l}\text { Dyrbye et } \\
\text { al. (2011) } \\
\text { (10) }\end{array}$ & $\begin{array}{l}\text { EUA } \\
7 \text { instituições }\end{array}$ & $\begin{array}{l}\text { Transversal } \\
\text { População total }\end{array}$ & $\begin{array}{l}2.248 \\
\text { estudantes } \\
(52,4 \%)\end{array}$ & $\begin{array}{l}\text { Burnout, } \\
\text { depressão, } \\
\text { qualidade de } \\
\text { vida, } \\
\text { sonolência, } \\
\text { stress }\end{array}$ & $\begin{array}{l}\text { Sócio-demográfico, } \\
\text { MBI (22), PRIME-MD } \\
\text { (22), Sf-8 (8), Epworth } \\
\text { (8), PSS (10) }\end{array}$ & $\begin{array}{l}\text { Internet } \\
\text { (2007) }\end{array}$ & $\begin{array}{l}\text { - Mais de } 20 \% \text { dos } \\
\text { estudantes apresentaram } \\
\text { cada uma das variáveis } \\
\text { estudadas } \\
\text { - Mais de } 80 \% \text { dos } \\
\text { estudantes apresentaram } \\
\text { pelo menos uma } \\
\text { manifestação de angústia }\end{array}$ & - Viés de resposta \\
\hline $\begin{array}{l}\text { Reed et al. } \\
\text { (2011) (11) }\end{array}$ & $\begin{array}{l}\text { EUA } \\
7 \text { instituições }\end{array}$ & $\begin{array}{l}\text { Transversal } \\
\text { População total }\end{array}$ & $\begin{array}{l}1.192 \\
\text { estudantes } \\
\text { do } 1^{\circ} \text { e } 2^{\mathrm{a}} \\
\text { ano do } \\
\text { curso } \\
(58 \%)\end{array}$ & $\begin{array}{l}\text { Estrutura } \\
\text { curricular } \\
\text { (sistema de } \\
\text { notas), burnout, } \\
\text { qualidade de } \\
\text { vida, stress }\end{array}$ & $\begin{array}{l}\text { Sócio-demográfico } \\
\text { (inclui itens sobre } \\
\text { eventos pessoas e } \\
\text { pensamentos de } \\
\text { desistência do curso), } \\
\text { PSS (10), MBI (22), } \\
\text { SF-8 (8) }\end{array}$ & $\begin{array}{l}\text { Internet } \\
\text { (2007) }\end{array}$ & $\begin{array}{l}\text {-Maior exaustão emocional } \\
\text { quando relato de maior } \\
\text { quantidade de horas em } \\
\text { provas } \\
\text {-Menor burnout quando relato } \\
\text { de maior quantidade de horas } \\
\text { em experiências clínicas } \\
\text {-Sistema de notas com mais } \\
\text { de } 3 \text { categorias relacionado a } \\
\text { maior stress e burnout }\end{array}$ & $\begin{array}{l}\text {-Viés de resposta } \\
\text {-Desenho transversal } \\
\text { - Não foi possível avaliar } \\
\text { influência currículo oculto } \\
\text {-Currículo avaliado pelo relato } \\
\text { da universidade, não pela } \\
\text { frequência real dos estudantes }\end{array}$ \\
\hline $\begin{array}{l}\text { Dyrbye et } \\
\text { al. (2012) } \\
(12)\end{array}$ & $\begin{array}{l}\text { EUA } \\
7 \text { instituições }\end{array}$ & $\begin{array}{l}\text { Transversal } \\
\text { População total }\end{array}$ & $\begin{array}{l}2.682 \\
\text { estudantes } \\
(61 \%)\end{array}$ & $\begin{array}{l}\text { Saúde mental } \\
\text { positiva, } \\
\text { burnout, } \\
\text { profissionalismo, } \\
\text { eventos } \\
\text { pessoais }\end{array}$ & $\begin{array}{l}\text { Sócio-demográfico } \\
\text { (inclui itens sobre } \\
\text { eventos pessoais, } \\
\text { ideação suicida, } \\
\text { pensamentos sobre } \\
\text { desistência do curso } \\
\text { e comportamento } \\
\text { profissional), MHC-SF } \\
\text { (14), MBI (22) }\end{array}$ & $\begin{array}{l}\text { Internet } \\
\text { (2009) }\end{array}$ & $\begin{array}{l}\text {-Saúde mental positiva } \\
\text { correlaciona-se com } \\
\text { profissionalismo e eventos } \\
\text { pessoais }\end{array}$ & $\begin{array}{l}\text { - Viés de resposta } \\
\text {-Desenho transversal } \\
\text {-Uso de medidas de auto-relato } \\
\text {-MHF-SF não abrange todos os } \\
\text { componentes da saúde mental } \\
\text {-"Social desirability bias" }\end{array}$ \\
\hline \multicolumn{9}{|c|}{ Europa } \\
\hline Autores & $\begin{array}{c}\text { País } \\
\text { Número } \\
\text { Instituições }\end{array}$ & $\begin{array}{c}\text { Desenho } \\
\text { estudo } \\
\text { Tipo amostra } \\
\end{array}$ & $\begin{array}{l}\text { Participan- } \\
\text { tes } \\
\text { (taxa de }\end{array}$ & $\begin{array}{l}\text { Variáveis } \\
\text { estudadas }\end{array}$ & $\begin{array}{c}\text { Instrumentos } \\
\text { utilizados } \\
\text { (número de itens) }\end{array}$ & $\begin{array}{c}\text { Coleta de } \\
\text { dados } \\
\text { (ano) }\end{array}$ & Principais resultados & Limitações declaradas \\
\hline
\end{tabular}




\begin{tabular}{|c|c|c|c|c|c|c|c|c|}
\hline \multicolumn{9}{|c|}{ América do Norte } \\
\hline Autores & $\begin{array}{c}\text { País } \\
\text { Número } \\
\text { Instituições }\end{array}$ & $\begin{array}{c}\text { Desenho } \\
\text { estudo } \\
\text { Tipo amostra }\end{array}$ & $\begin{array}{l}\text { Participan- } \\
\text { tes } \\
\text { (taxa de } \\
\text { resposta) } \\
\end{array}$ & $\begin{array}{l}\text { Variáveis } \\
\text { estudadas }\end{array}$ & $\begin{array}{c}\text { Instrumentos } \\
\text { utilizados } \\
\text { (número de itens) }\end{array}$ & $\begin{array}{l}\text { Coleta de } \\
\text { dados } \\
\text { (ano) }\end{array}$ & Principais resultados & Limitações declaradas \\
\hline & & & resposta) & & & & & \\
\hline $\begin{array}{l}\text { Boor et al. } \\
\text { (2008) (13) }\end{array}$ & $\begin{array}{l}\text { Holanda } \\
\\
6 \text { instituições } \\
12 \text { departamentos } \\
14 \text { estudantes de } \\
\text { cada } \\
\text { departamento }\end{array}$ & $\begin{array}{l}\text { Transversal } \\
\text { Quanti- } \\
\text { qualitativo } \\
\text { Amostra } \\
\text { conveniência }\end{array}$ & $\begin{array}{l}154 \\
\text { estudantes } \\
(91,7 \%) \\
\text { (quantitativo) } \\
14 \\
\text { estudantes } \\
\text { (qualitativo) }\end{array}$ & $\begin{array}{l}\text { Ambiente de } \\
\text { ensino, estágio } \\
\text { hospitalar } \\
\text { ginecologia e } \\
\text { obstetrícia }\end{array}$ & PHEEM (40) & $\begin{array}{l}\text { Quantitativo } \\
\text { Questionários } \\
\text { impressos } \\
(2003 \text { / 2005) } \\
\\
\text { Qualitativo } \\
\text { Entrevista semi- } \\
\text { estruturada } \\
\text { (2006-2007) }\end{array}$ & $\begin{array}{l}\text {-Diferença significa entre } \\
\text { o melhor e o pior } \\
\text { departamento na } \\
\text { avaliação do ambiente de } \\
\text { ensino } \\
\text {-As diferenças são } \\
\text { determinadas pelo grau } \\
\text { de participação dos } \\
\text { alunos nas atividades, } \\
\text { pelo envolvimento dos } \\
\text { preceptores no papel } \\
\text { educacional e pela } \\
\text { organização do estágio }\end{array}$ & $\begin{array}{l}\text { - Generalização dos resultados } \\
\text { (restritos aos estágios de } \\
\text { ginecologia e obstetrícia) }\end{array}$ \\
\hline $\begin{array}{l}\text { van Hell et } \\
\text { al. (2009) } \\
(14)\end{array}$ & $\begin{array}{l}\text { Holanda } \\
8 \text { hospitais }\end{array}$ & $\begin{array}{l}\text { Transversal } \\
\text { População total }\end{array}$ & $\begin{array}{l}133 \\
\text { internos } \\
(94 \%)\end{array}$ & $\begin{array}{l}\text { Ambiente de } \\
\text { ensino, tempo } \\
\text { em atividades } \\
\text { no internato }\end{array}$ & $\begin{array}{l}\text { PHEEM (40), registro } \\
\text { diário do tempo } \\
\text { utilizado em } 8 \text { tipos } \\
\text { de atividades nos } \\
\text { estágios }\end{array}$ & $\begin{array}{l}\text { Questionários } \\
\text { impressos } \\
\text { (data não } \\
\text { especificada) }\end{array}$ & $\begin{array}{l}\text {-Relação positiva entre } \\
\text { percepção do ambiente } \\
\text { de ensino com o tempo } \\
\text { dedicado a atividades } \\
\text { com pacientes }\end{array}$ & $\begin{array}{l}\text { - Uso do escore global do } \\
\text { PHEEM pode ter mascarado } \\
\text { diferenças importantes } \\
\text { - Uso de medidas de auto-relato } \\
\text { sobre o tempo das atividades } \\
\text { - Desenho transversal }\end{array}$ \\
\hline
\end{tabular}

\begin{tabular}{|c|c|c|c|c|c|c|c|c|}
\hline \multicolumn{9}{|c|}{ Oceania } \\
\hline Autores & $\begin{array}{c}\text { País } \\
\text { Número } \\
\text { Instituições }\end{array}$ & $\begin{array}{c}\text { Desenho } \\
\text { estudo } \\
\text { Tipo amostra }\end{array}$ & $\begin{array}{l}\text { Participan- } \\
\text { tes } \\
\text { (taxa de } \\
\text { resposta) }\end{array}$ & $\begin{array}{l}\text { Variáveis } \\
\text { estudadas }\end{array}$ & $\begin{array}{c}\text { Instrumentos } \\
\text { utilizados } \\
\text { (número de itens) }\end{array}$ & $\begin{array}{l}\text { Coleta de } \\
\text { dados } \\
\text { (ano) }\end{array}$ & Principais resultados & Limitações declaradas \\
\hline $\begin{array}{l}\text { Hillis et al. } \\
\text { (2010) (15) }\end{array}$ & $\begin{array}{l}\text { Austrália } \\
\text { Nova } \\
\text { Zelândia } \\
5 \text { instituições }\end{array}$ & $\begin{array}{l}\text { Transversal } \\
\text { Amostra } \\
\text { conveniência }\end{array}$ & $\begin{array}{l}1.328 \\
\text { estudantes } \\
(26 \%)\end{array}$ & $\begin{array}{l}\text { Percepções } \\
\text { sobre bem- } \\
\text { estar, serviços } \\
\text { de apoio, } \\
\text { stigma }\end{array}$ & $\begin{array}{l}\text { Questionário } \\
\text { desenvolvido para } \\
\text { investigar percepção } \\
\text { dos estudantes sobre } \\
\text { serviços de apoio e } \\
\text { conhecimento sobre } \\
\text { bem estar }\end{array}$ & $\begin{array}{l}\text { Questionários } \\
\text { impressos } \\
\text { Internet } \\
(2007)\end{array}$ & $\begin{array}{l}\text {-71\% dos estudantes } \\
\text { tinham conhecimento } \\
\text { sobre os serviços de } \\
\text { suporte disponíveis nas } \\
\text { escolas } \\
\text {-Menos da metade dos } \\
\text { estudantes relataram que } \\
\text { os serviços eram } \\
\text { adequadamente } \\
\text { oferecidos }\end{array}$ & $\begin{array}{l}\text { - Viés de seleção (baixa taxa de } \\
\text { resposta) }\end{array}$ \\
\hline $\begin{array}{l}\text { Warnecke } \\
\text { et al. } \\
\text { (2011) (18) }\end{array}$ & $\begin{array}{l}\text { Austrália } \\
3 \text { instituições }\end{array}$ & $\begin{array}{l}\text { Ensaio clínico } \\
\text { randomizado } \\
\text { controlado }\end{array}$ & $\begin{array}{l}65 \\
\text { estudantes } \\
\text { dos últimos } \\
\text { dois anos } \\
\text { de curso }\end{array}$ & $\begin{array}{l}\text { Prática de } \\
\text { meditação para } \\
\text { reduzir stress } \\
\text { entre } \\
\text { estudantes dos }\end{array}$ & PSS (10), DASS (42) & $\begin{array}{l}\text { Questionários } \\
\text { impressos } \\
\text { Internet }\end{array}$ & $\begin{array}{l}\text { - Maiores escores de } \\
\text { ansiedade e estresse dos } \\
\text { estudantes do que } \\
\text { população normativa } \\
\text { - Redução dos escores de }\end{array}$ & $\begin{array}{l}\text { - Tamanho da amostra pequeno } \\
\text { - Período curto de } \\
\text { acompanhamento (8 semanas) } \\
\text { - Adesão modesta } \\
\text {-Diário de atividades autorrelato }\end{array}$ \\
\hline
\end{tabular}




\begin{tabular}{|c|c|c|c|c|c|c|c|c|}
\hline \multicolumn{9}{|c|}{ Oceania } \\
\hline Autores & $\begin{array}{c}\text { País } \\
\text { Número } \\
\text { Instituições }\end{array}$ & $\begin{array}{c}\text { Desenho } \\
\text { estudo } \\
\text { Tipo amostra }\end{array}$ & $\begin{array}{l}\text { Participan- } \\
\text { tes } \\
\text { (taxa de } \\
\text { resposta) }\end{array}$ & $\begin{array}{l}\text { Variáveis } \\
\text { estudadas }\end{array}$ & $\begin{array}{c}\text { Instrumentos } \\
\text { utilizados } \\
\text { (número de itens) }\end{array}$ & $\begin{array}{l}\text { Coleta de } \\
\text { dados } \\
\text { (ano) }\end{array}$ & Principais resultados & Limitações declaradas \\
\hline & & & $\begin{array}{l}(35,1 \%) \\
\text { Intervenção } \\
31 \text { estudantes } \\
\text { Controle } \\
34 \text { estudantes } \\
\end{array}$ & $\begin{array}{l}\text { últimos anos do } \\
\text { curso }\end{array}$ & & (2009) & $\begin{array}{l}\text { estresse e ansiedade } \\
\text { após intervenção } \\
\text { - Manutenção dos escores } \\
\text { mais baixos } 8 \text { semanas } \\
\text { após intervenção }\end{array}$ & $\begin{array}{l}\text {-Baixa adesão (intervenção de } \\
\text { difícil aplicabilidade) } \\
\text {-Altas taxas de desistência no } \\
\text { grupo da intervenção }\end{array}$ \\
\hline
\end{tabular}

\begin{tabular}{|c|c|c|c|c|c|c|c|c|}
\hline \multicolumn{9}{|c|}{ Ásia } \\
\hline Autores & $\begin{array}{c}\text { País } \\
\text { Número } \\
\text { Instituições }\end{array}$ & $\begin{array}{c}\text { Desenho } \\
\text { estudo } \\
\text { Tipo amostra }\end{array}$ & $\begin{array}{c}\text { Participan- } \\
\text { tes } \\
\text { (taxa de } \\
\text { resposta) }\end{array}$ & $\begin{array}{l}\text { Variáveis } \\
\text { estudadas }\end{array}$ & $\begin{array}{c}\text { Instrumentos } \\
\text { utilizados } \\
\text { (número de itens) }\end{array}$ & $\begin{array}{l}\text { Coleta de } \\
\text { dados } \\
\text { (ano) }\end{array}$ & Principais resultados & Limitações declaradas \\
\hline $\begin{array}{l}\text { Roh et al. } \\
\text { (2009) (17) }\end{array}$ & $\begin{array}{l}\text { Coreia do Sul } \\
36 \\
\text { instituições }\end{array}$ & $\begin{array}{l}\text { Transversal } \\
\text { População total }\end{array}$ & $\begin{array}{l}7.357 \\
\text { estudantes } \\
(52,2 \%)\end{array}$ & $\begin{array}{l}\text { Tratamento } \\
\text { para depressão }\end{array}$ & $\begin{array}{l}\text { Sócio-demográfico } \\
\text { (inclui itens sobre } \\
\text { conhecimento de } \\
\text { problemas de saúde } \\
\text { mental), BDI (21) }\end{array}$ & $\begin{array}{l}\text { Questionários } \\
\text { impressos } \\
(2006)\end{array}$ & $\begin{array}{l}\text {-Idade mais avançada e } \\
\text { conhecimento sobre } \\
\text { etiologia e tratamento da } \\
\text { depressão são fatores } \\
\text { importantes que } \\
\text { influenciam a procura por } \\
\text { tratamento entre } \\
\text { estudantes }\end{array}$ & $\begin{array}{l}\text { - Viés de seleção } \\
\text { - BDI não é instrumento de } \\
\text { diagnóstico de depressão }\end{array}$ \\
\hline $\begin{array}{l}\text { Roh et al. } \\
\text { (2010) (18) }\end{array}$ & $\begin{array}{l}\text { Coreia do Sul } \\
36 \\
\text { instituições }\end{array}$ & $\begin{array}{l}\text { Transversal } \\
\text { População total }\end{array}$ & $\begin{array}{l}7.357 \\
\text { estudantes } \\
(52,2 \%)\end{array}$ & $\begin{array}{l}\text { Depressão, } \\
\text { desempenho } \\
\text { acadêmico }\end{array}$ & $\begin{array}{l}\text { Sócio-demográfico } \\
\text { (inclui item sobre } \\
\text { desempenho } \\
\text { acadêmico), MINI-PR } \\
\text { (9) }\end{array}$ & $\begin{array}{l}\text { Questionários } \\
\text { impressos } \\
(2006)\end{array}$ & $\begin{array}{l}\text {-Maior prevalência de } \\
\text { depressão entre mulheres } \\
\text {-Maior prevalência de } \\
\text { depressão entre } \\
\text { estudantes do } 1^{\circ} \text { ao } 3^{\circ} \\
\text { ano do curso } \\
\text {-Estudantes com } \\
\text { depressão relataram pior } \\
\text { desempenho acadêmico } \\
\end{array}$ & $\begin{array}{l}\text { - Viés de resposta } \\
\text { - Desenho transversal } \\
\text { - Medidas de auto-relato } \\
\text { - Viés de seleção } \\
\text {-Não avaliou variáveis como } \\
\text { taxas de desistência do curso, } \\
\text { uso de álcool e drogas }\end{array}$ \\
\hline
\end{tabular}

EUA: Estados Unidos da América; MBI: Maslach Burnout Inventory; PRIME-MD: Primary Care Evaluation of Mental Disorder; SF-8: Medical Outcomes Study 8-Item Short-Form; LASA: Linear Analogue Self Assessment Well-being Survey; IRI: Interpersonal Reactivity Index; CES-D: Center for Epidemiologic Studies-Depression scale; MSWBI: Medical Student Well Being Index; PSS: Perceived Stress Scale; PHO-9: Patient Health Questionnaire; MHC-SF: Mental Health Continuum Short Form; PHEEM: Postgraduate Hospital Educational Environment Measure; DASS: Depression, Anxiety and Stress Scale; BDI: Beck Depression Inventory; MINI-PR: Mini International Neuropsychiatric Interview 


\section{Referências}

1. Dyrbye LN, Thomas MR, Huntington JL, Lawson KL, Novotny PJ, Sloan JA, et al. Personal life events and medical student burnout: a multicenter study. Acad Med. 2006;81(4):374-84.

2. Dyrbye LN, Thomas MR, Huschka MM, Lawson KL, Novotny PJ, Sloan JA, et al. A multicenter study of burnout, depression, and quality of life in minority and nonminority US medical students. Mayo Clin Proc. 2006;81(11):1435-42.

3. Thomas MR, Dyrbye LN, Huntington JL, Lawson KL, Novotny PJ, Sloan JA, et al. How do distress and well-being relate to medical student empathy? A multicenter. J Gen Intern Med. 2007;22(2):177-83.

4. Dyrbye LN, Thomas MR, Massie FS, Power DV, Eacker A, Harper W, et al. Burnout and suicidal ideation among U.S. medical students. Ann Intern Med. 2008;149(5):334-41.

5. Dyrbye LN, Thomas MR, Harper W, Massie FS, Jr., Power DV, Eacker A, et al. The learning environment and medical student burnout: a multicentre study. Med Educ. 2009;43(3):274-82.

6. Goebert D, Thompson D, Takeshita J, Beach C, Bryson P, Ephgrave K, et al. Depressive symptoms in medical students and residents: a multischool study. Acad Med. 2009;84(2):236-41.

7. Dyrbye LN, Thomas MR, Power DV, Durning S, Moutier C, Massie FS, et al. Burnout and serious thoughts of dropping out of medical school: a multi-institutional study. Acad Med. 2010;85(1):94-102.

8. Sen S, Kranzler HR, Krystal JH, Speller H, Chan G, Gelernter J, et al. A prospective cohort study investigating factors associated with depression. Arch Gen Psychiatry. 2010;67(6):557-65.

9. Dyrbye LN, Schwartz A, Downing SM, Szydlo DW, Sloan JA, Shanafelt TD. Efficacy of a brief screening tool to identify medical students in distress. Acad Med. 2011;86(7):907-14.

10. Dyrbye LN, Harper W, Durning SJ, Moutier C, Thomas MR, Massie FS, Jr., et al. Patterns of distress in US medical students. Med Teach. 2011;33(10):834-9.

11. Reed DA, Shanafelt TD, Satele DW, Power DV, Eacker A, Harper W, et al. Relationship of pass/fail grading and curriculum structure with well-being among. Acad Med. 2011;86(11):1367-73. 12. Dyrbye LN, Harper W, Moutier C, Durning SJ, Power DV, Massie FS, et al. A multiinstitutional study exploring the impact of positive mental health on. Acad Med. 2012;87(8):102431.

13. Boor K, Scheele F, van der Vleuten CP, Teunissen PW, den Breejen EM, Scherpbier AJ. How undergraduate clinical learning climates differ: a multi-method case study. Med Educ. 2008;42(10):1029-36.

14. van Hell EA, Kuks JB, Cohen-Schotanus J. Time spent on clerkship activities by students in relation to their perceptions. Med Educ. 2009;43(7):674-9.

15. Hillis JM, Perry WR, Carroll EY, Hibble BA, Davies MJ, Yousef J. Painting the picture: Australasian medical student views on wellbeing teaching. Med J Aust. 2010;192(4):188-90. 
16. Warnecke E, Quinn S, Ogden K, Towle N, Nelson MR. A randomised controlled trial of the effects of mindfulness practice on medical. Med Educ. 2011;45(4):381-8.

17. Roh MS, Jeon $\mathrm{HJ}$, Kim H, Cho HJ, Han SK, Hahm BJ. Factors influencing treatment for depression among medical students: a nationwide. Med Educ. 2009;43(2):133-9.

18. Roh M-S, Hahm B-J, Lee DH, Suh DH. Evaluation of empathy among Korean medical students: a cross-sectional study using the Korean Version of the Jefferson Scale of Physician Empathy. Teach Learn Med. 2010;22(3):167-71. 
Apêndice B - Cálculo e interpretação do tamanho do efeito

Situação 1: Duas amostras independentes (teste t) quando há população normativa ou grupo controle

$$
d=\left(M_{2}-M_{1}\right) / s
$$

Onde:

$\mathrm{d}=$ coeficiente $\mathrm{d}$ de Cohen;

$\mathrm{M}_{1}=$ média da população normativa ou grupo controle

$\mathrm{M}_{2}=$ média da população estudada

$\mathrm{s}=$ desvio padrão da população normativa ou grupo controle

Situação 2: Duas amostras independentes (teste t) quando não há população normativa ou grupo controle

$$
d=\left(M_{2}-M_{1}\right) / s_{p}
$$

$\mathrm{d}=$ coeficiente $\mathrm{d}$ de Cohen;

$M_{1}=$ média do grupo 1

$M_{2}=$ média do grupo 2

$\mathrm{s}_{\mathrm{p}}=$ desvio padrão combinado

$$
s_{p}=\sqrt{\frac{\left(N_{\mathrm{A}}-1\right) s_{\mathrm{A}}^{2}+\left(N_{\mathrm{B}}-1\right) s_{\mathrm{B}}^{2}}{N_{\mathrm{A}}+N_{\mathrm{B}}-2}}
$$

Onde:

$\mathrm{s}_{\mathrm{p}}=$ desvio padrão combinado

$\mathrm{N}_{\mathrm{A}}=$ tamanho da amostra do grupo $\mathrm{A}$

$\mathrm{S}_{\mathrm{A}}=$ desvio padrão do grupo $A$

$\mathrm{N}_{\mathrm{B}}=$ tamanho da amostra do grupo $\mathrm{B}$

$S_{B}$ - desvio padrão do grupo $B$ 
Situação 3: Duas amostras dependentes (teste t pareado)

$$
d=\frac{M_{\mathrm{dif}}}{S_{\mathrm{av}}}
$$

Onde:

$d$ = coeficiente $d$ de Cohen;

$\mathrm{M}_{1}=$ diferença das médias

$\mathrm{S}_{\mathrm{AV}}=$ desvio padrão médio

$$
S_{\mathrm{av}}=\sqrt{\frac{s_{\mathrm{pré}}^{2}+S_{\mathrm{pós}}^{2}}{2}}
$$

Onde:

$\mathrm{S}_{\mathrm{AV}}=$ desvio padrão médio

$S_{\text {pré }}=$ desvio padrão momento 1

$\mathrm{S}_{\text {pós }}=$ desvio padrão momento 2

Situação 4: Mais de duas amostras independentes (ANOVA)

$$
f=\sqrt{\frac{\eta^{2}}{1-\eta^{2}}}
$$

Onde:

$f=$ coeficiente $f$ de Cohen

$\eta=$ coeficiente eta

$$
\eta^{2}=\frac{\text { Soma dos quadrados entre grupos }}{\text { Soma dos quadrados totais }}
$$


Interpretação do tamanho do efeito

\begin{tabular}{|l|c|c|c|}
\hline \multirow{2}{*}{ Coeficiente } & \multicolumn{3}{|c|}{ Tamanho do efeito* $^{*}$} \\
\cline { 2 - 4 } & Pequeno & Médio & Grande \\
\hline $\boldsymbol{d}$ & 0,20 & 0,50 & 0,80 \\
\hline $\boldsymbol{f}$ & 0,10 & 0,25 & 0,40 \\
\hline $\boldsymbol{R}^{2}$ & 0,02 & 0,13 & 0,26 \\
\hline
\end{tabular}

${ }^{*}$ Cohen (1988)

\section{Referências}

Cohen, Jacob. Statistical power analysis for the Behavioral Sciences. 2nd ed. Hillsdale, NJ: Lawrence Erlbaum; 1988.

Cumming, Geoff. Understanding the new statistics: effect sizes, confidence intervals, and meta-analysis. New York: Routledge; 2012.

Ellis, Paul D. The Essential Guide to Effect Sizes: Statistical Power, MetaAnalysis, and the Interpretation of Research Results. Cambridge: Cambridge University Press; 2010. 